\title{
Ratiometric Flapping Force Probe That Works in Polymer Gels
}

\author{
Takuya Yamakado, and Shohei Saito* \\ Graduate School of Science, Kyoto University, Kitashirakawa Oiwake-cho, Sakyo-ku, Kyoto 606-8502, Japan. \\ KEYWORDS: force probe, mechanochemistry, dual fluorescence, polymer gels, flapping molecules.
}

\begin{abstract}
A ratiometric flapping force probe that can evaluate the nanoscale stress concentration in the polymer chain network of common organogels has been developed. Stress-dependent dual-fluorescence properties of the chemically doped flapping force probe has been demonstrated even when the probe is solvated in the wet materials (Figure 1). The fluorescence ratiometric analysis is robust against the local concentration change induced by the macroscopic polymer deformation. While the force-responsive FRET dyads, widely used in mechanobiology, are sensitive to the distance and orientation of the two chromophores, the flapping fluorophore works as a single-component flexible force probe regardless of the FRET efficiency. Realtime and reversible spectral response to the mechanical stress is observed with a low threshold on the order of sub-MPa compression due to its conformational flexibility. The previously reported flapping probe only shows a negligible response in the solvated environments because the undesired spontaneous planarization occurs in the $S_{1}$ excited state, even without mechanical force. The excited-state engineering by changing the flapping wings from the anthraceneimide units to the pyreneimide units endows this molecule with the force probe function in the wet conditions. The structurally modified force probe also has an advantage in terms of a wide dynamic range of the fluorescence response in solvent-free elastomers, which enabled the ratiometric fluorescence imaging of the molecular-level stress concentration during the crack growth in a stretched polyurethane film. The percentage of the stressed force probes has been experimentally estimated to be approximately $30-40 \%$ before the fracture of the elastomers. The flapping force probe is useful for elucidating the toughening mechanism of recently focused unique topological gels and elastomers at molecular level.
\end{abstract}

\section{INTRODUCTION}

Polymer gels are composed of polymer chain network swollen with solvents. Hydrogels have been widely used for drug delivery systems ${ }^{1}$ and biocompatible materials ${ }^{2}$ due to their high solvent retention properties and flexibility. In addition to these classical applications, functional gels attract increasing attention in wearable electronics, ${ }^{3}$ actuators, ${ }^{4}$ and soft robotics. ${ }^{5}$

Polymer gels have an inherent problem in fragility because of the low volume fraction of polymer chains and inhomogeneous network structure. ${ }^{6}$ To make tough polymer gels, many strategies have been proposed in these decades, ${ }^{7,8}$ leading to the development of tough hydrogels incorporating a double network structure, ${ }^{9-12}$ non-covalent sacrificial bonds, ${ }^{13-16}$ nanoparticles, ${ }^{18-21}$ and a crystal structure. ${ }^{22,23}$ These materials are designed to dissipate the energy of the mechanical stress concentrated on the specific polymer chains, ${ }^{24}$ as it has also been reported for elastomers. ${ }^{25-29}$ Furthermore, to overcome the heterogeneity of polymer networks, unique polymer networks have been studied based on 1) multi-arm macromers with uniform chain length $^{31-34}$ and 2) polymer gels with rotaxane-based slidable cross-links. ${ }^{23,35-37}$ These nanoscopic polymer designs are intrinsically important to create polymer gels with remarkable mechanical properties. However, it remains challenging to directly elucidate the toughening mechanism at the nanoscale. ${ }^{38}$

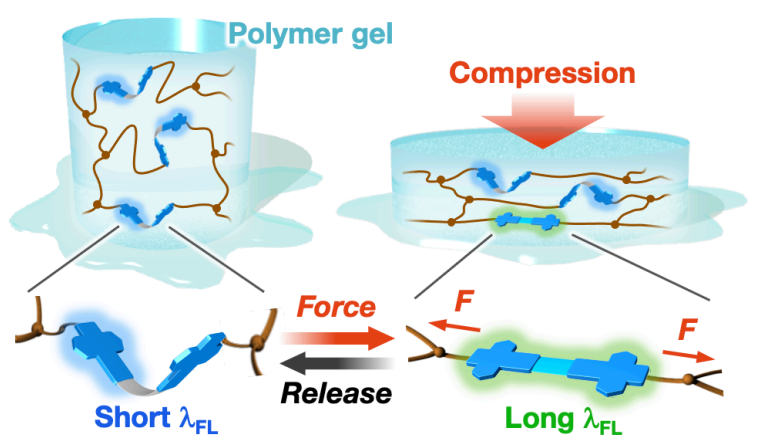

Figure 1. Schematic illustration of the compression-induced fluorescence change of a common organogel chemically doped with the flapping force probe (FLAP). $\lambda_{\mathrm{FL}}$ : Fluorescence wavelength.

On the other hand, polymer mechanochemistry has been rapidly developed as a related area. ${ }^{39,40}$ A variety of mechanophores exhibit color changes ${ }^{41-52}$ and/or luminescence responses ${ }^{25,53-60}$ when a relatively weak covalent bond undergoes the intramolecular cleavage by mechanical stimuli, as represented by spiropyran. While these mechanophores are widely used for developing mechanoresponsive materials, ${ }^{61-64}$ they could also be used as "force probes" to evaluate molecular-level forces transmitted in the polymer chain network, as long as the chemical doping of the mechanophore does not have a significant influence in the intrinsic mechanical properties of host polymers. ${ }^{65,66}$ Recently, several examples have been reported to demonstrate quantitative mapping of the local stress distribution in multi-network elastomers during the crack propagation. ${ }^{67-70}$ In these reports, the important role of the sacrificial bonds 
in the toughening mechanism of the topological polymers has been demonstrated. Mechanoresponsive system with a reversible response is more useful, ${ }^{71-78}$ which allows us to investigate local force distribution in the elastic polymer deformation. To evaluate the stress applied to fragile polymer gels, flexible force probes are more suitable, which should have a lower force threshold than that required for the covalent bond scission $(>$ $200 \mathrm{pN}$ ). FRET dyads would be an alternative to probe such the small forces. ${ }^{79-82}$ Supramolecular structural changes, ${ }^{83-87}$ such as the unravelling of the DNA linker, ${ }^{88,89}$ induce a fluorescence
(FL) response with the perturbation of the FRET efficiency. The force threshold to cleave hydrogen bonds of DNA/proteins has been estimated as tens of piconewtons, which is one or two orders of magnitude lower than that of conventional mechanophores, ${ }^{79-82}$ although the FRET efficiency is sensitive to multiple parameters such as the distance and the relative orientation of the two chromophores. ${ }^{83}$ (a) Previous work

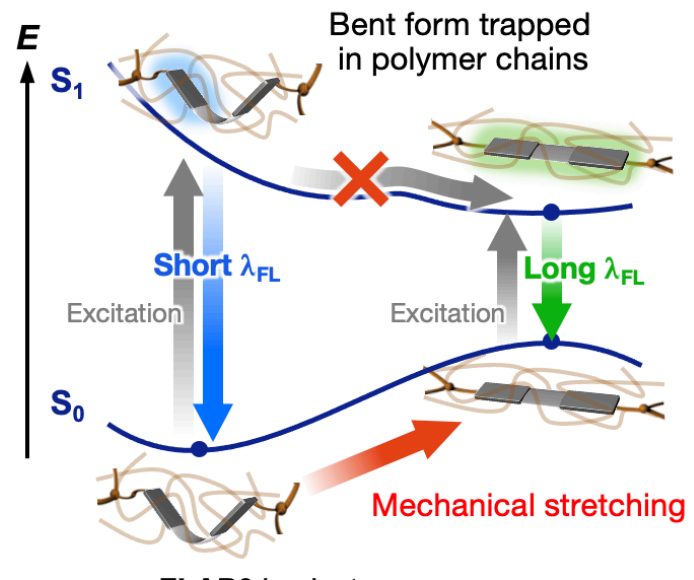

FLAPO in elastomers

(c)

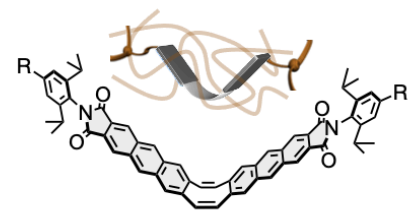

FLAPO in elastomers

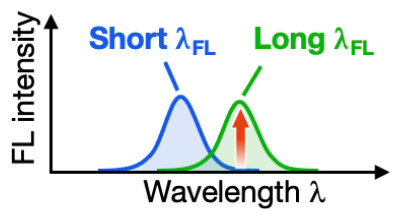

FL ratio $=I_{\text {Long }} / I_{\text {Short }}$

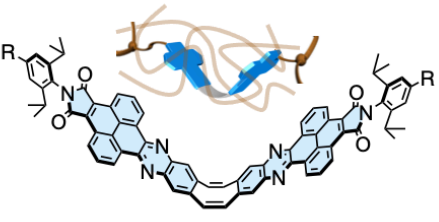

FLAP1 in elastomers

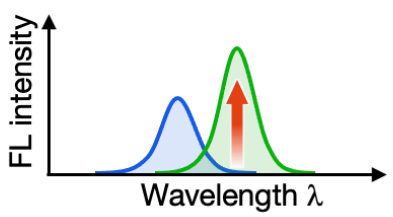

Larger FL ratio (b)

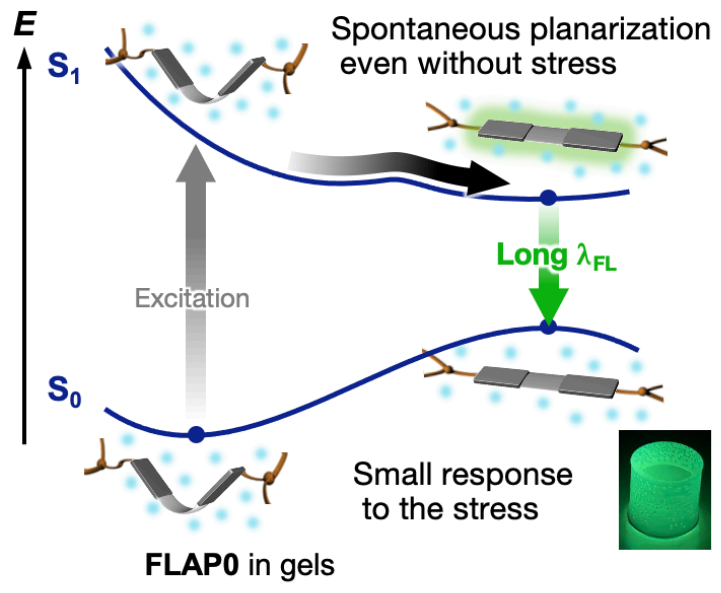

(d)

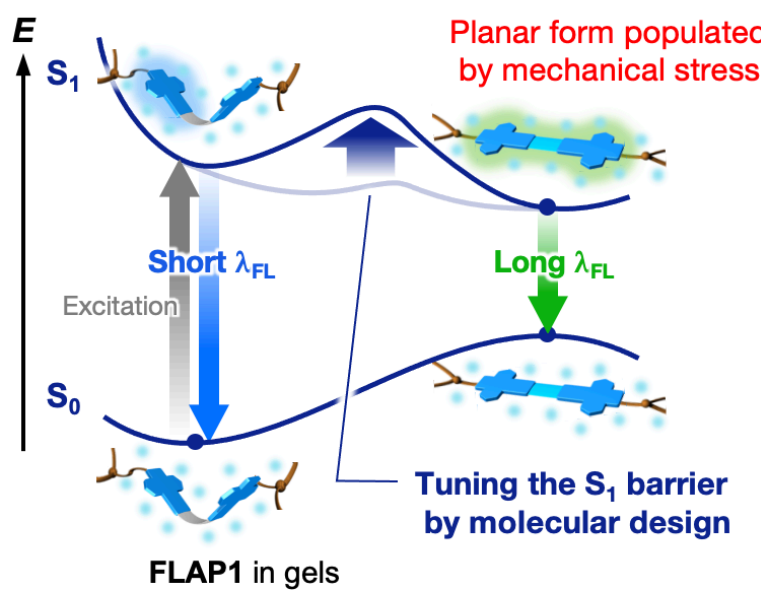

Figure 2. (a) Synthesis of segmented polyurethane elastomer with chemically doped FLAP0 as a force probe. (b) The $\mathrm{S}_{0}$ and $\mathrm{S}_{1}$ energy profiles of FLAP0 in the presence of solvent molecules. A photograph of the FLAP0-doped organogel is shown in the inset. (c) The patterns of the FL spectral change of FLAP0 and FLAP1 by stretching films of the solvent-free elastomers. (d) The excited-state engineering of the $\mathrm{S}_{1}$ energy profile in the wet conditions by changing the molecular structure from FLAP0 into FLAP1. 
Flapping molecule (FLAP) provide another category of the conformationally flexible force probe, ${ }^{90}$ which is unique due to its single-component dual FL properties originating from the interchangeable bent and planar conformations. ${ }^{91,92}$ FLAP is a promising ratiometric force probe to obtain the high signal-tonoise ratio in a simple experimental setup by canceling out the effects of the local probe concentration, excitation source variation, and light scattering by the sample. We recently reported a flapping force probe FLAP0 bearing the anthraceneimide wings (Figure $2 \mathrm{a}$ and $2 \mathrm{c}$ ). ${ }^{90}$ In the narrow free volume of the solvent-free elastomers, FLAP0 was surrounded by the polymer chains, suppressing the spontaneous planarization in the $S_{1}$ excited state. As a result, only the short $\lambda_{\mathrm{FL}}$ band of the bent form was observed in the steady-state FL spectrum of FLAP0doped unstretched film, while the compulsory planarization in the $\mathrm{S}_{0}$ ground state was induced by stretching the film, accompanied by the enhancement of the long $\lambda_{\mathrm{FL}}$ band (Figure $2 \mathrm{a}$ and $2 c)$. In the previous report, the ratiometric FL analysis of the FLAP0-doped polyurethanes revealed that the local stress concentration is twice as biased at crosslinkers than at main chains of the polymer network, particularly in a strain-hardening region. ${ }^{90}$ With these results in hand, we hypothesized that the flapping force probes would also be useful for quantifying local stress concentration in gels, which are more fragile than elastomers (Figure 1). However, FLAP0 only showed negligible FL response to the mechanical stress in organogels, because the solvated FLAP0 molecule underwent the spontaneous conformational planarization in the $\mathrm{S}_{1}$ excited state, emitting the long $\lambda_{\mathrm{FL}}$ band even without mechanical stress (Figure $2 \mathrm{~b}$ ). To solve this problem, the molecular design of the FLAP force probe has been modified from the flapping anthraceneimide (FLAP0) to the flapping pyreneimide (FLAP1). Tuning the excited-state energy profile with a higher $S_{1}$ barrier partially suppressed the $\mathrm{S}_{1}$ planarization, and realized the mechanical response in polymer gels (Figure 2d). Namely, the distribution of the planar $S_{1}$ species of FLAP1 became more populated only when the mechanical stress was applied. The excited-state engineering by changing FLAP0 into FLAP1 also resulted in the improvement of the dynamic range of the stress-induced FL spectral change in the stretched elastomers (Figure 2c).

\section{RESULTS AND DISCUSSION}

\section{Synthesis and Characterization of the Force Probes}

Molecular design was conceived based on the previously obtained insight. In a series of flapping acene dimers, we have reported that $\pi$-extension of the rigid wings of FLAP suppresses the spontaneous excited-state planarization. ${ }^{93,94}$ Since this suppression is necessary for designing the force probe working in gels, we here selected a flapping wing with a large $\pi$-conjugated system. Since the condensation reaction of pyrene dione and aromatic amines is reliable to construct large aromatic wings, ${ }^{95}$ we adopted the synthetic approach toward "pyrazaacenes" ${ }^{16}$ for the scheme.

Synthesis of a pyrene dione derivative 1 was performed with a bulky 2,6-diisopropylphenyl group on the nitrogen atom (Figure 3), according to the previous study. ${ }^{97}$ The 2,6-diisopropylphenyl group was introduced to prevent the aggregation of the fluorophore in solution or polymers. Reactions of the rigid wings, a pyrene dione derivative $\mathbf{3}$, with the flexible COT joint, tetramine of dibenzo $[a, e]$ cyclooctatetraene $4^{98}$ was conducted in a mixed solvent of chloroform and acetic acid under heating, providing FLAP1-H as a model compound of the force probe in 72\% yield. FLAP1-OH was synthesized from 9, in which the hydroxy groups were introduced at the $\mathrm{R}^{1}$ position as a reactive group for polymerization. Note that mesityl groups (Mes) were attached to the $\mathrm{R}^{2}$ position to improve solubility. Wing1-H and Wing1-OH (see Figure $4 \mathrm{~b}$ and Section 2 in SI) were synthesized as reference compounds by the reaction of $o$ phenylenediamine with $\mathbf{1}$ or $\mathbf{2}$.

Structural characterization of the flapping force probe was conducted by single-crystal X-ray crystallography. While Wing1-OH readily gave crystals suitable for single-crystal Xray structure analysis (Figure S3.2), the crystals of FLAP1-OH and FLAP1-BC (capped with the butylcarbamoyloxy groups at the probe termini) were not suitable for the measurement. We finally obtained the single-crystal X-ray structure of FLAP1$\mathbf{O H}^{\prime}$ with a 3,5-di-tert-butylphenyl group instead of mesityl groups. As shown in Figure 3b, FLAP1-OH' has a V-shaped structure in crystals, and the bending angles of the central cyclooctatetraene (COT), defined by the inset of Figure 5a, are $44.2^{\circ}$ and $45^{\circ}$, which are comparable to those of the previously reported flapping molecules..$^{33,99}$

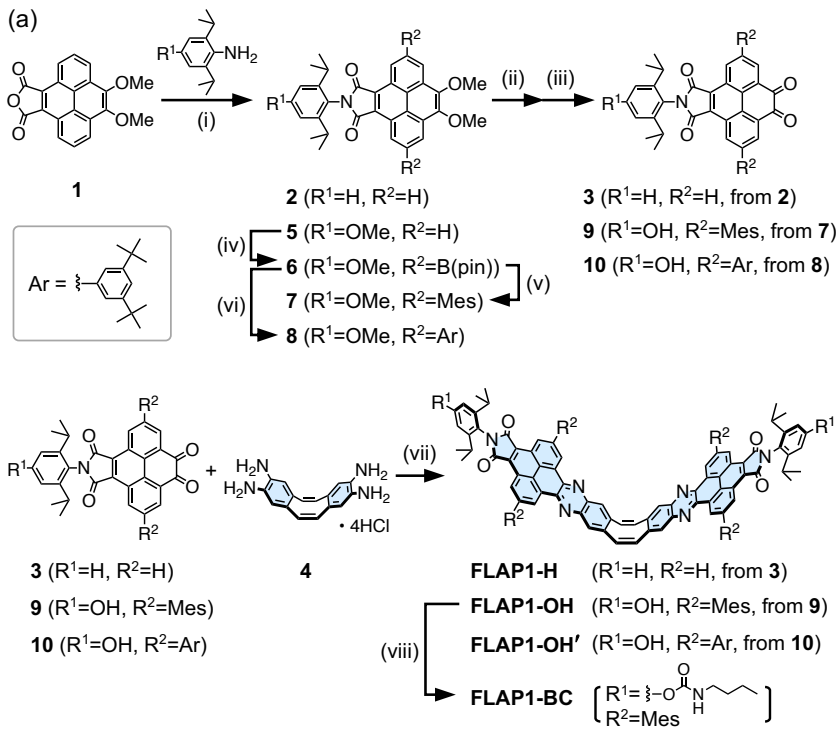

(b)

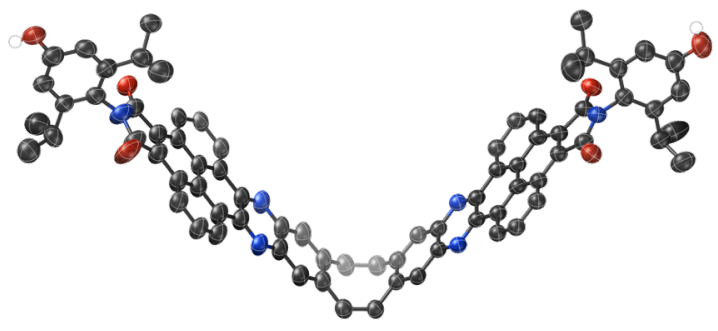

Figure 3. (a) Synthesis of the flapping pyreneimides. Mes: mesityl groups. Conditions: (i) $\mathrm{HOAc}, 135^{\circ} \mathrm{C}$; (ii) $\mathrm{BBr}_{3}, \mathrm{CH}_{2} \mathrm{Cl}_{2},-78{ }^{\circ} \mathrm{C}$ to r.t.; (iii) $\mathrm{Ag}_{2} \mathrm{O}, \mathrm{CH}_{2} \mathrm{Cl}_{2}$, r.t.; (iv) $[\mathrm{Ir}(\mu-\mathrm{OMe})(\mathrm{cod})]_{2}, 4,4^{\prime}$-di-tertbutyl-2,2'-bipyridyl, $\mathrm{B}_{2}$ (pin) $)_{2}$, tert-butyl methyl ether/mesitylene, $70{ }^{\circ} \mathrm{C}$; (v) mesityl bromide, SPhos Pd G2, methyltrioctylammonium chloride, toluene $/ \mathrm{K}_{2} \mathrm{CO}_{3}$ aq., $100{ }^{\circ} \mathrm{C}$; (vi) 1-bromo-3,5-ditert-butylbenzene, SPhos Pd G2, methyltrioctylammonium chloride, toluene $/ \mathrm{K}_{2} \mathrm{CO}_{3}$ aq., $100{ }^{\circ} \mathrm{C}$; (vii) $\mathrm{CHCl}_{3} / \mathrm{HOAc}, 75^{\circ} \mathrm{C}$; (viii) butyl isocyanate, $\mathrm{Et}_{3} \mathrm{~N}$, toluene, $110^{\circ} \mathrm{C}$. (b) Single crystal X-ray structure analysis of FLAP1-OH'. Thermal ellipsoids were drawn at the $50 \%$ probability level. Hydrogen atoms except for $\mathrm{OH}$ groups and 3,5-di-tert-butylphenyl groups were omitted for clarity. 


\section{Dual Fluorescence in Solution}

Optical properties of FLAP1-H were measured in toluene to confirm whether the excited-state planarization of the new force probe was properly suppressed. As shown in Figure 4a, the absorption spectrum showed a maximum at $447 \mathrm{~nm}$, and the peak of the FL spectrum was around $479 \mathrm{~nm}$ with a small Stokes shift $\left(1720 \mathrm{~cm}^{-1}\right)$. On the other hand, the conventional anthracene-based force probe (FLAP0-H) showed the spontaneous planarization in toluene and gave the FL spectrum peaked at $525 \mathrm{~nm}$ with a large Stokes shift $\left(4800 \mathrm{~cm}^{-1}\right)$ (Figure 5a, inset). ${ }^{92}$ This result suggests that FLAP1-H emits FL mainly from the bent form due to the effective suppression of the excitedstate planarization as expected. The FL quantum yield of FLAP1-H was 0.44 in toluene. More importantly, FLAP1-H showed a small FL peak at $523 \mathrm{~nm}$ in addition to the maximum around $460 \mathrm{~nm}$, and the spectral shape at the longer wavelength region was similar to that of FLAP0-H. When the FL spectrum of FLAP1-H was measured in a rigid PMMA matrix, in which the conformation planarization of FLAP is not allowed due to the confined space with small free volume, ${ }^{100}$ the peak at 523 nm disappeared, as shown by the blue dotted line. Such spectral change was not observed in Wing1-H (Figure 4b), indicating the long-wavelength FL of FLAP1-H was emitted from a partially populated planar form in the excited state. This assignment was supported by the fact that the FL lifetime of FLAP1$\mathbf{H}$ can be fitted by two components (SI, Section 4.3).

Variable-temperature FL spectra of FLAP1-H were measured in toluene to gain insight into the equilibrium between the bent and planar forms in the $\mathrm{S}_{1}$ excited state. Relative FL intensity of the long-wavelength component got decreased as the temperature became lower or higher than $233 \mathrm{~K}$ (Figures $4 \mathrm{c}$ and 4d). On the other hand, such behavior was not observed in Wing1-H (Figure S4.5). Since there was no concentration dependence in the shape of the absorption and FL spectra (Figure S4.1), and no significant changes were observed in the variabletemperature excitation spectra of FLAP1-H (Figure S4.4), the possibility of the presence of impurities or any structural changes in the ground state was excluded. The variable-temperature FL spectra in Figure 4c and 4d are typical to the dual FL system based on the equilibrium in the excited state (Figure 4f), 101,102 and the parameters related to this equilibrium $\left(E_{\mathrm{a}}\right.$ and $\Delta H$ in $\mathrm{S}_{1}$ ) can be calculated by Stevens-Ban plot ${ }^{101,103}$ based on the area ratio of the two FL bands and the measurement temperature. Assuming that the FL spectral shape of the planar FLAP1-H was similar to that of flapping anthracene, the activation energy $E_{\text {a }}$ was estimated to be $4.3 \mathrm{kcal} / \mathrm{mol}$, and the enthalpy change $\Delta H$ was around $-0.6 \mathrm{kcal} / \mathrm{mol}$ in $\mathrm{S}_{1}$ (Figure $4 \mathrm{e}$ ). The activation barrier of FLAP1-H for the $\mathrm{S}_{1}$ planarization is larger than the energy difference between the bent and planar forms, which is in stark contrast to the flapping anthracene (FLAP0-H) showing fast planarization dynamics in $\mathrm{S}_{1}{ }^{92}$
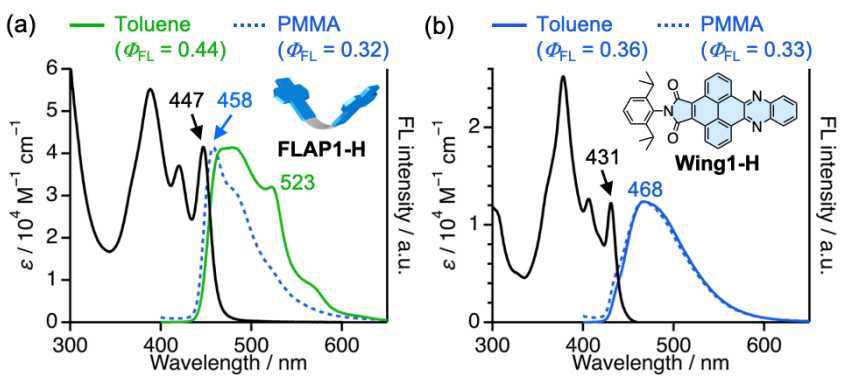

(c)

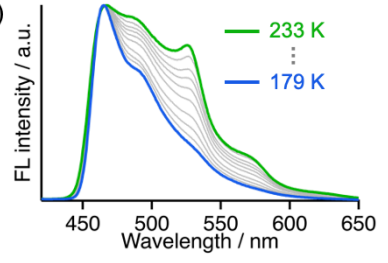

(e)

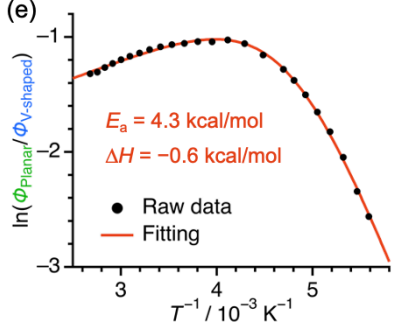

(d)

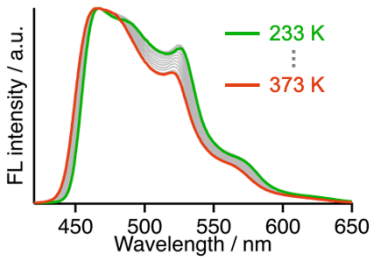

(f)

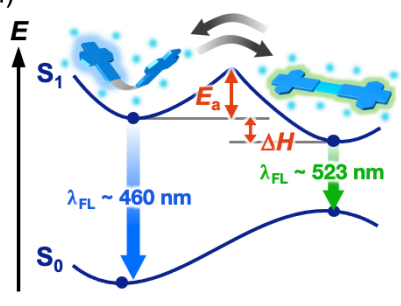

Figure 4. Optical properties of the pyreneimide-based force probe in toluene. (a) Absorption and FL spectra of FLAP1-H, compared with those of the reference compound (Wing1-H). (c, d) Variable temperature FL spectra of FLAP1-H. (e) Stevens-Ban plot of the FL quantum yield ratio of the $\mathrm{V}$-shaped and planar forms of FLAP1-H. (See Section 4.2 in SI for details on spectral decomposition.) (f) Energy profile that accounts for the dual FL of FLAP1H. 


\section{Interpretation of the Dual Fluorescence by Calculations}

DFT calculations were performed to explain why the excited state planarization of FLAP1-H was suppressed in the solution. Model compounds FLAP0', FLAP1', and Wing1' were treated, in which the 2,6-diisopropylphenyl groups of the original compounds were replaced by hydrogen atoms. Although the calculated results were sensitive to the level of theory, we adopted the PBE0/6-31+G(d)/PCM(toluene) level because the calculated absorption wavelength of Wing1' is close to the experimental results, and the shape of the $S_{1}$ energy diagram of FLAP1' is qualitatively in agreement with the Stevens-Ban plot (SI, Section 5.3). Figures 5a and 5b show the energy profiles of FLAP0' and FLAP1' in the $\mathrm{S}_{0}$ and $\mathrm{S}_{1}$ states delineated by changing the COT bending angle by $2.5^{\circ}$. In $\mathrm{S}_{0}$, the bent forms $\left(\theta \sim 40^{\circ}\right)$ are the most stable for both FLAPs due to the ring strain of COT, and the conformational relaxation in $\mathrm{S}_{1}$ occurs from these structures. Interestingly, the energy diagram of the $\mathrm{S}_{1}$ state is quite different between FLAP0' and FLAP1', where FLAP0' partially flattens to a shallow V-shaped form $(\theta$ $=29.5^{\circ}$ ) followed by a complete planarization with a very small energy barrier $(\sim 0.2 \mathrm{kcal} / \mathrm{mol})$, consistent with the observed green FL (inset of Figure 5a) and previously reported ultrafast dynamics in the excited state. On the other hand, FLAP1' showed a larger energy barrier $(\sim 1.3 \mathrm{kcal} / \mathrm{mol})$ between the bent and planar forms than FLAP0' . Although these results are qualitative, the difference in the planarization behavior can be interpreted from the viewpoint of molecular orbital distribution. In FLAP0', the frontier orbitals are delocalized over the whole molecular frame including the central COT ring, in which the orbital phase is favorable for planarization (Figure 5c). On the other hand, LUMO of FLAP1' is localized on the electron-withdrawing imide moiety without the contribution of the COT moiety (Figure 5d), suggesting that planarization is less prone to occur. This difference in the orbital distribution is also consistent with the charge-transfer (CT) nature of the FL from the bent form of FLAP1-H, experimentally evaluated by LippertMataga plot (SI, Section 4.4). ${ }^{104,105}$ Note that the FL derived from the planar form, peaked at $523 \mathrm{~nm}$ in toluene, showed less solvent dependence (Figure S4.13), consistent with the similarly delocalized HOMO and LUMO over the planar molecular frame $\left(\theta=0^{\circ}\right)$ of FLAP1'. The excited-state engineering based on the molecular orbitals (de)localization is useful for designing dual-fluorescence molecules with desired optical properties.
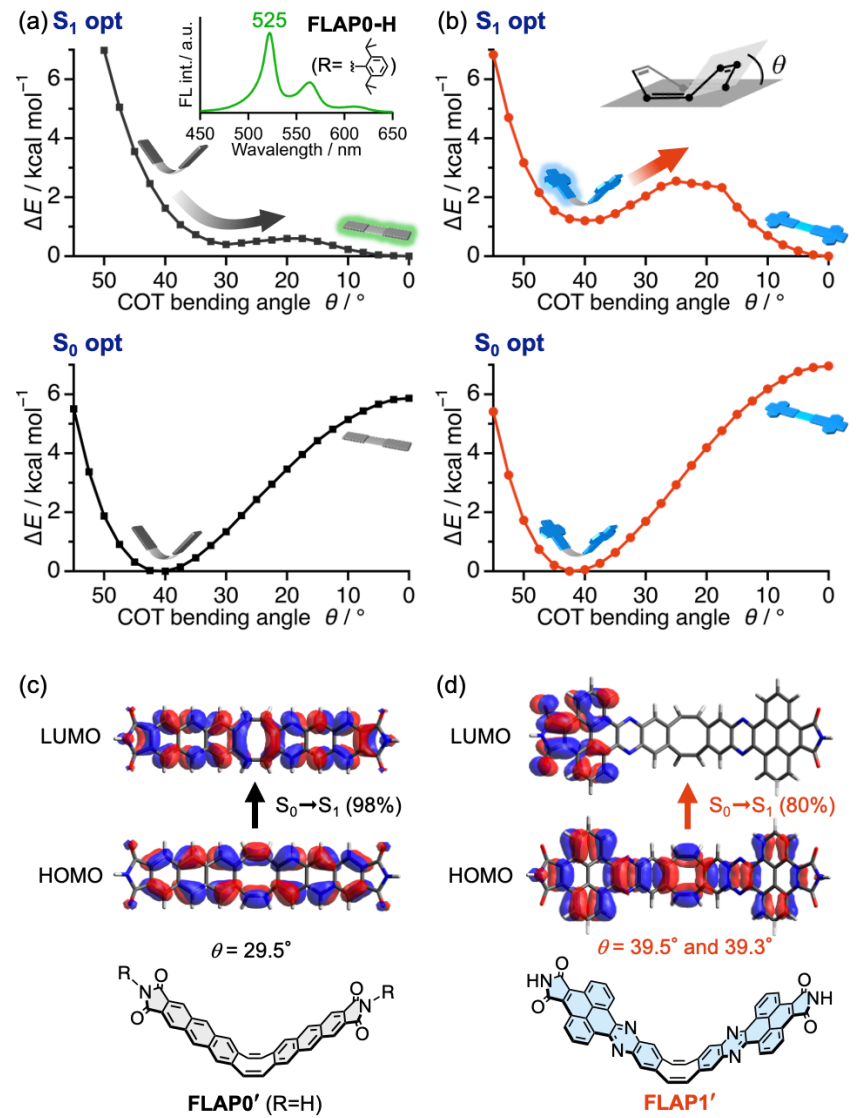

Figure 5. $\mathrm{S}_{0}$ and $\mathrm{S}_{1}$ energy profiles of (a) FLAP0' and (b) FLAP1'. COT bending angle $\theta$ was defined by the dihedral angle shown in the inset of (b). (c, d) Kohn-Sham orbitals of FLAP0' and FLAP1' displaying the distinct $\mathrm{S}_{1}$ electronic character at the $\mathrm{S}_{0}$-optimized bent geometries. The inset of (a) shows FL spectra of FLAP0-H measured in toluene for comparison with FLAP1-H. Geometry optimizations were performed at the (TD-)PBE0/6$31+\mathrm{G}(\mathrm{d}) / \mathrm{PCM}$ (toluene) level. 
(a)
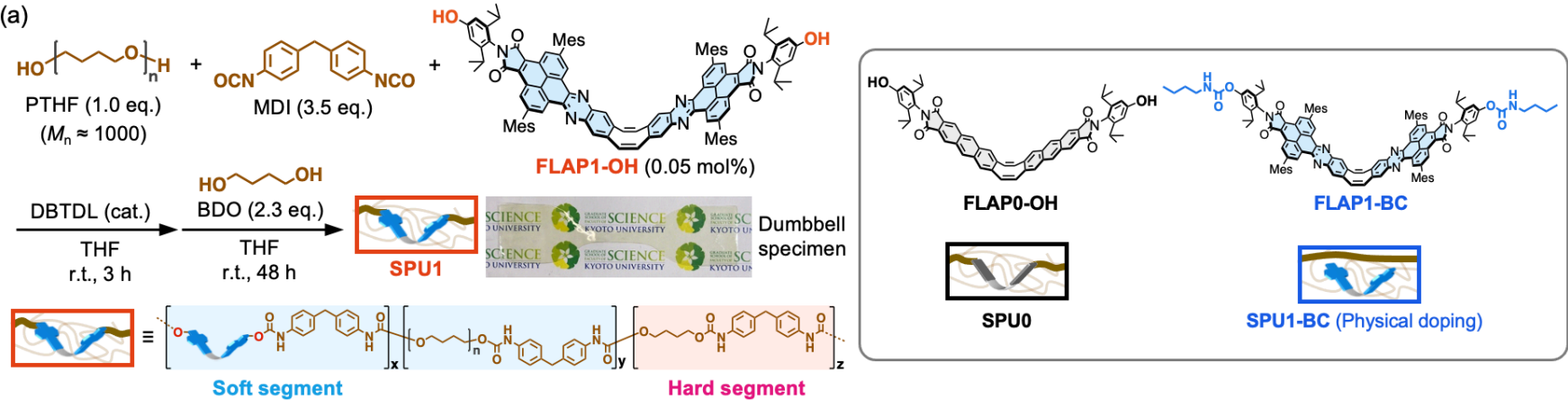

Soft segment
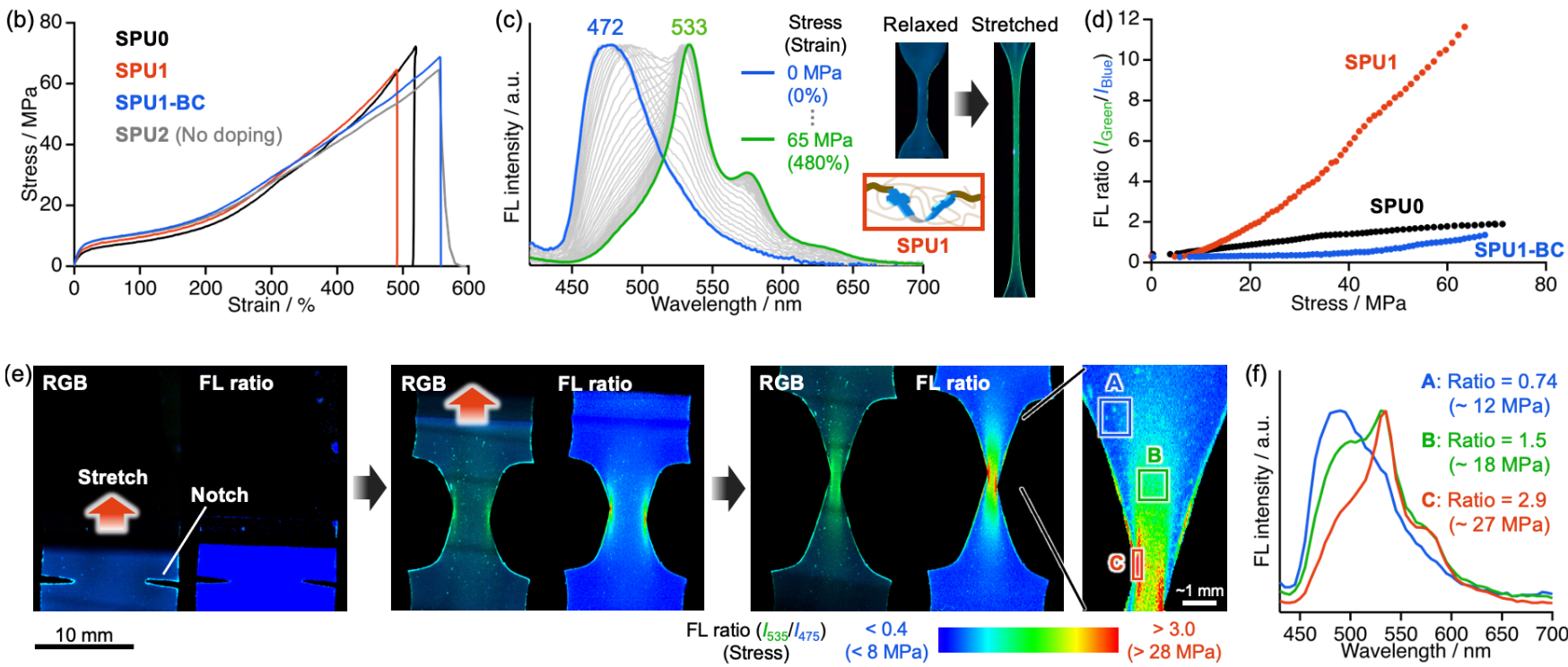

Figure 6. (a) Synthesis of segmented polyurethane elastomer (SPU1) chemically doped with FLAP1-OH as a force probe. (b) Stress-strain curves of the SPUs. (c) FL spectral change of SPU1 during the tensile test. Photographs of the specimen under UV light are shown beside. (d) FL intensity ratio plotted against nominal stress in the tensile test. $I_{533 \mathrm{~nm}} / I_{472 \mathrm{~nm}}$ was used as the ratio for SPU1 and SPU1-BC, and $I_{525 \mathrm{~nm}} / I_{474 \mathrm{~nm}}$ was used for SPU0. (e) Photographs (RGB) and stress mapping (FL ratio) of the notched SPU1 film. The images were recorded using a hyperspectral camera, and the photographs were reconstructed from RGB channels $(R=700 \mathrm{~nm}, \mathrm{G}=545 \mathrm{~nm}, \mathrm{~B}=480 \mathrm{~nm}$ ). (f) FL spectra averaged over the regions A-C shown in the left panel (bandwidth: 5nm), and the estimated local stress based on the panel (d). (g) Energy profile of FLAP1' obtained by constrained geometry optimization, in which the distance between terminal hydrogen atoms $(x)$ was fixed to the given extension distance $(\Delta x)$. The elongation distance was calculated by taking the $\mathrm{S}_{0}$ optimized structure $(x=23.1 \AA)$ as the initial geometry. The calculation was conducted on the (TD-)PBE0/6-31+G(d)/PCM(toluene) level.

\section{Improved Dynamic Range of the FL Ratio Change}

Since the photophysical properties of FLAP1-H in solution have been clarified, the FL response of FLAP1-OH as a force probe was demonstrated in the stretched elastomers. Since the FL spectrum of FLAP1-BC (bearing the butylcarbamoyloxy groups at the termini) in toluene was similar to that of FLAP1H (Figure S4.3), the mesityl groups and urethane moiety would not affect the photophysical properties of the force probe introduced into polyurethane. First, FLAP1-OH was incorporated into segmented polyurethane (SPU) composed of poly(tetrahydrofuran) (PTHF), methylenediphenyl 4,4'-diisocyanate (MDI), and 1,4-butanediol (BDO). This is a widely used polymer for introducing various mechanophores, ${ }^{39}$ and $0.1-0.2 \mathrm{~mm}$ thick dumbbell-shaped specimens were prepared (Figure 6a). In the same way, the following three polymers, 1) SPU0 chemically doped (covalently incorporated) with FLAP0-OH, 2) SPU1BC physically (non-covalently) doped with FLAP1-BC, and 3) SPU2 without any force probe were prepared as control experiments (Figure S6.1). The synthesized polyurethanes were characterized by ${ }^{1} \mathrm{H}$ NMR spectra, and the ratio of soft segments to hard segments was confirmed to be $1: 2.3$, the same as the preparation ratio (Figures S6.2-S6.5). On the contrary, the ${ }^{1} \mathrm{H}$ NMR signal of the incorporated force probe was not observed due to the minimal amount of addition. Besides, the thermal properties of the synthesized SPUs measured by differential scanning calorimetry (DSC) were comparable to previously reported similar polyurethanes (Figure S6.7) ${ }^{84}$

The stress-strain curves obtained from tensile tests of the prepared specimens are shown in Figure 6b. Stress was calculated as nominal stress. The mechanical properties of the synthesized SPUs were comparable regardless of the presence of the probe, indicating that the addition of the flapping force probe has little effect on the mechanical properties. The FL spectrum of SPU1 was monitored during the tensile tests (Figure $6 \mathrm{c}$ ). The relative intensity of the FL band at $472 \mathrm{~nm}$, emitted from the bent form of FLAP, became decreased, and the FL peak at $533 \mathrm{~nm}$ concomitantly increased with a characteristic vibrational band at $575 \mathrm{~nm}$, assigned to the FL emitted from the 
planarized form of FLAP. The distinct blue-to-green FL color change occurred rapidly and reversibly, which can be clearly recognized by the naked eye (Supporting Movie 1). Note that the average distance between the fluorescent probes was approximately $20 \mathrm{~nm}$, estimated from the concentration of FLAP in the specimen (SI, Section 6.1). Since the distance is much farther than that for FRET $(<10 \mathrm{~nm})$, the FRET-induced FL perturbation can be ignored.

The FL intensity ratio at $533 \mathrm{~nm}$ and $472 \mathrm{~nm}\left(I_{533} / I_{472}\right)$ was plotted against stress. The FL intensity ratio monotonically increased from about 0.3 up to $\approx 11$ (Figure $6 \mathrm{~d}$ ). In contrast, when the same measurement was performed for SPU0 incorporating FLAP0, the FL intensity ratio only reached up to $\approx 2$ (Figure S6.10). The wider dynamic range in the FL ratio of FLAP1 is an important advantage of the new flapping force probe. The FL spectra of the negative control specimen SPU1-BC showed little response by stretching, as expected. However, only when the film was strongly stretched with over $40 \mathrm{MPa}$ stress, a small spectral change was observed, which might be related to the strain-induced crystallization of the polymer chains (Figure S6.9-S6.12). Therefore, we only discuss the response of SPU1 below $40 \mathrm{MPa}$. The ratiometric FL imaging of the notched SPU1 specimen was performed with a hyperspectral camera (Figure 6e). As shown Supporting Movie 2, the FL intensity ratio increases in the crack front region just before the crack propagation, while it returns to a small ratio after the crack propagation completed at the corresponding region. From the relationship between the stress and the FL ratio in Figure 6d, the average stress was estimated in each of the three regions A-C (Figure $6 \mathrm{e}$, right). As a result, the local stress distribution in the range of 12-27 MPa were visualized with the submillimeter spatial resolution. The ratiometric FL imaging enables sensitive and reversible stress mapping due to the conformational flexibility of the flapping force probe.

\section{Synthesis of Crosslinked Polyurethanes and Preparation of the Organogels}

To demonstrate the efficacy of the force probe FLAP1 in wet materials, crosslinked polyurethanes (PU) were synthesized (Figure 7a). Poly(tetrahydrofuran) (PTHF) and hexamethylene diisocyanate (HDI) were selected as the main chain components, while triethanolamine (TEA) was used as the crosslinker. ${ }^{90}$ The crosslinking density, defined as the molar fraction of TEA to all monomers, was set to $8.7 \%$. A trace amount of FLAP1-OH $(0.01 \mathrm{~mol} \%$ to HDI) was added to the solution of the mixture of the monomers, and the polymerization was initiated by a tin catalyst (DBTDL). The resulting solution was poured into a poly(tetrafluoroethylene) (PTFE) mold to prepare a dry cylindrical specimen of PU1. Organogels were prepared by swelling the crosslinked polyurethane PU1 with organic solvents. By using cyclopentyl methyl ether (CPME) as a less volatile solvent (Figure 7b), the FL spectra of the bent and planar forms of FLAP1-H were well separated. The cylindrical specimens of PUO and PU1 were prepared using a custom-made PTFE mold and immersed in CPME for more than 48 hours to reach the equilibrium swelling (Figure S8.1), designated as Gel0 and Gel1, respectively. The swelling ratio $V / V_{0}$, defined as the volume ratio before and after swelling, was approximately 4.3. Figures $7 \mathrm{~d}$ and $7 \mathrm{e}$ show the spectral change in absorption before and after swelling. As seen in the photographs, the blue FL of PU1 was preserved even after swelling, while PUO showed a significant FL change by swelling. Since the intrinsic sensitivities of the force probes FLAP0 and FLAP1 would be comparable (SI, Section 7.5), the planarization of FLAP0 should not be caused by swelling pressure, unlike the example of the mechanophores activated by swelling glassy PMMA. ${ }^{106,107}$ Rather, FLAP0 in Gel0 would undergo the spontaneous $\mathrm{S}_{1}$ planarization when surrounded by solvent molecules. On the other hand, the undesired $\mathrm{S}_{1}$ planarization was almost completely suppressed for FLAP1 in Gel1.
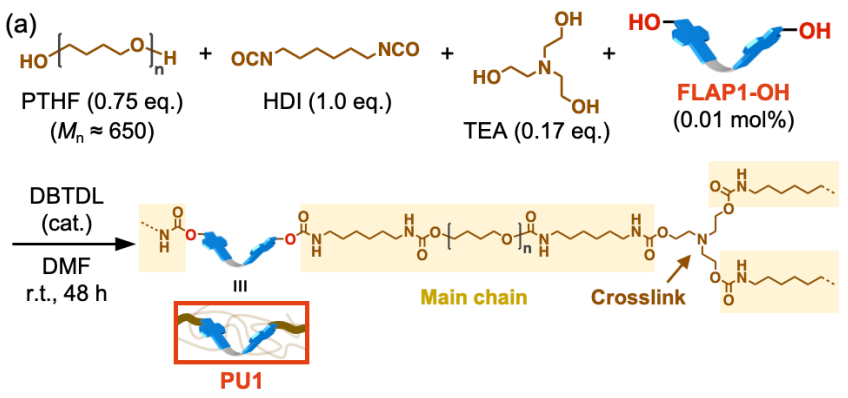

(b)

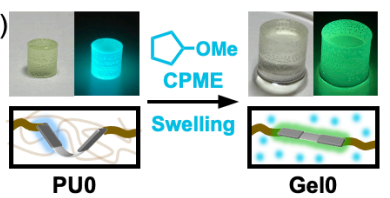

(d).

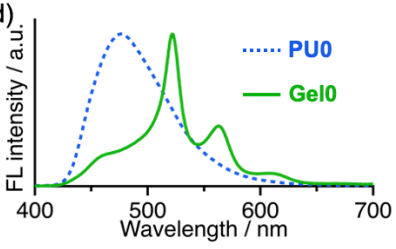

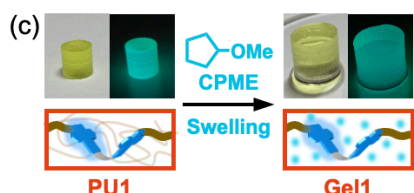

(e).

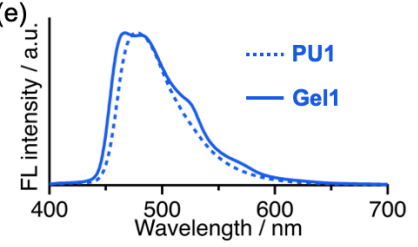

Figure 7. (a) Synthesis of the crosslinked polyurethane elastomer (PU1) chemically doped with FLAP1-OH as a force probe. Cylindrical specimens of (b) Gel0 and (c) Gel1 prepared by swelling the corresponding crosslinked PU elastomers with cyclopentyl methyl ether (CPME). FL spectra of (d) Gel0 and (e) Gel1 compared to those before swelling.

\section{Fluorescence Response by Compressing the Organogels}

Compression tests of the cylindrical gel specimens were successfully conducted (Figure 8a and Supporting Movie 3), while the tensile tests using the dumbbell specimens were difficult due to the fragility of the gel materials. Although the fracture strain was considerably dependent on the individual samples, Gel0 and Gel1 showed the similar stress-strain curves in Figure 8b. In contrast, the FL spectra of Gel0 and Gel1 showed distinct behaviors upon the compression (Figures 8c and 8d), where the bottom surface of the cylindrical specimen was observed using the same experimental setup shown in Figure 9a. The ratio of FL intensity at $480 \mathrm{~nm}$ and $523 \mathrm{~nm}$ was monitored during the compression test, whose values were plotted against the nominal (engineering) strain, stress, and strain energy density in Figures 8e, 8f, and 8g, respectively. While the dynamic range of the FL response of Gel1 was limited due to its fragility compared to the solvent-free PU1, the quantitative analysis was well performed with the sufficient signal-to-noise ratio. The control material, Gel0, gave the negative results in the spectroscopic analysis (Figure S9.3). 
(a)

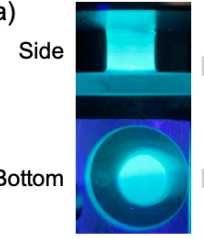

$0 \%$ strain

(c)
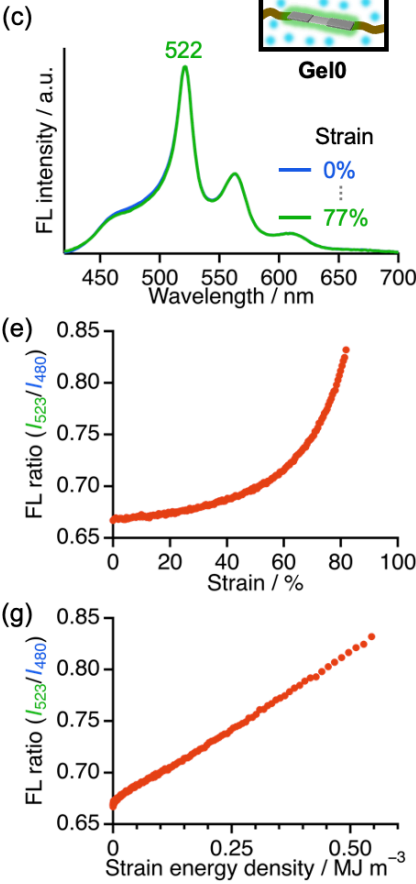

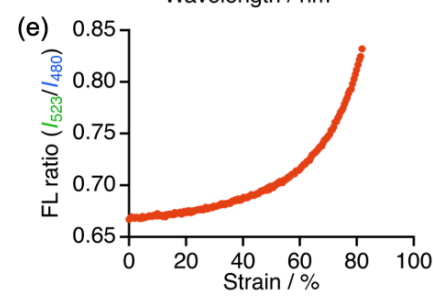

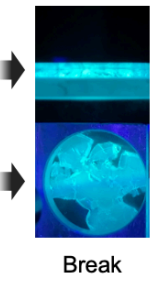

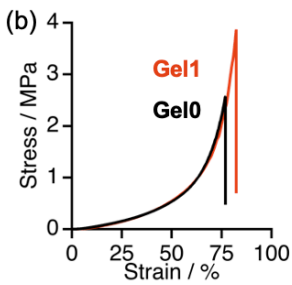

(d)
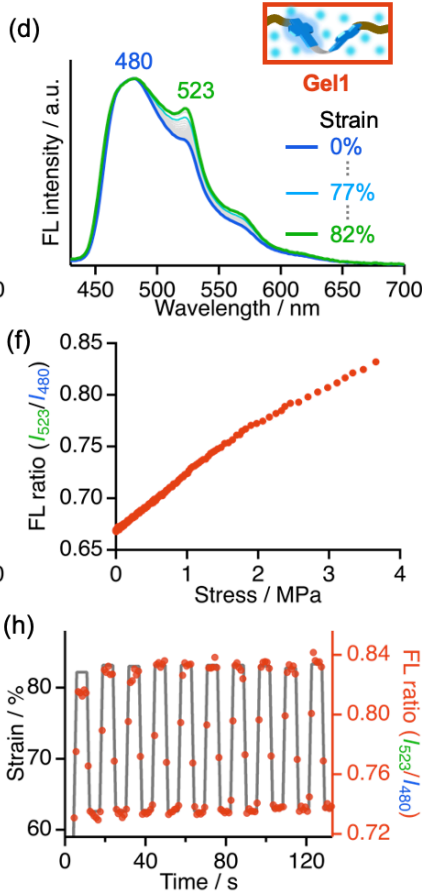

Figure 8. (a) Photographs of the compression process of a cylindrical specimen of Gel1 under UV light $(365 \mathrm{~nm})$. (b) Nominal stress-strain curves of the gels. FL spectral change of (c) Gel0 and (d) Gel1 during the compression test. FL intensity ratio plotted against (e) strain, (f) stress, and (g) strain energy density in the compression test. (h) Reversible response of the FL ratio during ten cycles of compression and release processes.

Interestingly, the FL response of Gel1 was different from that of the corresponding solvent-free elastomer in the lowstress region $(<1 \mathrm{MPa})$ (Figure $8 \mathrm{f}$ and S7.7), where PU1 did not show the change in the FL intensity ratio. The FL ratio showed an excellent linear relationship when the strain energy density, defined as the area under the stress-strain curve, was taken as the abscissa (Figure 8g). These results suggested that the polymer chains were pre-stretched by swelling before compression, although the degree was not remarkable. The FL response of Gel1 was reversible, and the cycling test with a strain rate of $0.14 \mathrm{~s}^{-1}$ (Figures S9.4) showed that the FL intensity ratio can follow the strain or stress quickly (Figure $8 \mathrm{~h}$ ).

\section{Real-time Stress Mapping of the Compressed Organogels by Ratiometric Fluorescence Imaging}

Visualization of the non-uniform stress distribution on the gel was demonstrated. We applied pressure to the plate-shaped Gel1 with metal stamps using the experimental setup shown in Figure $9 \mathrm{a}-\mathrm{c}$. With the naked eye, it was difficult to distinguish the degree of the mechanical stress applied under each alphabetical stamp. However, the ratiometric FL imaging showed that the local stress was more applied under the "L" and "P" metal stamps rather than "F" and "A" (Figure 9d and Supporting
Movie 4), which probably originates from the slightly different thicknesses of these metal stamps. Since the bottom area of the cylindrical specimen in Figure 8 largely changed upon compression, a calibration curve was obtained to estimate the true stress from the observed FL intensity ratio, by tracking and correcting the bottom area change (Figure 9e and S9.5). According to this estimation, true compression stresses applied on the regions $\mathrm{A}-\mathrm{C}$ of Gel1 were quantitatively evaluated in the range of $0-1 \mathrm{MPa}$ with the submillimeter spatial resolution (Figure $9 \mathrm{~d}$ and 9f).
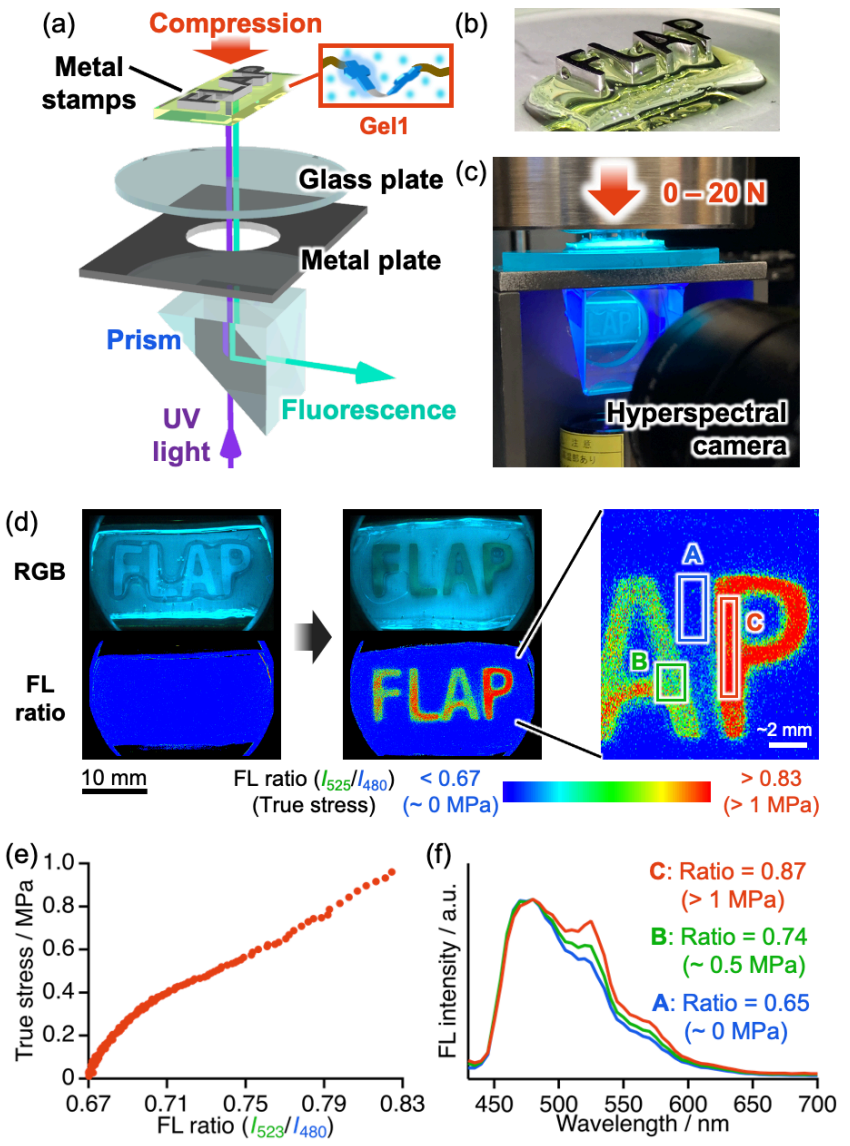

Figure 9. (a) Experimental setup for the cyclic compression test of Gel1 using metal stamps. Photographs of (b) metal stamps placed on Gel1. (c) The bottom of the gel was observed with a hyperspectral camera through the prism. (d) Photographs (RGB) and stress mapping (FL ratio) of Gel1 compressed by metal stamps. The images were obtained in the same protocol as Figure 6. (e) Calibration curve for estimating true stress from the observed FL ratio of Gel1, obtained from Figure 8f with the consideration of the change in the bottom area of the gels. (f) FL spectra averaged over the regions A-C shown in the panel (d) (bandwidth: $5 \mathrm{~nm}$ ), and the local true stress estimated from the calibration curve in the panel (e).

\section{ASSOCIATED CONTENT}

\section{Supporting Information}

Experimental and theoretical details (PDF)

Movie 1 showing the reversible FL response of the SPU1 film (MP4) 
Movie 2 showing the ratiometric imaging of the stress applied to the notched SPU1 film (MP4)

Movie 3 showing compression of the cylindrical Gel1 specimen (MP4)

Movie 4 showing the ratiometric imaging of the stress applied to Gel1 by the metal stamps (MP4)

\section{Accession Codes}

CCDC 2122594 and 2122595 contains the supplementary crystallographic data for this paper. These data can be obtained free of charge via www.ccdc.cam.ac.uk/data_request/cif, or by emailing data_request@ccdc.cam.ac.uk, or by contacting The Cambridge Crystallographic Data Centre, 12 Union Road, Cambridge CB2 1EZ, UK; fax: +44 1223336033.

\section{AUTHOR INFORMATION}

\section{Corresponding Author}

Shohei Saito: saito.shohei.4c@kyoto-u.ac.jp

\section{Author}

Takuya Yamakado

\section{Notes}

The authors declare no competing financial interest.

\section{ACKNOWLEDGMENT}

JST PRESTO (FRONTIER) and JST FOREST Grant Numbers JPMJPR16P6 (S.S.) and JPMJFR201L (S.S.), JSPS KAKENHI Grant Number JP21H01917 (S.S), and JSPS Fellowships Grant Number JP19J22034 (T.Y). Inoue Foundation for Science (S.S.) and Toray Science Foundation (S.S.). We thank Prof. Hideki Yorimitsu and Prof. Hiroshi Kamitakahara (Kyoto University) for their help with the high-resolution mass spectrometry measurements.

\section{REFERENCES}

(1) Li, J.; Mooney, D. J. Designing hydrogels for controlled drug delivery. Nat. Rev. Mater. 2016, 1, 16071.

(2) Lee, K. Y.; Mooney, D. J. Hydrogels for Tissue Engineering. Chem. Rev. 2001, 101, 1869-1880.

(3) Lim, H.-R.; Kim, H. S.; Qazi, R.; Kwon, Y.-T.; Jeong, J.-W.; Yeo, W.-H. Advanced Soft Materials, Sensor Integrations, and Applications of Wearable Flexible Hybrid Electronics in Healthcare, Energy, and Environment. Adv. Mater. 2020, 32, 1901924.(review)

(4) Hines, L.; Petersen, K.; Lum, G. Z.; Sitti, M. Soft Actuators for Small-Scale Robotics. Adv. Mater. 2017, 29, 1603483.(review)

(5) Yang, C.; Suo, Z. Hydrogel ionotronics. Nat. Rev. Mater. 2018, $3,125-142$.

(6) Calvert, P. Hydrogels for Soft Machines. Adv. Mater. 2009, 21, 743-756. (review)

(7) Creton, C. 50th Anniversary Perspective: Networks and Gels: Soft but Dynamic and Tough. Macromolecules 2017, 50, 82978316.

(8) Zhao, X.; Chen, X.; Yuk, H.; Lin, S.; Liu, X.; Parada, G. Soft Materials by Design: Unconventional Polymer Networks Give Extreme Properties. Chem. Rev. 2021, 121, 4309-4372.

(9) Gong, J. P.; Katsuyama, Y.; Kurokawa, T.; Osada, Y. DoubleNetwork Hydrogels with Extremely High Mechanical Strength. Adv. Mater. 2003, 15, 1155-1158.

(10) Gong, J. P. Why are double network hydrogels so tough? Soft Matter 2010, 6, 2583-2590.

(11) Matsuda, T.; Kawakami, R.; Namba, R.; Nakajima, T.; Gong, J. $\mathrm{P}$. Mechanoresponsive self-growing hydrogels inspired by muscle training. Science 2019, 363, 504-508.
(12) Wang, Z.; Zheng, X.; Ouchi, T.; Kouznetsova, T. B.; Beech, H. K.; Av-Ron, S.; Matsuda, T.; Bowser, B. H.; Wang, S.; Johnson, J. A.; Kalow, J. A.; Olsen, B. D.; Gong, J. P.; Rubinstein, M.; Craig, S. L. Toughening hydrogels through force-triggered chemical reactions that lengthen polymer strands. Science 2021, 374, 193-196.

(13) Tuncaboylu, D. C.; Sari, M.; Oppermann, W.; Okay, O. Tough and Self-Healing Hydrogels Formed via Hydrophobic Interactions. Macromolecules 2011, 44, 4997.

(14) Sun, J.-Y.; Zhao, X.; Illeperuma, W. R. K.; Chaudhuri, O.; Oh, K. H.; Mooney, D. J.; Vlassak, J. J.; Suo, Z. Highly stretchable and tough hydrogels. Nature 2012, 489, 133-136.

(15) Guo, M.; Pitet, L. M.; Wyss, H. M.; Vos, M.; Dankers, P. Y. W.; E. W. Meijer Tough Stimuli-Responsive Supramolecular Hydrogels with Hydrogen-Bonding Network Junctions. J. Am. Chem. Soc. 2014, 136, 6969-6977.

(16) Dai, X.; Zhang, Y.; Gao, L.; Bai, T.; Wang, W.; Cui, Y.; Liu, W. A Mechanically Strong, Highly Stable, Thermoplastic, and SelfHealable Supramolecular Polymer Hydrogel. Adv. Mater. 2017, 29, 1702616.

(17) Lei, H.; Dong, L.; Li, Y.; Zhang, J.; Chen, H.; Wu, J,; Zhang, Y.; Fan, Q.; Xue, B.; Qin, M.; Chen, B.; Cao, Y.; Wang. W. Stretchable hydrogels with low hysteresis and antifatigue fracture based on polyprotein cross-linkers. Nat. Commun. 2020, 11, 4032.

(18) Haraguchi, K.; Takehisa, T. Nanocomposite Hydrogels: A Unique Organic-Inorganic Network Structure with Extraordinary Mechanical, Optical, and Swelling/De-swelling Properties. Adv. Mater. 2002, 14, 1120-1124.

(19) Gao, G.; Du, G.; Sun, Y.; Fu, J. Self-Healable, Tough, and Ultrastretchable Nanocomposite Hydrogels Based on Reversible Polyacrylamide/Montmorillonite Adsorption. ACS Appl. Mater. Interfaces 2015, 7, 5029-5037.

(20) Shao, C.; Chang, H.; Wang, M.; Xu, F.; Yang, J. High-Strength, Tough, and Self-Healing Nanocomposite Physical Hydrogels Based on the Synergistic Effects of Dynamic Hydrogen Bond and Dual Coordination Bonds. ACS Appl. Mater. Interfaces 2017, 9, 28305-28318.

(21) Li, H.-J.; Jiang, H.; Haraguchi, K. Ultrastiff, Thermoresponsive Nanocomposite Hydrogels Composed of Ternary PolymerClay-Silica Networks. Macromolecules 2018, 51, 529-539.

(22) Lin, S.; Lui, X.; Liu, J.; Yuk, H.; Loh, H.-C.; Parada, G. A.; Settens, C.; Song, J.; Masic, A.; McKinley, G. H.; Zhao, X. Antifatigue-fracture hydrogels. Sci. Adv. 2019, 5, eaau8528.

(23) Liu, C.; Morimoto, N.; Jiang, L.; Kawahara, S.; Noritomi, T.; Yokoyama, H.; Mayumi, K.; Ito, K. Tough hydrogels with rapid self-reinforcement. Science 2021, 372, 1078-1081.

(24) Zhao, X. Multi-scale multi-mechanism design of tough hydrogels: building dissipation into stretchy networks. Soft Matter 2014, 10, 672-687.

(25) Ducrot, E.; Chen, Y.; Bulters, M.; Sijbesma, R. P.; Creton. C. Toughening Elastomers with Sacrificial Bonds and Watching Them Break. Science 2014, 344, 186-189.

(26) Neal, J. A.1 Mozhdehi, D.; Guan, Z. Enhancing Mechanical Performance of a Covalent Self-Healing Material by Sacrificial Noncovalent Bonds. J. Am. Chem. Soc. 2015, 137, 4846-4850.

(27) Filippidi, E.; Cristiani, T. R.; Eisenbach, C. D.; Waite, J. H.; Israelachvili, J. N.; Ahn, B. K.; Valentine, M. T. Toughening elastomers using mussel-inspired iron-catechol complexes. Science 2017, 358, 502-505.

(28) Wu, J.; Cai, L.-H.; Weitz, D. A. Tough Self-Healing Elastomers by Molecular Enforced Integration of Covalent and Reversible Networks. Adv. Mater. 2017, 29, 1702616.

(29) Gotoh, H.; Liu, C.; Imran, A. B.; Hara, M.; Seki, T.; Mayumi, K.; Ito, K.; Takeoka, Y. Optically transparent, high-toughness elastomer using a polyrotaxane cross-linker as a molecular pulley. Sci. $A d v . \mathbf{2 0 1 8 , ~ 4 , ~ e a a t 7 6 2 9 . ~}$

(30) Sakai, H.; Aoki, D.; Seshimo, K.; Mayumi, K.; Nishitsuji, S.; Kurose, T.; Ito, H.; Otsuka, H. Visualization and Quantitative Evaluation of Toughening Polymer Networks by a Sacrificial Dynamic Cross-Linker with Mechanochromic Properties. ACS Macro Lett. 2020, 9, 1108-1113. 
(31) Sakai, T.; Matsunaga, T.; Yamamoto, Y.; Ito, C.; Yoshida, R.; Suzuki, S.; Sasaki, N.; Shibayama, M.; Chung, U. Design and Fabrication of a High-Strength Hydrogel with Ideally Homogeneous Network Structure from Tetrahedron-like Macromonomers. Macromolecules 2008, 41, 5379-5384.

(32) Sakai, T.; Akagi, Y.; Matsunaga, T.; Kurakazu, M.; Chung, U.; Shibayama, M. Highly Elastic and Deformable Hydrogel Formed from Tetra-arm Polymers. Macromol. Rapid Commun. 2010, 31, 1954-1959.

(33) Kamata, H.; Akagi, Y.; Kayasuga-Kariya, Y.; Chung, U.; Sakai, T. "Nonswellable" Hydrogel Without Mechanical Hysteresis. Science 2014, 343, 873-875.

(34) Li, X.; Nakagawa, S.; Tsuji, Y.; Watanabe, N.; Shibayama, M. Polymer gel with a flexible and highly ordered three-dimensional network synthesized via bond percolation. Sci. Adv. 2019, 5, eaax8647.

(35) Okumura, Y.; Ito, K. The Polyrotaxane Gel: A Topological Gel by Figure-of-Eight Cross-links. Adv. Mater. 2001, 13, 485-487.

(36) Imran, A. B.; Esaki, K.; Gotoh, H.; Seki, T.; Ito, K.; Sakai, Y.; Takeoka, Y. Extremely stretchable thermosensitive hydrogels by introducing slide-ring polyrotaxane cross-linkers and ionic groups into the polymer network. Nat. Commun. 2014, 5, 4124.

(37) Choi, S.; Kwon, T.; Coskun, A.; Choi, J. W. Highly elastic binders integratingpolyrotaxanes for siliconmicroparticle anodes in lithiumion batteries. Science 2017, 357, 279-283.

(38) Chen, Y.; Sanoja, G.; Creton, C. Mechanochemistry unveils stress transfer during sacrificial bond fracture of tough multiple network elastomers. Chem. Sci. 2021, 12, 11098-11108.

(39) Chen, Y.; Mellot, G.; van Luijk, D.; Creton, C.; Sijbesma, R. P. Mechanochemical tools for polymer materials. Chem. Soc. Rev. 2021, 50, 4100-4140.

(40) O'Neill R. T.; Boulatov, R. The many flavours of mechanochemistry and its plausible conceptual underpinnings. Nat. Rev. Chem 2021, 5, 148-167.

(41) Davis, D. A.; Hamilton, A.; Yang, J.; Cremar, L. D.; Van Gough, D.; Potisek, S. L.; Ong, M. T.; Braun, P. V.; Martinez, T. J.; White, S. R.; Moore, J. S.; Sottos, N. R. Force-Induced Activation of Covalent Bonds in Mechanoresponsive Polymeric Materials. Nature 2009, 459, 68-72.

(42) Gossweiler, G. R.; Kouznetsova, T. B.; Craig, S. L. Force-Rate Characterization of Two Spiropyran-Based Molecular Force Probes. J. Am. Chem. Soc. 2015, 137, 6148-6151.

(43) Lin, Y.; Barbee, M. H.; Chang, C.-C.; Craig, S. L. Regiochemical Effects on Mechanophore Activation in Bulk Materials. J. Am. Chem. Soc. 2018, 140, 15969-15975.

(44) Barbee, M. H.; Kouznetsova, T.; Barrett, S. L.; Gossweiler, G. R.; Lin, Y.; Rastogi, S. K.; Brittain, W. J.; Craig, S. L. Substituent Effects and Mechanism in a Mechanochemical Reaction. $J$. Am. Chem. Soc. 2018, 140, 12746-12750.

(45) Robb, M. J.; Kim, T. A.; Halmes, A. J.; White, S. R.; Sottos, N. R.; Moore, J. S. Regioisomer-Specific Mechanochromism of Naphthopyran in Polymeric Materials. J. Am. Chem. Soc. 2016, 138, 12328-12331.

(46) McFadden, M. E.; Robb, M. J. Force-Dependent Multicolor Mechanochromism from a Single Mechanophore. J. Am. Chem. Soc. 2019, 141, 11388-11392.

(47) Versaw, B. A.; McFadden, M. E.; Husic, C. C.; Robb, M. J. Designing Naphthopyran Mechanophores with Tunable Mechanochromic Behavior. Chem. Sci. 2020, 11, 4525-4530.

(48) Imato, K.; Otsuka, H. Reorganizable and stimuli-responsive polymers based on dynamic carbonecarbon linkages in diarylbibenzofuranones. Polymer 2018, 137, 395-413.

(49) Imato, K.; Irie, A.; Kosuge, T.; Ohishi, T.; Nishihara, M.; Takahara, A; Otsuka, H. Mechanophores with a Reversible Radical System and Freezing-Induced Mechanochemistry in Polymer Solutions and Gels. Angew. Chem. Int. Ed. 2015, 54, 6168-6172.

(50) Imato, K.; Kanehara, T.; Ohishi, T.; Nishihara, M.; Yajima, H.; Ito, M.; Takahara, A.; Otsuka, H. Mechanochromic Dynamic Covalent Elastomers: Quantitative Stress Evaluation and Autonomous Recovery. ACS Macro Lett. 2015, 4, 1307-1311.
(51) Ishizuki, K.; Aoki, D.; Goseki, R.; Otsuka, H. Multicolor Mechanochromic Polymer Blends That Can Discriminate between Stretching and Grinding. ACS Macro Lett. 2018, 7, 556-560.

(52) Kosuge, T.; Zhu, X.; Lau, V. M.; Aoki, D.; Martinez, T. J.; Moore, J. S.; Otsuka, H. Multicolor Mechanochromism of a Polymer/ Silica Composite with Dual Distinct Mechanophores. J. Am. Chem. Soc. 2019, 141, 1898-1902

(53) Chen, Y.; Spiering, A. J. H.; Karthikeyan, S.; Peters, G. W. M.; Meijer, E. W.; Sijbesma, R. P. Mechanically Induced Chemiluminescence from Polymers Incorporating a 1,2-Dioxetane Unit in the Main Chain. Nat. Chem. 2012, 4, 559-562.

(54) Song, Y.-K.; Lee, K.-H.; Hong, W.-S.; Cho, S.-Y.; Yu, H.-C.; Chung, C.-M. Fluorescence sensing of microcracks based on cycloreversion of a dimeric anthracene moiety. J. Mater. Chem. 2012, 22, 1380-1386.

(55) Kabb, C. P.; O’Bryan, C. S.; Morley, C. D.; Angelini, T. E.; Sumerlin, B. S. Anthracene-based mechanophores for compression-activated fluorescence in polymeric networks. Chem. Sci. 2019, 10, 7702-7708.

(56) Göstl, R.; Sijbesma, R. P. $\pi$-extended anthracenes as sensitive probes for mechanical stress. Chem. Sci. 2016, 7, 370.

(57) Stratigaki, M.; Baumann, C.; van Breemen, L. C. A.; Heuts, J. P. A.; Sijbesma, R. P.; Göstl, R. Fractography of poly( $N$-isopropylacrylamide) hydrogel networks crosslinked with mechanofluorophores using confocal laser scanning microscopy. Polym. Chem. 2020, 11, 358-366.

(58) Baumann, C.; Stratigaki, M.; Centeno, S. P.; Göstl, R. Multicolor Mechanofluorophores for the Quantitative Detection of Covalent Bond Scission in Polymers. Angew. Chem. Int. Ed. 2021, 60, 13287-13293.

(59) Kato, S.; Ishizuki, K.; Aoki, D.; Goseki, R.; Otsuka, H. Freezing Induced Mechanoluminescence of Polymer Gels. ACS Macro Lett. 2018, 7, 1087-1091.

(60) Kato, S.; Furukawa, S.; Aoki, D.; Goseki, R.; Oikawa, K.; Tsuchiya, K.; Shimada, N.; Maruyama, A.; Numata, K.; Otsuka, H. Crystallization-Induced Mechanofluorescence for Visualization of Polymer Crystallization. Nat. Commun. 2021, 12, 126.

(61) Brown, C. L.; Craig, S. L. Molecular engineering of mechanophore activity for stress-responsive polymeric materials. Chem. Sci. 2015, 6, 2158-2165.

(62) Li, J.; Nagamani, C; Moore, J. S. Polymer Mechanochemistry: From Destructive to Productive. Acc. Chem. Res. 2015, 48, 2181-2190.

(63) Deneke, N.; Rencheck, M. L.; Davis, C. S. An engineer's introduction to mechanophores. Soft Matter 2020, 16, 6230 6252 .

(64) Chen, Z.; Mercer, J. A. M.; Zhu, X.; Romaniuk, J. A. H.; Cegelski, L.; Martinez, T. J.; Burns, N. Z.; Xia, Y. Mechanochemical unzipping of insulating polyladderene to semiconducting polyacetylene. Science 2017, 357, 475-479.

(65) Stratigaki, M.; Göstl, R. Methods for Exerting and Sensing Force in Polymer Materials Using Mechanophores. ChemPlusChem 2020, 85, 1095-1103

(66) He, S.; Stratigaki, M.; Centeno, S. P.; Dreuw, A.; Göstl, R. Tailoring the Properties of Optical Force Probes for Polymer Mechanochemistry. Chem. Eur. J. 2021, 27, 15889-15897.

(67) Chen, Y.; Yeh, C. J.; Qi, Y.; Long, R.; Creton, C. From forceresponsive molecules to quantifying and mapping stresses in soft materials. Sci. Adv. 2020, 6, eaaz5093.

(68) Slootman, J.; Waltz, V.; Yeh, C. J.; Baumann, C.; Göstl, R.; Comtet, J.; Creton, C. Quantifying Rate- and Temperature-Dependent Molecular Damage in Elastomer Fracture. Phys. Rev. X 2020, 10, 041045

(69) Chen, Y.; Sanoja, G.; Creton, C. Mechanochemistry unveils stress transfer during sacrificial bond fracture of tough multiple network elastomers. Chem. Sci. 2021, 12, 11098-11108.

(70) Chen, Y.; Yeh, C. J.; Guo, Q.; Qi, Y.; Long R.; Creton, C. Fast reversible isomerization of merocyanine as a tool to quantify stress history in elastomers. Chem. Sci. 2021, 12, 1693-1701.

(71) Gossweiler, G. R.; Hewage, G. B.; Soriano, G.; Wang, Q.; Welshofer, G. W.; Zhao, X.; Craig, S. L. Mechanochemical 
Activation of Covalent Bonds in Polymers with Full and Repeatable Macroscopic Shape Recovery. ACS Macro Lett. 2014, 3, 216-219.

(72) Wang, T.; Zhang, N.; Dai, J.; Li, Z.; Bai, W.; Bai, R. Novel Reversible Mechanochromic Elastomer with High Sensitivity: Bond Scission and Bending-Induced Multicolor Switching. ACS Appl. Mater. Interfaces 2017, 9, 11874-11881.

(73) Filonenko, G. A.; Khusnutdinova, J. R. Dynamic Phosphorescent Probe for Facile and Reversible Stress Sensing. Adv. Mater. 2017, 22, 1700563 .

(74) Filonenko, G. A.; Lugger, J. A. M.; Liu, C.; van Heesijk, E. P. A.; Hendrix, M. M. R. M.; Weber, M.; Müller, C.; Hensen, E. J. M.; Sijbesma, R. P.; Pidko, E. A. Tracking Local Mechanical Impact in Heterogeneous Polymers with Direct Optical Imaging Angew. Chem. Int. Ed. 2018, 57, 16385-16390.

(75) Fast, reversible mechanochromism of regioisomeric oxazine mechanophores: Developing in situ responsive force probes for polymeric materials. Chem 2021, 7, 1081-1091.

(76) Raisch, M.; Maftuhin, W.; Walter, M.; Sommer, M. A mechanochromic donor-acceptor torsional spring. Nat. Commun. 2021, 12,4243 .

(77) Sagara, Y.; Traeger, H.; Li, J.; Okado, Y.; Schrettl, S.; Tamaoki, N; Weder, C. Mechanically Responsive Luminescent Polymers Based on Supramolecular Cyclophane Mechanophores. J. Am Chem. Soc. 2021, 143, 5519.

(78) Traeger, H.; Sagara, Y.; Kiebala, D. J.; Schrettl, S.; Weder, C. Folded Perylene Diimide Loops as Mechanoresponsive Motifs. Angew. Chem. Int. Ed. 2021, 60, 16191-16199.

(79) Freikamp, A.; Cost, A.-L.; Grashoff, C. The Piconewton Force Awakens: Quantifying Mechanics in Cells, Trends in Cell Biol. 2016, 26, 838-847.

(80) Liu, Y.; Galior, K.; Ma, V. P.-Y.; Salaita, K. Molecular Tension Probes for Imaging Forces at the Cell Surface, Acc. Chem. Res. 2017, 50, 2915-2924.

(81) Grashoff, C.; Hoffman, B. D.; Brenner, M. D.; Zhou, R.; Parsons, M.; Yang, M. T.; McLean, M. A.; Sligar, S. G.; Chen, C. S.; Ha, T.; Schwartz, M. A. Measuring mechanical tension across vinculin reveals regulation of focal adhesion dynamics. Nature $\mathbf{2 0 1 0}$, 466, 263-267.

(82) Brockman, J. M.; Blanchard, A. T.; Ma, V. P.-Y.; Derricotte, W. D.; Zhang, Y.; Fay, M. E.; Lam, W. A.; Evangelista, F. A.; Mattheyses, A. L.; Salaita, K. Mapping the 3D orientation of piconewton integrin traction forces. Nat. Methods 2018, 15, 115118.

(83) Ogi, S.; Sugiyasu, K.; Takeuchi, M. Synthesis of a Doubly Strapped Light-Harvesting Porphyrin Bearing Energy Donor Molecules Hanging on to the Straps: An Attempt toward Macroscopic Control over Molecular Conformation That Affects the Efficiency of Fluorescence Resonance Energy Transfer. Bull. Chem. Soc. Jpn. 2011, 84, 40-48.

(84) Sagara, Y.; Karman, M.; Verde-Sesto, E.; Matsuo, K.; Kim, Y.; Tamaoki, N.; Weder, C. Rotaxanes as Mechanochromic Fluorescent Force Transducers in Polymers. J. Am. Chem. Soc. 2018, 140, 1584- 1587.

(85) Sagara, Y.; Karman, M.; Seki, A.; Pannipara, M.; Tamaoki, N.; Weder, C. Rotaxane-Based Mechanophores Enable Polymers with Mechanically Switchable White Photoluminescence. ACS Cent. Sci. 2019, 5, 874-881

(86) Muramatsu, T.; Sagara, Y.; Traeger, H.; Tamaoki, N.; Weder, C. Mechanoresponsive Behavior of a Polymer-Embedded RedLight Emitting Rotaxane Mechanophore. ACS Appl. Mater. Interfaces 2019, 11, 24571-24576.

(87) Muramatsu, T.; Okado, Y.; Traeger, H.; Schrettl, S.; Tamaoki, N.; Weder, C.; Sagara, Y. Rotaxane-Based Dual Function Mechanophores Exhibiting Reversible and Irreversible Responses. J. Am. Chem. Soc. 2021, 143, 9884-9892.

(88) Merindol, R.; Delechiave, G.; Heinen, L.; Catalani, L. H.; Walther, A. Modular Design of Programmable Mechanofluorescent DNA Hydrogels. Nat. Commun. 2019, 10, 528.
(89) Creusen, G.; Schmidt, R. S.; Walther, A. One-Component DNA Mechanoprobes for Facile Mechanosensing in Photopolymerized Hydrogels and Elastomers. ACS Macro Lett. 2021, 10, 671678.

(90) Kotani, R.; Yokoyama, S.; Nobusue, S.; Yamaguchi, S.; Osuka, A.; Yabu, H.; Saito, S. Bridging pico-to-nanoNewton: Ratiometric Force Probe for Nanoscale Polymer Physics Before Damage. arXiv:2011.00202v2.

(91) Yuan, C.; Saito, S.; Camacho, C.; Irle, S.; Hisaki, I.; Yamaguchi, S. A $\pi$-Conjugated System with Flexibility and Rigidity That Shows Environment-Dependent RGB Luminescence. J. Am. Chem. Soc. 2013, 135, 24, 8842-8845.

(92) Kotani, R.; Sotome, H.; Okajima, H.; Yokoyama, S.; Nakaike, Y.; Kashiwagi, A.; Mori, C.; Nakada, Y.; Yamaguchi, S.; Osuka, A.; Sakamoto, A.; Miyasaka, H.; Saito, S. Flapping Viscosity Probe That Shows Polarity-Independent Ratiometric Fluorescence. J. Mater. Chem. C 2017, 5, 5248-5256.

(93) Yamakado, T.; Takahashi, S.; Watanabe, K.; Matsumoto, Y.; Osuka, A.; Saito, S. Conformational Planarization versus Singlet Fission: Distinct Excited-State Dynamics of CyclooctatetraeneFused Acene Dimers. Angew. Chem. Int. Ed. 2018, 57, 54385443.

(94) Yamakado, T.; Otsubo, K.; Osuka, A.; Saito, S. Compression of a Flapping Mechanophore Accompanied by Thermal Void Collapse in a Crystalline Phase. J. Am. Chem. Soc. 2018, 140, 62456248 .

(95) Borissov, A.; Maruya, Y. K.; Moshiniha, L.; Wong, W.-S.; ŻyłaKarwowska, M.; Stępien, M. Recent Advances in Heterocyclic Nanographenes and Other Polycyclic Heteroaromatic Compounds. Chem. Rev. 2021, DOI: 10.1021/acs.chemrev.1c00449.

(96) Mateo-Alonso, A. Pyrene-fused pyrazaacenes: from small molecules to nanoribbons. Chem. Soc. Rev. 2014, 43, 6311-6324.

(97) Wu, Z.-H.; Sun, W.-J.; Tian, H.-H.; Yu, Z.-F.; Guo, R.-X.; Shao, X.; Zhang, H.-Li. 9,10-Imide-Pyrene-Fused Pyrazaacenes (IPPA) as N-Type Doping Materials for High-Performance Nonvolatile Organic Field Effect Transistor Memory Devices. $A d v$. Electron. Mater. 2019, 5, 1800598.

(98) Suga, K.; Yamakado, T.; Saito, S. Nitrogen-Substitution in the Flapping Wings of Cyclooctatetraene-Fused Molecules. Bull. Chem. Soc. Jpn. 2021, 94, 1999-2002.

(99) Kimura, R.; Kuramochi, H.; Liu, P.; Yamakado, T.; Osuka, A.; Tahara, T.; Saito, S. Flapping Peryleneimide as a Fluorogenic Dye with High Photostability and Strong Visible-Light Absorption. Angew. Chem. Int. Ed. 2020, 59, 16430-16435.

(100) Goto, Y.; Omagari, S.; Sato, R.; Yamakado, T.; Achiwa, R.; Dey, N.; Suga, K.; Vacha, M.; Saito, S. Dynamic Polymer Free Volume Monitored by Single-Molecule Spectroscopy of a Dual Fluorescent Flapping Dopant. J. Am. Chem. Soc. 2021, 143, 14306 14313.

(101) Grabowski, Z. R.; Rotkiewicz, K.; Rettig, W. Structural Changes Accompanying Intramolecular Electron Transfer: Focus on Twisted Intramolecular Charge-Transfer States and Structures. Chem. Rev. 2003, 103, 3899-4032.

(102) Behera, S. K.; Park, S. Y.; Gierschner, J. Dual Emission: Classes, Mechanisms, and Conditions. Angew. Chem. Int. Ed. 2021, 60, 22624-22638

(103) Stevens, B.; Ban, M. I. Trans. Faraday Soc. 1964, 60, 15151523.

(104) Lippert, E. V. Z. Elektrochem. 1957, 61, 962-975.

(105) Mataga, N.; Kaifu, Y.; Koizumi, M. Bull. Chem. Soc. Jpn. 1956, 29, 465-470.

(106) Lee, C. K.; Diesendruck, C. E.; Lu, E.; Pickett, A. N.; May, P. A.; Moore, J. S.; Braun, P. V. Solvent Swelling Activation of a Mechanophore in a Polymer Network. Macromolecules 2014, 47, 2690-2694.

(107) Clough, J. M.; van der Gucht, J.; Sijbesma, R. P. Mechanoluminescent Imaging of Osmotic Stress-Induced Damage in a Galssy Polymer Network. Macromolecules 2017, 50, 2043-2053. 
Table of Contents artwork

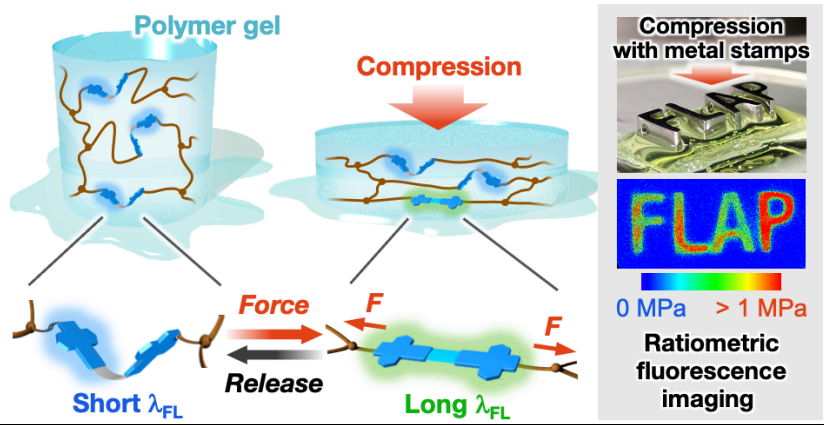




\section{Supporting Information}

\section{Ratiometric Flapping Force Probe That Works in Polymer Gels}

Takuya Yamakado, and Shohei Saito*

Graduate School of Science, Kyoto University, Kitashirakawa Oiwake-cho, Sakyo-ku, Kyoto 606-8502, Japan.

\section{Contents}

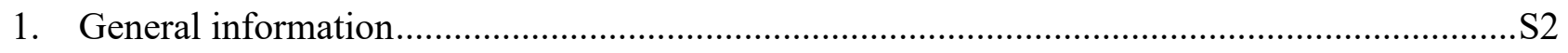

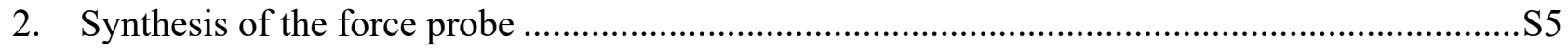

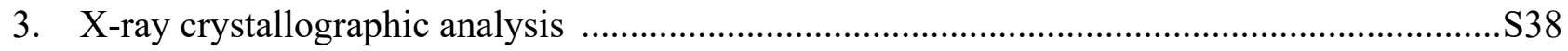

4. Photophysical properties of the force probe in solution ......................................................... 40

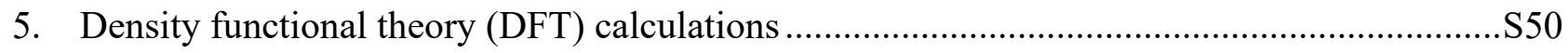

6. Synthesis and properties of the segmented polyurethanes (SPUs) .............................................. 60

7. Synthesis and properties of the crosslinked polyurethanes (PUs) before swelling ...................S68

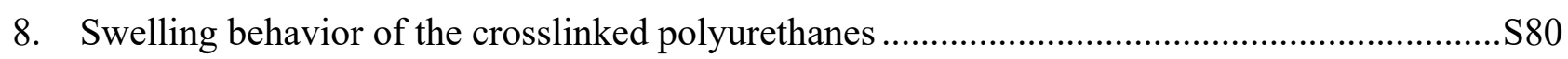

9. Mechanical and photophysical properties of the polyurethanes gels ......................................S81

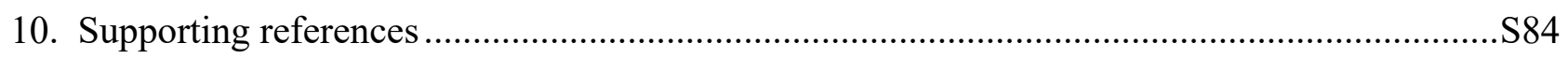




\section{General information}

\section{Synthesis}

All reagents and solvents were of commercial grade and were used without further purification unless otherwise noted. Thin-layer chromatography (TLC) was carried out on aluminum sheets coated with silica gel $60 \mathrm{~F}_{254}$ (Merck). Column chromatography was performed on Wakogel ${ }^{\circledR} \mathrm{C}-300$ or $\mathrm{C}-400 .{ }^{1} \mathrm{H}$ and ${ }^{13} \mathrm{C}$ NMR spectra were recorded on a JEOL ECA-600 (600 MHz for ${ }^{1} \mathrm{H}$ and $151 \mathrm{MHz}$ for $\left.{ }^{13} \mathrm{C}\right)$ spectrometer. Chemical shifts were reported in ppm relative to the residual solvents as internal standards $\left(\mathrm{CHCl}_{3}: \delta=7.26 \mathrm{ppm}\right.$ for ${ }^{1} \mathrm{H}$ and $\delta=77.16 \mathrm{ppm}$ for ${ }^{13} \mathrm{C}$. Tetchachloroethane- $d_{2}: \delta=6.00 \mathrm{ppm}$ for ${ }^{1} \mathrm{H}$ and $\delta=73.78 \mathrm{ppm}$ for ${ }^{13} \mathrm{C}$. THF- $d_{8}: \delta$ $=3.58 \mathrm{ppm}$ for ${ }^{1} \mathrm{H}$ ). High-resolution atmospheric-pressure-chemical-ionization time-of-flight massspectrometry (HR-APCI-TOF-MS) was recorded on a Bruker micrOTOF spectrometer. High-resolution matrix-assisted laser desorption/ionization time-of-flight mass spectrometry (HR-MALDI-TOF-MS) was conducted with a Bruker Autoflex III spectrometer. Compounds $\mathbf{1}^{[\mathrm{S} 1]}$ and $\mathbf{4}^{[\mathrm{S} 2]}$ were synthesized according to the reported methods. FLAP0-OH and FLAP0-H were prepared following the previous reports. ${ }^{[\mathrm{S} 3]}$

\section{Photophysical measurements}

UV-visible absorption spectra were recorded on a Shimadzu UV-3600 spectrometer. Steady-state fluorescence (FL) and excitation spectra were recorded on a JASCO FP-8500 spectrofluorometer. Absolute fluorescence quantum yields were determined on a Hamamatsu Photonics C9920-02S. FL lifetimes were measured on a Hamamatsu Photonics Quantaurus-Tau C11367. Variable temperature measurements were performed using a Unisoku CoolSpeK UV USP-203-B cryostat. All measurements of solution samples were conducted using a 10-mm square quartz cell unless otherwise noted. FL spectra plotted in wavenumber units were calculated considering the Jacobian factor $\left(|\mathrm{d} \lambda / \mathrm{d} \tilde{v}|=\tilde{v}^{-2}\right)$. Curve fitting was performed by using (non)linear least square algorithms in the Igor Pro 8.04 software.

\section{Single-crystal X-ray diffractometry}

X-ray crystallographic data was collected at $-180{ }^{\circ} \mathrm{C}$ with a Rigaku XtaLAB P200 diffractometer equipped with a copper MicroMax007HF generator, VariMax-Cu optics, and a PILATUS 200K twodimensional detector. The structure was solved by direct method SHELXT ${ }^{[\mathrm{S} 4]}$ and refined by SHELXL ${ }^{[\mathrm{S} 5]}$ programs. All non-hydrogen atoms were refined anisotropically, and all hydrogen atoms were placed using AFIX instructions. Crystallographic data have been deposited in the Cambridge Crystallographic Data Center with the CCDC numbers of 2122594 (Wing1-OH) and 2122595 (FLAP1-OH'). 


\section{Measurements of the polymer samples}

Tensile tests were carried out using a Shimadzu Autograph AGS-X with a 1-kN load cell at crosshead. Differential scanning calorimetry (DSC) was conducted on a Hitachi High-Tech Science DSC7000X. Realtime FL measurements of PU specimens were performed using an Otsuka Electronics Multichannel Photodetector MCPD-6800. FL imaging was conducted by a EBA JAPAN hyperspectral camera NH-8. The FL spectra of each pixel of the hyperspectral camera was corrected according to Figure S1.1.

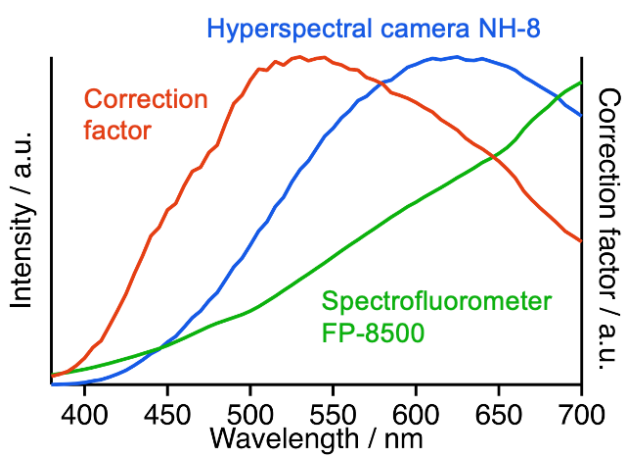

Figure S1.1. Spectra of the standard halogen lamp acquired by the spectrofluorometer and the hyperspectral camera. From these spectra, the spectral correction factor for the hyperspectral camera was obtained.

Uniaxial tensile tests were conducted on dumbbell-shaped specimens prepared in Section 6.1 and 7.1 in SI. Stress-stress curves are displayed as nominal stress $\left(\sigma_{N}\right)$ versus nominal strain $\left(\varepsilon_{N}\right)$ defined as below:

$$
\sigma_{N}=\frac{f}{S_{0}}, \quad \varepsilon_{N}=\frac{\Delta L}{L_{0}}
$$

where $f$ is an applied force, $S_{0}$ is an initial cross-sectional area, $L_{0}$ is an initial gauge length $(10 \mathrm{~mm})$, and $\Delta L$ is an elongation. Toughness was calculated as the integrated area under a stress-strain curve. Young's modulus is defined as the slope of stress-strain curves at $0-5 \%$ strain. Tensile velocity was fixed at $100 \mathrm{~mm} \mathrm{~min}^{-1}$, corresponding to strain rate of $0.17 \mathrm{~s}^{-1}$, unless otherwise noted.

\section{Experimental setup for real-time collection of FL/absorption spectra during tensile tests}

Real-time FL/absorption measurements of PU specimens during the tensile tests were performed according to the previous study ${ }^{[\mathrm{S} 3]}$ with a modified setup, where the light source and the detector follow the center of the stretched polymer by using linear guides and pulleys (Figure S1.2 and S1.3). The FL spectra were recorded with a two-second exposure time, and the specimens were excited with a UV LED ( $\left.\lambda_{\mathrm{ex}} \sim 365 \mathrm{~nm}\right)$. For the measurements of absorption spectra, an exposure time was set to 0.8 second. 
(a)

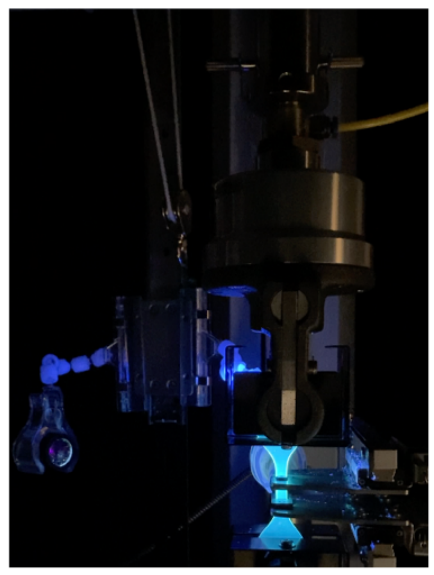

(c)

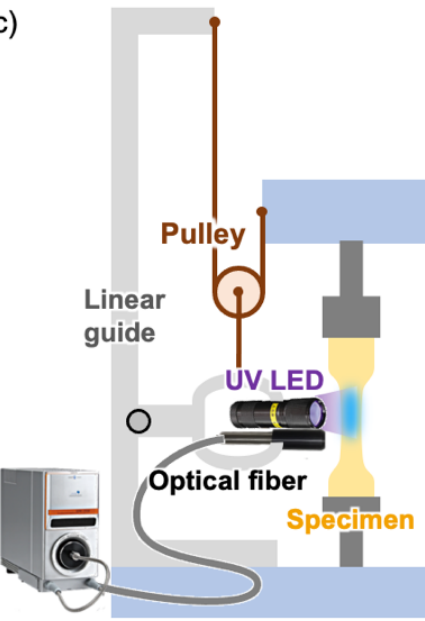

(b)
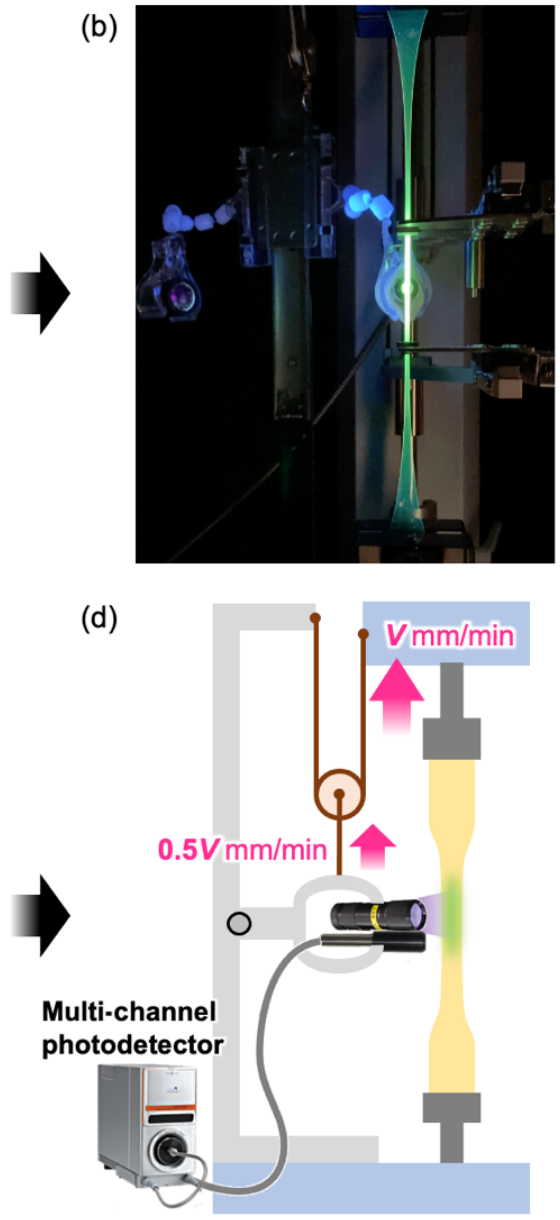

Figure S1.2. $(a, b)$ Photographs and $(c, d)$ schematic illustration of the experimental setup for real-time collection of FL spectra.

(a)

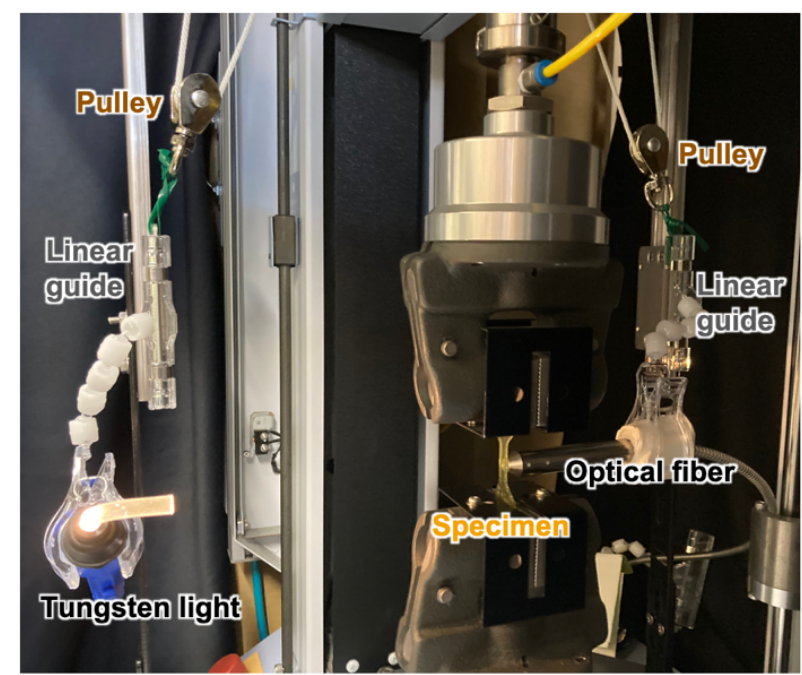

(b)

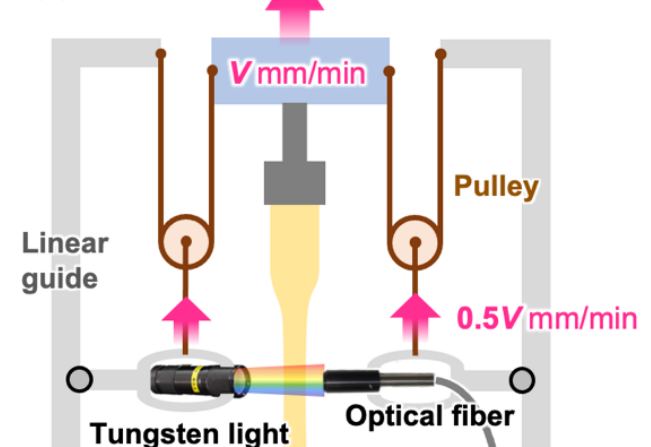

Multi-channel photodetector

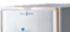

Figure S1.3. (a) Photographs and (c) schematic illustration of the experimental setup for real-time collection of absorption spectra. 


\section{Synthesis of the force probes}

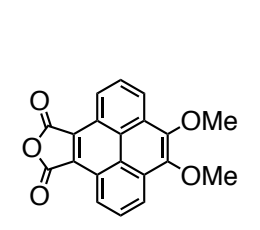

1

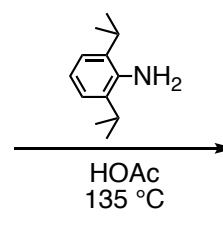

.

,

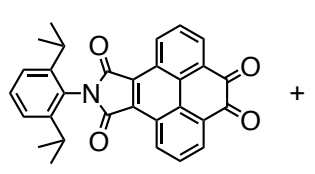

3

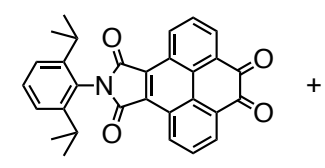

3
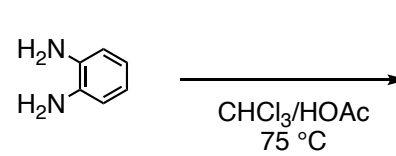

$75^{\circ} \mathrm{C}$

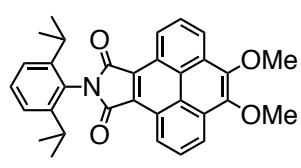

2

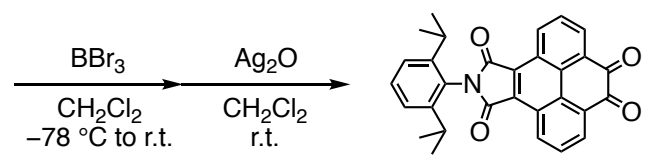

3

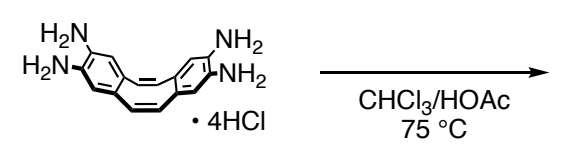

4

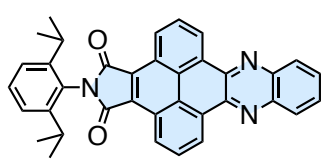

Wing1-H

Figure S2.1. Synthesis of the flapping pyreneimide (FLAP1-H) and the reference compound (Wing1-H).

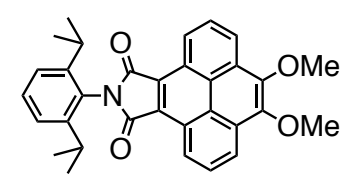

\section{$N$-(2,6-Diisopropylphenyl)-9,10-dimethoxypyrene-4,5-dicarboximide (2):}

Compound 1 (1.47 g, $4.42 \mathrm{mmol})$, acetic acid (50 mL), and 2,6-diisopropylaniline (2.0 mL, $11 \mathrm{mmol})$ were placed in a Schlenk flask. The reaction mixture was stirred for $16 \mathrm{~h}$ at $135^{\circ} \mathrm{C}$, and then the solvent was evaporated under reduced pressure. The resultant solid was dissolved into dichloromethane, and washed with water and aqueous $\mathrm{NaHCO}_{3}$ solution. The organic layer was dried over anhydrous $\mathrm{Na}_{2} \mathrm{SO}_{4}$ and the solvent was removed under reduced pressure. The crude mixture was purified by silica-gel column chromatography (eluent: hexane/dichloromethane, 1:1) to give $2(2.09 \mathrm{~g}, 4.25 \mathrm{mmol}, 96 \%)$ as an orange solid.

${ }^{1} \mathrm{H}$ NMR $\left(\mathrm{CDCl}_{3}\right.$, r.t., $\left.600 \mathrm{MHz}\right): \delta / \mathrm{ppm}=9.42(\mathrm{~d}, J=7.2 \mathrm{~Hz}, 2 \mathrm{H}), 8.72(\mathrm{~d}, J=6.6 \mathrm{~Hz}, 2 \mathrm{H}), 8.24(\mathrm{t}, J=8.1$ $\mathrm{Hz}, 2 \mathrm{H}), 7.51$ (t, $J=8.1 \mathrm{~Hz}, 1 \mathrm{H}), 7.36(\mathrm{~d}, J=7.8 \mathrm{~Hz}, 2 \mathrm{H}), 4.26$ (s, 6H), 2.96 (sept, $J=6.9 \mathrm{~Hz}, 2 \mathrm{H}$ ), and 1.23 $(\mathrm{d}, J=6.6 \mathrm{~Hz}, 12 \mathrm{H}) ;{ }^{13} \mathrm{C}\left\{{ }^{1} \mathrm{H}\right\} \mathrm{NMR}\left(\mathrm{CDCl}_{3}\right.$, r.t., $\left.151 \mathrm{MHz}\right): \delta / \mathrm{ppm}=170.0,147.9,144.8,130.3,128.9$, 128.4, 127.8, 127.2, 125.5, 124.6, 124.2, 123.8, 122.7, 61.4, 29.6, and 24.2. HRMS (APCI/TOF) $m / z:[M]^{+}$ Calcd for $\mathrm{C}_{32} \mathrm{H}_{29} \mathrm{NO}_{4} 491.2091$; Found 491.2088. 


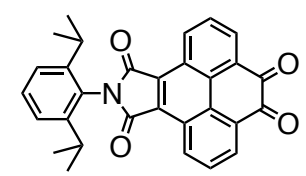

\section{$N$-(2,6-Diisopropylphenyl)-9,10-dioxo-9,10-dihydropyrene-4,5-dicarboximide (3):}

Compound 2 (2.08 g, $4.23 \mathrm{mmol})$ was placed in a three-neck flask, and the flask was purged with argon. Anhydrous dichloromethane $(180 \mathrm{~mL})$ was added to the flask, and the solution was cooled to $-78{ }^{\circ} \mathrm{C}$. Then, 1.0 $\mathrm{M}$ boron tribromide solution in dichloromethane $(17 \mathrm{~mL}, 17 \mathrm{mmol})$ was added dropwise, and the mixture was allowed to warm to room temperature with stirring. After $9 \mathrm{~h}$, the reaction was quenched with water at $0{ }^{\circ} \mathrm{C}$, and the mixture was extracted with dichloromethane. To the organic layer was added silver(I) oxide (3.52 g, $15.2 \mathrm{mmol}$ ), and the reaction mixture was sonicated for $10 \mathrm{~min}$ at room temperature. The resultant mixture was filtered through a Celite pad, and the filtrate was dried over $\mathrm{Na}_{2} \mathrm{SO}_{4}$ and concentrated under reduced pressure. The crude mixture was purified by silica-gel column chromatography (eluent: dichloromethane) to obtain $3(1.25 \mathrm{~g}, 2.72 \mathrm{mmol}, 64 \%)$ as an orange solid.

${ }^{1} \mathrm{H} \mathrm{NMR}\left(\mathrm{CDCl}_{3}\right.$, r.t., $\left.600 \mathrm{MHz}\right): \delta / \mathrm{ppm}=9.50\left(\mathrm{dd}, J_{1}=8.4 \mathrm{~Hz}, J_{2}=1.2 \mathrm{~Hz}, 2 \mathrm{H}\right) 8.71\left(\mathrm{dd}, J_{1}=7.5 \mathrm{~Hz}, J_{2}=\right.$ $1.5 \mathrm{~Hz}, 2 \mathrm{H}), 8.00$ (t, $J=7.8 \mathrm{~Hz}, 2 \mathrm{H}), 7.52$ (t, $J=7.8 \mathrm{~Hz}, 1 \mathrm{H}), 7.52$ (d, $J=7.8 \mathrm{~Hz}, 2 \mathrm{H}), 2.86$ (sept, $J=6.9 \mathrm{~Hz}$, $2 \mathrm{H})$, and $1.22(\mathrm{~d}, J=7.2 \mathrm{~Hz}, 12 \mathrm{H}) ;{ }^{13} \mathrm{C}\left\{{ }^{1} \mathrm{H}\right\} \mathrm{NMR}\left(\mathrm{CDCl}_{3}\right.$, r.t., $\left.151 \mathrm{MHz}\right): \delta / \mathrm{ppm}=179.5,168.8,147.7$, 134.4, 133.1, 131.7, 130.6, 130.4, 130.1, 128.0, 126.5, 126.0, 124.3, 29.7, and 24.2. HRMS (APCI/TOF) $m / z$ : $[M+\mathrm{H}]^{+}$Calcd for $\mathrm{C}_{30} \mathrm{H}_{24} \mathrm{NO}_{4} 462.1700$; Found 462.1702 .

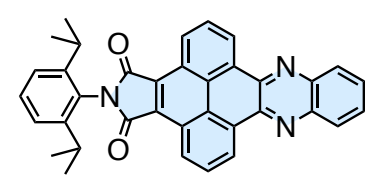

\section{$N$-(2,6-Diisopropylphenyl)phenanthro[4,5-abc]phenazine-4,5-dicarboximide (Wing1-H):}

Compound $3(152 \mathrm{mg}, 0.330 \mathrm{mmol})$ and $o$-phenylenediamine $(36 \mathrm{mg}, 0.33 \mathrm{mmol}$ ) were placed in a twoneck flask, and the flask was purged with argon. Then, chloroform $(8.6 \mathrm{~mL})$ and acetic acid $(5.2 \mathrm{~mL})$ were added to the flask and the mixture was stirred at $85^{\circ} \mathrm{C}$. After $1 \mathrm{~h}$, the solvent was evaporated under reduced pressure, and the crude product was purified by recrystallization from the mixture of diethyl ether and acetic acid to afford Wing1-H (194 mg, quant.) as a yellow solid.

${ }^{1} \mathrm{H}$ NMR (tetrachloroethane- $\left.d_{2}, 120^{\circ} \mathrm{C}, 600 \mathrm{MHz}\right): \delta / \mathrm{ppm}=9.89(\mathrm{~d}, J=7.8 \mathrm{~Hz}, 2 \mathrm{H}), 9.59(\mathrm{~d}, J=7.8 \mathrm{~Hz}, 2 \mathrm{H})$, $8.48(\mathrm{~m}, 2 \mathrm{H}), 8.33(\mathrm{t}, J=7.8 \mathrm{~Hz}, 2 \mathrm{H}), 7.99(\mathrm{~m}, 2 \mathrm{H}), 7.56(\mathrm{t}, J=7.8 \mathrm{~Hz}, 1 \mathrm{H}), 7.40(\mathrm{~d}, J=7.8 \mathrm{~Hz}, 2 \mathrm{H}), 3.04$ (sept, $J=6.9 \mathrm{~Hz}, 2 \mathrm{H}$ ), and $1.31(\mathrm{~d}, J=7.2 \mathrm{~Hz}, 12 \mathrm{H}) ;{ }^{13} \mathrm{C}\left\{{ }^{1} \mathrm{H}\right\}$ NMR (tetrachloroethane- $d_{2}, 120^{\circ} \mathrm{C}, 151 \mathrm{MHz}$ ): $\delta / \mathrm{ppm}=169.2,147.8,142.6,142.1,130.2,130.0,129.9,129.5,128.7,128.4,128.1,127.5,127.1,126.9$, 
124.8, 123.8, 29.4, and 23.8. HRMS (APCI/TOF) $m / z$ : $[M]^{+}$Calcd for $\mathrm{C}_{36} \mathrm{H}_{27} \mathrm{~N}_{3} \mathrm{O}_{2}$ 533.2098; Found 533.2094. UV-visible absorption (in $\left.\mathrm{CH}_{2} \mathrm{Cl}_{2}\right): \lambda_{\max }\left(\varepsilon / \mathrm{M}^{-1} \mathrm{~cm}^{-1}\right)=279\left(6.6 \times 10^{4}\right)$ and $415 \mathrm{~nm}\left(5.3 \times 10^{4}\right)$. Fluorescence (in $\mathrm{CH}_{2} \mathrm{Cl}_{2}, \lambda_{\mathrm{ex}}=365 \mathrm{~nm}$ ): $\lambda_{\max }=518$ and $555 \mathrm{~nm} ; \Phi_{\mathrm{F}}=0.42 ; \tau_{\mathrm{F}}=2.4 \mathrm{~ns}\left(\lambda_{\mathrm{obs}}=518 \mathrm{~nm}\right.$ ).

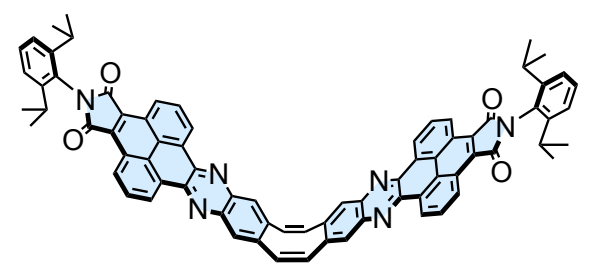

COT-fused $N$-(2,6-diisopropylphenyl)phenanthro[4,5-abc]phenazine-4,5-dicarboximide dimer (FLAP1-H):

Compound 3 (92 mg, $0.20 \mathrm{mmol}$ ) and 4 (41 mg, $0.10 \mathrm{mmol})$ was placed in a Schlenk flask, and the flask was purged with argon. Then, chloroform $(2.6 \mathrm{~mL})$ and acetic acid $(1.6 \mathrm{~mL})$ were added to the flask and the mixture was stirred at $75^{\circ} \mathrm{C}$. After $17.5 \mathrm{~h}$, the mixture was diluted with chloroform and extracted with aqueous $\mathrm{NaHCO}_{3}$ solution. The organic layer was dried over $\mathrm{Na}_{2} \mathrm{SO}_{4}$, and concentrated under reduced pressure. The crude mixture was purified by recrystallization from hot chlorobenzene to furnish FLAP1-H (80 mg, 7.2 mmol, $72 \%$ ) as a yellow solid.

${ }^{1} \mathrm{H}$ NMR (tetrachloroethane- $\left.d_{2}, 120^{\circ} \mathrm{C}, 600 \mathrm{MHz}\right): \delta / \mathrm{ppm}=9.77(\mathrm{~d}, J=7.8 \mathrm{~Hz}, 4 \mathrm{H}), 9.53(\mathrm{~d}, J=7.8 \mathrm{~Hz}, 4 \mathrm{H})$, $8.30(\mathrm{~s}, 4 \mathrm{H}), 8.25$ (t, $J=8.1 \mathrm{~Hz}, 4 \mathrm{H}), 7.54(\mathrm{t}, J=7.8 \mathrm{~Hz}, 2 \mathrm{H}), 7.47$ (s, 4H), 7.38 (d, $J=7.8 \mathrm{~Hz}, 4 \mathrm{H}), 3.01$ (sept, $J=6.6 \mathrm{~Hz}, 4 \mathrm{H})$, and $1.29(\mathrm{~d}, J=6.6 \mathrm{~Hz}, 24 \mathrm{H}) ;{ }^{13} \mathrm{C}\left\{{ }^{1} \mathrm{H}\right\} \mathrm{NMR}\left(\mathrm{CDCl}_{3} /\right.$ trichloroacetic acid, r.t., $\left.151 \mathrm{MHz}\right): \delta /$ $\mathrm{ppm}=169.7,147.7,143.1,140.8,137.3,134.0,131.2,131.0,130.0,129.2,128.8,128.4,126.3,126.0,125.4$, 125.3, 124.5, 29.7, and 24.2 (Note: due to the low solubility of FLAP1-H, trichloroacetic acid was added to dissolve it as a protonated species). HRMS (APCI/TOF) $m / z$ : $[M]^{-}$Calcd for $\mathrm{C}_{76} \mathrm{H}_{54} \mathrm{~N}_{6} \mathrm{O}_{4}$ 1114.4212; Found 1114.4169. UV-visible absorption (in $\left.\mathrm{CH}_{2} \mathrm{Cl}_{2}\right): \lambda_{\max }\left(\varepsilon / \mathrm{M}^{-1} \mathrm{~cm}^{-1}\right)=279\left(6.6 \times 10^{4}\right)$ and $415 \mathrm{~nm}\left(5.3 \times 10^{4}\right)$. Fluorescence (in $\mathrm{CH}_{2} \mathrm{Cl}_{2}, \lambda_{\mathrm{ex}}=365 \mathrm{~nm}$ ): $\lambda_{\max }=518$ and $555 \mathrm{~nm} ; \Phi_{\mathrm{F}}=0.42 ; \tau_{\mathrm{F}}=2.4 \mathrm{~ns}\left(\lambda_{\mathrm{obs}}=518 \mathrm{~nm}\right)$. 


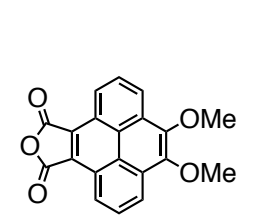

1

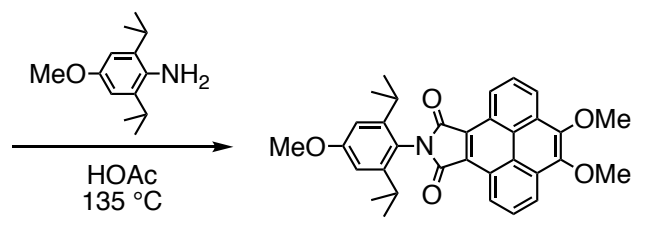

5

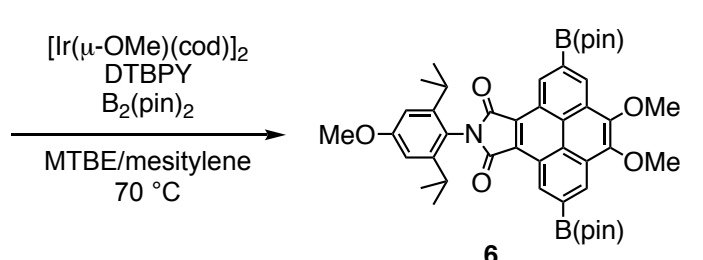

6

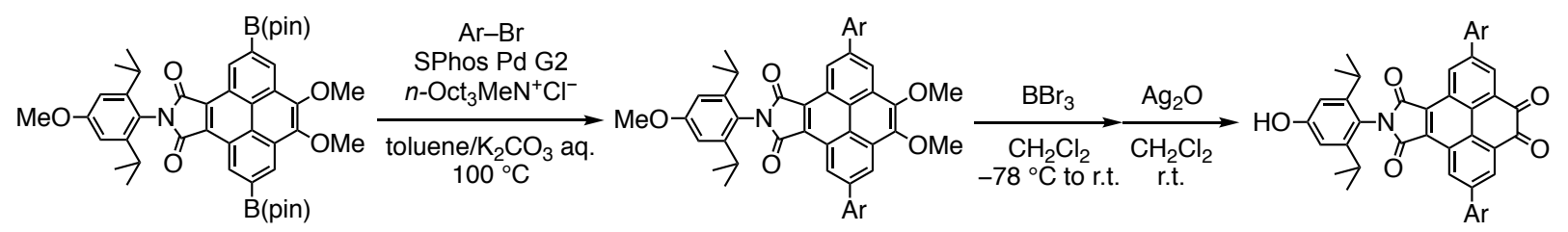

6

$7(\mathrm{Ar}=$ mesityl $)$

$8(\mathrm{Ar}=3,5$-di-tert-butylphenyl)
9 (Ar=mesityl)

10 ( $\mathrm{Ar}=3,5$-di-tert-butylphenyl)<smiles></smiles>

9

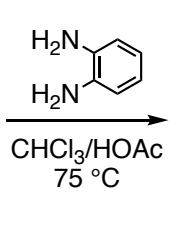

$5^{\circ} \mathrm{C}$

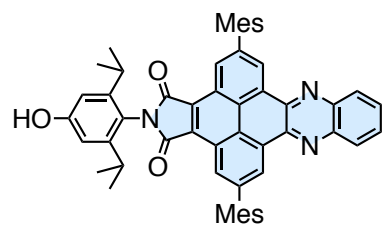

Wing1-OH

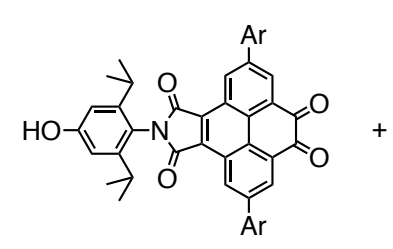

$9($ Ar = mesityl $)$

10 ( $\mathrm{Ar}=3,5$-di-tert-butylphenyl)

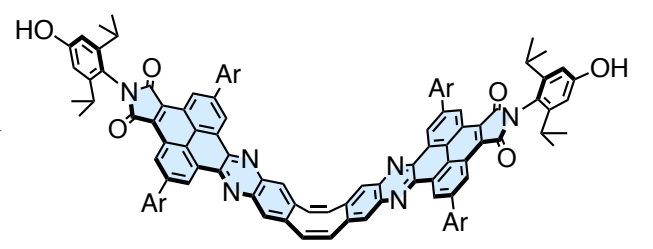

FLAP1-OH ( $\mathrm{Ar}=$ mesityl)

FLAP1-OH' ( $\mathrm{Ar}=3,5$-di-tert-butylphenyl)

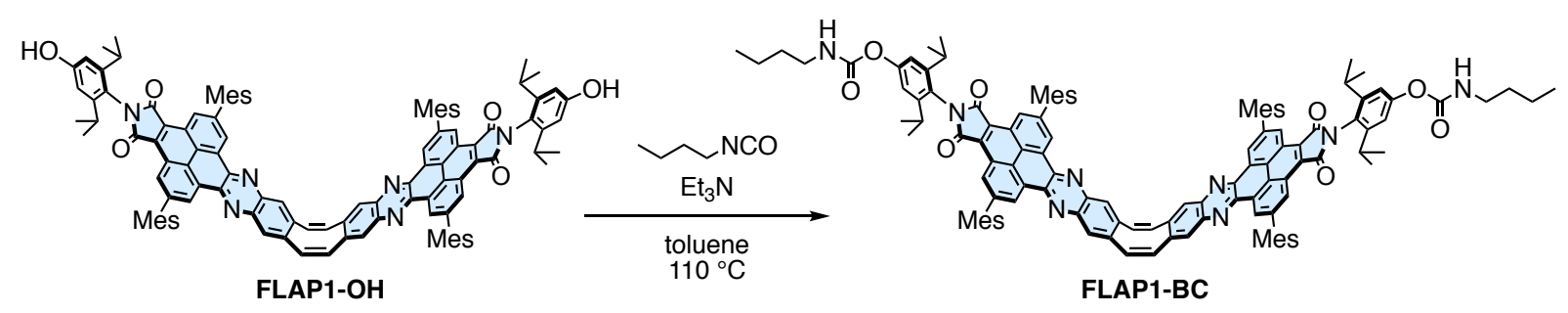

Figure S2.2. Synthesis of the precursors (5-10), the compounds for X-ray crystallography (Wing1-OH, FLAP1-OH'), the force probe (FLAP1-OH), and the dopant for control experiments (FLAP1-BC). 


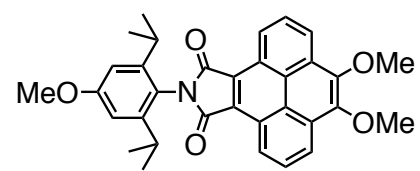

\section{$N$-(2,6-Diisopropyl-4-methoxyphenyl)-9,10-dimethoxypyrene-4,5-dicarboximide (5):}

Compound 1 (4.98 g, $15.0 \mathrm{mmol})$, acetic acid $(170 \mathrm{~mL})$, and 2,6-diisopropyl-4-methoxyaniline (3.42 g, $16.5 \mathrm{mmol}$ ) were placed in a Schlenk flask. The reaction mixture was stirred for $101 \mathrm{~h}$ at $135{ }^{\circ} \mathrm{C}$, and then the solvent was evaporated under reduced pressure. The resultant solid was dissolved into dichloromethane, and washed with water and aqueous $\mathrm{HCl}$ solution. The organic layer was dried over anhydrous $\mathrm{Na}_{2} \mathrm{SO}_{4}$ and the solvent was removed under reduced pressure. The crude mixture was purified by silica-gel column chromatography (eluent: hexane/dichloromethane, 1:1) to give 5 (5.67 g, $10.9 \mathrm{mmol}, 72 \%)$ as an orange solid.

${ }^{1} \mathrm{H} \mathrm{NMR}\left(\mathrm{CDCl}_{3}\right.$, r.t., $\left.600 \mathrm{MHz}\right): \delta / \mathrm{ppm}=9.42(\mathrm{~d}, J=7.8 \mathrm{~Hz}, 2 \mathrm{H}), 8.71(\mathrm{~d}, J=7.8 \mathrm{~Hz}, 2 \mathrm{H}), 8.23(\mathrm{t}, J=7.5$ $\mathrm{Hz}, 2 \mathrm{H}), 6.87(\mathrm{~s}, 2 \mathrm{H}), 4.25(\mathrm{~s}, 6 \mathrm{H}), 3.91(\mathrm{~s}, 3 \mathrm{H}), 2.92$ (sept, $J=6.6 \mathrm{~Hz}, 2 \mathrm{H})$, and $1.22(\mathrm{~d}, J=6.6 \mathrm{~Hz}, 12 \mathrm{H})$; ${ }^{13} \mathrm{C}\left\{{ }^{1} \mathrm{H}\right\} \mathrm{NMR}\left(\mathrm{CDCl}_{3}\right.$, r.t., $\left.151 \mathrm{MHz}\right): \delta / \mathrm{ppm}=170.3,160.9,149.4,144.8,128.9,128.4,127.8,125.5,124.6$, $123.8,122.7,119.8,109.7,61.4,55.5,29.8$, and 24.2. HRMS (APCI/TOF) $m / z:[M]^{+}$Calcd for $\mathrm{C}_{33} \mathrm{H}_{31} \mathrm{NO}_{5}$ 521.2197; Found 521.2191.

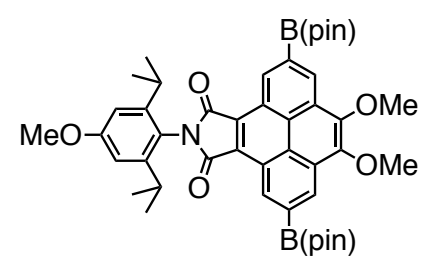

$N$-(2,6-Diisopropyl-4-methoxyphenyl)-9,10-dimethoxy-2,7-bis(4,4,5,5-tetramethyl-1,3,2-dioxaborolan-2yl)pyrene-4,5-dicarboximide (6):

In a two-neck flask were placed compound 5 (5.62 g, $10.8 \mathrm{mmol})$, bis(pinacolato)diboron (6.02 g, 23.7 mmol), (1,5-cyclooctadiene)(methoxy)iridium(I) dimer (179 mg, $0.270 \mathrm{mmol})$, and 4,4'-di-tert-butyl-2,2'dipyridyl (DTBPY, $145 \mathrm{mg}, 0.540 \mathrm{mmol}$ ), and the flask was purged with argon. Then, methyl tert-butyl ether (MTBE, $162 \mathrm{~mL}$ ) and mesitylene $\left(54 \mathrm{~mL}\right.$ ) were added, and the mixture was stirred at $70{ }^{\circ} \mathrm{C}$. After $14.5 \mathrm{~h}$, methanol $(220 \mathrm{~mL})$ was added, and the precipitate was collected by filtration and washed with methanol. The product was dried under reduced pressure at $150{ }^{\circ} \mathrm{C}$ to remove mesitylene, giving 6 ( $\left.8.15 \mathrm{~g}, 10.5 \mathrm{mmol}, 97 \%\right)$ as an orange solid.

${ }^{1} \mathrm{H} \mathrm{NMR}\left(\mathrm{CDCl}_{3}\right.$, r.t., $\left.600 \mathrm{MHz}\right): \delta / \mathrm{ppm}=9.78(\mathrm{~s}, 2 \mathrm{H}), 9.10(\mathrm{~s}, 2 \mathrm{H}), 6.85(\mathrm{~s}, 2 \mathrm{H}), 4.26(\mathrm{~s}, 6 \mathrm{H}), 3.91(\mathrm{~s}, 3 \mathrm{H})$, 2.90 (sept, $J=6.9 \mathrm{~Hz}, 2 \mathrm{H}), 1.45(\mathrm{~s}, 24 \mathrm{H})$, and $1.21(\mathrm{~d}, J=7.2 \mathrm{~Hz}, 12 \mathrm{H}) ;{ }^{13} \mathrm{C}\left\{{ }^{1} \mathrm{H}\right\} \mathrm{NMR}\left(\mathrm{CDCl}_{3}\right.$, r.t., 151 $\mathrm{MHz}): \delta / \mathrm{ppm}=170.1,160.8,149.5,144.9,129.8,128.7,128.60,128.57,126.8,124.3,120.0,109.5,84.6$, 
61.4, 55.5, 29.7, 25.2, and 24.2 (Note: 18 peaks were observed for the 19 unique carbons, in which 1 peak was not observed due to broadening). HRMS (APCI/TOF) $m / z$ : $[M]^{-}$Calcd for $\mathrm{C}_{45} \mathrm{H}_{53}{ }^{10} \mathrm{~B}_{2} \mathrm{NO}_{9}$ 771.3985; Found 771.3962 .

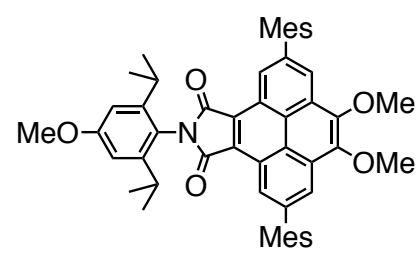

$N$-(2,6-Diisopropyl-4-methoxyphenyl)-2,7-dimesityl-9,10-dimethoxypyrene-4,5-dicarboximide (7):

Compound 6 (3.00 g, $3.88 \mathrm{mmol})$ and SPhos Pd G2 (140 mg, $0.194 \mathrm{mmol})$ were placed in a three-neck flask, and the flask was purged with argon. Here, SPhos Pd G2 is a commercially available 2nd generation SPhos precatalyst, that is, chloro(2-dicyclohexylphosphino-2',6'-dimethoxy-1,1'-biphenyl)[2-(2'-amino-1,1'biphenyl)]palladium(II). Then, to the mixture were added anhydrous toluene $(78 \mathrm{~mL})$, mesityl bromide $(1.74$ $\mathrm{mL}, 11.6 \mathrm{mmol})$, aqueous $\mathrm{K}_{2} \mathrm{CO}_{3}$ solution $(2.0 \mathrm{M}, 39 \mathrm{~mL})$, and methyltrioctylammonium chloride $(0.16 \mathrm{~g}, 0.39$ mmol). The reaction mixture was stirred at $100{ }^{\circ} \mathrm{C}$ for $1.5 \mathrm{~h}$ and then diluted with dichloromethane. After washing with water, the organic layer was dried over $\mathrm{Na}_{2} \mathrm{SO}_{4}$ and concentrated under reduced pressure. The crude mixture was purified by silica-gel column chromatography (eluent: hexane/dichloromethane, 1:1) to obtain 7 (2.77 g, $3.65 \mathrm{mmol}, 94 \%)$ as an orange solid.

${ }^{1} \mathrm{H}$ NMR $\left(\mathrm{CDCl}_{3}\right.$, r.t., $\left.600 \mathrm{MHz}\right): \delta / \mathrm{ppm}=9.24(\mathrm{~s}, 2 \mathrm{H}), 8.55(\mathrm{~s}, 2 \mathrm{H}), 7.07(\mathrm{~s}, 4 \mathrm{H}), 6.86(\mathrm{~s}, 2 \mathrm{H}), 4.23(\mathrm{~s}, 6 \mathrm{H})$, $3.91(\mathrm{~s}, 3 \mathrm{H}), 2.94(\mathrm{sept}, J=6.6 \mathrm{~Hz}, 2 \mathrm{H}), 2.42(\mathrm{~s}, 6 \mathrm{H}), 2.10(\mathrm{~s}, 12 \mathrm{H})$, and $1.22(\mathrm{~d}, J=6.6 \mathrm{~Hz}, 12 \mathrm{H}) ;{ }^{13} \mathrm{C}\left\{{ }^{1} \mathrm{H}\right\}$ $\operatorname{NMR}\left(\mathrm{CDCl}_{3}\right.$, r.t., $\left.151 \mathrm{MHz}\right): \delta / \mathrm{ppm}=170.1,160.8,149.4,145.0,141.1,138.7,137.3,136.1,128.9,128.6$, 128.5, 124.9, 124.7, 124.4, 124.0, 119.9, 109.6, 61.5, 55.4, 29.7, 24.2, 21.31, and 21.26. HRMS (APCI/TOF) $m / z:[M]^{+}$Calcd for $\mathrm{C}_{51} \mathrm{H}_{51} \mathrm{NO}_{5}$ 757.3762; Found 757.3757.

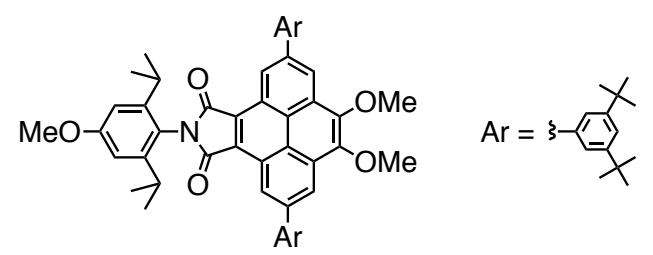

2,7-Bis(3,5-di-tert-butylphenyl)- $N$-(2,6-diisopropyl-4-methoxyphenyl)-9,10-dimethoxypyrene-4,5dicarboximide (8): 
Compound 6 (155 mg, $0.200 \mathrm{mmol})$ and SPhos Pd G2 (7.2 mg, $0.010 \mathrm{mmol})$, and 1-bromo-3,5-di-tertbutylbenzene (162 mg, $0.600 \mathrm{mmol})$ were placed in a three-neck flask, and the flask was purged with argon. Then, to the mixture were added anhydrous toluene $(4.0 \mathrm{~mL})$, aqueous $\mathrm{K}_{2} \mathrm{CO}_{3}$ solution $(2.0 \mathrm{M}, 2.0 \mathrm{~mL})$, and methyltrioctylammonium chloride ( 1 drop). The reaction mixture was stirred at $100{ }^{\circ} \mathrm{C}$ for $3 \mathrm{~h}$ and then diluted with dichloromethane. After washing with water, the organic layer was dried over $\mathrm{Na}_{2} \mathrm{SO}_{4}$ and concentrated under reduced pressure. The crude mixture was purified by silica-gel column chromatography (eluent: hexane/dichloromethane, $2: 1)$ to obtain 8 (152 $\mathrm{mg}, 0.170 \mathrm{mmol}, 85 \%)$ as an orange solid.

${ }^{1} \mathrm{H}$ NMR $\left(\mathrm{CDCl}_{3}\right.$, r.t., $\left.600 \mathrm{MHz}\right): \delta / \mathrm{ppm}=9.81(\mathrm{~d}, J=1.8 \mathrm{~Hz}, 2 \mathrm{H}), 9.06(\mathrm{~d}, J=1.8 \mathrm{~Hz}, 2 \mathrm{H}), 7.93(\mathrm{~d}, J=1.2$ $\mathrm{Hz}, 4 \mathrm{H}), 7.70$ (t, $J=1.5 \mathrm{~Hz}, 2 \mathrm{H}), 6.99$ (s, 2H), 4.42 (s, 6H), 3.99 (s, 3H), 3.10 (sept, $J=6.9 \mathrm{~Hz}, 2 \mathrm{H}), 1.58$ (s, $36 \mathrm{H})$, and $1.36(\mathrm{~d}, J=6.6 \mathrm{~Hz}, 12 \mathrm{H}) ;{ }^{13} \mathrm{C}\left\{{ }^{1} \mathrm{H}\right\} \mathrm{NMR}\left(\mathrm{CDCl}_{3}\right.$, r.t., $\left.151 \mathrm{MHz}\right): \delta / \mathrm{ppm}=170.4,161.0,151.8$, 149.4, 145.3, 142.2, 140.6, 129.1, 128.7, 125.0, 124.5, 123.0, 122.3, 121.7, 119.8, 109.9, 61.5, 55.5, 35.3, 31.8, 29.8, and 24.2 (Note: 22 peaks were observed for the 23 unique carbons, in which 2 peaks were overlapped). HRMS (APCI/TOF) $m / z:[M]^{-}$Calcd for $\mathrm{C}_{61} \mathrm{H}_{71} \mathrm{NO}_{5}$ 897.5338; Found 897.5321.

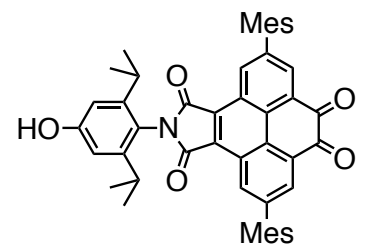

$N$-(4-Hydroxy-2,6-diisopropylphenyl)-2,7-dimesityl-9,10-dioxo-9,10-dihydropyrene-4,5-dicarboximide (9):

Compound 7 (2.74 g, $3.62 \mathrm{mmol})$ was placed in a three-neck flask, and the flask was purged with argon. Anhydrous dichloromethane $(160 \mathrm{~mL})$ was added to the flask, and the solution was cooled to $-78{ }^{\circ} \mathrm{C}$. Then, 1.0 $\mathrm{M}$ boron tribromide solution in dichloromethane $(20 \mathrm{~mL}, 20 \mathrm{mmol})$ was added dropwise, and the mixture was allowed to warm to room temperature with stirring. After $15 \mathrm{~h}$, the reaction was quenched with water at $0{ }^{\circ} \mathrm{C}$, and the mixture was extracted with dichloromethane. To the organic layer was added silver(I) oxide (3.02 g, $13.0 \mathrm{mmol}$ ), and the reaction mixture was sonicated for $10 \mathrm{~min}$ at room temperature. The resultant mixture was filtered through a Celite pad, and the filtrate was dried over $\mathrm{Na}_{2} \mathrm{SO}_{4}$ and concentrated under reduced pressure. The crude mixture was purified by silica-gel column chromatography (eluent: dichloromethane) to obtain $9(1.91 \mathrm{~g}, 2.67 \mathrm{mmol}, 74 \%)$ as an orange solid.

${ }^{1} \mathrm{H}$ NMR $\left(\mathrm{CDCl}_{3}\right.$, r.t., $\left.600 \mathrm{MHz}\right): \delta / \mathrm{ppm}=9.29(\mathrm{~d}, J=1.2 \mathrm{~Hz}, 2 \mathrm{H}), 8.55(\mathrm{~d}, J=1.8 \mathrm{~Hz}, 2 \mathrm{H}), 7.02(\mathrm{~s}, 4 \mathrm{H})$, $6.77(\mathrm{~s}, 2 \mathrm{H}), 5.18(\mathrm{~s}, 1 \mathrm{H}), 2.81$ (sept, $J=6.9 \mathrm{~Hz}, 2 \mathrm{H}), 2.37$ (s, 6H), $2.10(\mathrm{~s}, 12 \mathrm{H})$, and 1.17 (d, $J=6.6 \mathrm{~Hz}$, $12 \mathrm{H}) ;{ }^{13} \mathrm{C}\left\{{ }^{1} \mathrm{H}\right\} \mathrm{NMR}\left(\mathrm{CDCl}_{3}\right.$, r.t., $\left.151 \mathrm{MHz}\right): \delta / \mathrm{ppm}=179.8,169.0,157.2,149.6,143.7,138.1,136.1,135.6$, 134.9, 134.4, 130.5, 130.4, 128.8, 128.2, 126.3, 119.2, 111.4, 29.6, 24.1, 21.2, and 21.1. HRMS (APCI/TOF) $m / z:[M]^{+}$Calcd for $\mathrm{C}_{48} \mathrm{H}_{43} \mathrm{NO}_{5}$ 713.3136; Found 713.3132. 


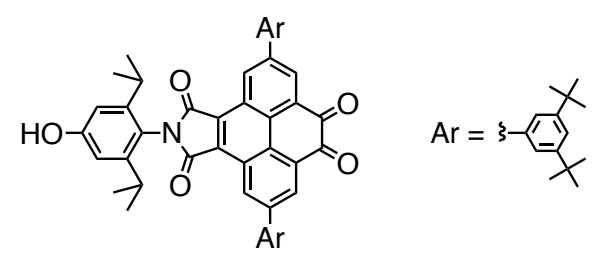

2,7-Bis(3,5-di-tert-butylphenyl)- $N$-(4-hydroxy-2,6-diisopropylphenyl)-9,10-dioxo-9,10-dihydropyrene4,5-dicarboximide (10):

Compound 8 (152 mg, $0.169 \mathrm{mmol})$ was placed in a three-neck flask, and the flask was purged with argon. Anhydrous dichloromethane $(8.5 \mathrm{~mL})$ was added to the flask, and the solution was cooled to $-78{ }^{\circ} \mathrm{C}$. Then, 1.0 $\mathrm{M}$ boron tribromide solution in dichloromethane $(0.93 \mathrm{~mL}, 0.93 \mathrm{mmol})$ was added dropwise, and the mixture was allowed to warm to room temperature with stirring. After $6 \mathrm{~h}$, the reaction was quenched with water at $0{ }^{\circ} \mathrm{C}$, and the mixture was extracted with dichloromethane. To the organic layer was added silver(I) oxide (141 $\mathrm{mg}, 0.608 \mathrm{mmol}$ ), and the reaction mixture was sonicated for $10 \mathrm{~min}$ at room temperature. The resultant mixture was filtered through a Celite pad, and the filtrate was dried over $\mathrm{Na}_{2} \mathrm{SO}_{4}$ and concentrated under reduced pressure. The crude mixture was purified by silica-gel column chromatography (eluent: dichloromethane) to obtain 10 (91 $\mathrm{mg}, 0.11 \mathrm{mmol}, 63 \%)$ as an orange solid.

${ }^{1} \mathrm{H}$ NMR $\left(\mathrm{CDCl}_{3}\right.$, r.t., $\left.600 \mathrm{MHz}\right): \delta / \mathrm{ppm}=9.73(\mathrm{~d}, J=1.8 \mathrm{~Hz}, 2 \mathrm{H}), 8.98(\mathrm{~d}, J=2.4 \mathrm{~Hz}, 2 \mathrm{H}), 7.69(\mathrm{~d}, J=1.8$ $\mathrm{Hz}, 4 \mathrm{H}), 7.60$ (t, $J=1.5 \mathrm{~Hz}, 2 \mathrm{H}), 6.83(\mathrm{~s}, 2 \mathrm{H}), 5.27$ (s, 1H), 2.87 (sept, $J=6.9 \mathrm{~Hz}, 2 \mathrm{H}), 1.45$ (s, 36H), and 1.23 $(\mathrm{d}, J=7.2 \mathrm{~Hz}, 12 \mathrm{H}) ;{ }^{13} \mathrm{C}\left\{{ }^{1} \mathrm{H}\right\} \mathrm{NMR}\left(\mathrm{CDCl}_{3}\right.$, r.t., $\left.151 \mathrm{MHz}\right): \delta / \mathrm{ppm}=179.9,169.3,157.4,152.2,149.6$, $144.1,137.9,132.4,131.9,130.5,130.4,128.3,126.5,123.4,122.0,119.0,111.5,35.3,31.7,29.7$, and 24.2. HRMS (APCI/TOF) $m / z:[M]^{-}$Calcd for $\mathrm{C}_{58} \mathrm{H}_{63} \mathrm{NO}_{5}$ 853.4712; Found 853.4722.

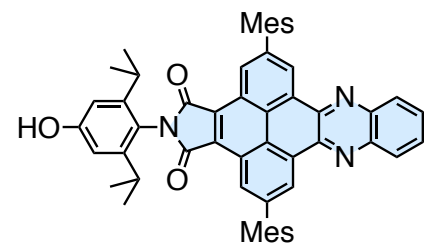

\section{$\mathrm{N}$-(4-Hydroxy-2,6-diisopropylphenyl)-2,7-dimesitylphenanthro[4,5-abc]phenazine-4,5-dicarboximide (Wing1-OH):}

Compound 9 (128 mg, $0.180 \mathrm{mmol})$ and $o$-phenylenediamine $(20 \mathrm{mg}, 0.18 \mathrm{mmol})$ were placed in a Schlenk flask, and the flask was purged with argon. Then, chloroform $(4.7 \mathrm{~mL})$ and acetic acid $(2.8 \mathrm{~mL})$ were added to the flask and the mixture was stirred at $70{ }^{\circ} \mathrm{C}$. After $12 \mathrm{~h}$, the solvent was evaporated under reduced pressure, and the crude product was purified by silica-gel column chromatography (eluent: chloroform) to afford 
Wing1-OH (115 mg, 81\%) as a yellow solid. Slow evaporation of $\mathrm{CDCl}_{3}$ solution of Wing1-OH gave yellow crystals suitable for the single crystal X-ray diffractometry.

${ }^{1} \mathrm{H} \mathrm{NMR}\left(\mathrm{CDCl}_{3}, 60^{\circ} \mathrm{C}, 600 \mathrm{MHz}\right): \delta / \mathrm{ppm}=9.72(\mathrm{~d}, J=1.8 \mathrm{~Hz}, 2 \mathrm{H}), 9.41(\mathrm{~d}, J=1.2 \mathrm{~Hz}, 2 \mathrm{H}), 8.34(\mathrm{~m}, 2 \mathrm{H})$, 7.89 (m, 2H), 7.08 (s, 4H), 6.78 (s, 2H), 4.82 (s, 1H), 2.94 (sept, J=6.9 Hz, 2H), 2.43 (s, 6H), 2.16 (s, 12H), and $1.21(\mathrm{~d}, J=7.2 \mathrm{~Hz}, 12 \mathrm{H}) ;{ }^{13} \mathrm{C}\left\{{ }^{1} \mathrm{H}\right\} \mathrm{NMR}\left(\mathrm{CDCl}_{3}, 60^{\circ} \mathrm{C}, 151 \mathrm{MHz}\right): \delta / \mathrm{ppm}=169.9,157.1,150.0,143.0$, 142.9, 142.3, 138.4, 137.5, 136.2, 130.5, 130.4, 129.9, 129.0. 128.69, 128.64, 127.9, 125.5, 120.2, 111.3, 29.7, 24.1, 21.29, and 21.25 (Note: 23 peaks were observed for the 24 unique carbons, in which 2 peaks were overlapped). HRMS (APCI/TOF) $m / z$ : $[M]^{-}$Calcd for $\mathrm{C}_{54} \mathrm{H}_{47} \mathrm{~N}_{3} \mathrm{O}_{3}$ 785.3623; Found 785.3650.

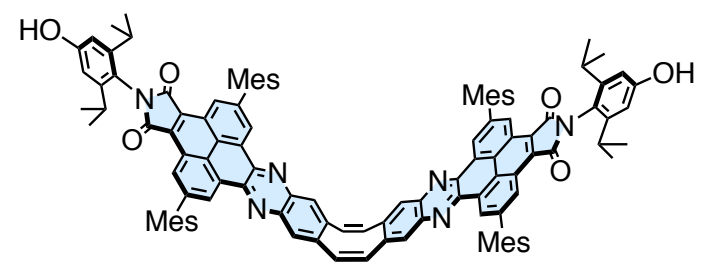

COT-fused $N$-(4-hydroxy-2,6-diisopropylphenyl)-2,7-dimesitylphenanthro[4,5-abc]phenazine-4,5dicarboximide dimer (FLAP1-OH):

Compound $9(1.53 \mathrm{~g}, 2.14 \mathrm{mmol})$ and $4(440 \mathrm{mg}, 1.07 \mathrm{mmol})$ was placed in a three-neck flask, and the flask was purged with argon. Then, 1,2-dichloroethane (DCE, $15 \mathrm{~mL})$ and acetic acid $(9 \mathrm{~mL})$ were added to the flask and the mixture was stirred at $95{ }^{\circ} \mathrm{C}$. After $22 \mathrm{~h}$, the solvent was evaporated under reduced pressure, and the resultant solid was washed with dichloromethane. The crude product was purified by reprecipitation from the mixture of chloroform and hexane for three times to afford FLAP1-OH (1.21 g, $0.747 \mathrm{mmol}, 70 \%)$ as a yellow solid.

${ }^{1} \mathrm{H}$ NMR $\left(\mathrm{CDCl}_{3}, 60{ }^{\circ} \mathrm{C}, 600 \mathrm{MHz}\right): \delta / \mathrm{ppm}=9.66(\mathrm{~s}, 4 \mathrm{H}), 9.33(\mathrm{~d}, J=1.2 \mathrm{~Hz}, 4 \mathrm{H}), 8.12(\mathrm{~s}, 4 \mathrm{H}), 7.33(\mathrm{~s}, 4 \mathrm{H})$, $6.99(\mathrm{~s}, 8 \mathrm{H}), 6.74$ (s, 4H), 4.71 (d, $J=1.8 \mathrm{~Hz}, 2 \mathrm{H}), 2.88$ (sept, $J=6.6 \mathrm{~Hz}, 4 \mathrm{H}), 2.40$ (s, 12H), 2.06 (s, 24H), and $1.17(\mathrm{~d}, J=7.2 \mathrm{~Hz}, 24 \mathrm{H}) ;{ }^{13} \mathrm{C}\left\{{ }^{1} \mathrm{H}\right\}$ NMR $\left(\mathrm{CDCl}_{3} /\right.$ trichloroacetic acid, r.t., $\left.151 \mathrm{MHz}\right): \delta / \mathrm{ppm}=170.0$, $156.8,149.9,143.1,141.8,141.7,138.8,137.9,137.1,135.8,133.8,130.5,129.9,128.6,128.5,128.0,127.2$, 127.1, 125.6, 119.3, 111.6, 29.7, 25.1, 21.3 and 21.2 (Note: due to the low solubility of FLAP1-OH, trichloroacetic acid was added to dissolve it as a protonated species). HRMS (MALDI/TOF) $\mathrm{m} / \mathrm{z}$ : $[\mathrm{M}]^{+}$Calcd for $\mathrm{C}_{112} \mathrm{H}_{94} \mathrm{~N}_{6} \mathrm{O}_{6}$ 1618.7229; Found 1618.727. UV-visible absorption (in $\left.\mathrm{CH}_{2} \mathrm{Cl}_{2}\right): \lambda_{\max }\left(\varepsilon / \mathrm{M}^{-1} \mathrm{~cm}^{-1}\right)=279$ $\left(6.6 \times 10^{4}\right)$ and $415 \mathrm{~nm}\left(5.3 \times 10^{4}\right)$. Fluorescence (in $\left.\mathrm{CH}_{2} \mathrm{Cl}_{2}, \lambda_{\mathrm{ex}}=365 \mathrm{~nm}\right): \lambda_{\max }=518$ and $555 \mathrm{~nm} ; \Phi_{\mathrm{F}}=$ $0.42 ; \tau_{\mathrm{F}}=2.4 \mathrm{~ns}\left(\lambda_{\mathrm{obs}}=518 \mathrm{~nm}\right)$. 


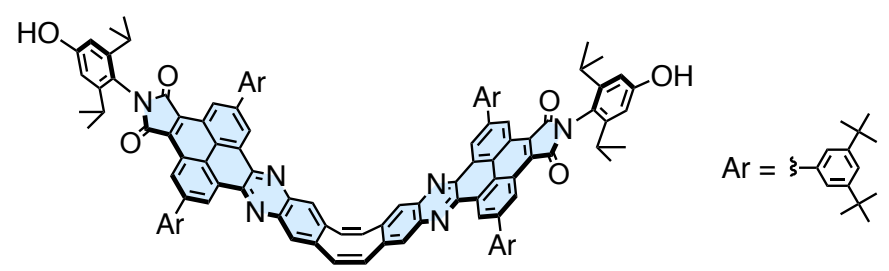

COT-fused 2,7-bis(3,5-di-tert-butylphenyl)- $N$-(4-hydroxy-2,6-diisopropylphenyl)phenanthro[4,5-abc] phenazine-4,5-dicarboximide dimer (FLAP1-OH'):

Compound 10 (91 mg, $0.11 \mathrm{mmol})$ and $4(22 \mathrm{mg}, 0.053 \mathrm{mmol})$ was placed in a three-neck flask, and the flask was purged with argon. Then, 1,2-dichloroethane (DCE, $2.8 \mathrm{~mL})$ and acetic acid $(1.6 \mathrm{~mL})$ were added to the flask and the mixture was stirred at $95{ }^{\circ} \mathrm{C}$. After $23.5 \mathrm{~h}$, the solvent was evaporated under reduced pressure, and the resultant solid was dissolved into dichloromethane and washed with aqueous $\mathrm{NaHCO}_{3}$ solution. The organic layer was dried over $\mathrm{Na}_{2} \mathrm{SO}_{4}$ and concentrated under reduced pressure. The crude product was purified by silica-gel column chromatography (eluent: chloroform/ethyl acetate, 50:1) to obtain FLAP1-OH' (61 mg, $0.032 \mathrm{mmol}, 60 \%$ ) as a yellow solid. Slow diffusion of $n$-octane into a benzonitrile solution of FLAP1-OH' gave yellow crystals suitable for the single crystal X-ray diffractometry.

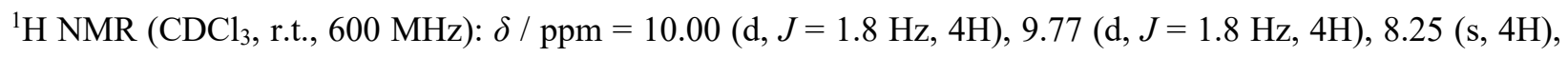
$8.74(\mathrm{~d}, J=1.8 \mathrm{~Hz}, 8 \mathrm{H}), 7.60(\mathrm{t}, J=1.8 \mathrm{~Hz}, 4 \mathrm{H}), 7.41(\mathrm{~s}, 4 \mathrm{H}), 6.78(\mathrm{~s}, 4 \mathrm{H}), 4.93$ (s, 2H), 2.92 (sept, $6.6 \mathrm{~Hz}$, $4 \mathrm{H}), 1.49(\mathrm{~s}, 72 \mathrm{H})$, and $1.20(\mathrm{~d}, J=6.6 \mathrm{~Hz}, 24 \mathrm{H}) ;{ }^{13} \mathrm{C}\left\{{ }^{1} \mathrm{H}\right\} \mathrm{NMR}\left(\mathrm{CDCl}_{3}\right.$, r.t., $\left.151 \mathrm{MHz}\right): \delta / \mathrm{ppm}=170.1$, 157.1, 151.9, 149.8, 143.2, 142.9, 141.6, 139.9, 139.7, 133.6, 130.2, 129.2, 128.5, 127.9, 126.5, 126.3, 125.5, 122.8, 122.5, 119.7, 111.4, 35.3, 31.8, 29.7, and 24.1. HRMS (MALDI/TOF) $m / z:[M+\mathrm{H}]^{+}$Calcd for $\mathrm{C}_{132} \mathrm{H}_{135} \mathrm{~N}_{6} \mathrm{O}_{6}$ 1900.0438; Found 1900.052. 


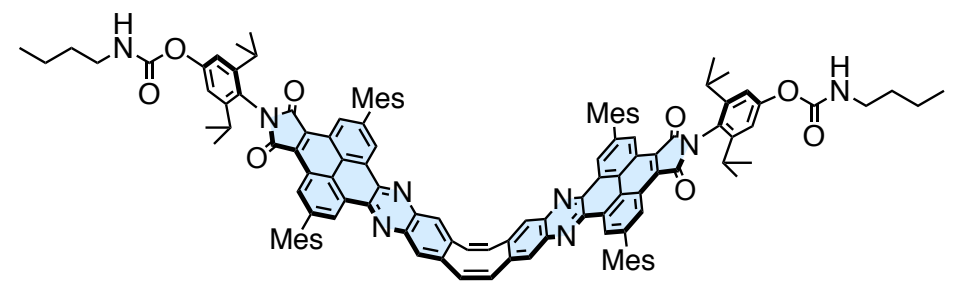

COT-fused $N$-(4-butylcarbamoyloxy-2,6-diisopropylphenyl)-2,7-dimesitylphenanthro[4,5-abc] phenazine-4,5-dicarboximide dimer (FLAP1-BC):

FLAP1-OH (130 mg, $0.080 \mathrm{mmol}$ ) was placed in a Schlenk flask, and the flask was purged with argon. Then, anhydrous toluene $(8.0 \mathrm{~mL})$, butyl isocyanate $(0.45 \mathrm{~mL}, 4.0 \mathrm{mmol})$, and triethylamine $(0.56 \mathrm{~mL}, 4.0 \mathrm{mmol})$ were added, and the mixture was stirred at $110^{\circ} \mathrm{C}$ for $9 \mathrm{~h}$. The solvent was evaporated under reduced pressure, and the residue was purified by silica-gel column chromatography (eluent: chloroform/ethyl acetate, 100:1) to give FLAP1-BC (116 mg, $0.064 \mathrm{mmol}, 80 \%$ ) as a yellow solid.

${ }^{1} \mathrm{H}$ NMR (tetrachloroethane- $\left.d_{2}, 100{ }^{\circ} \mathrm{C}, 600 \mathrm{MHz}\right): \delta / \mathrm{ppm}=9.66(\mathrm{~s}, 4 \mathrm{H}), 9.37(\mathrm{~s}, 4 \mathrm{H}), 8.21(\mathrm{~s}, 4 \mathrm{H}), 7.38(\mathrm{~s}$, 4H), 7.13 (s, 4H), 7.11 (s, 8H), 4.96 (s, 2H), 3.35 (m, 4H), 2.97 (sept, J = 6.9 Hz, 4H), 2.47 (s, 12H), 2.18 (s, 24H), $1.65(\mathrm{~m}, 4 \mathrm{H}), 1.49(\mathrm{~m}, 4 \mathrm{H}), 1.23(\mathrm{~d}, J=7.2 \mathrm{~Hz}, 24 \mathrm{H})$, and $1.03(\mathrm{t}, J=7.2 \mathrm{~Hz}, 6 \mathrm{H}) ;{ }^{13} \mathrm{C}\left\{{ }^{1} \mathrm{H}\right\} \mathrm{NMR}$ (tetrachloroethane- $d_{2}, 50{ }^{\circ} \mathrm{C}, 151 \mathrm{MHz}$ ): $\delta / \mathrm{ppm}=169.1,153.9,152.3,149.1,142.6,141.7,141.3,139.3$, 137.7, 137.3, 135.7, 133.2, 129.9, 128.8, 128.6. 128.4, 128.2, 128.1, 127.3, 125.0, 123.5, 116.8, 40.9, 31.7, 29.4, 23.8, 21.1, 21.0, 19.8, and 13.6. HRMS (MALDI/TOF) $\mathrm{m} / \mathrm{z}$ : $[M+\mathrm{H}]^{+}$Calcd for $\mathrm{C}_{112} \mathrm{H}_{113} \mathrm{~N}_{8} \mathrm{O}_{8} 1817.8676$; Found 1817.867. 


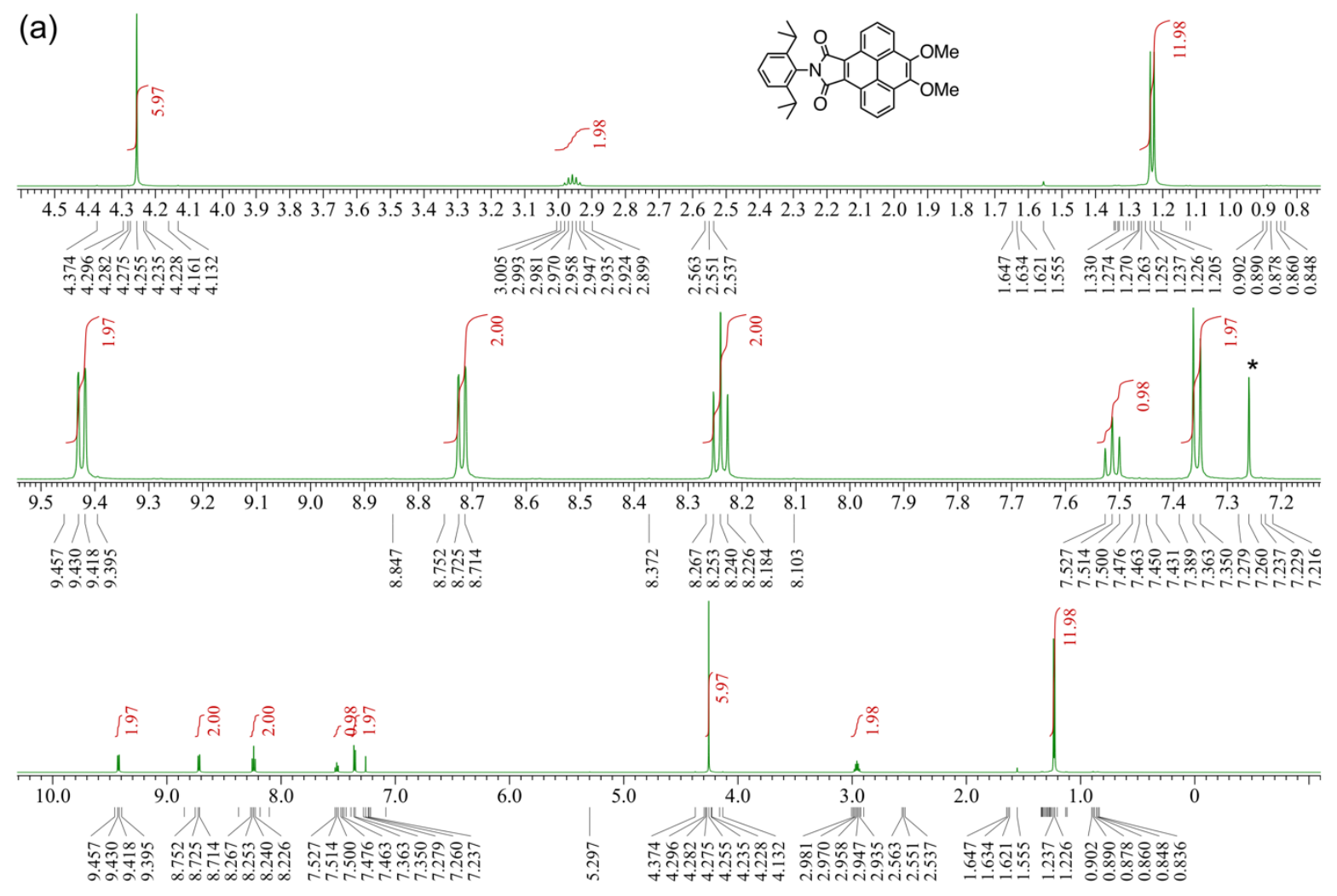

(b)
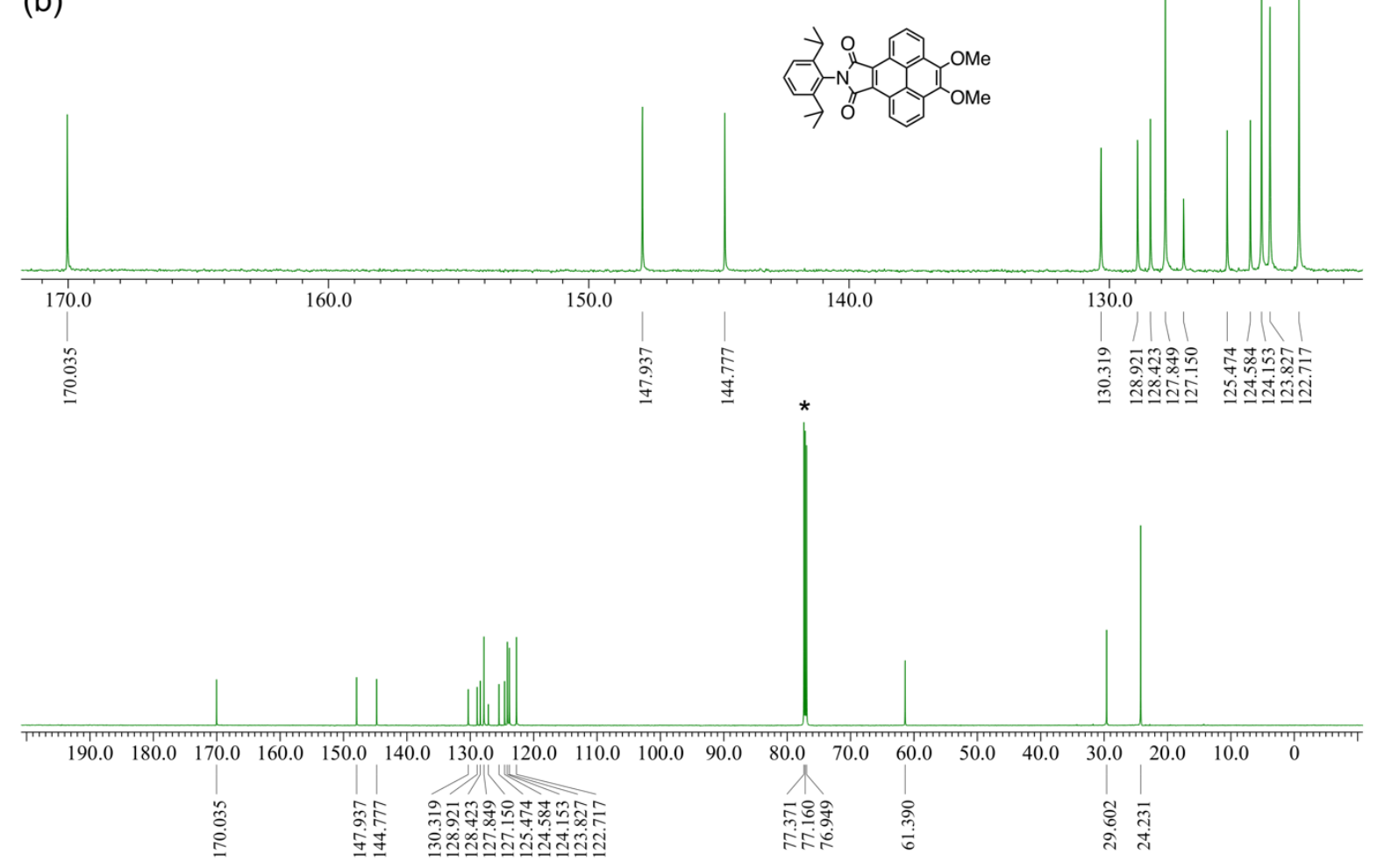

Figure S2.3. (a) ${ }^{1} \mathrm{H}$ NMR and (b) ${ }^{13} \mathrm{C}\left\{{ }^{1} \mathrm{H}\right\}$ NMR spectra of 2 in $\mathrm{CDCl}_{3}$ at room temperature. Peaks marked with asterisks indicate residual solvents. 
(a)
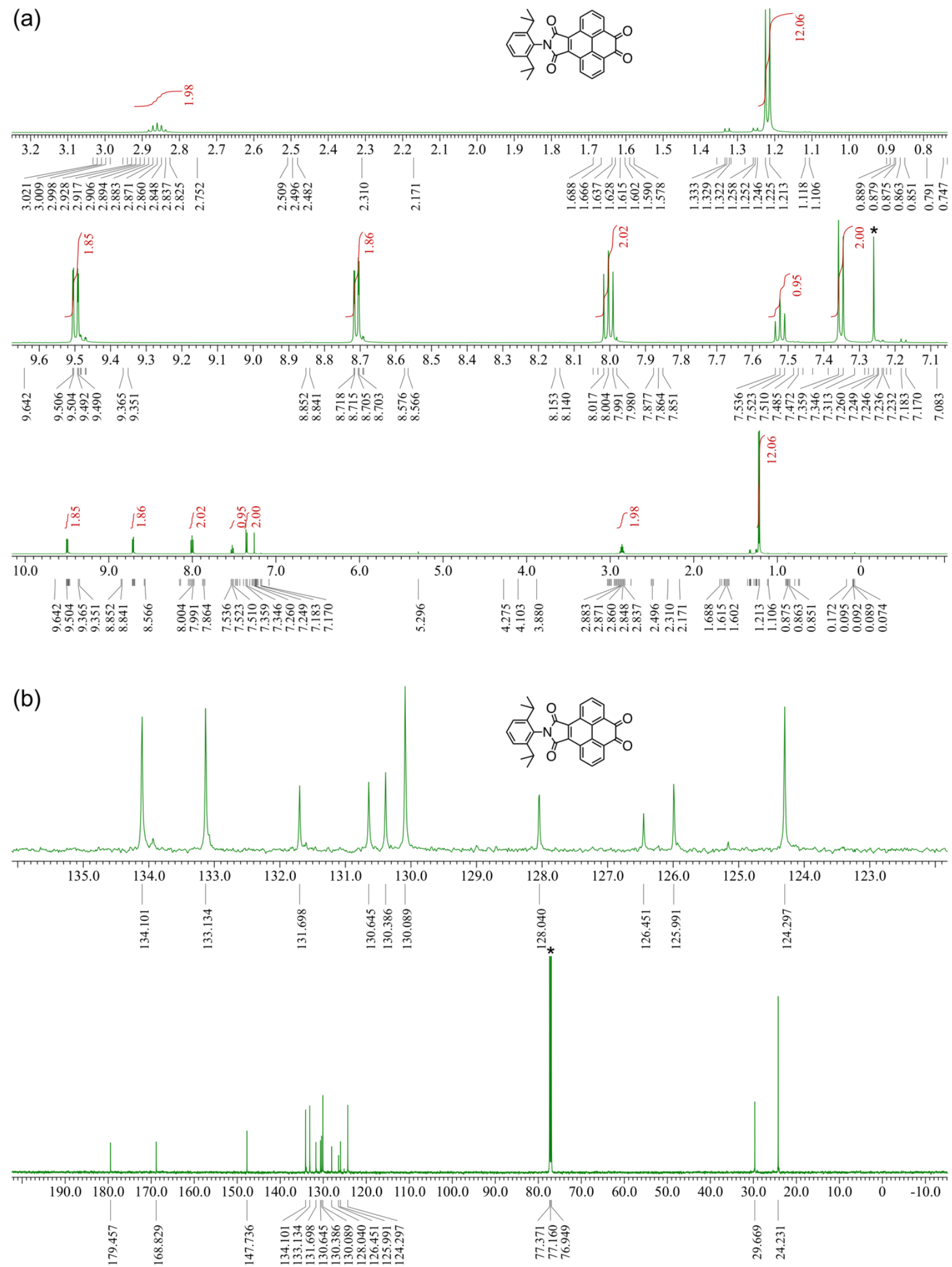

Figure S2.4. (a) ${ }^{1} \mathrm{H}$ NMR and (b) ${ }^{13} \mathrm{C}\left\{{ }^{1} \mathrm{H}\right\}$ NMR spectra of 3 in $\mathrm{CDCl}_{3}$ at room temperature. Peaks marked with asterisks indicate residual solvents. 
(a)
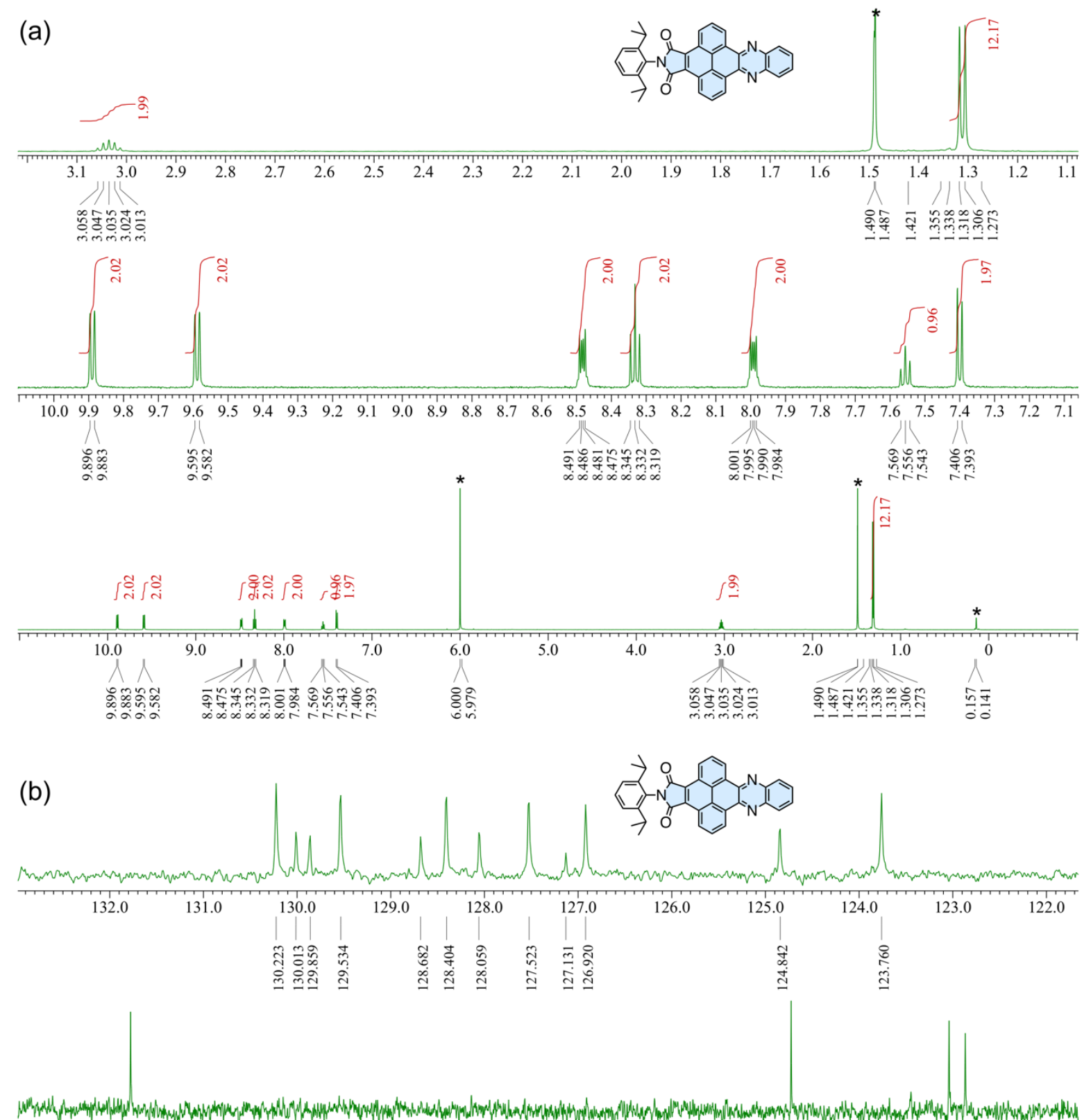

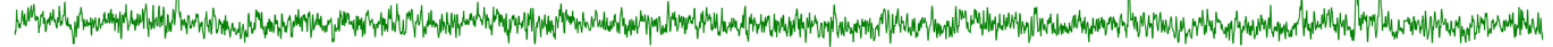

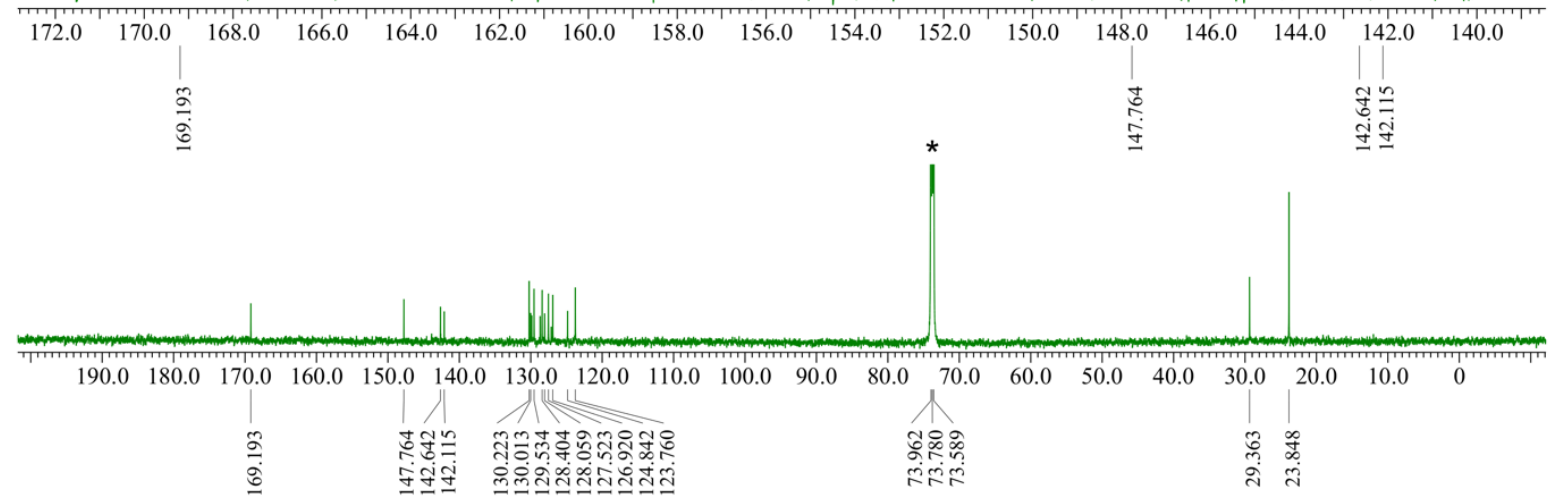

Figure S2.5. (a) ${ }^{1} \mathrm{H}$ NMR and (b) ${ }^{13} \mathrm{C}\left\{{ }^{1} \mathrm{H}\right\}$ NMR spectra of Wing1-H in tetrachloroethane- $d_{2}$ at $120{ }^{\circ} \mathrm{C}$. Peaks marked with asterisks indicate residual solvents or impurities. 

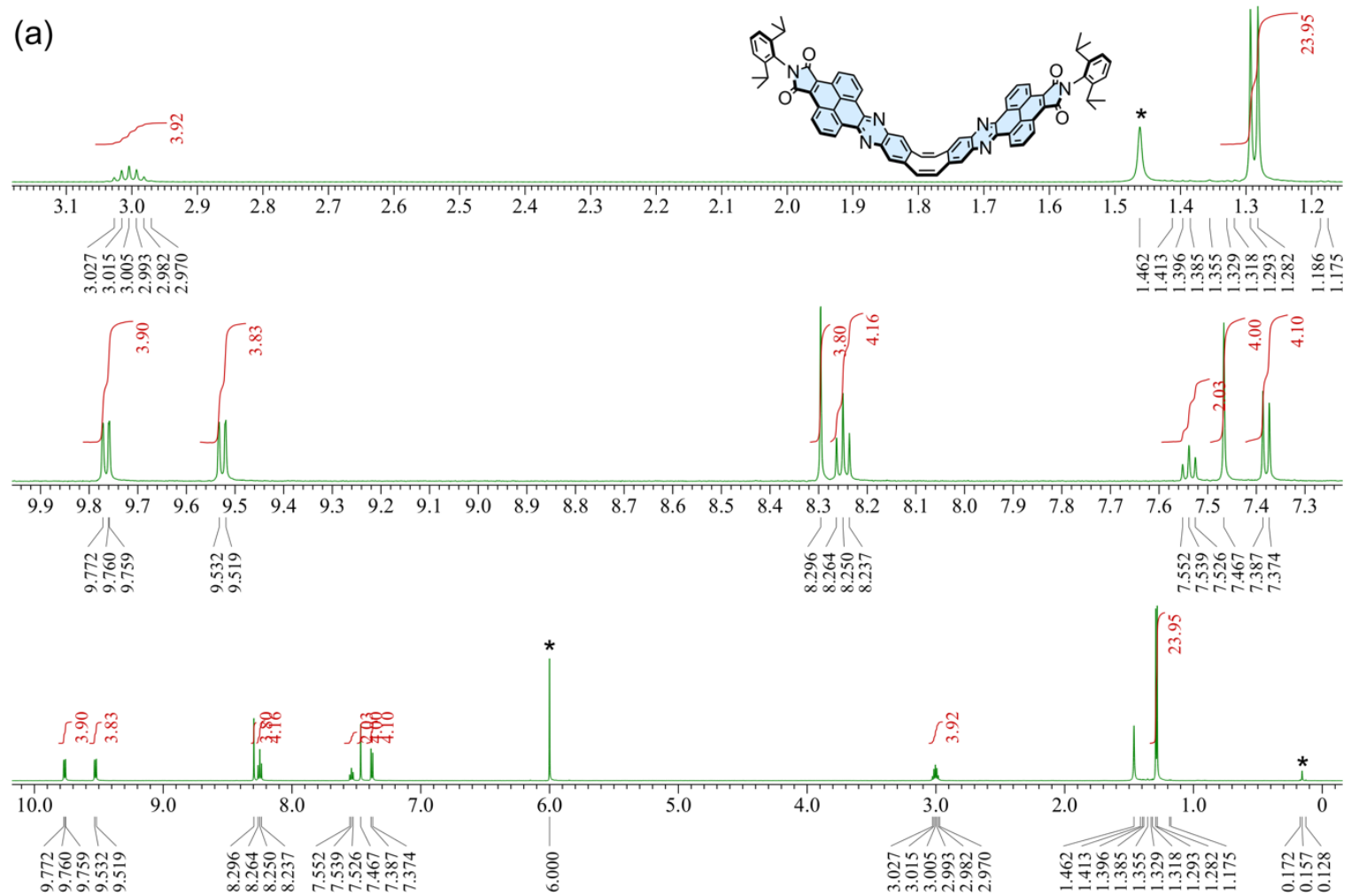

(b)

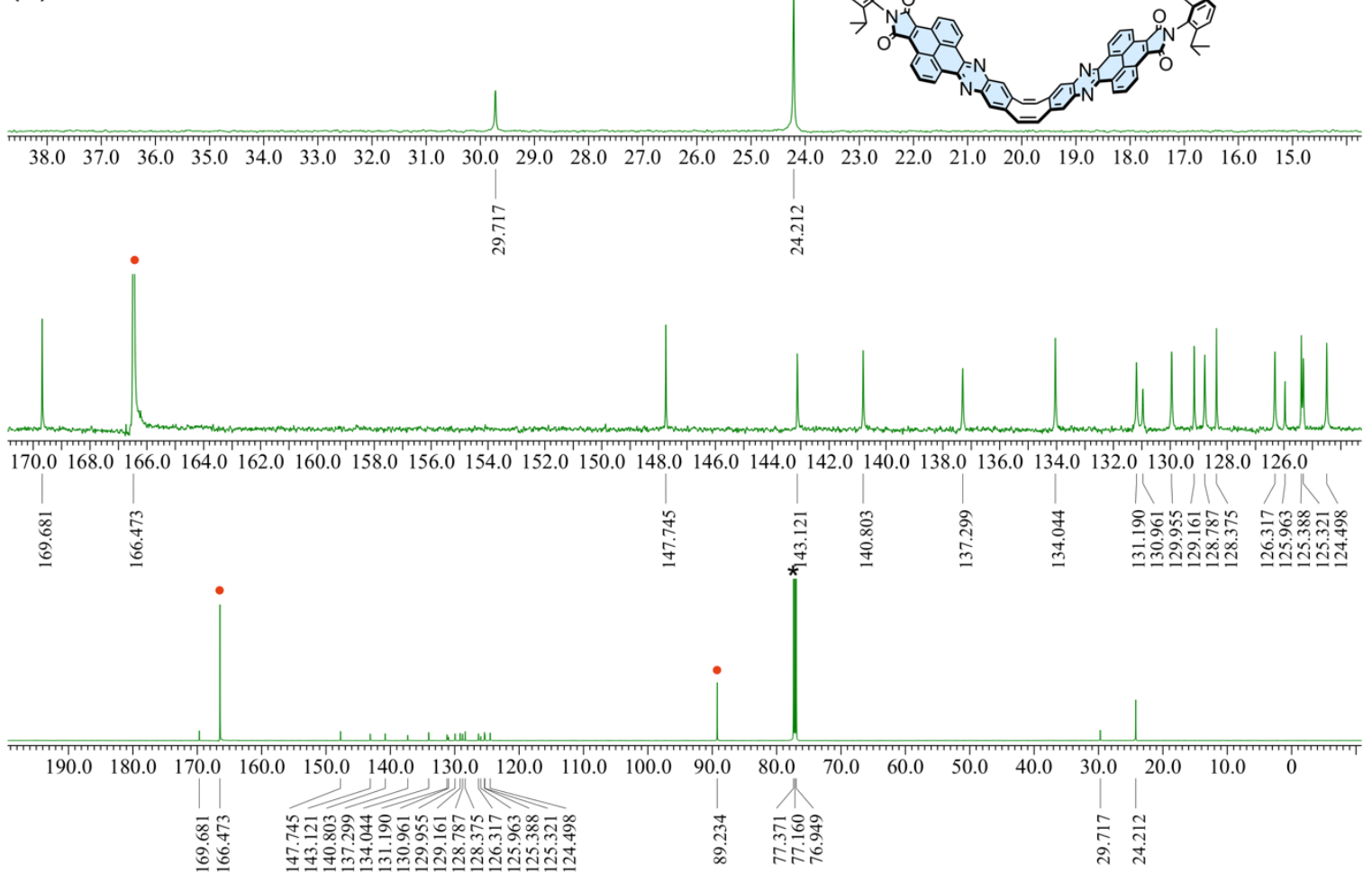

Figure S2.6. (a) ${ }^{1} \mathrm{H}$ NMR spectra of FLAP1-H in tetrachloroethane- $d_{2}$ at $120{ }^{\circ} \mathrm{C}$ and (b) ${ }^{13} \mathrm{C}\left\{{ }^{1} \mathrm{H}\right\}$ NMR spectra of FLAP1-H in $\mathrm{CDCl}_{3} /$ trichloroacetic acid at room temperature. Peaks marked with asterisks indicate residual solvents or impurities, and red circles correspond to peaks derived from trichloroacetic acid. 

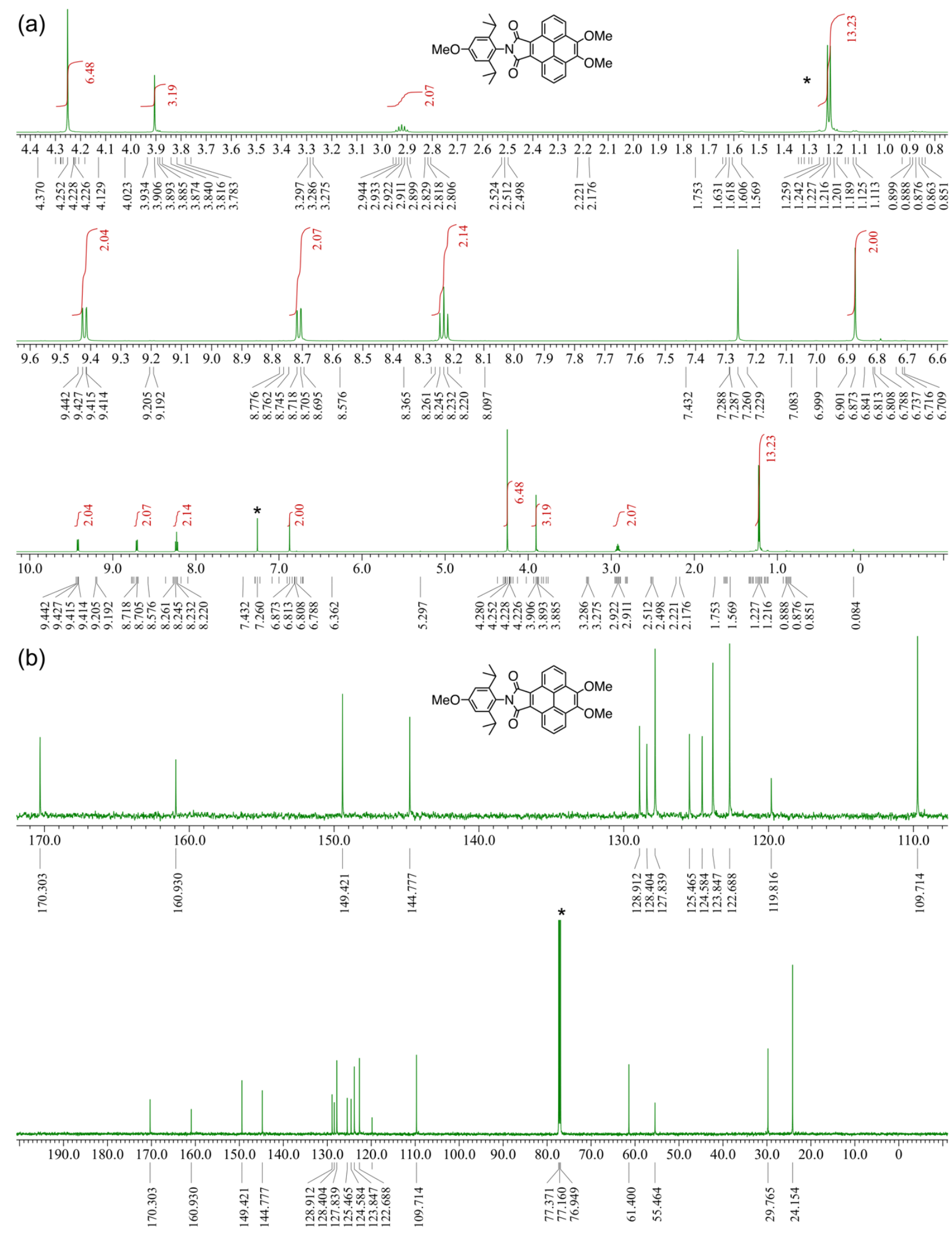

Figure S2.7. (a) ${ }^{1} \mathrm{H}$ NMR and (b) ${ }^{13} \mathrm{C}\left\{{ }^{1} \mathrm{H}\right\}$ NMR spectra of 5 in $\mathrm{CDCl}_{3}$ at room temperature. Peaks marked with asterisks indicate residual solvents. 
(a)
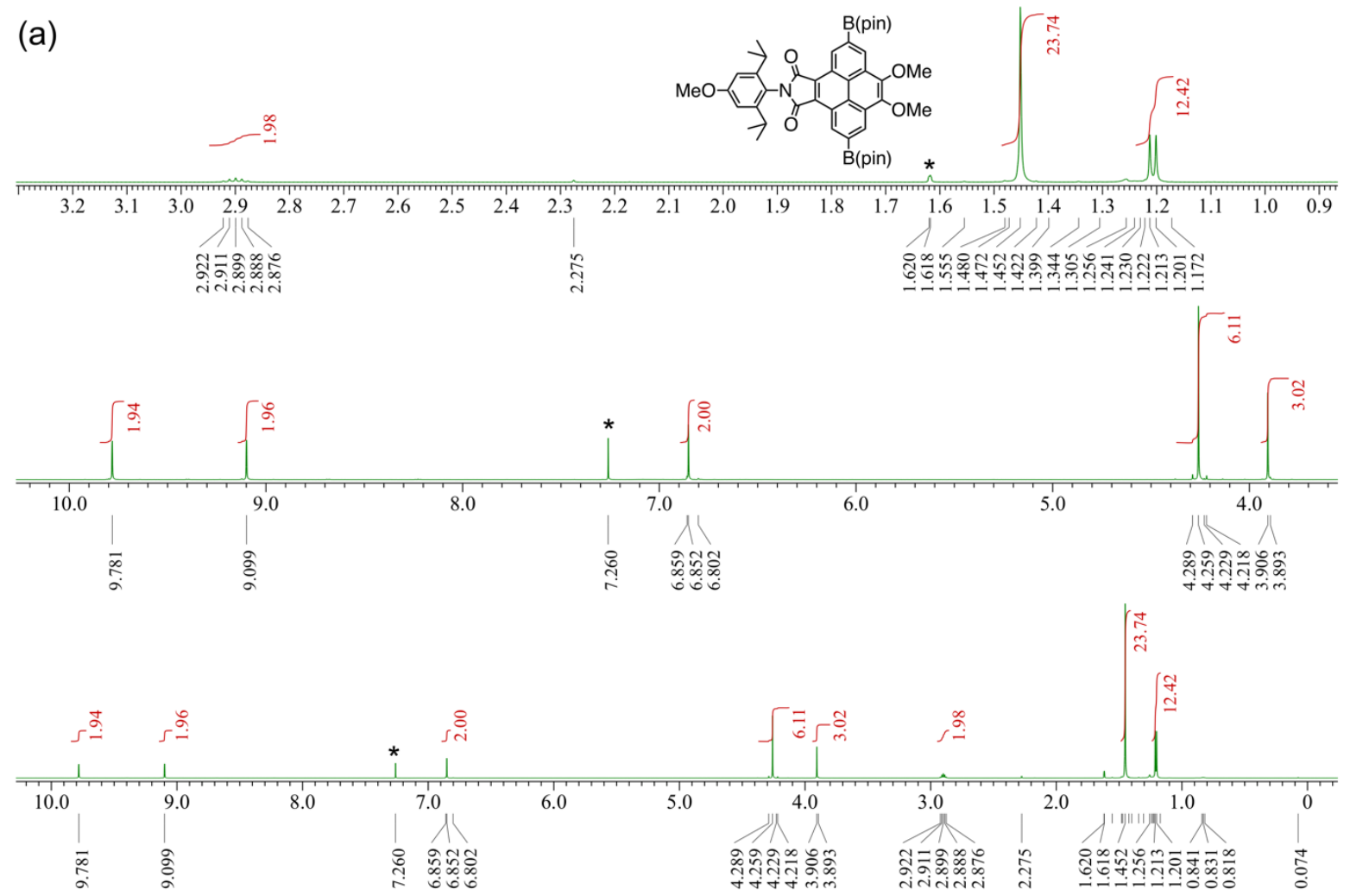

(b)
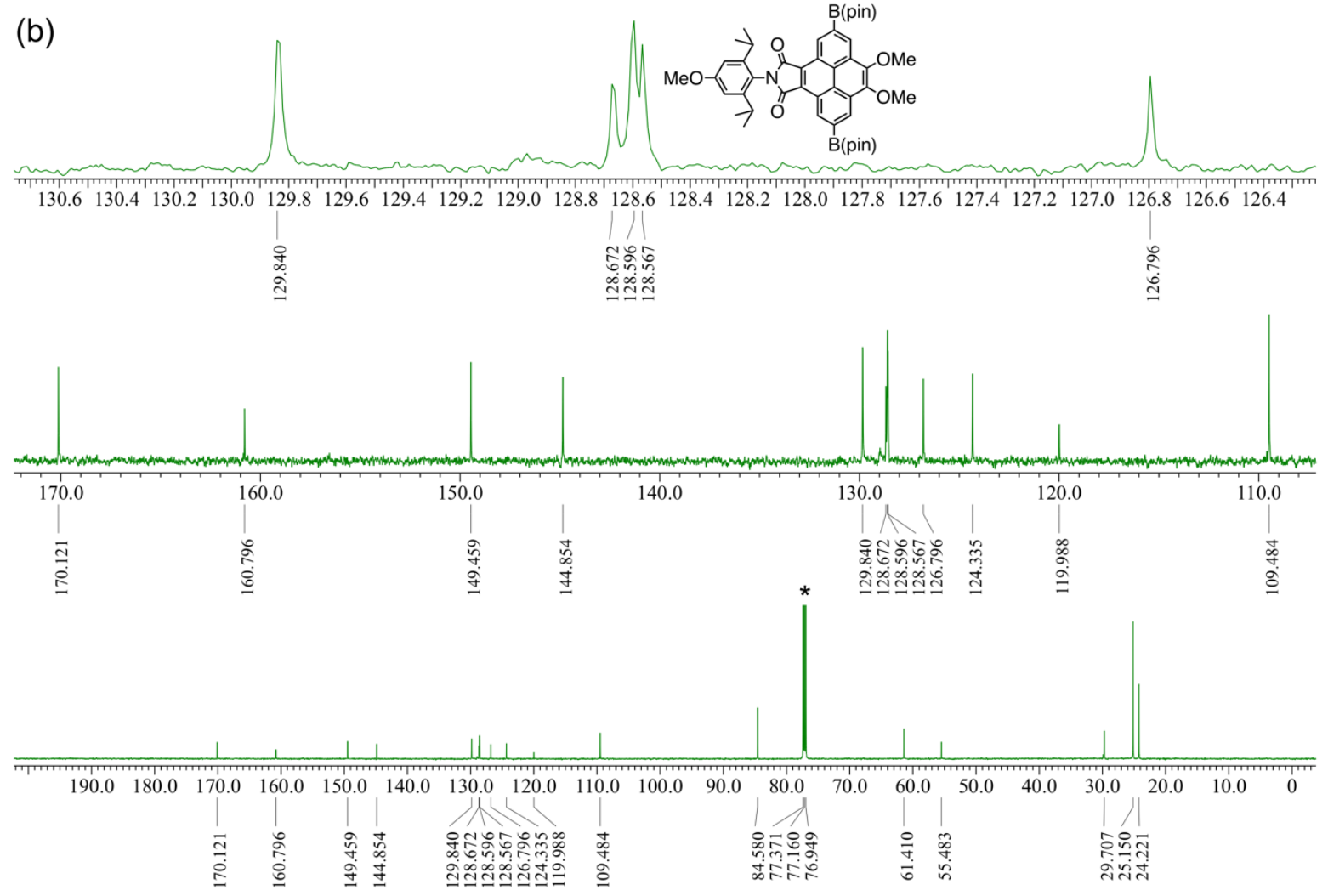

Figure S2.8. (a) ${ }^{1} \mathrm{H}$ NMR and (b) ${ }^{13} \mathrm{C}\left\{{ }^{1} \mathrm{H}\right\}$ NMR spectra of 6 in $\mathrm{CDCl}_{3}$ at room temperature. Peaks marked with asterisks indicate residual solvents. 
(a)

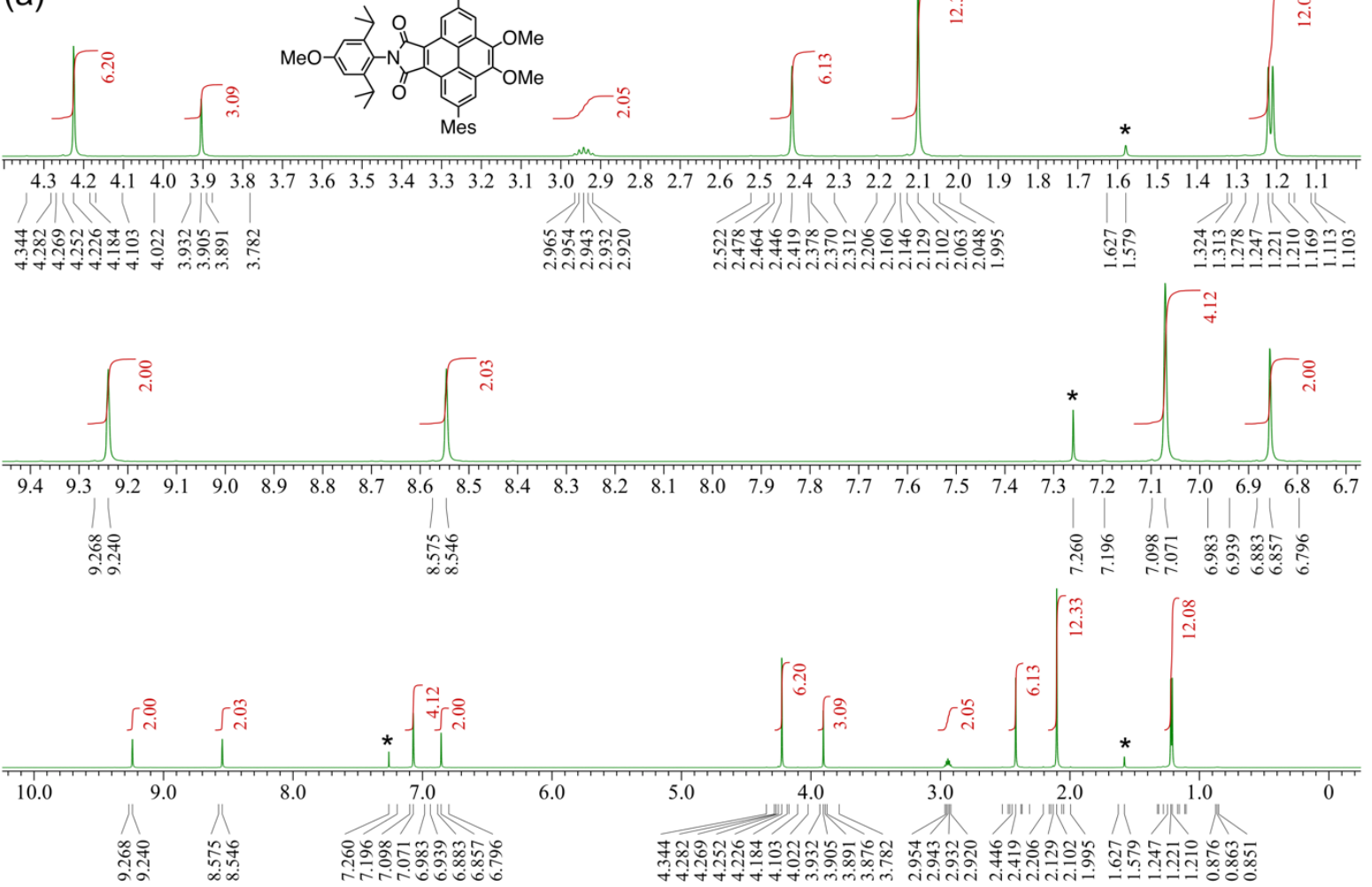

(b)
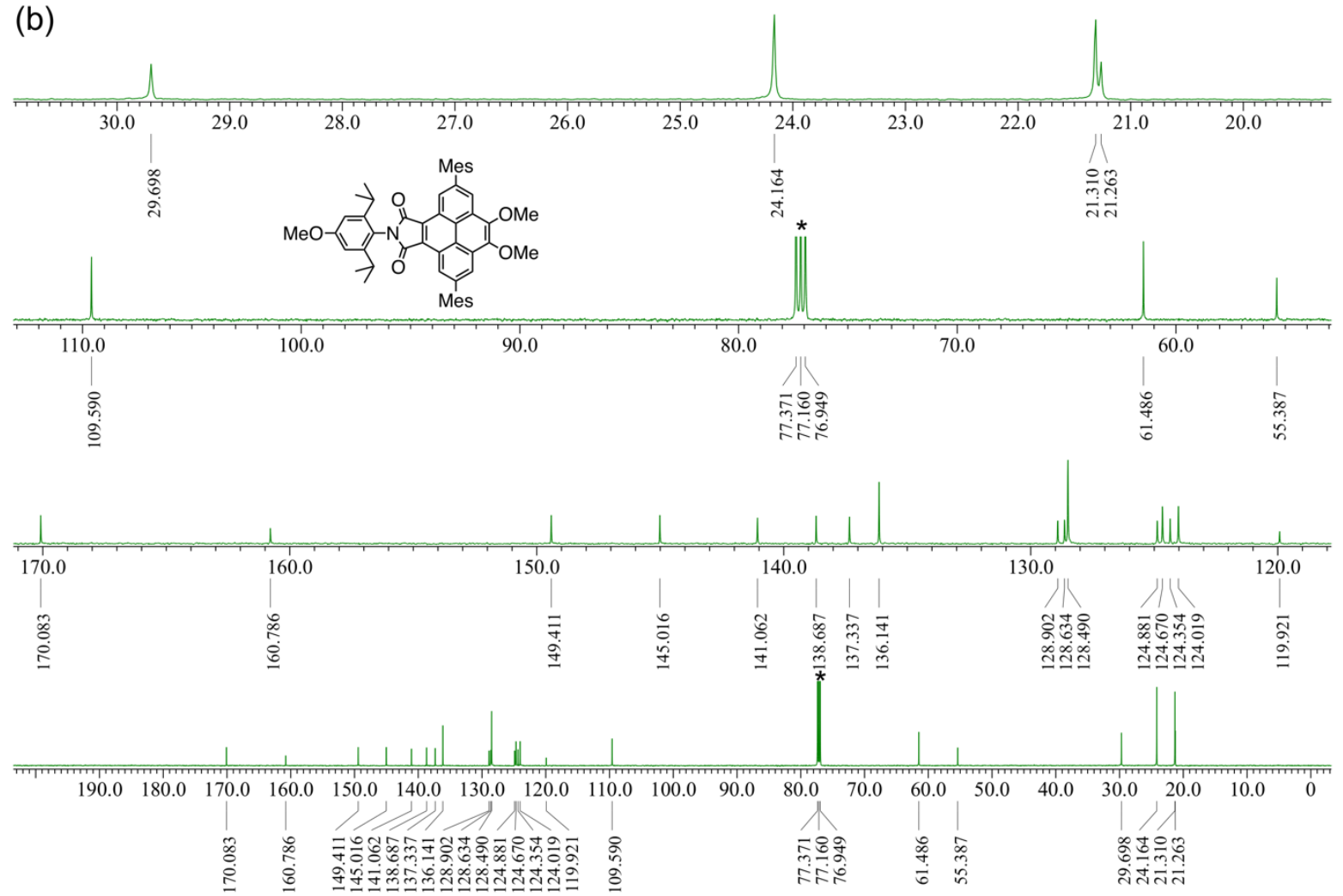

Figure S2.9. (a) ${ }^{1} \mathrm{H}$ NMR and (b) ${ }^{13} \mathrm{C}\left\{{ }^{1} \mathrm{H}\right\}$ NMR spectra of 7 in $\mathrm{CDCl}_{3}$ at room temperature. Peaks marked with asterisks indicate residual solvents or impurities. 
(a)
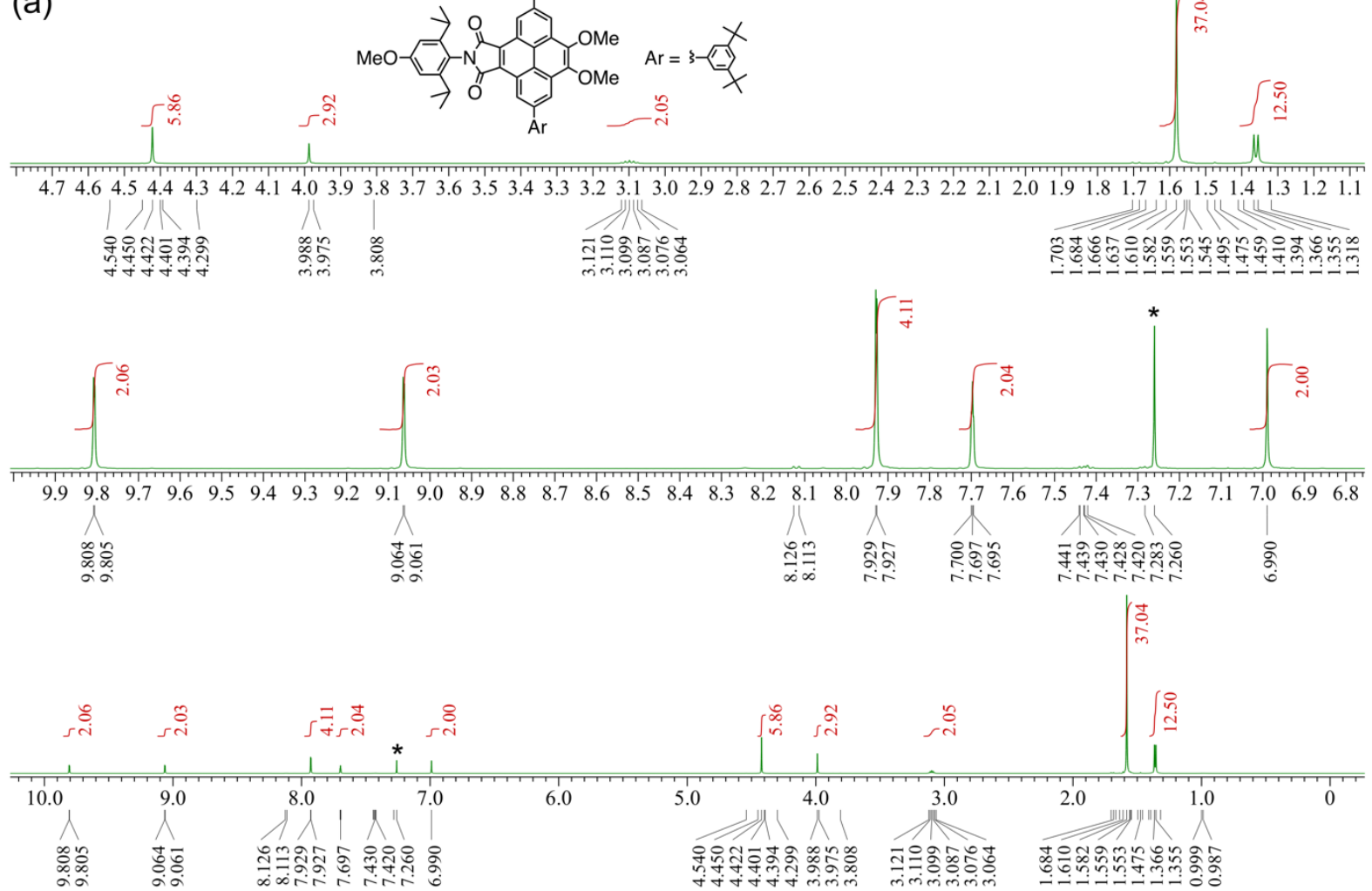

(b)
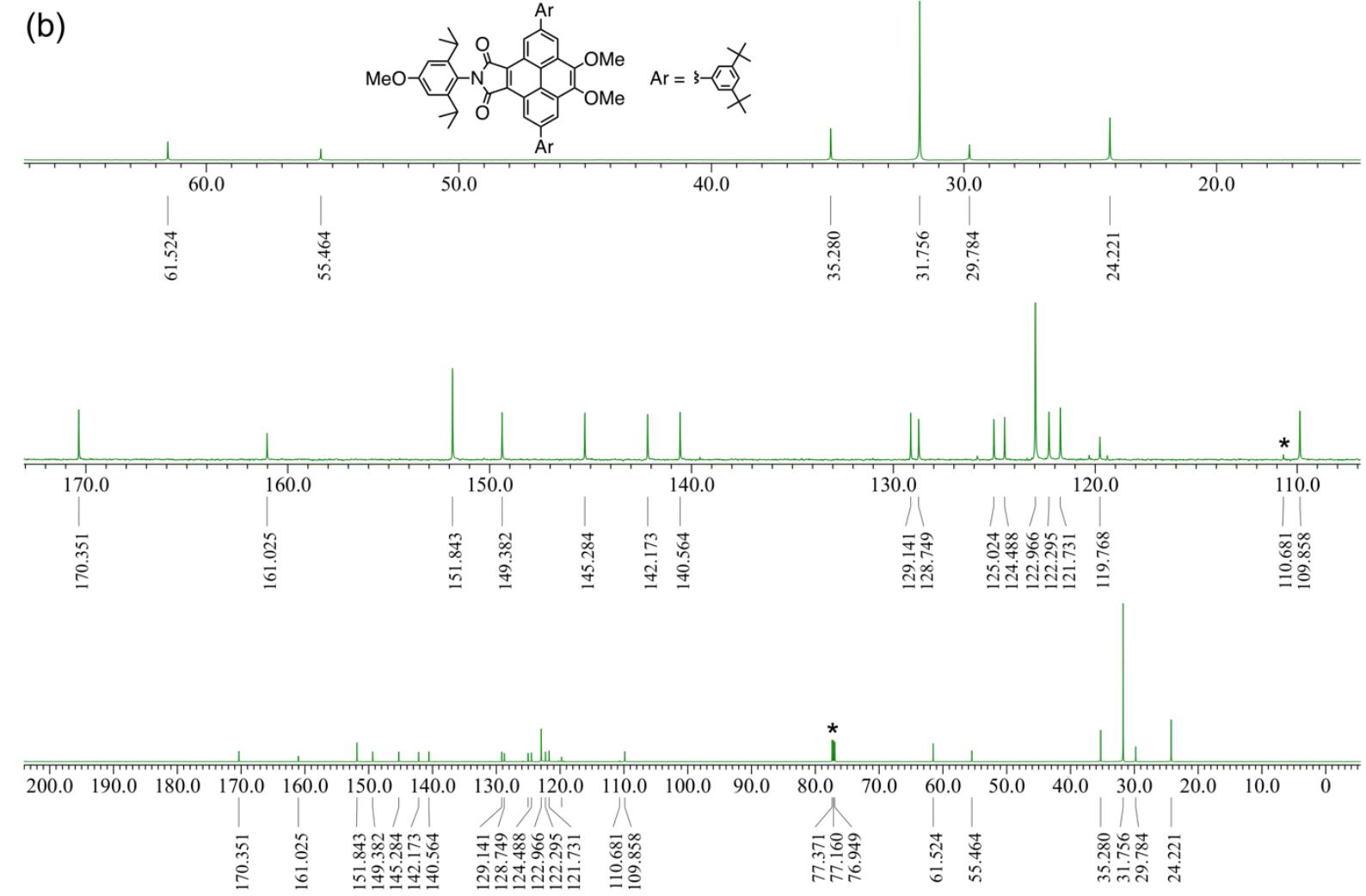

Figure S2.10. (a) ${ }^{1} \mathrm{H}$ NMR and (b) ${ }^{13} \mathrm{C}\left\{{ }^{1} \mathrm{H}\right\}$ NMR spectra of 8 in $\mathrm{CDCl}_{3}$ at room temperature. Peaks marked with asterisks indicate residual solvents or impurities. 

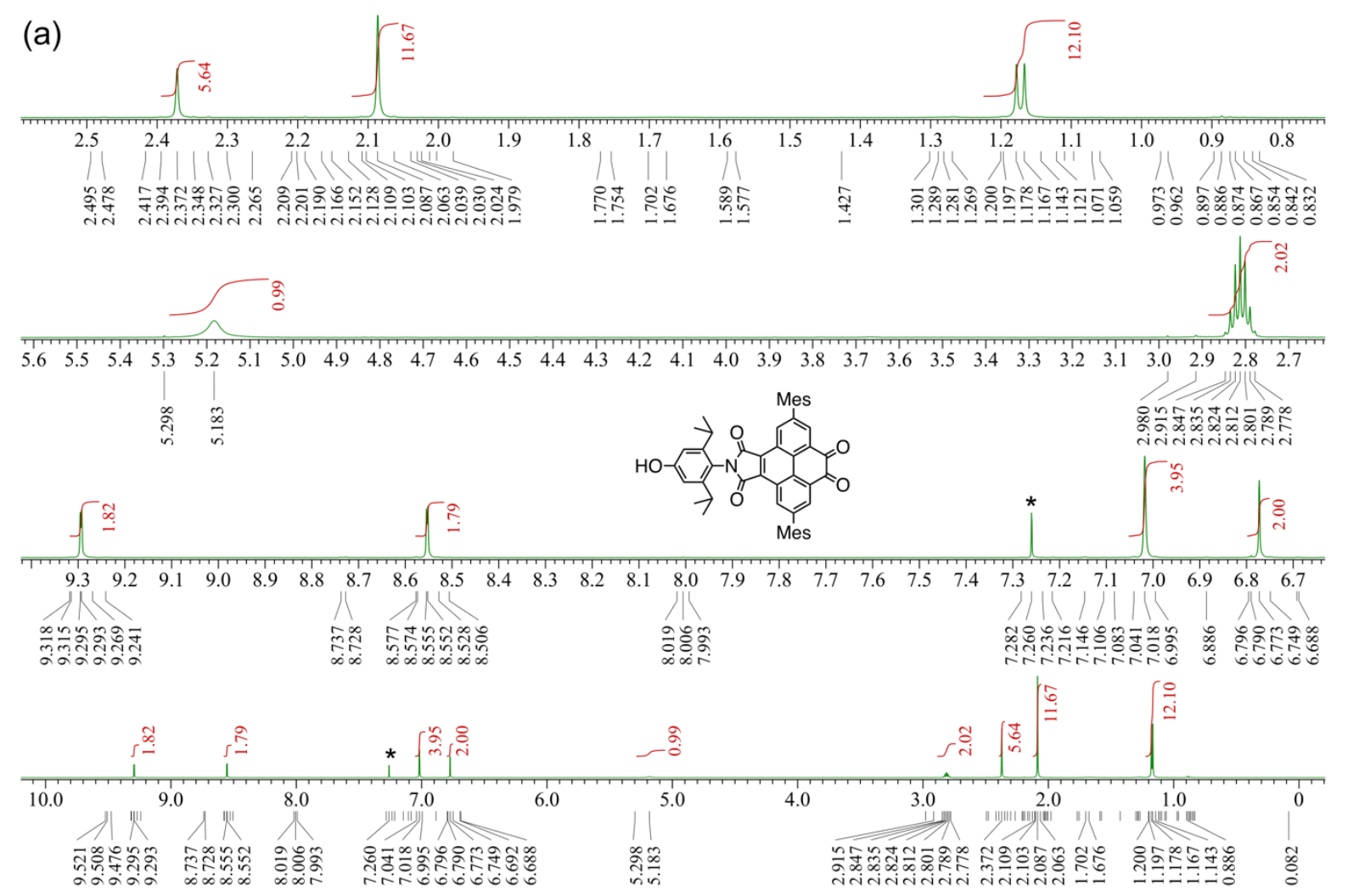

(b)

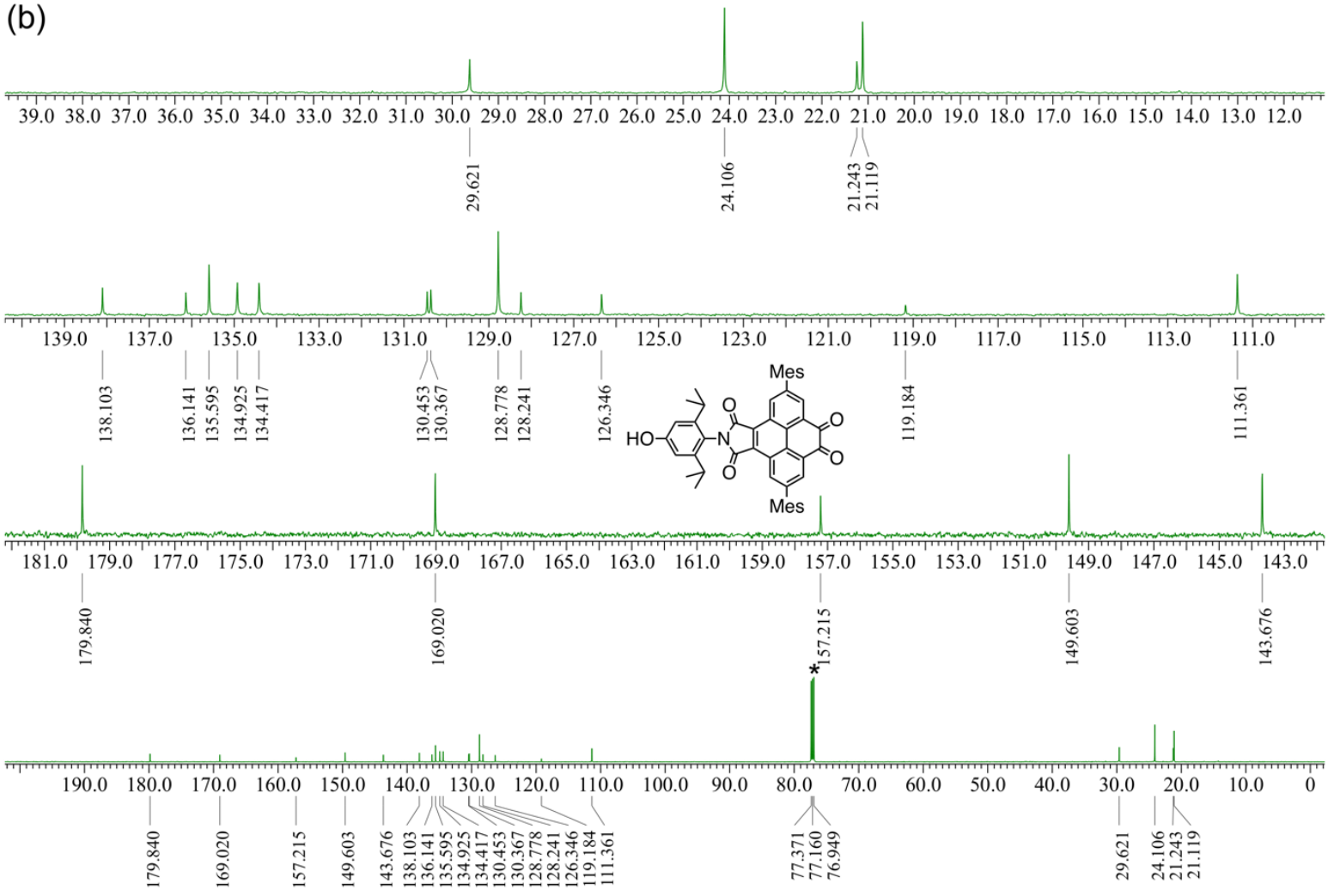

Figure S2.11. (a) ${ }^{1} \mathrm{H}$ NMR and (b) ${ }^{13} \mathrm{C}\left\{{ }^{1} \mathrm{H}\right\}$ NMR spectra of 9 in $\mathrm{CDCl}_{3}$ at room temperature. Peaks marked with asterisks indicate residual solvents or impurities. 


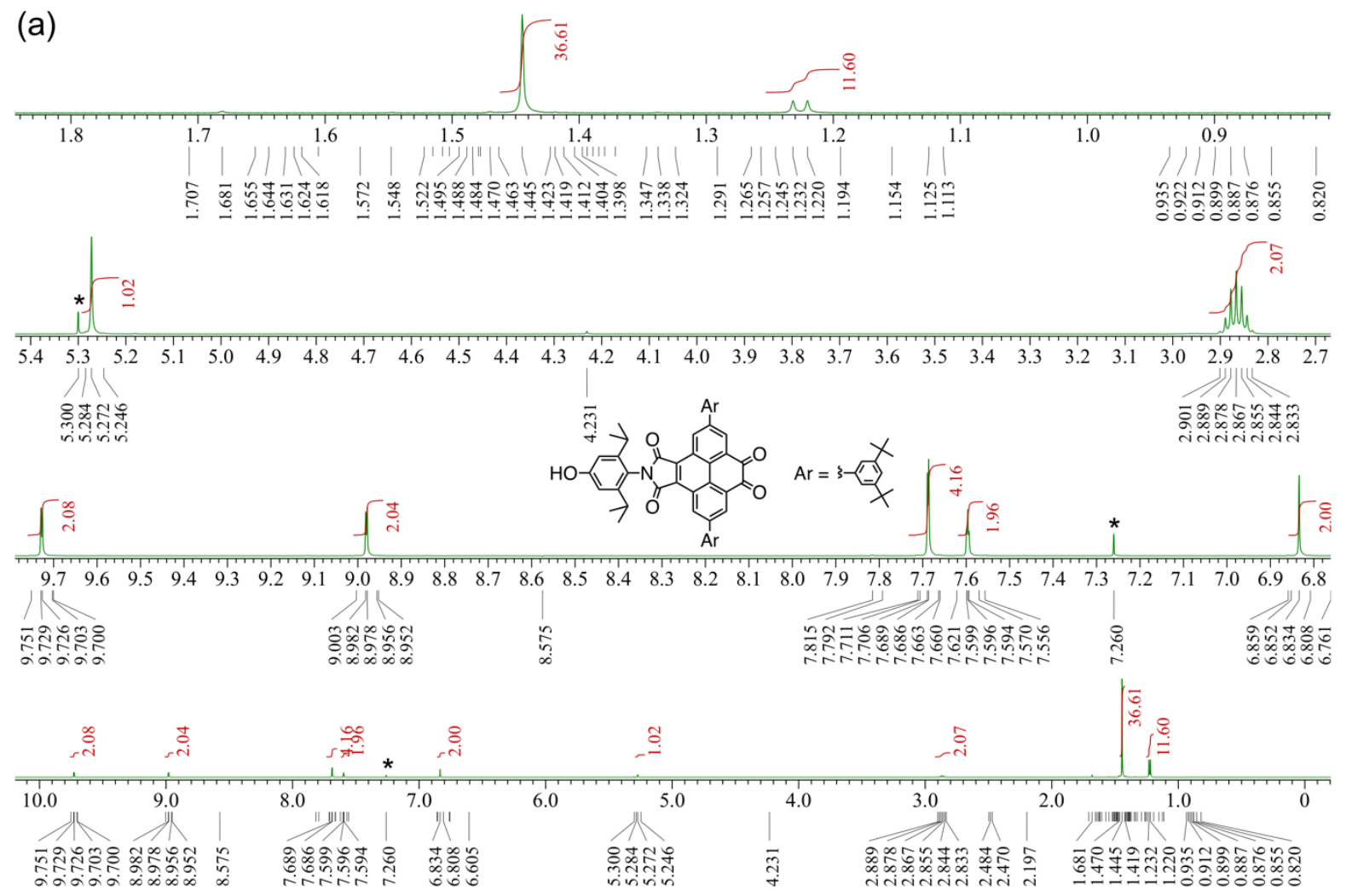

(b)

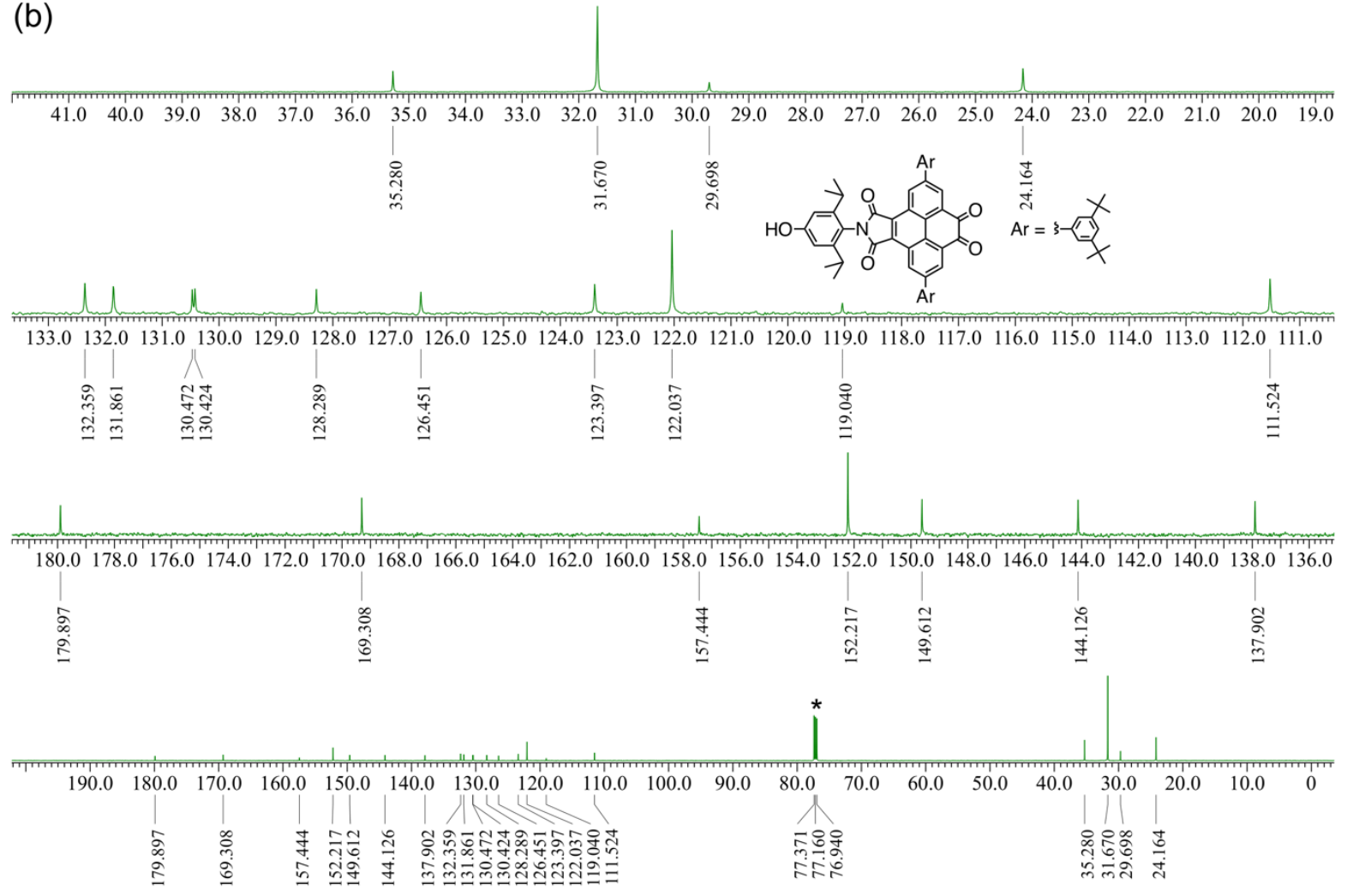

Figure S2.12. (a) ${ }^{1} \mathrm{H}$ NMR and (b) ${ }^{13} \mathrm{C}\left\{{ }^{1} \mathrm{H}\right\}$ NMR spectra of $\mathbf{1 0}$ in $\mathrm{CDCl}_{3}$ at room temperature. Peaks marked with asterisks indicate residual solvents or impurities. 
(a)
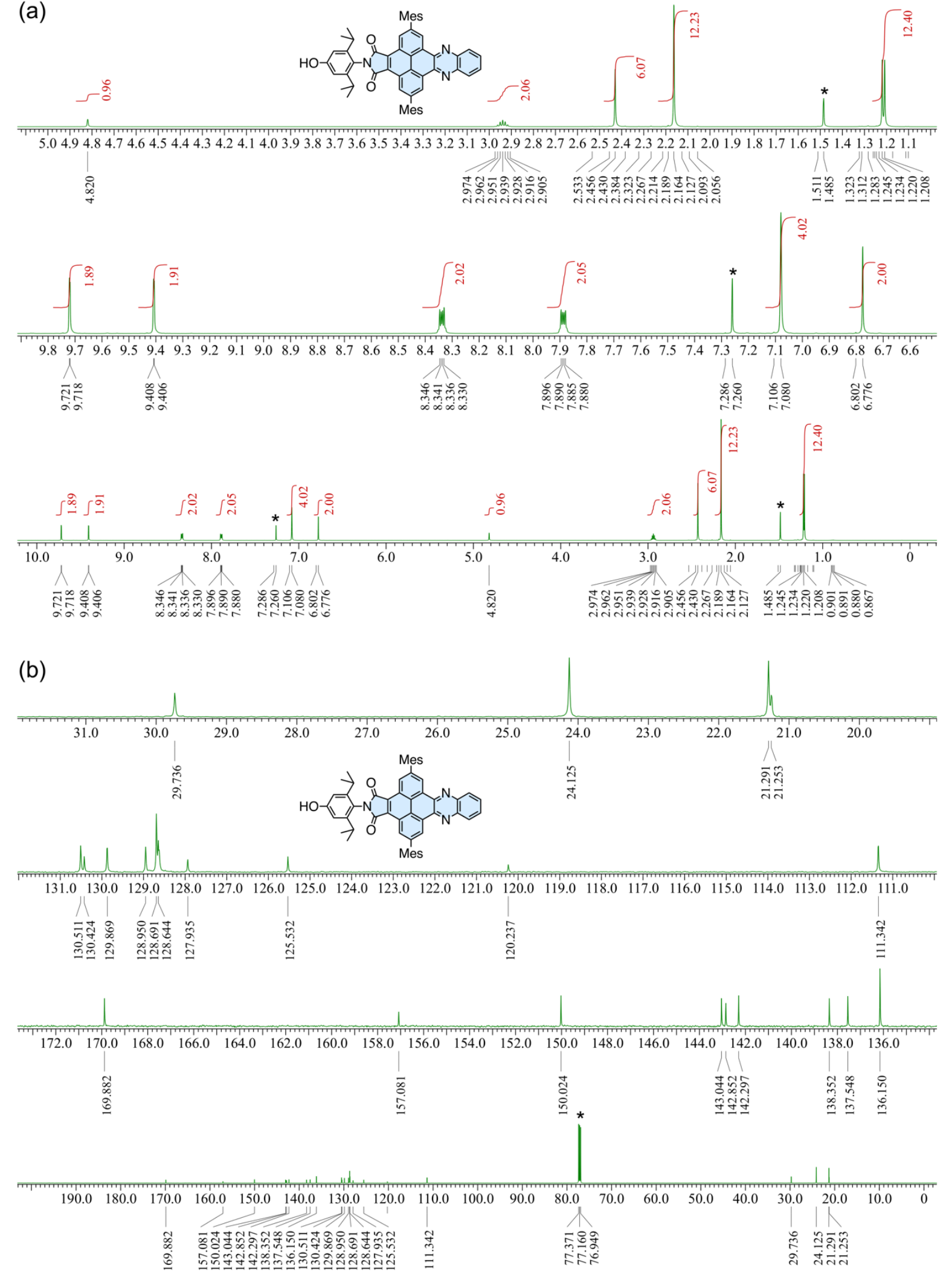

Figure S2.13. (a) ${ }^{1} \mathrm{H}$ NMR and (b) ${ }^{13} \mathrm{C}\left\{{ }^{1} \mathrm{H}\right\}$ NMR spectra of Wing1-OH in $\mathrm{CDCl}_{3}$ at $60{ }^{\circ} \mathrm{C}$. Peaks marked with asterisks indicate residual solvents or impurities. 
(a)
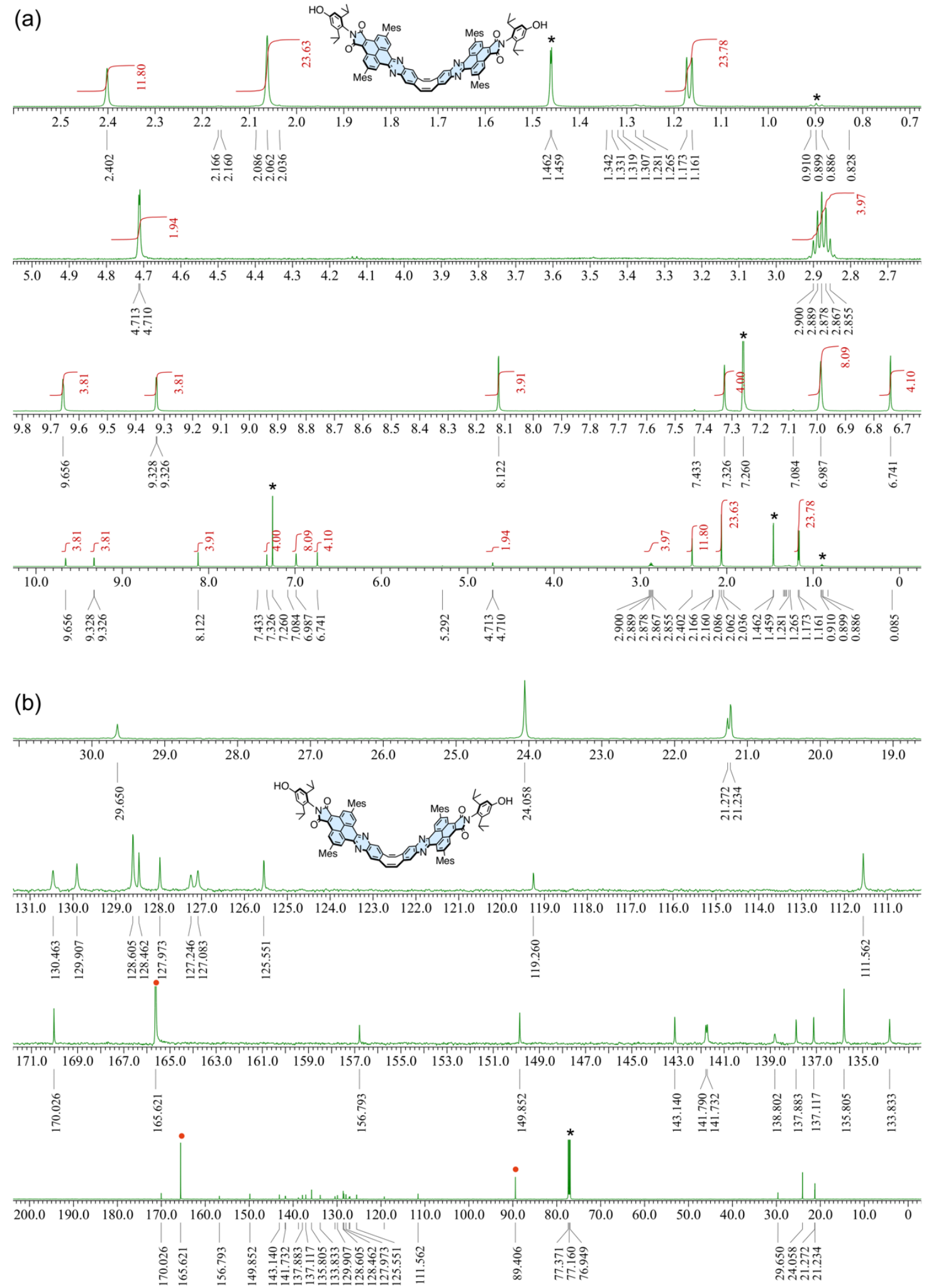

Figure S2.14. (a) ${ }^{1} \mathrm{H}$ NMR spectra of FLAP1-OH in $\mathrm{CDCl}_{3}$ at $60{ }^{\circ} \mathrm{C}$ and (b) ${ }^{13} \mathrm{C}\left\{{ }^{1} \mathrm{H}\right\}$ NMR spectra of FLAP1-OH in $\mathrm{CDCl}_{3}$ /trichloroacetic acid at room temperature. Peaks marked with asterisks indicate residual solvents or impurities, and red circles correspond to peaks derived from trichloroacetic acid. 


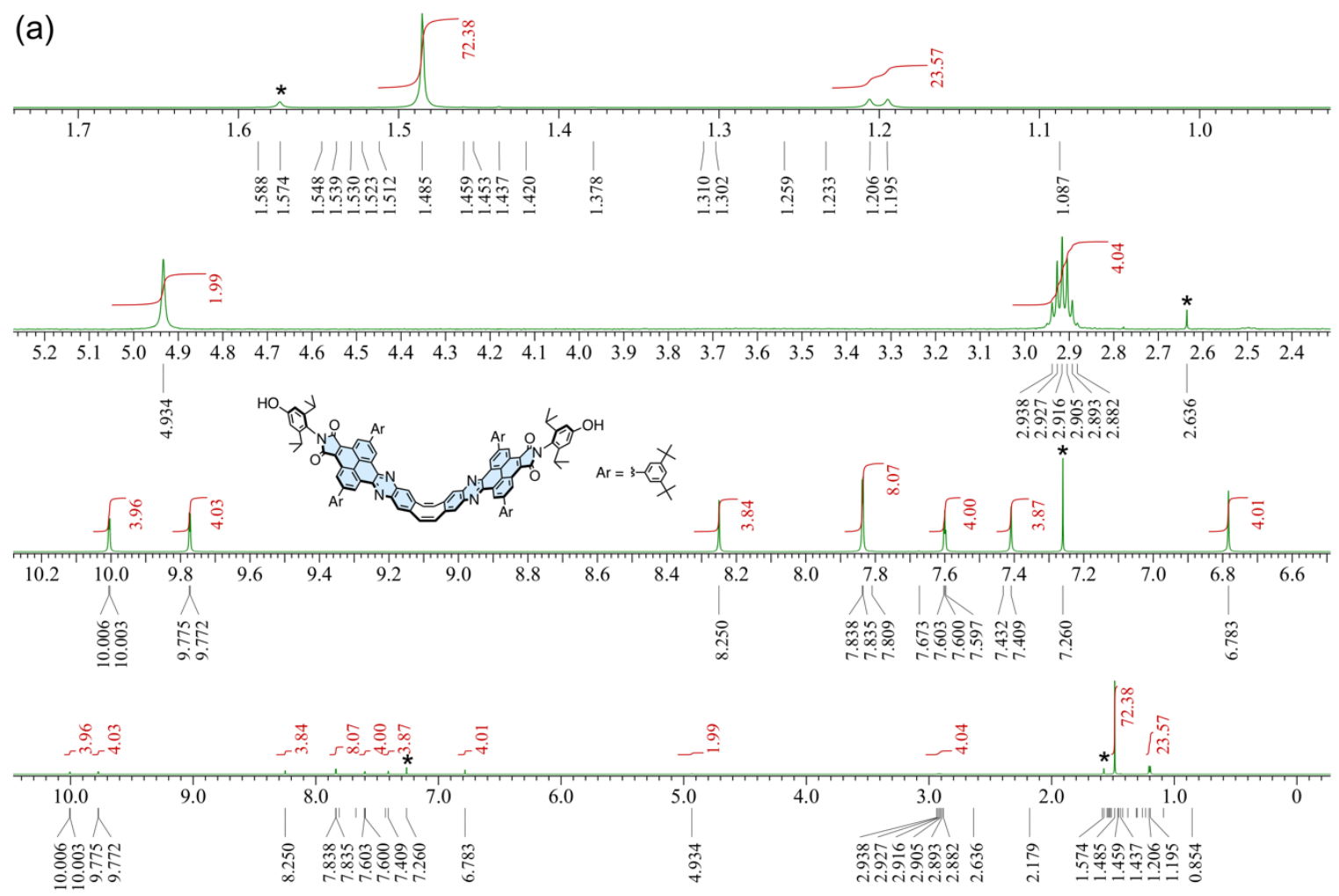

(b)
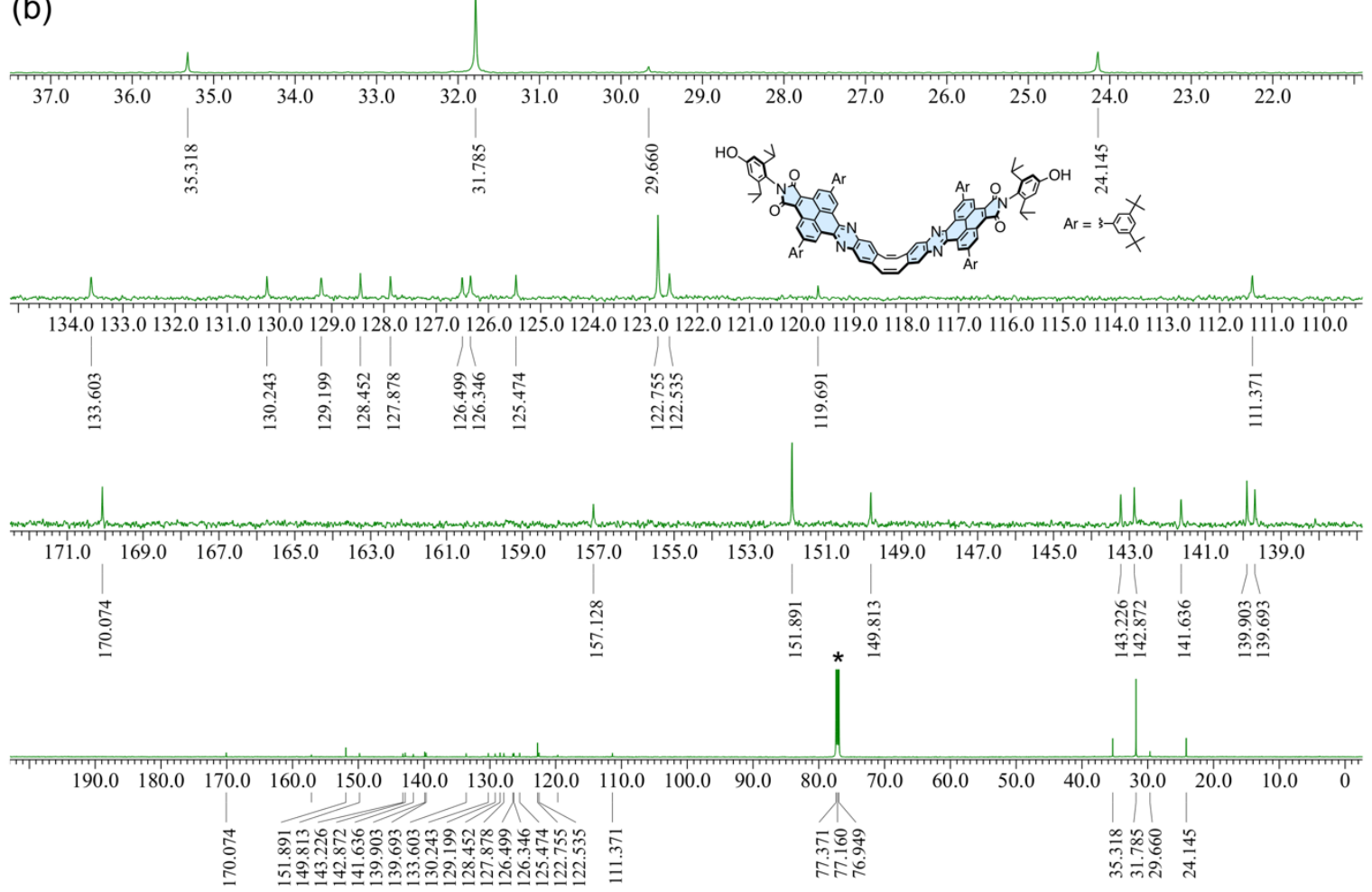

Figure S2.15. (a) ${ }^{1} \mathrm{H}$ NMR and (b) ${ }^{13} \mathrm{C}\left\{{ }^{1} \mathrm{H}\right\}$ NMR spectra of FLAP1-OH' in $\mathrm{CDCl}_{3}$ at room temperature.

Peaks marked with asterisks indicate residual solvents or impurities. 


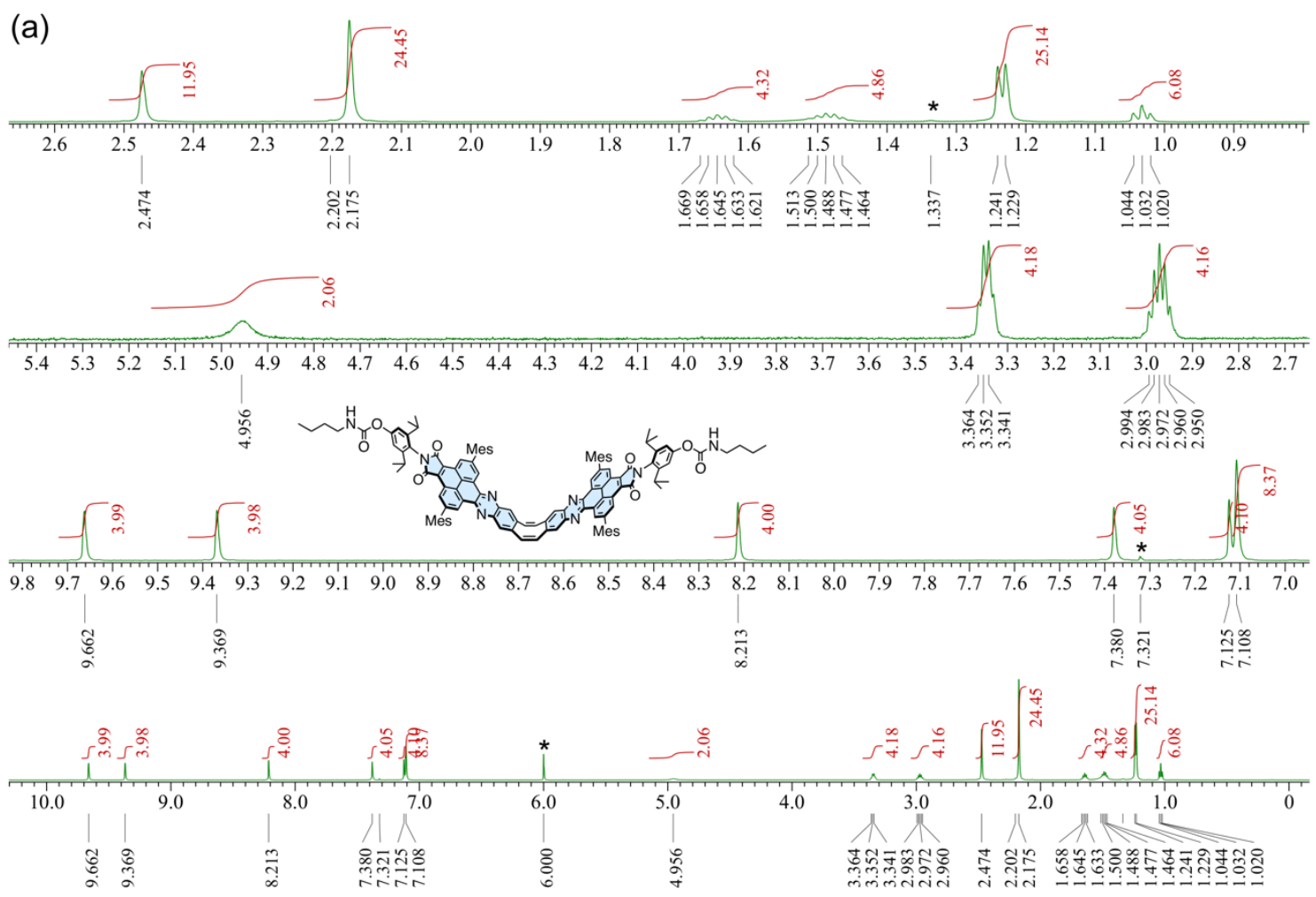

(b)
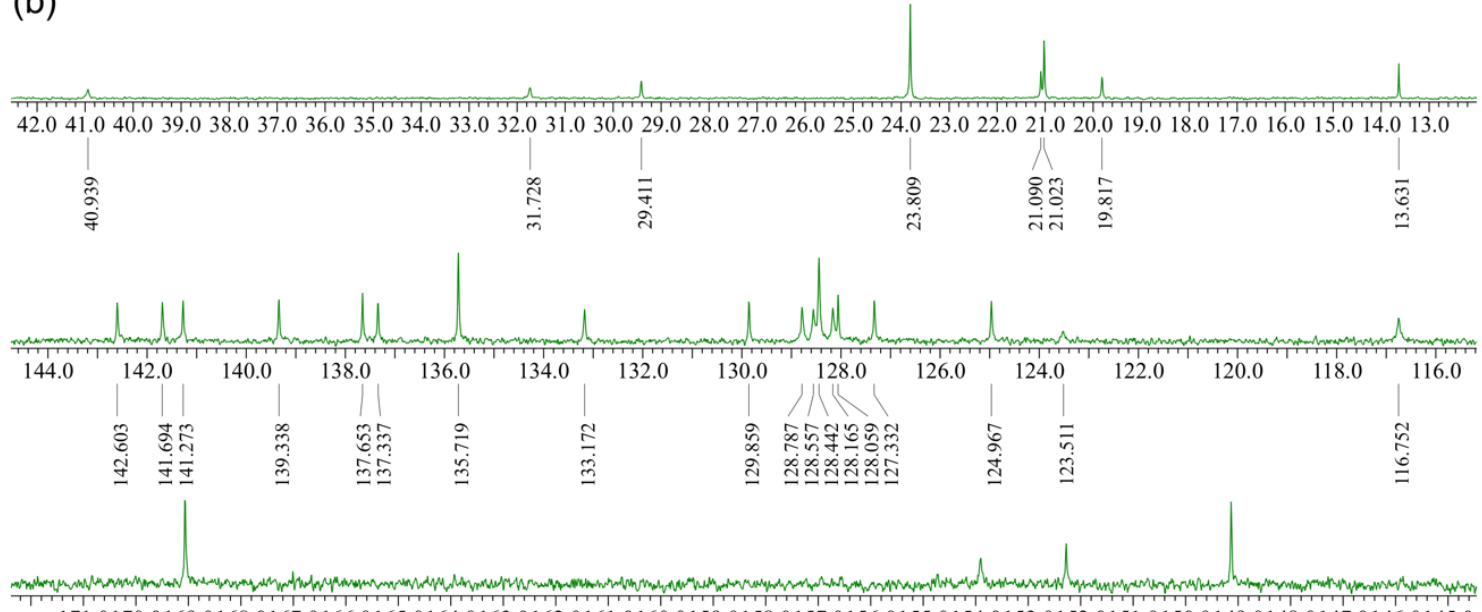
171.0170.0169.0168.0167.0166.0165.0164.0163.0162.0161.0160.0159.0158.0157.0156.0155.0154.0153.0152.0151.0150.0149.0148.0147.0146.0145.0

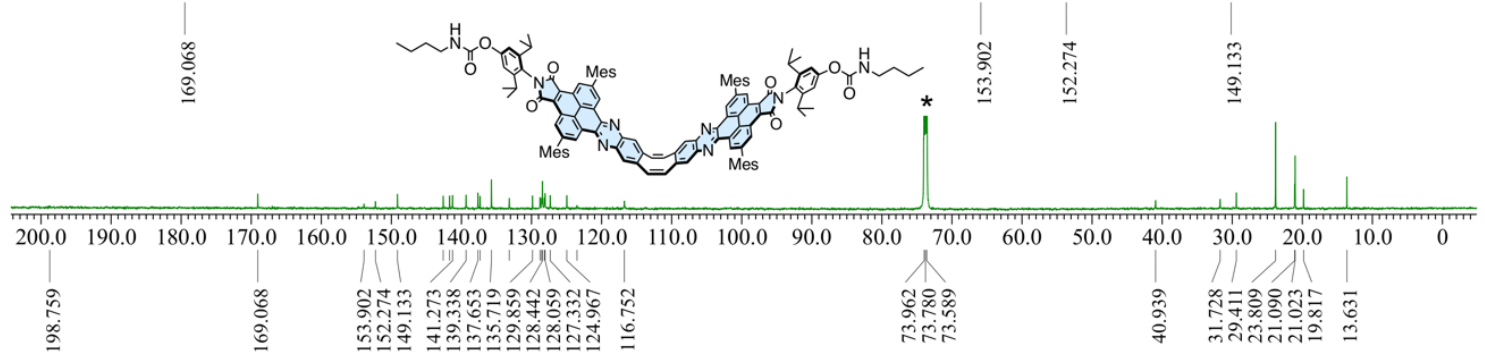

Figure S2.16. (a) ${ }^{1} \mathrm{H}$ NMR spectra of FLAP1-BC in tetrachloroethane- $d_{2}$ at $100{ }^{\circ} \mathrm{C}$ and (b) ${ }^{13} \mathrm{C}\left\{{ }^{1} \mathrm{H}\right\}$ NMR spectra of FLAP1-BC in tetrachloroethane- $d_{2}$ at $50{ }^{\circ} \mathrm{C}$. Peaks marked with asterisks indicate residual solvents or impurities. 


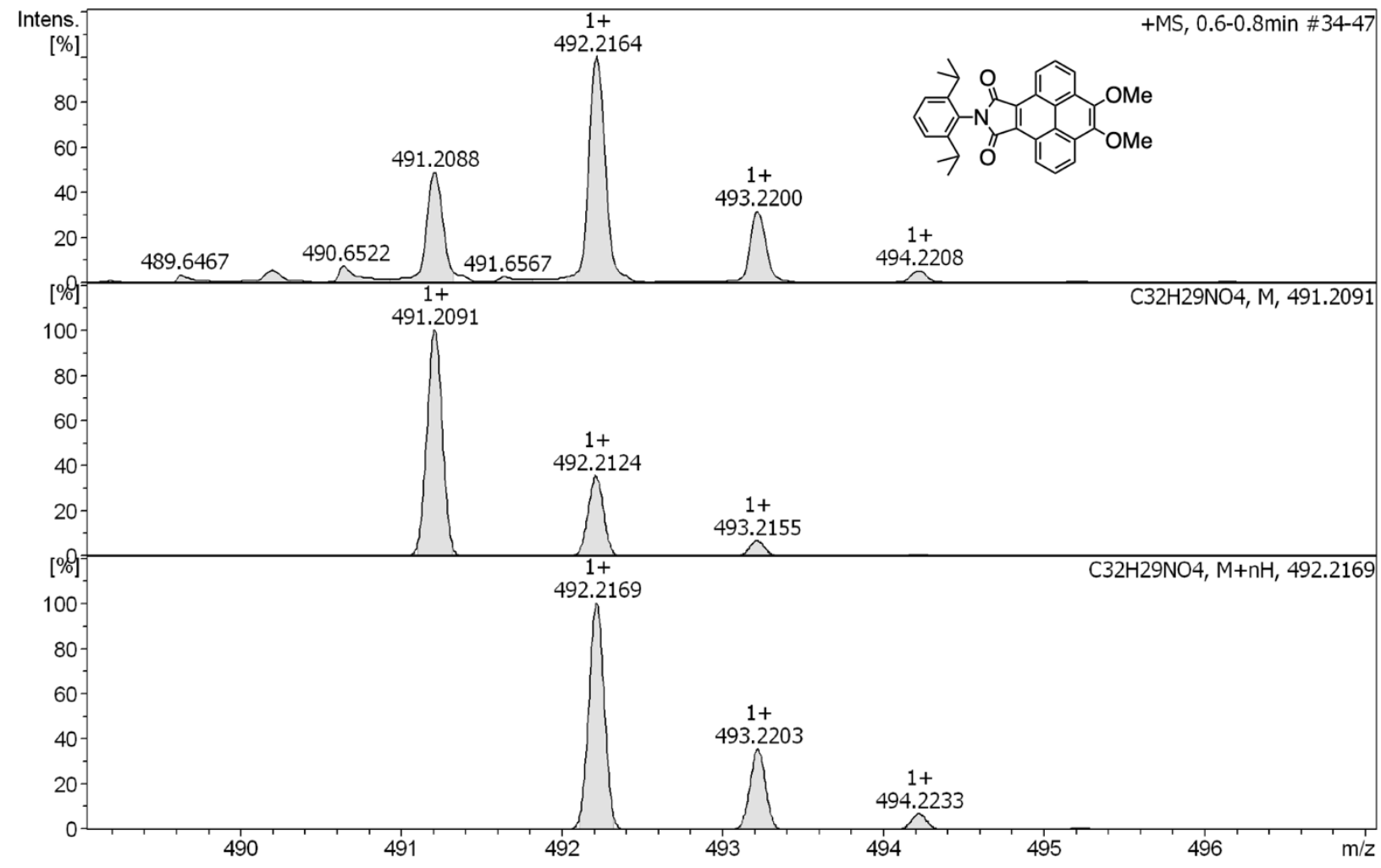

Figure S2.17. HR-APCI-TOF mass spectra of 2 (top: observed, bottom: simulated).

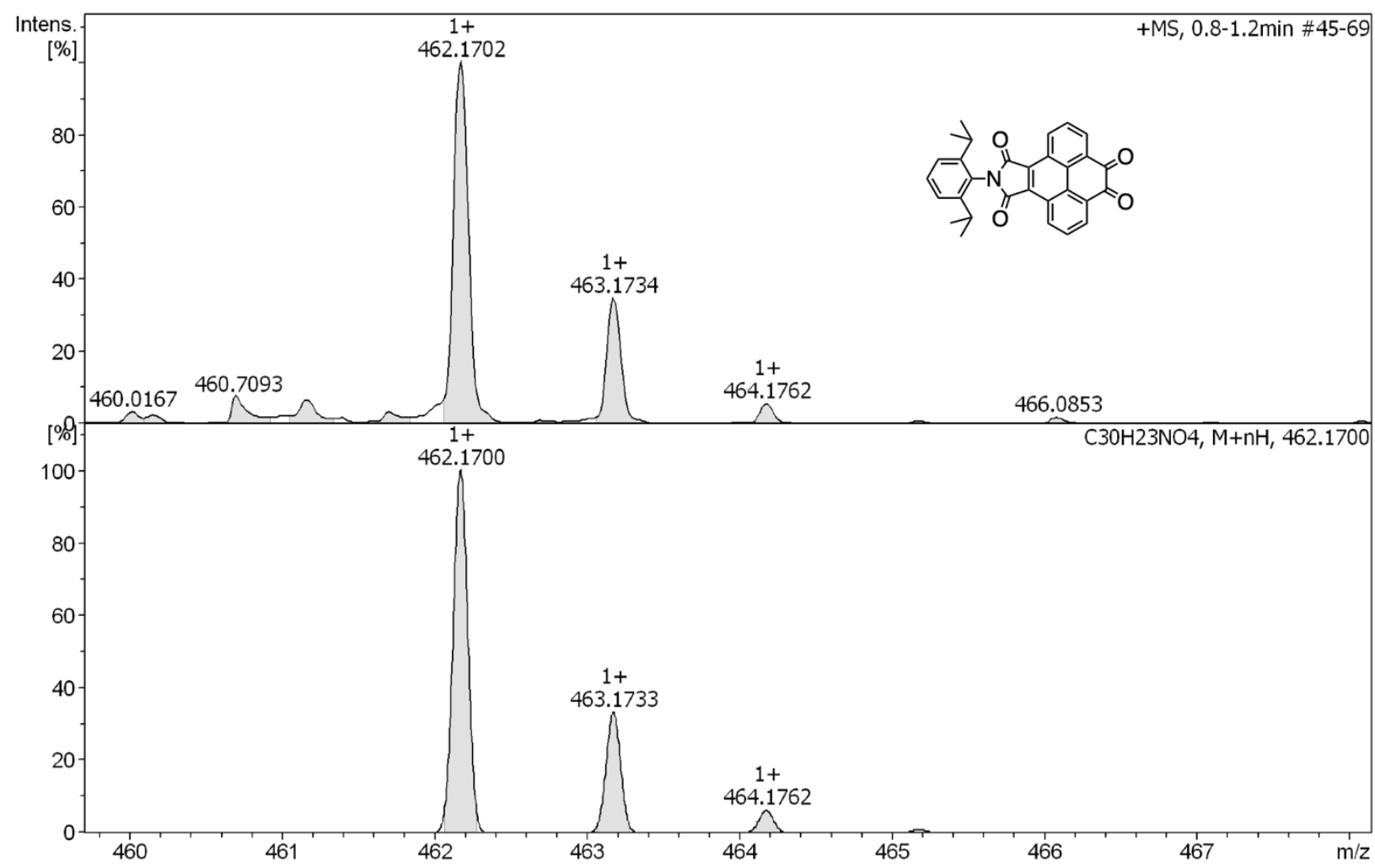

Figure S2.18. HR-APCI-TOF mass spectra of 3 (top: observed, bottom: simulated). 


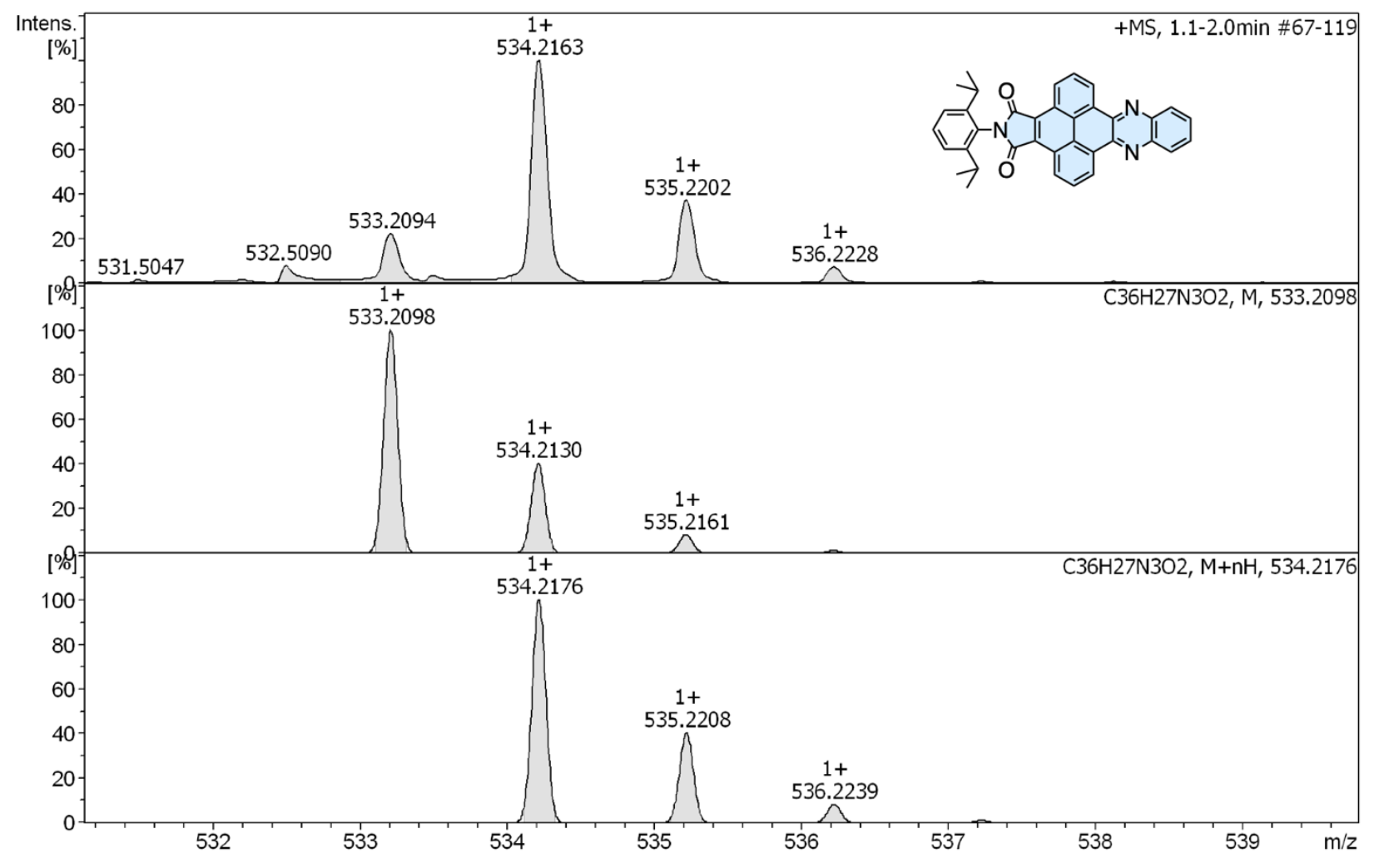

Figure S2.19. HR-APCI-TOF mass spectra of Wing1-H (top: observed, bottom: simulated).

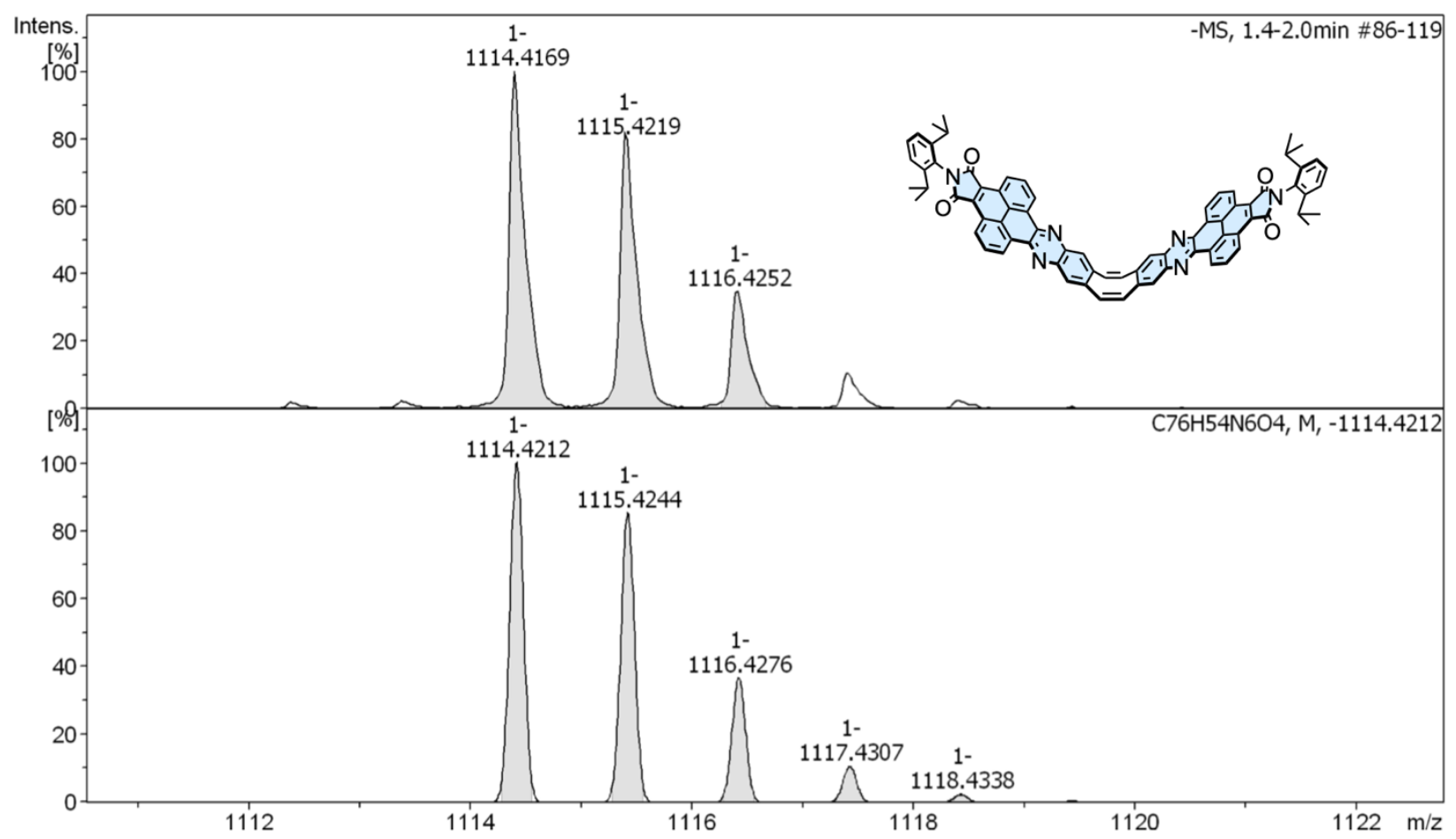

Figure S2.20. HR-APCI-TOF mass spectra of FLAP1-H (top: observed, bottom: simulated). 


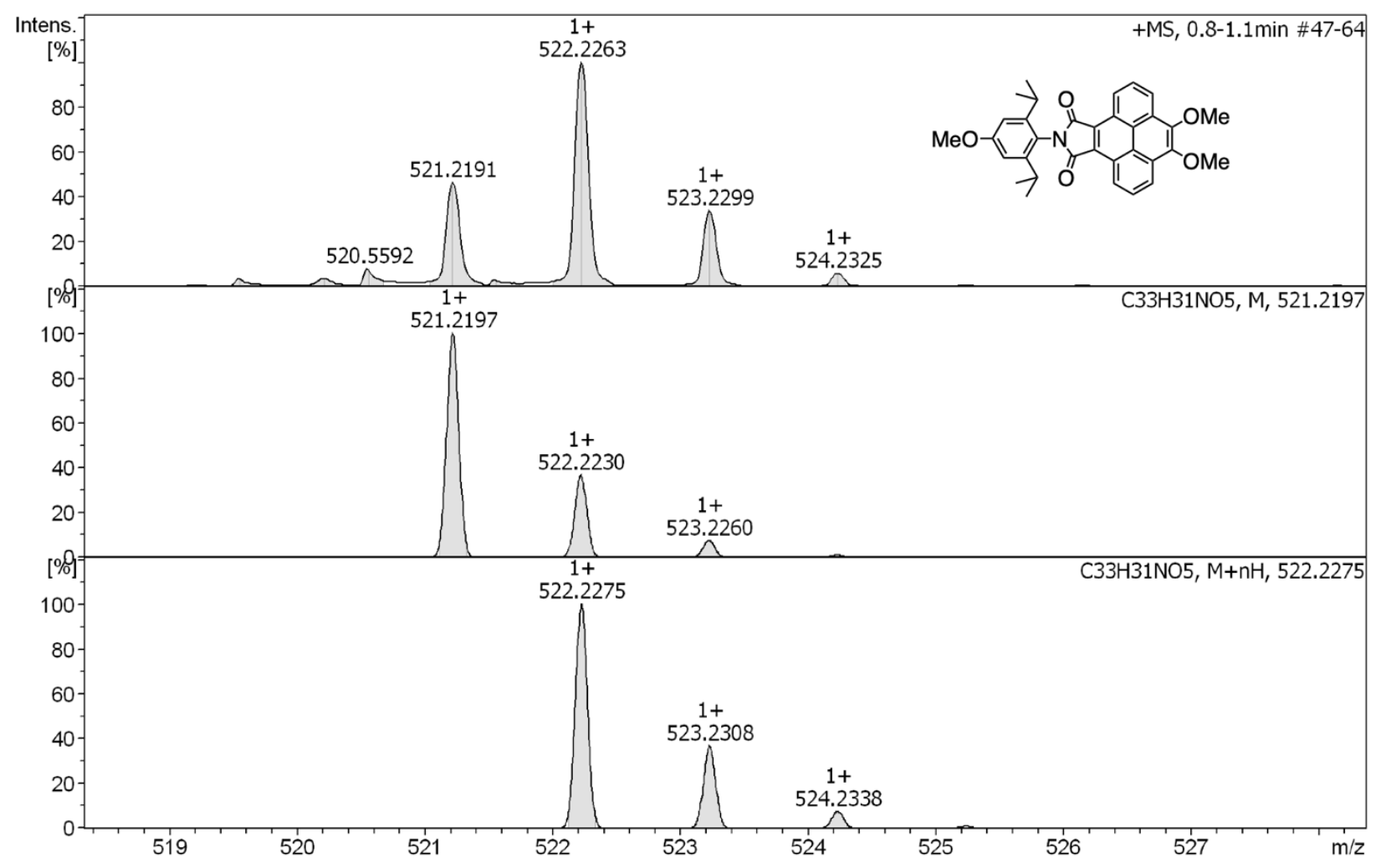

Figure S2.21. HR-APCI-TOF mass spectra of 5 (top: observed, bottom: simulated).

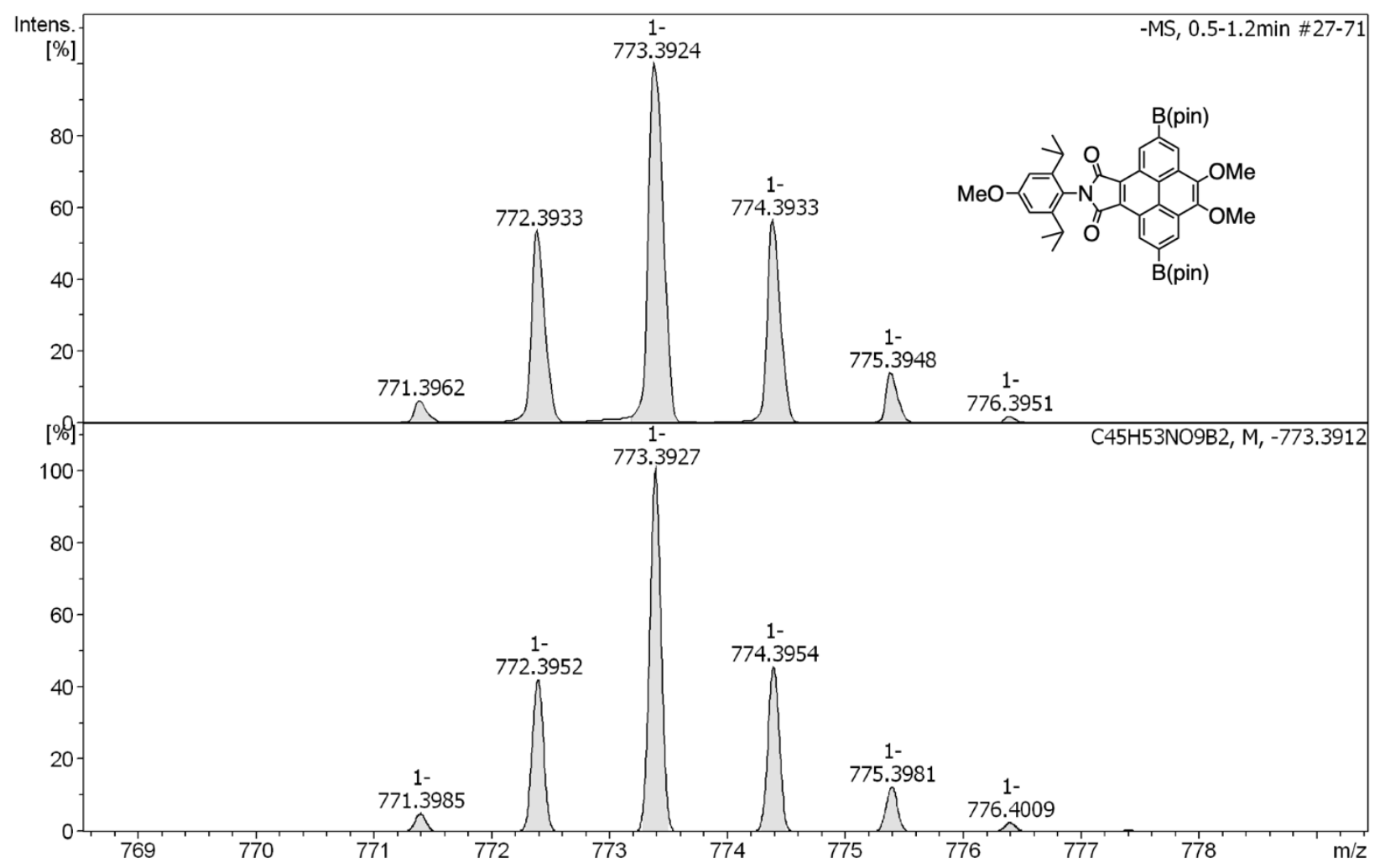

Figure S2.22. HR-APCI-TOF mass spectra of 6 (top: observed, bottom: simulated). 


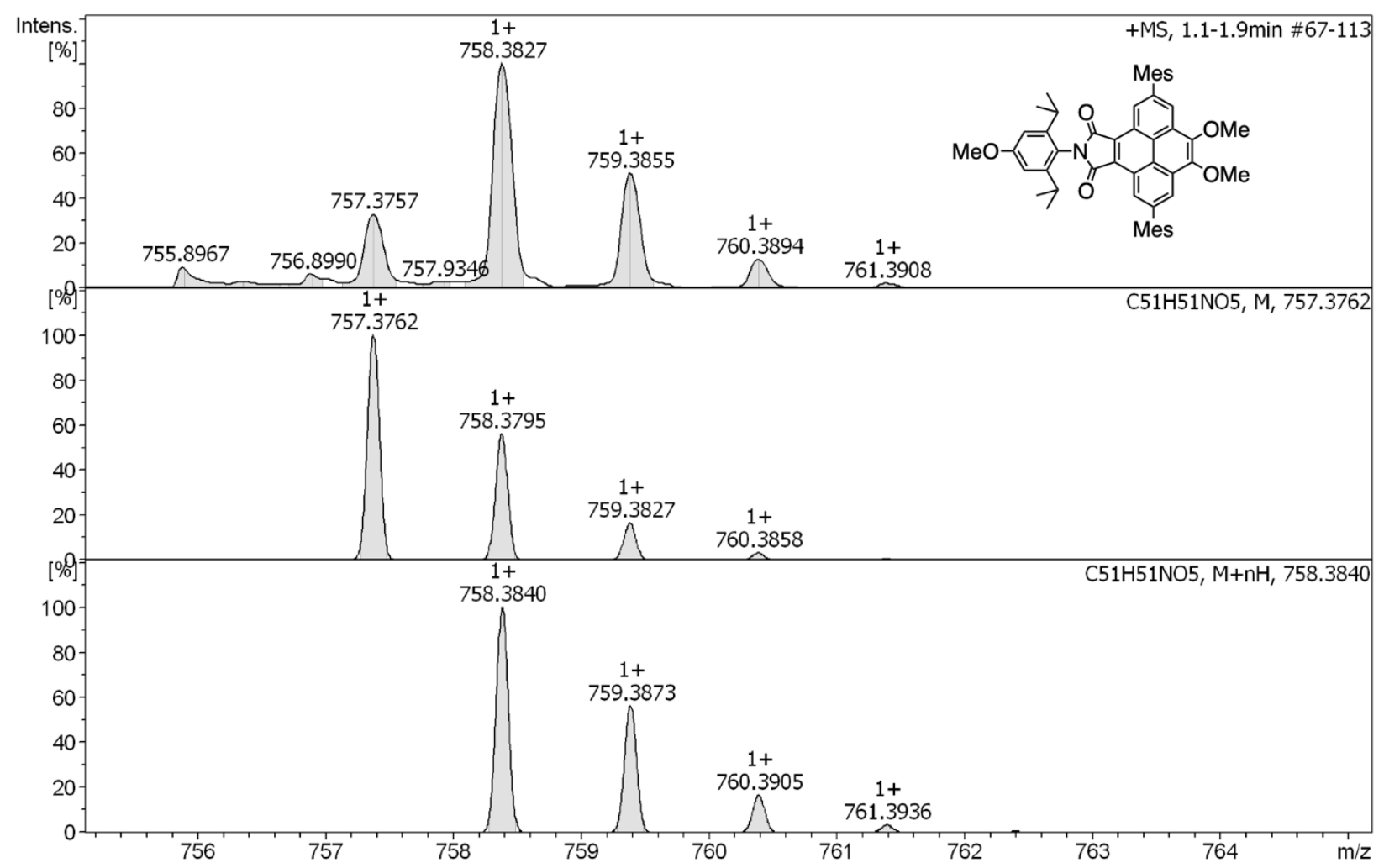

Figure S2.23. HR-APCI-TOF mass spectra of 7 (top: observed, bottom: simulated).

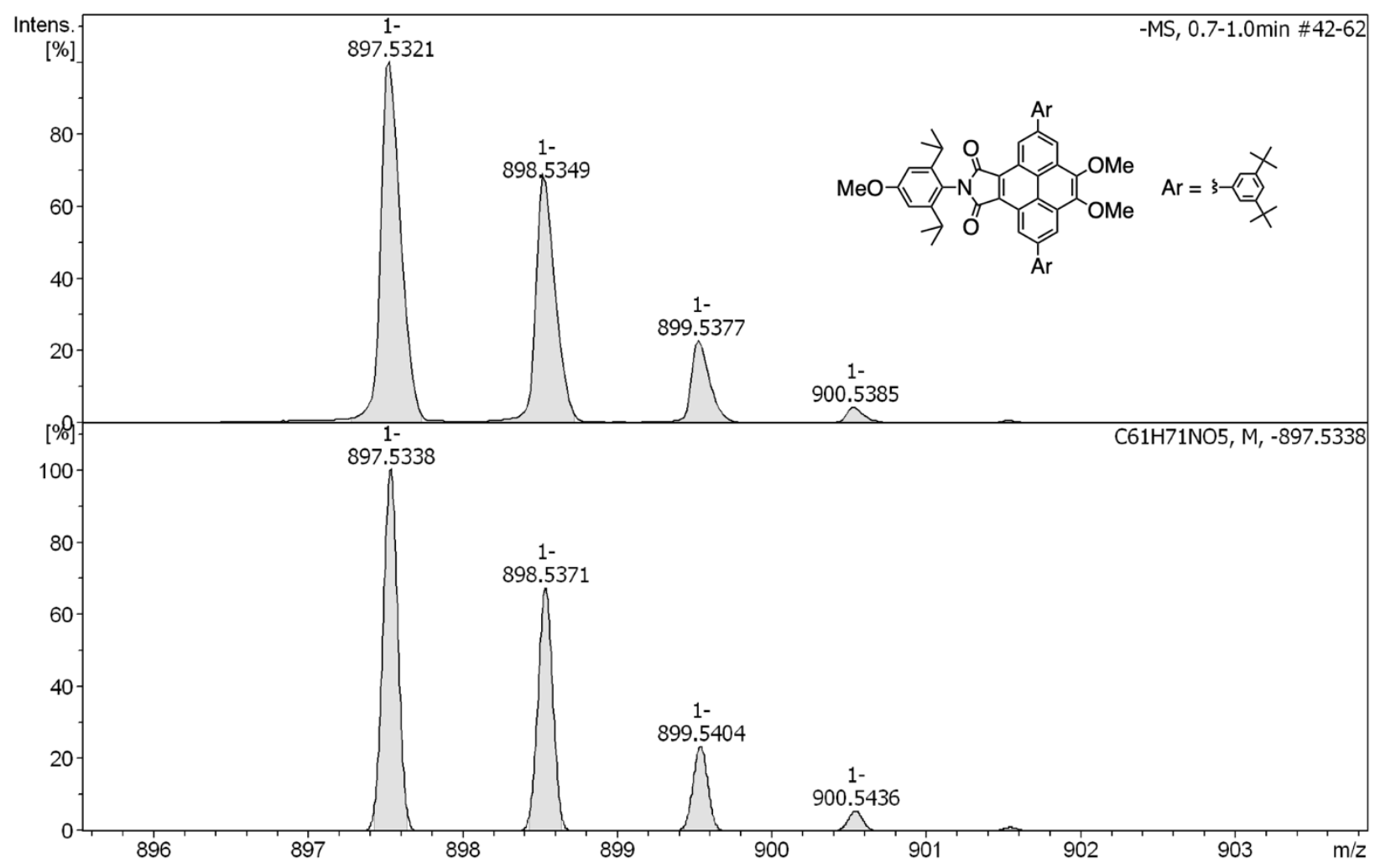

Figure S2.24. HR-APCI-TOF mass spectra of 8 (top: observed, bottom: simulated). 


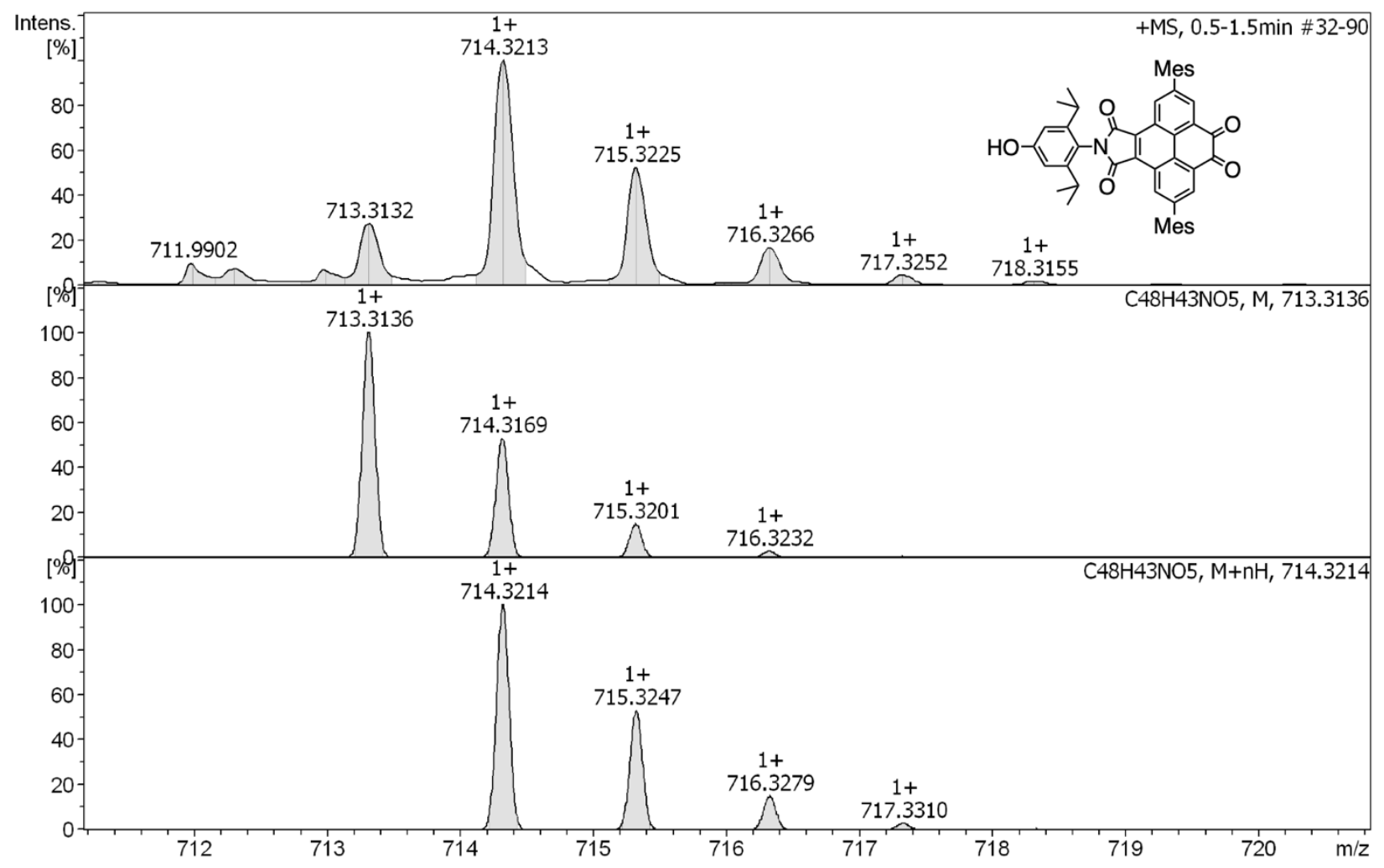

Figure S2.25. HR-APCI-TOF mass spectra of 9 (top: observed, bottom: simulated).

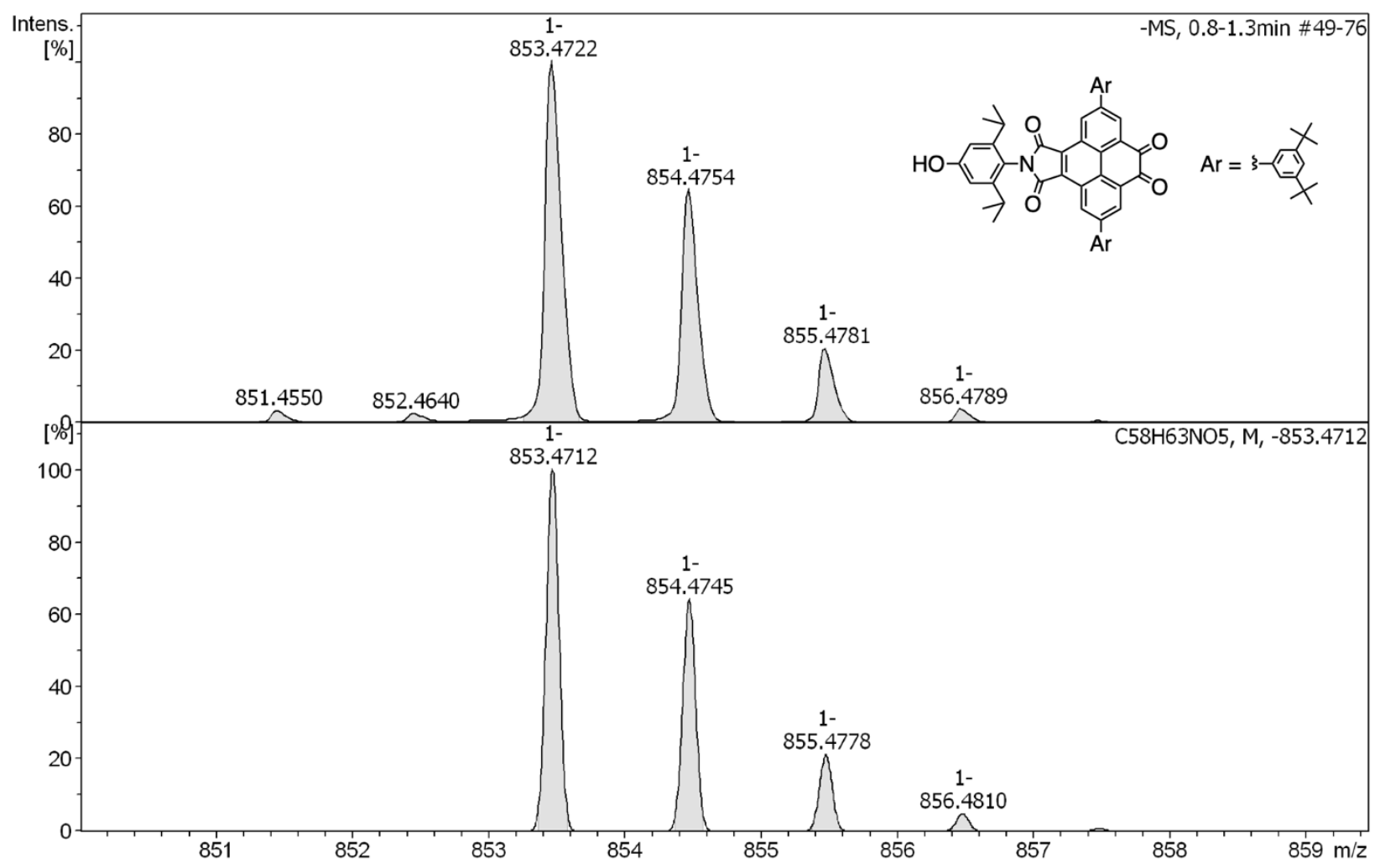

Figure S2.26. HR-APCI-TOF mass spectra of $\mathbf{1 0}$ (top: observed, bottom: simulated). 


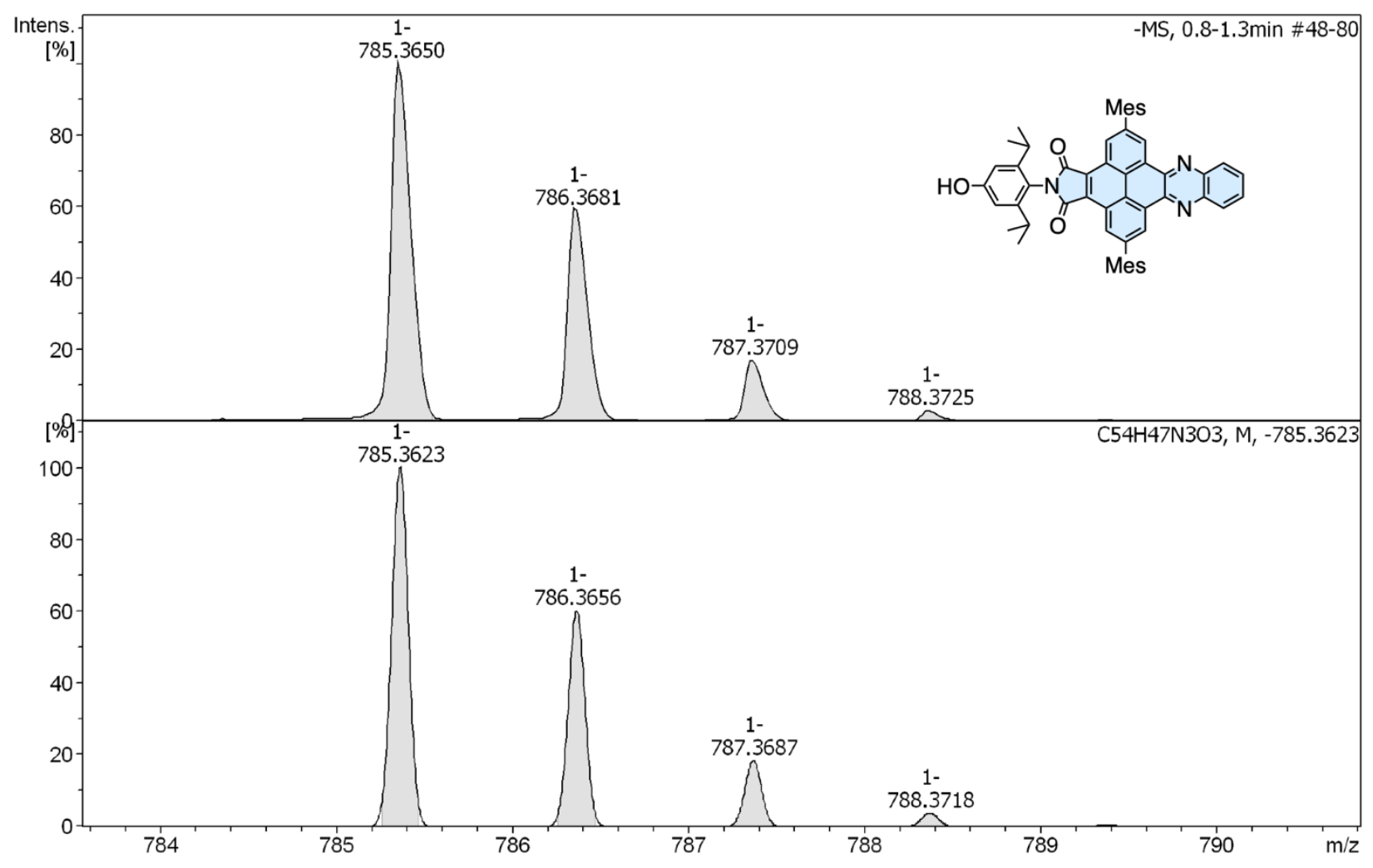

Figure S2.27. HR-APCI-TOF mass spectra of Wing1-OH (top: observed, bottom: simulated). 


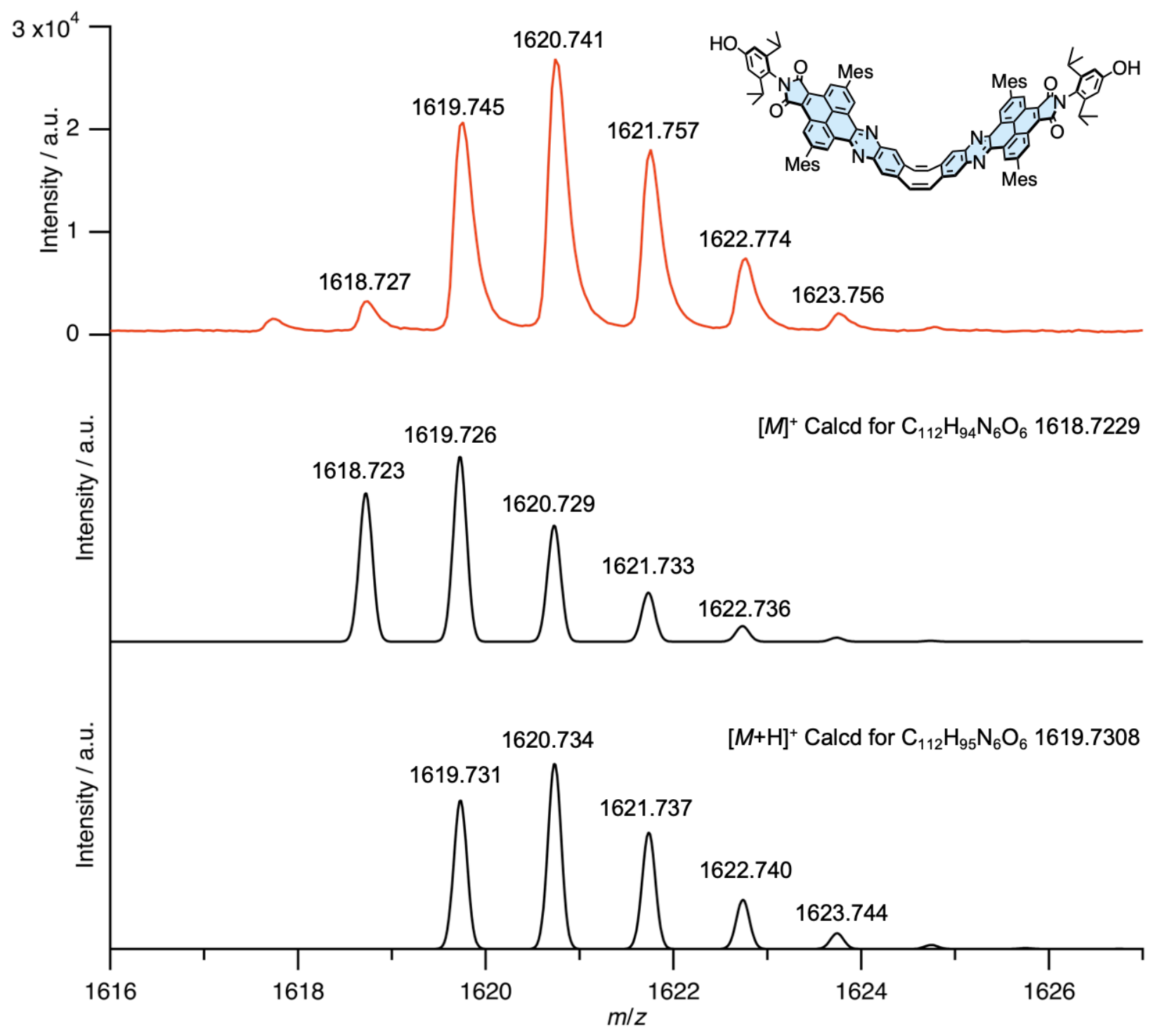

Figure S2.28. HR-MALDI-TOF mass spectra of FLAP1-OH (top: observed, bottom: simulated). 


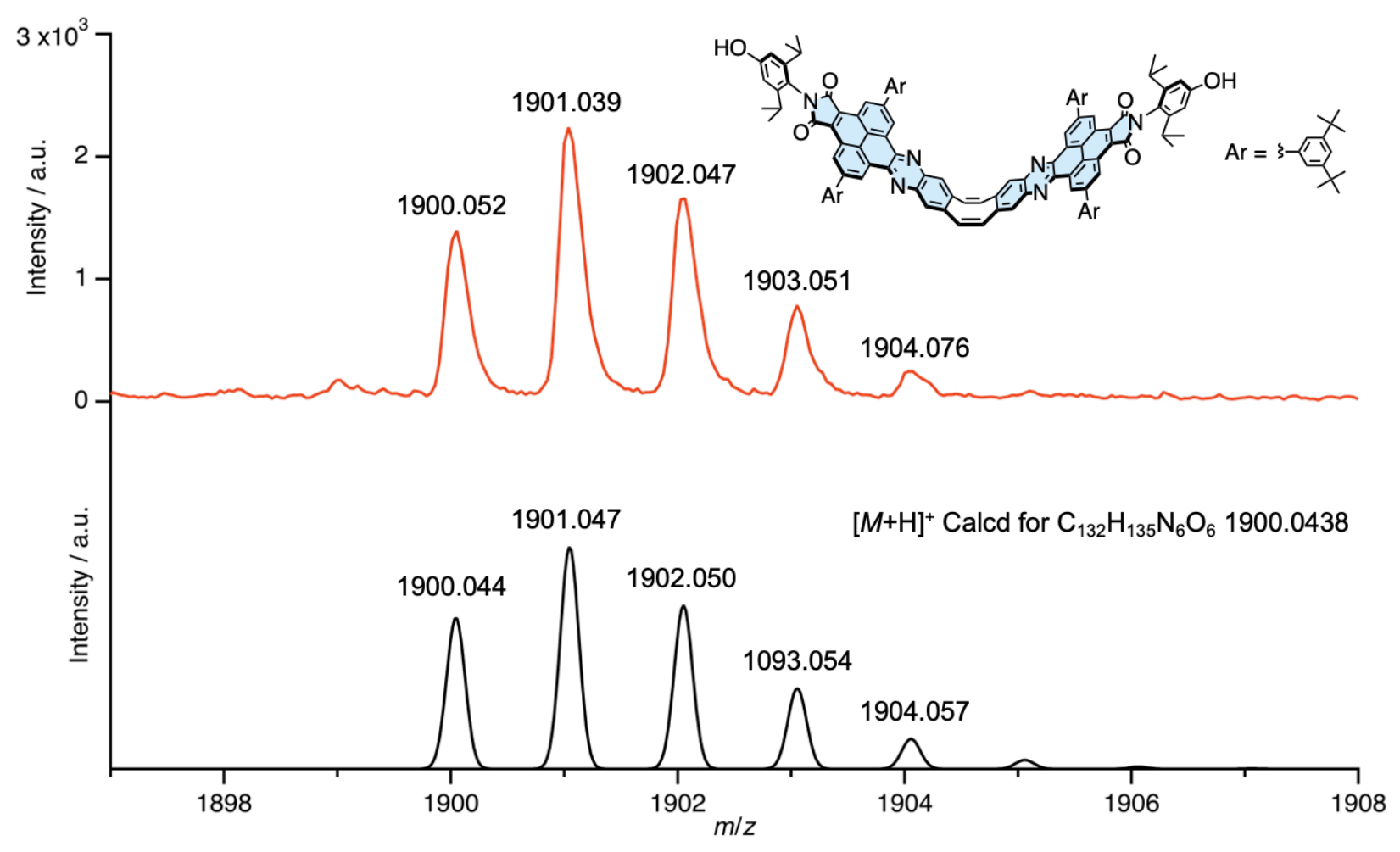

Figure S2.29. HR-MALDI-TOF mass spectra of FLAP1-OH' (top: observed, bottom: simulated).

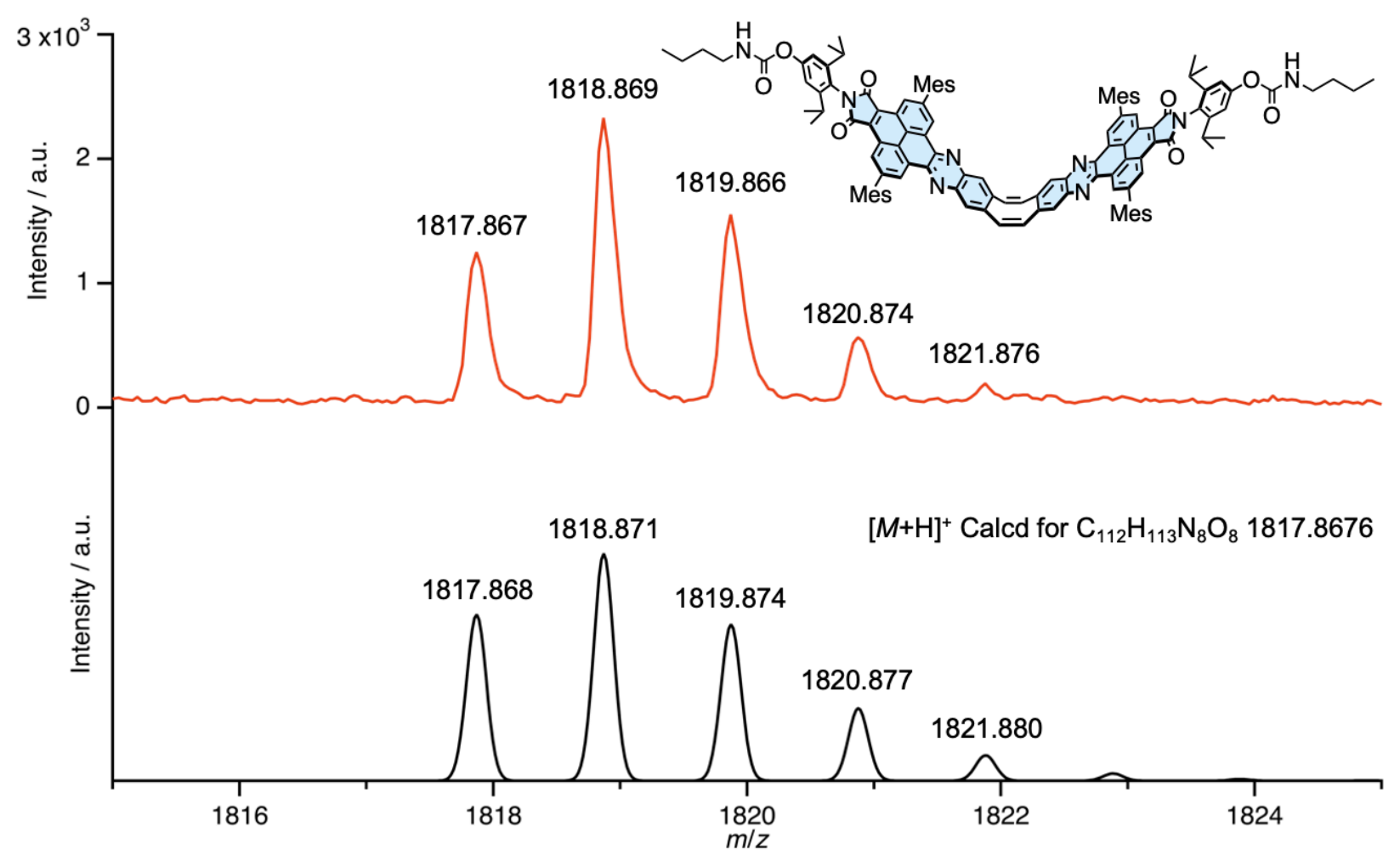

Figure S2.30. HR-MALDI-TOF mass spectra of FLAP1-BC (top: observed, bottom: simulated). 


\section{X-ray crystallographic analysis}

(a)

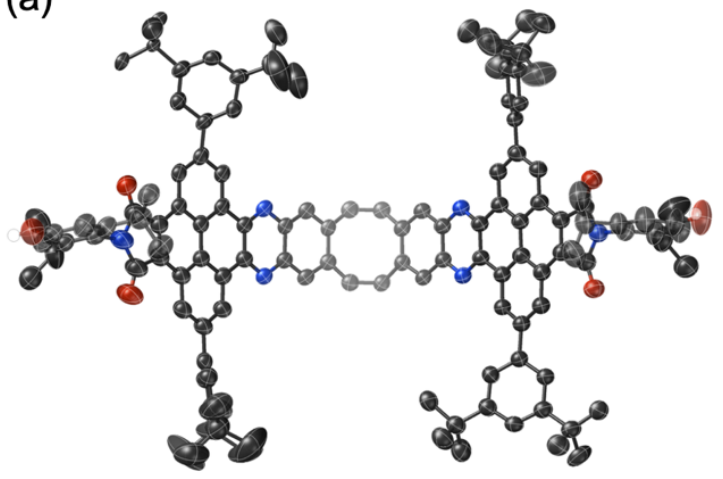

(b)

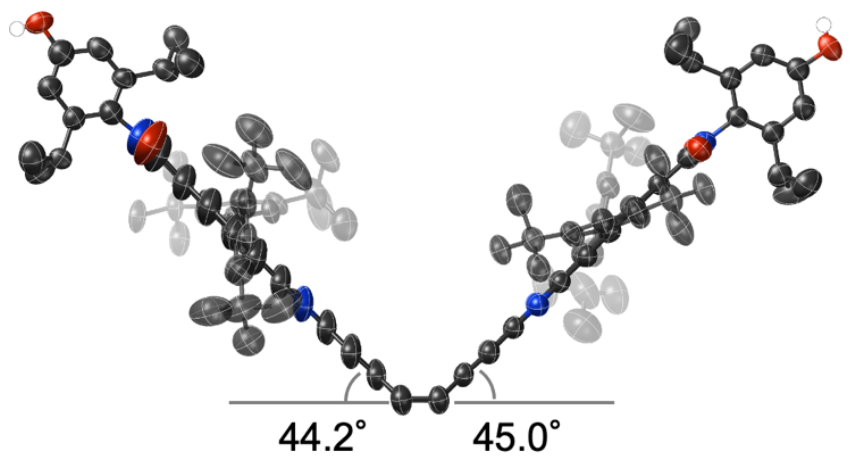

Figure S3.1. Crystal structure of FLAP1-OH' viewed from different directions. The COT bending angles (see Figure S5.2 for the definition) are shown in (b). Hydrogen atoms except for $\mathrm{OH}$ groups and disordered groups with low occupancy are omitted for clarity. Thermal ellipsoids are scaled to $50 \%$ probability.

(a)

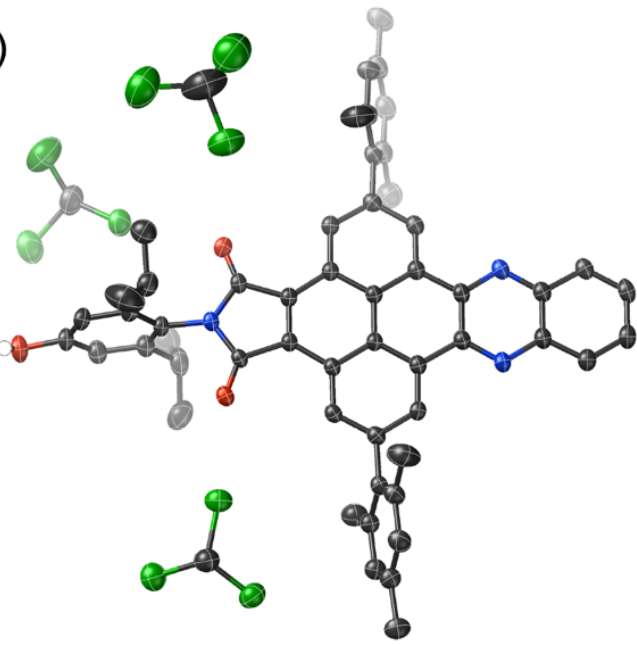

(b)

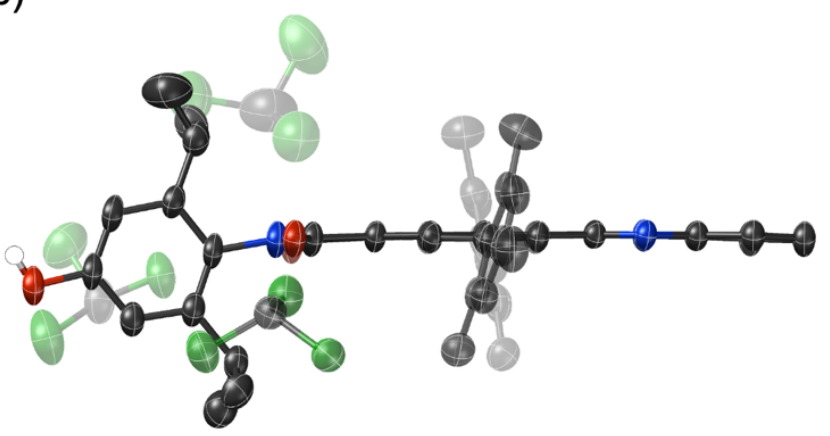

Figure S3.2. Crystal structure of Wing1-OH viewed from different directions. Hydrogen atoms except for $\mathrm{OH}$ groups and disordered solvent molecules with low occupancy are omitted for clarity. Thermal ellipsoids are scaled to $50 \%$ probability. 
Table S3.1. Crystal data of Wing1-OH and FLAP1-OH'.

\begin{tabular}{|c|c|c|}
\hline & Wing1-OH & FLAP1-OH' \\
\hline Formula & $\begin{array}{c}\mathrm{C}_{54} \mathrm{H}_{47} \mathrm{~N}_{3} \mathrm{O}_{3} . \\
3\left(\mathrm{CHCl}_{3}\right)\end{array}$ & $\mathrm{C}_{132} \mathrm{H}_{134} \mathrm{~N}_{6} \mathrm{O}_{6}$ \\
\hline Crystal system & triclinic & triclinic \\
\hline Space group & $P-1$ (No. 2) & $P-1$ (No. 2) \\
\hline$a / \AA$ & $13.2643(5)$ & $15.4670(5)$ \\
\hline$b / \AA$ & $14.5232(4)$ & $20.2490(7)$ \\
\hline$c / \AA$ & $15.8069(4)$ & 27.4203(9) \\
\hline$\alpha /^{\circ}$ & $80.507(2)$ & $87.637(3)$ \\
\hline$\beta 1^{\circ}$ & $86.172(3)$ & $87.0623)$ \\
\hline$\gamma /{ }^{\circ}$ & $64.941(3)$ & $80.183(3)$ \\
\hline$V / \AA^{3}$ & $2720.63(16)$ & $8446.3(5)$ \\
\hline$Z$ & 2 & 2 \\
\hline$T / \mathrm{K}$ & 93 & 93 \\
\hline$R_{1}[I>2 \sigma(I)]$ & 0.0942 & 0.0985 \\
\hline $\begin{array}{l}w R_{2} \\
\text { (all data) }\end{array}$ & 0.2679 & 0.3328 \\
\hline Completeness & 0.971 & 0.980 \\
\hline GOF & 1.068 & 1.015 \\
\hline CCDC No. & 2122594 & 2122595 \\
\hline
\end{tabular}

[a] Contributions to the scattering arising from the presence of disordered solvent molecules were removed by the SQUEEZE program in the PLATON software package. ${ }^{[\mathrm{S} 6]}$ 


\section{Photophysical properties of the force probe in solution}

\subsection{Absorption, fluorescence (FL) spectra at room temperature}

(a)

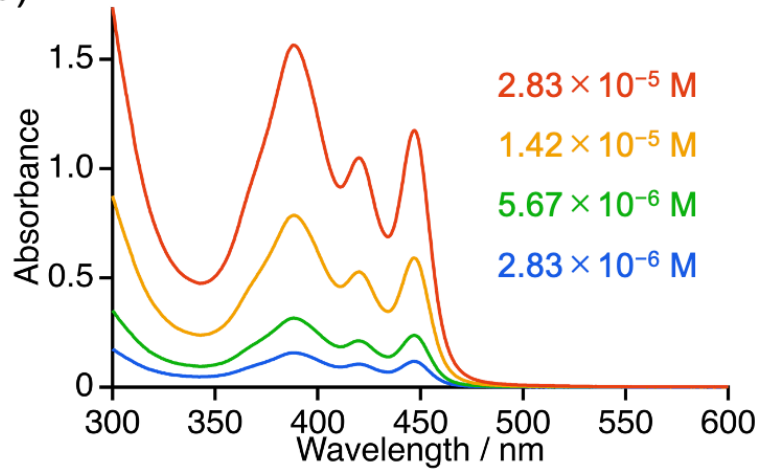

(b)

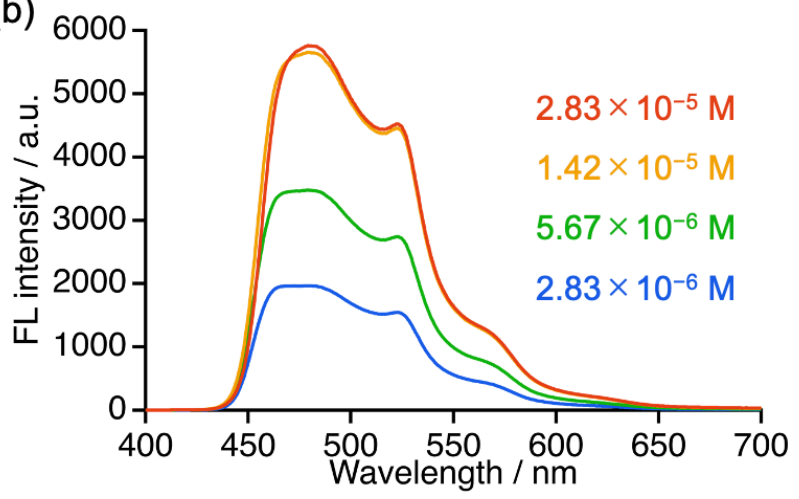

Figure S4.1. Photophysical properties of FLAP1-H in solution. (a) Concentration dependence of the absorption spectra in toluene. (b) Concentration dependence of the FL spectra in toluene $\left(\lambda_{\mathrm{ex}}=389 \mathrm{~nm}\right)$.

(a)

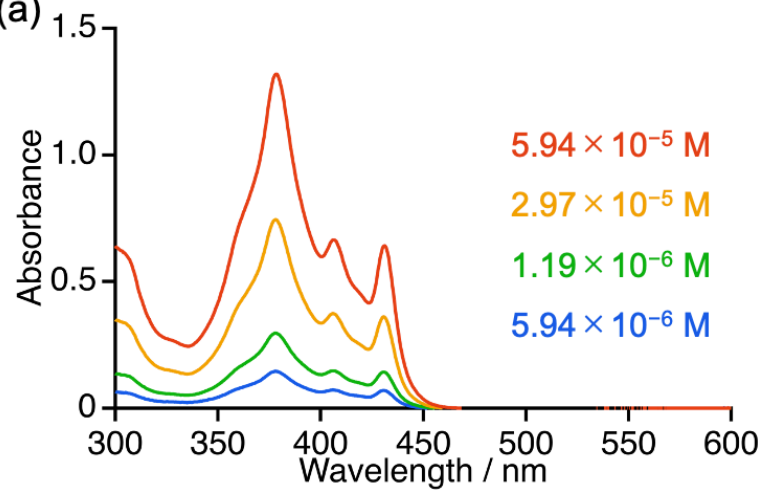

(b)

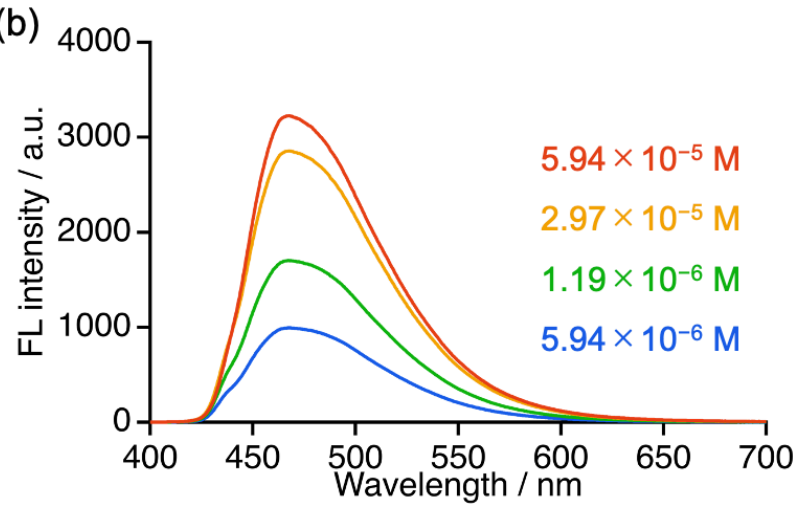

Figure S4.2. Photophysical properties of Wing1-H in solution. (a) Concentration dependence of the absorption spectra in toluene. (b) Concentration dependence of the FL spectra in toluene $\left(\lambda_{\mathrm{ex}}=378 \mathrm{~nm}\right)$.

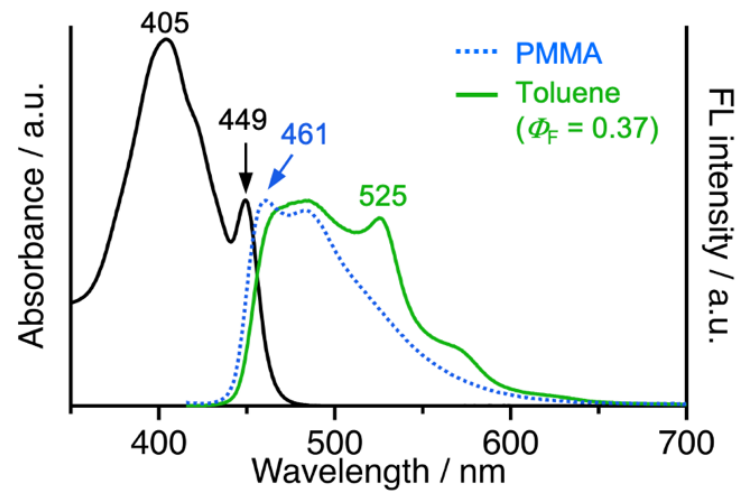

Figure S4.3. Absorption and FL spectra of FLAP1-BC in toluene and PMMA. 


\subsection{Variable temperature FL/excitation spectra and details of the Stevens-Ban plot}
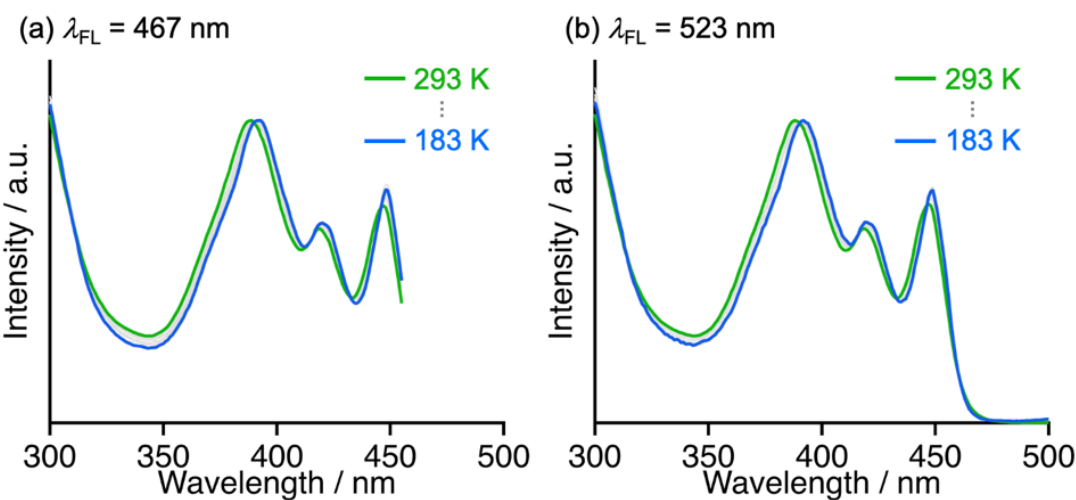

(c) $\lambda_{\mathrm{FL}}=568 \mathrm{~nm}$

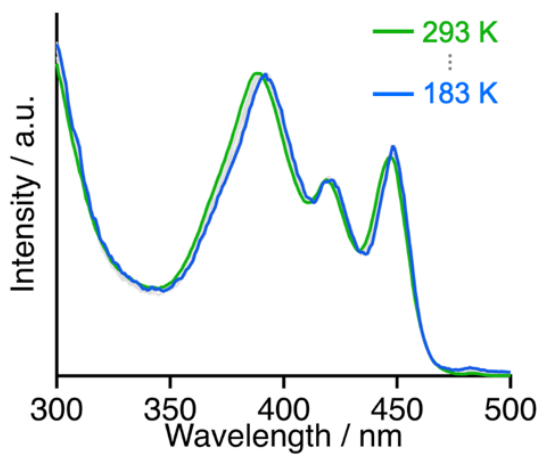

Figure S4.4. Variable temperature excitation spectra of FLAP1-H monitored at different FL wavelength in toluene.

(a)

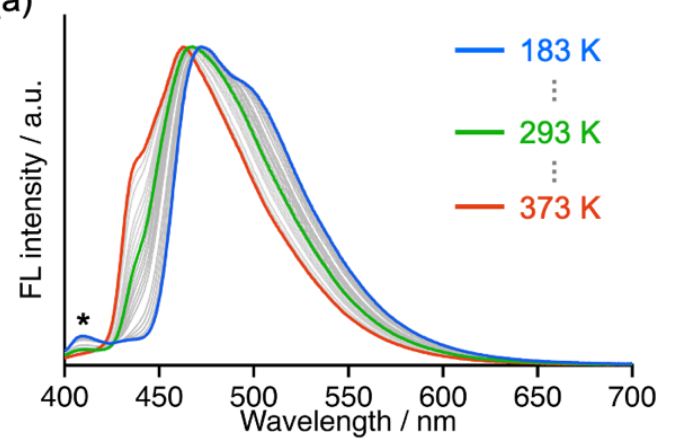

(b)

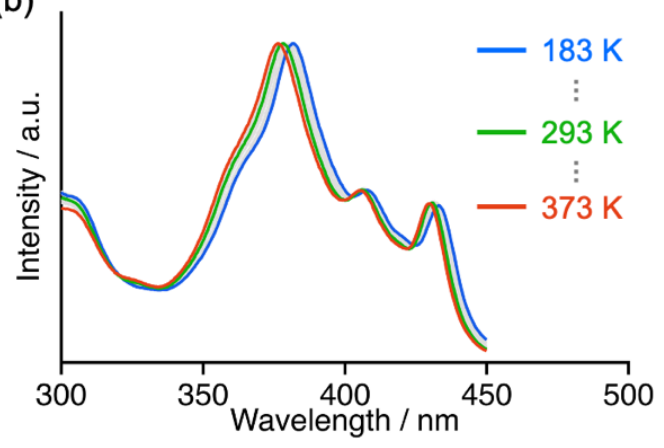

Figure S4.5. (a) Variable temperature FL spectra $\left(\lambda_{\mathrm{ex}}=389 \mathrm{~nm}\right)$ and (b) variable temperature excitation $\operatorname{spectra}\left(\lambda_{\mathrm{FL}}=467 \mathrm{~nm}\right)$ of Wing1-H monitored at different FL wavelength in toluene. 


\section{Details of the Stevens-Ban plot}

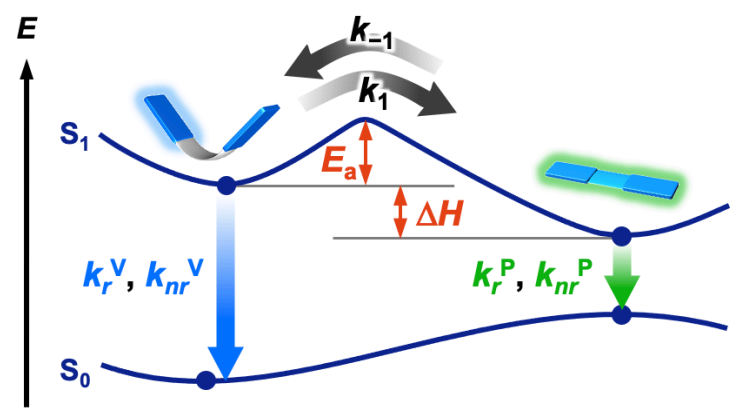

Figure S4.6. A kinetic model of the excited-state planarization of the flapping molecules.

The simple kinetic analysis in the steady-state approximation based on Figure S4.6 affords the relationship between the ratio of the FL quantum yield and the rate constants (Eq. 1). ${ }^{[\mathrm{S} 7]}$

$$
\frac{\Phi_{P}}{\Phi_{V}}=\frac{k_{r}^{P}}{k_{r}^{V}} \cdot \frac{k_{1}}{k_{-1}+k_{r}^{P}+k_{n r}^{P}}
$$

The temperature dependence of the planarization dynamics can be described as follows:

$$
\begin{gathered}
K_{e q}=\frac{k_{1}}{k_{-1}}=\exp \left(-\frac{\Delta G}{R T}\right) \\
k_{1}=A \exp \left(-\frac{E_{a}}{R T}\right)
\end{gathered}
$$

By assuming only the planarization dynamics depends on temperature, Eq. 1 can be transformed into

$$
\ln \frac{\Phi_{P}}{\Phi_{V}}=\ln \frac{k_{r}^{P}}{k_{r}^{V}}-\ln \left[\exp \left(\frac{\Delta G}{R T}\right)+\left(k_{r}^{P}+k_{n r}^{P}\right) A \exp \left(\frac{E_{a}}{R T}\right)\right]
$$

When the temperature-independent terms are written as constants ( $a$ and $b$ ), Eq. 4 is described as below:

$$
\ln \frac{\Phi_{P}}{\Phi_{V}}=-\ln \left[a \exp \left(\frac{\Delta H}{R} \cdot \frac{1}{T}\right)+b \exp \left(\frac{E_{a}}{R} \cdot \frac{1}{T}\right)\right]
$$

The left-hand side contains the ratio of the FL quantum yields of the V-shaped and the planar form of FLAP1$\mathbf{H}$, but since the shape of FL spectra of both species are different and overlapped, the quantum yield ratio cannot be directly calculated. Therefore, we performed the FL spectral decomposition using the spectral shape of the anthracene-based FLAP (FLAP) as a reference. 

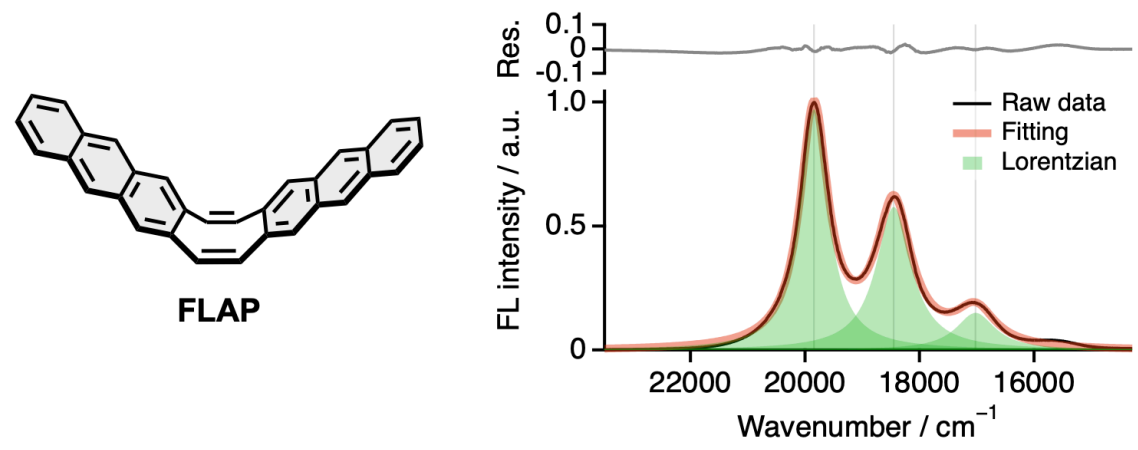

Figure S4.7 Chemical structure of FLAP and FL spectrum of FLAP in $\mathrm{CH}_{2} \mathrm{Cl}_{2}$ fitted with Lorentz functions.

Figure $\mathrm{S} 4.7$ shows the fluorescence spectrum of FLAP in $\mathrm{CH}_{2} \mathrm{Cl}_{2}$, which almost completely planarizes in the $\mathrm{S}_{1}$ and exhibits the characteristic FL spectrum from the planar conformation. ${ }^{[\mathrm{S} 8]}$ Since this FL spectrum can be well described as a sum of Lorentz functions (Eq. 6), we assumed that Lorentz functions could also represent the contribution of the planar form of FLAP1-H. This assumption can be rationalized because a characteristic FL spectrum similar to that of FLAP is observed when SPU1 is stretched (Figure 6c in the main text). Then, the remaining V-shaped contributions of FLAP1-H were approximated by a sum of log-normal distribution functions (Eq. 7) according to the literature. ${ }^{[S 9]}$ Finally, the obtained FL spectra of FLAP1-H were approximated by Eq. 8, and the FL quantum yield ratio was estimated by the area ratio of each function. Figure S4.9 demonstrates the fitting results at the representative temperatures in the Stevens-Ban plot.

$$
\begin{gathered}
f_{i}(\tilde{v})=I_{i} \cdot \frac{w_{i}^{2}}{4\left(\tilde{v}-\tilde{v}_{0 i}\right)^{2}+w_{i}^{2}} \\
g_{i}(\tilde{v})=I_{i} \exp \left\{-\ln 2\left[a_{i}^{-1} \ln \left(\frac{2\left(\tilde{v}-\tilde{v}_{0 i}\right) \sinh a_{i}}{w_{i}}+1\right)\right]^{2}\right\} \\
F(\tilde{v})=\sum_{i=1}^{3} f_{i}(\tilde{v})+\sum_{j=1}^{2} g_{j}(\tilde{v})
\end{gathered}
$$

(a)

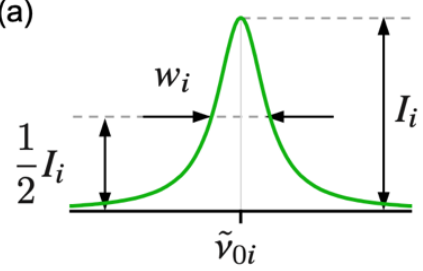

(b)

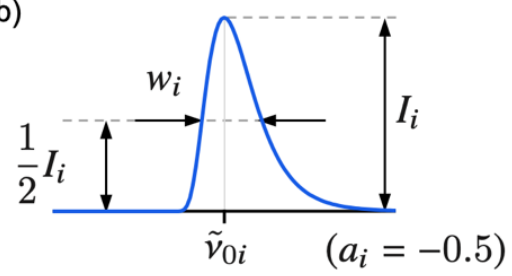

Figure S4.8 Parameters that characterize the shape of fitting functions: $I_{i}=$ intensity, $w_{i}=$ full width at half maximum, $\tilde{v}_{0 i}=$ peak wavenumber, $a_{i}=$ asymmetry parameter $\left(a_{i}=-0.5\right.$ was selected in the figure as an example. For larger $\left|a_{i}\right|$, the function becomes more asymmetric). 

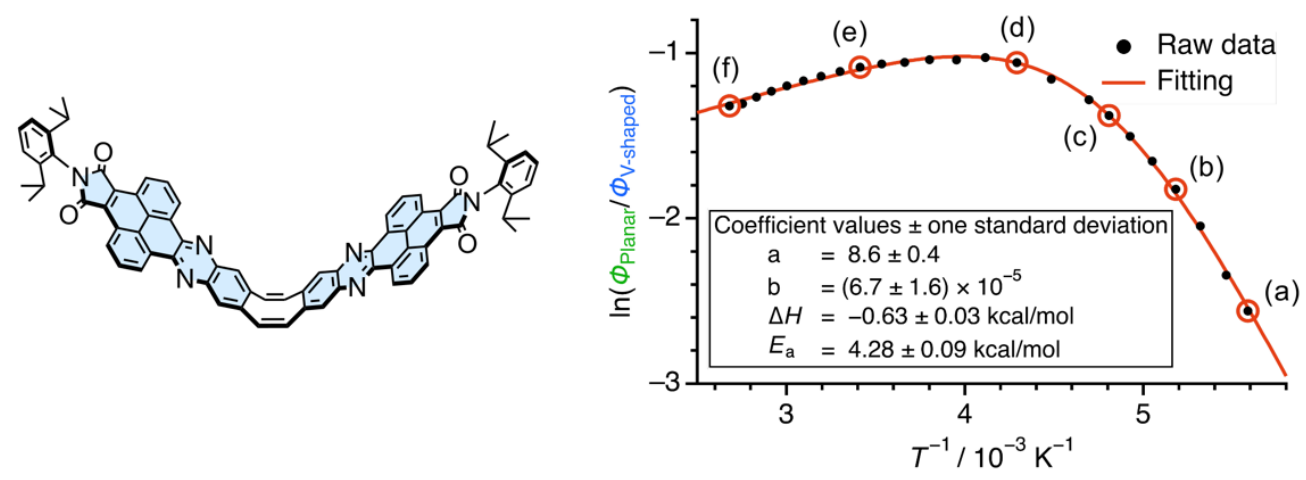

(a) $179 \mathrm{~K}$

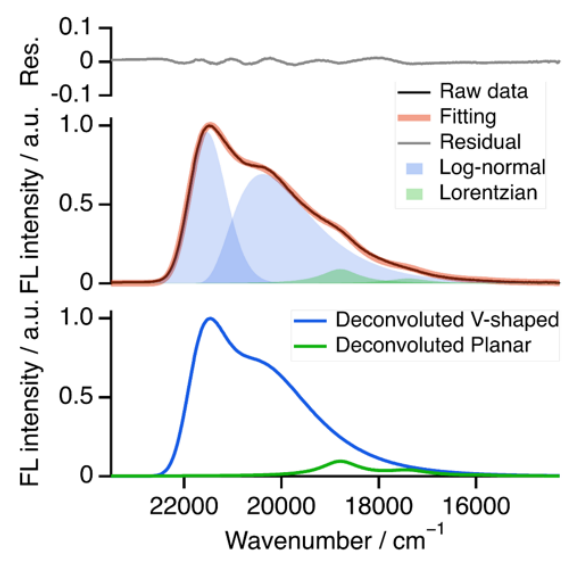

(d) $233 \mathrm{~K}$

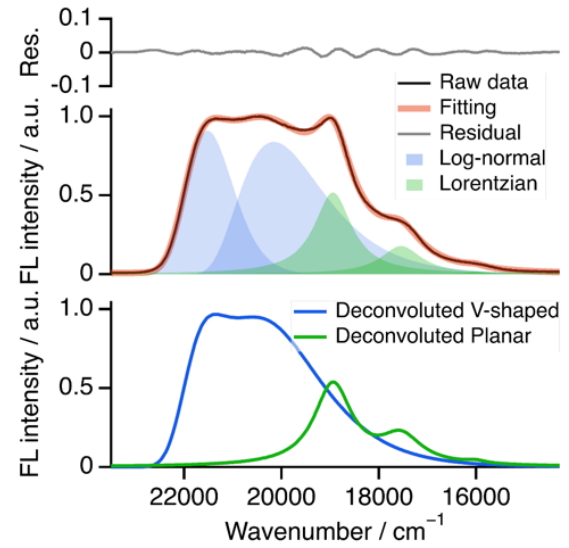

(b) $193 \mathrm{~K}$

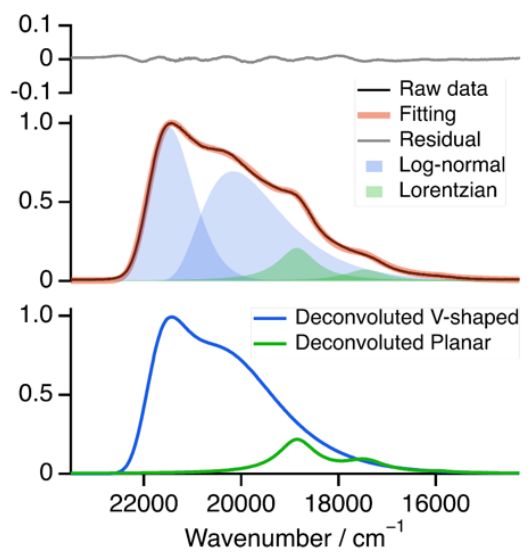

(e) $293 \mathrm{~K}$

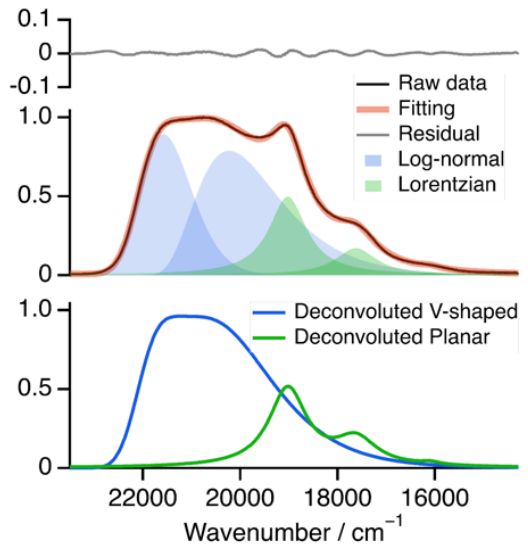

(c) $208 \mathrm{~K}$

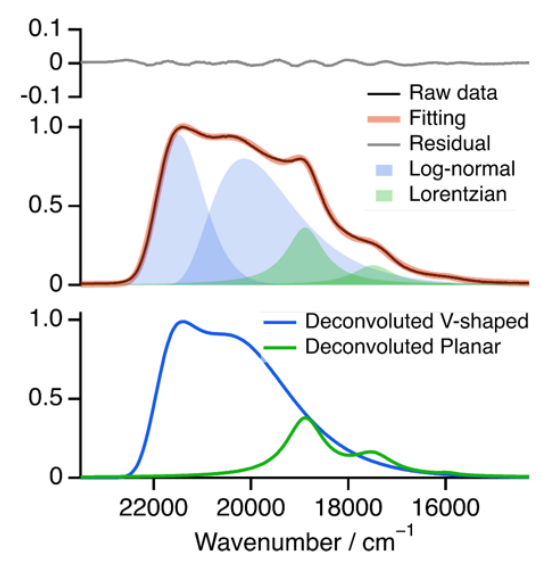

(f) $373 \mathrm{~K}$

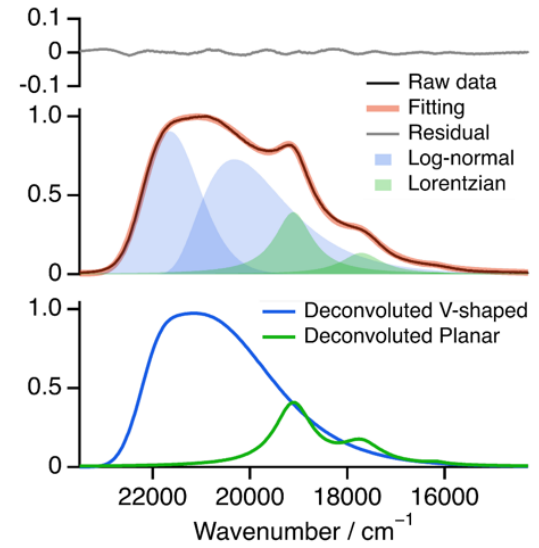

Figure S4.9. Stevens-Ban plot of FLAP1-H constructed from FL spectra measured in toluene, and the fitting results by Eq. 8 at the representative temperatures $(a-f)$. 


\subsection{Fluorescence lifetime analysis}

The fluorescence lifetime of FLAP1-H and Wing1-H was measured by fitting FL decay profiles ( $\lambda_{\mathrm{ex}}=$ $405 \mathrm{~nm}$ ) with single- or double-exponential functions. The goodness of fit was evaluated by $\chi^{2}$, and a doubleexponential model provided better results for FLAP1-H (Table S4.1) than a single-exponential function (Table S4.2). Short-lived components ( $\left.\tau_{1} \sim 0.1-0.2 \mathrm{~ns}\right)$ may originate from planarization dynamics in the excited state. The amplitude $A_{1}$ of the short-lifetime component ( $\tau_{1} \sim 0.1-0.2 \mathrm{~ns}$ ) was obtained as negative values at the longer fluorescence wavelengths. This negative amplitude would correspond to the rise of the long-wavelength FL signals, which suggests that it takes around 0.1-0.2 ns for the excited bent FLAP1-H molecule to planarize in $S_{1}$ and start to emit the long-wavelength fluorescence. After reaching the equilibrium in $S_{1}$, population of the both V-shaped and planar form decreased in the lifetime of $2.3 \mathrm{~ns}\left(\tau_{2}\right)$.

Table S4.1. FL lifetime of FLAP1-H in toluene fitted with a double-exponential function ${ }^{[\mathrm{a}]}$

\begin{tabular}{cccccc}
\hline$\lambda_{\mathrm{FL}} / \mathrm{nm}$ & $\chi^{2}$ & $\tau_{1} / \mathrm{ns}$ & $\tau_{2} / \mathrm{ns}$ & $A_{1}$ & $A_{2}$ \\
\hline 460 & 0.98 & 0.19 & 2.3 & 530 & 1440 \\
480 & 1.13 & 0.09 & 2.3 & -2080 & 1590 \\
500 & 1.08 & 0.14 & 2.3 & -1970 & 1640 \\
520 & 1.04 & 0.18 & 2.3 & -2130 & 1740 \\
540 & 0.98 & 0.15 & 2.3 & -1590 & 1650 \\
560 & 1.12 & 0.16 & 2.3 & -1690 & 1660 \\
\hline
\end{tabular}

$[\mathrm{a}] f(t)=A_{1} \exp \left(-t / \tau_{1}\right)+A_{2} \exp \left(-t / \tau_{2}\right)$

Table S4.2. FL lifetime of FLAP1-H and Wing1-H in toluene fitted with a single-exponential function

\begin{tabular}{cccc}
\hline & $\lambda_{\mathrm{FL}} / \mathrm{nm}$ & $\chi^{2}$ & $\tau / \mathrm{ns}$ \\
\hline & 460 & 3.02 & 2.2 \\
& 480 & 2.15 & 2.3 \\
FLAP1-H & 500 & 2.21 & 2.3 \\
& 520 & 1.68 & 2.3 \\
& 540 & 2.60 & 2.4 \\
& 560 & 3.92 & 2.3 \\
\hline Wing1-H & 467 & 1.20 & 9.5
\end{tabular}



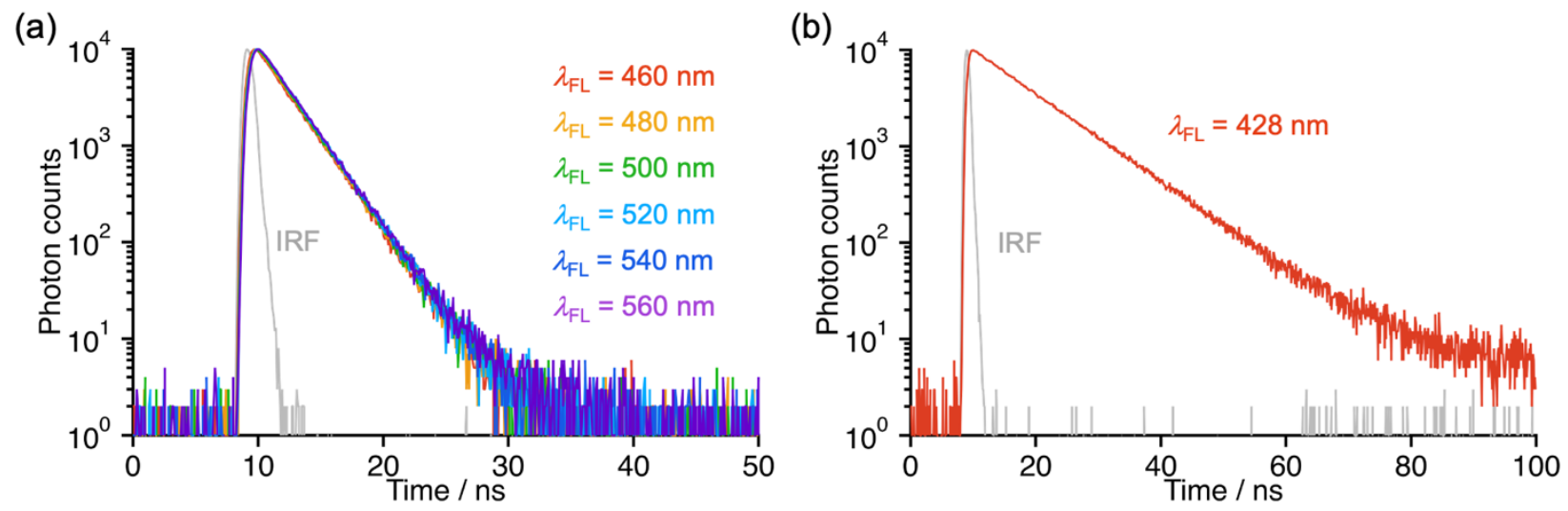

Figure S4.10. FL decay profiles of (a) FLAP1-H and (b) Wing1-H in toluene. 


\subsection{Solvent dependence of absorption/FL spectra and details of the Lippert-Mataga plot}

(a)

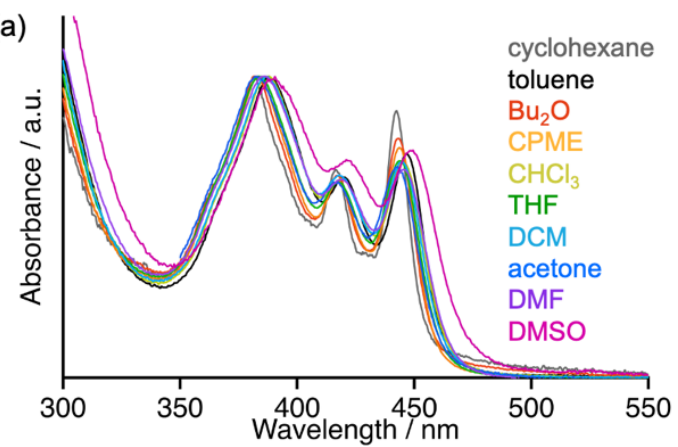

(c)

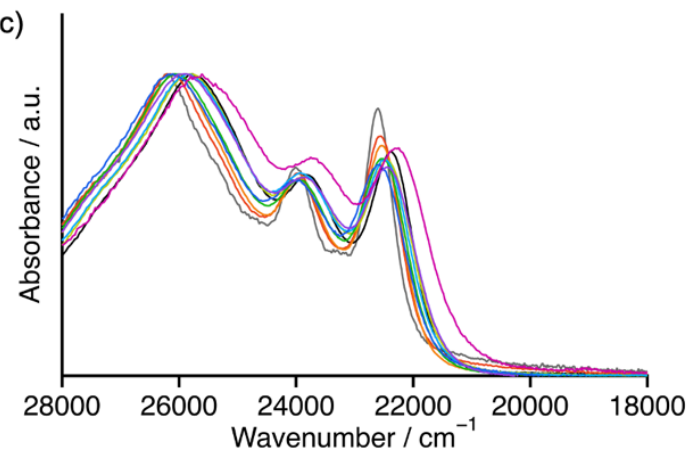

(b)

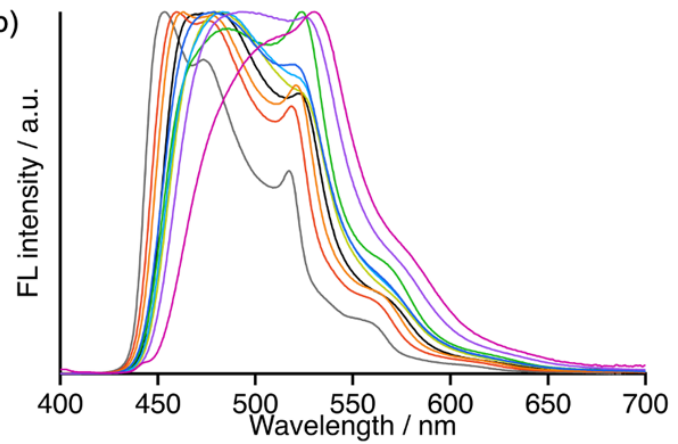

(d)

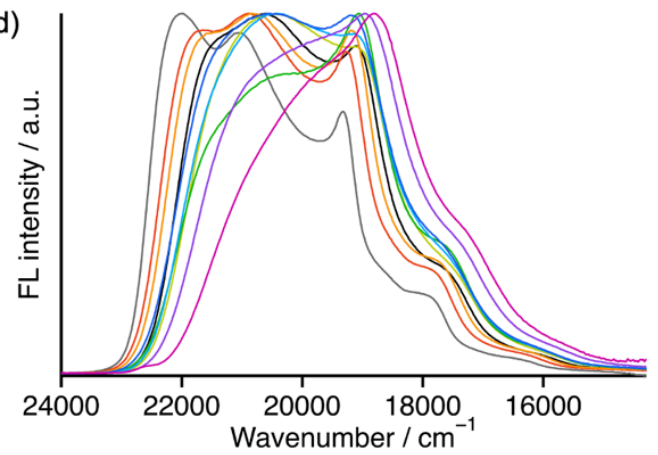

Figure S4.11. (a) Absorption and (b) FL spectra of FLAP1-H measured in different solvents. Figure (c) and (d) are the corresponding absorption and FL spectra plotted in wavenumber units.

(a)

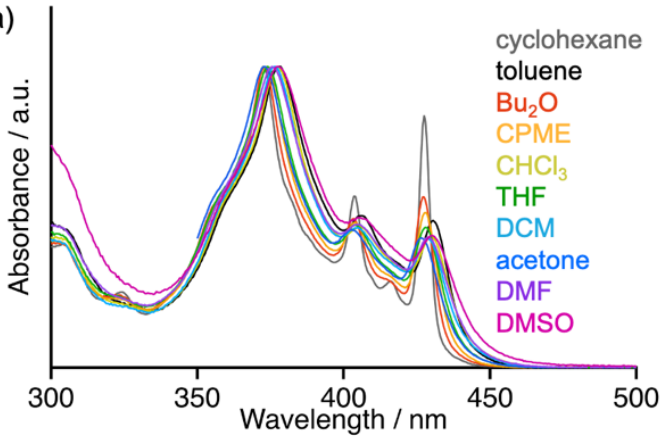

(c)

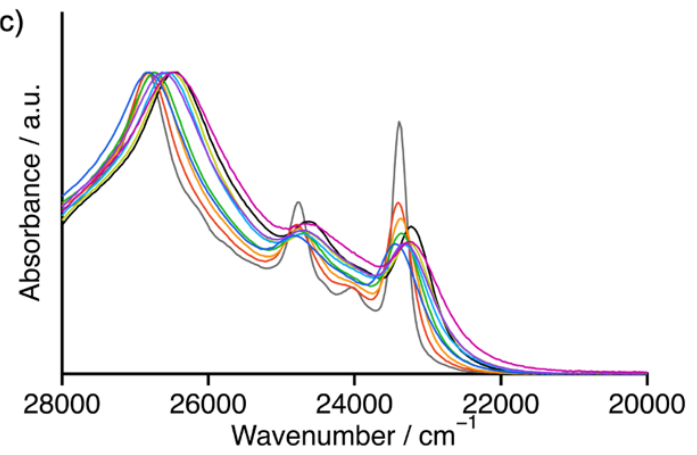

(b)

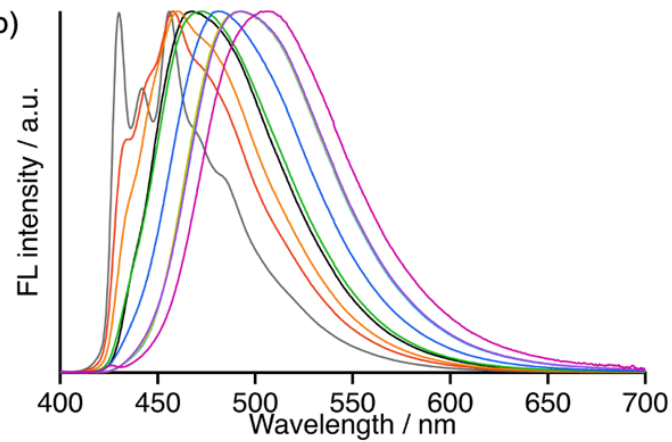

(d)

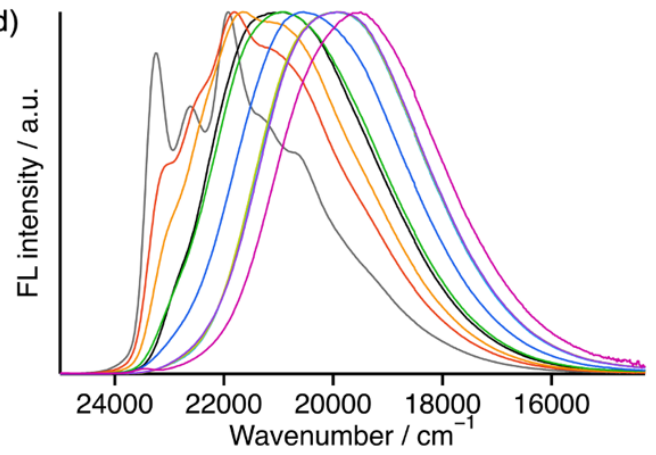

Figure S4.12. (a) Absorption and (b) FL spectra of Wing1-H measured in different solvents. Figure (c) and (d) are the corresponding absorption and FL spectra plotted in wavenumber units. 
Table S4.3. Optical properties of FLAP1-H measured in different solvents

\begin{tabular}{|c|c|c|c|c|c|c|}
\hline & $\Phi_{\mathrm{FL}}$ & $\begin{array}{c}\lambda_{\mathrm{abs}} / \mathrm{nm} \\
\left(\tilde{v}_{\mathrm{abs}} / \mathrm{cm}^{-1}\right)\end{array}$ & $\begin{array}{c}\lambda_{\mathrm{FL}, \mathrm{V}} / \mathrm{nm}^{[\mathrm{a}]} \\
\left(\tilde{v}_{\mathrm{FL}, \mathrm{V}} / \mathrm{cm}^{-1}\right)\end{array}$ & $\begin{array}{l}\text { Stokes shift } \\
\Delta \tilde{\nu}_{\mathrm{V}} / \mathrm{cm}^{-1}\end{array}$ & $\begin{array}{c}\lambda_{\mathrm{FL}, \mathrm{P}} / \mathrm{nm}^{[\mathrm{b}]} \\
\left(\tilde{v}_{\mathrm{FL}, \mathrm{P}} / \mathrm{cm}^{-1}\right)\end{array}$ & $\begin{array}{l}\text { Stokes shift } \\
\Delta \tilde{v}_{\mathrm{P}} / \mathrm{cm}^{-1}\end{array}$ \\
\hline Cyclohexane & 0.38 & $\begin{array}{c}443 \\
(22600)\end{array}$ & $\begin{array}{c}454 \\
(22000)\end{array}$ & 600 & $\begin{array}{c}518 \\
(19320)\end{array}$ & 3280 \\
\hline Toluene & 0.44 & $\begin{array}{c}447 \\
(22360)\end{array}$ & $\begin{array}{c}479 \\
(20640)\end{array}$ & 1720 & $\begin{array}{c}523 \\
(19100)\end{array}$ & 3260 \\
\hline $\mathrm{Bu}_{2} \mathrm{O}$ & 0.41 & $\begin{array}{c}444 \\
(22550)\end{array}$ & $\begin{array}{c}460 \\
(20900)\end{array}$ & 1650 & $\begin{array}{c}519 \\
(19270)\end{array}$ & 3280 \\
\hline CPME & 0.41 & $\begin{array}{c}444 \\
(22520)\end{array}$ & $\begin{array}{c}463 \\
(20810)\end{array}$ & 1710 & $\begin{array}{c}521 \\
(19180)\end{array}$ & 3340 \\
\hline $\mathrm{CHCl}_{3}$ & 0.40 & $\begin{array}{c}445 \\
(22420)\end{array}$ & $\begin{array}{c}482 \\
(20490)\end{array}$ & 1930 & $\begin{array}{c}525 \\
(19050)\end{array}$ & 3370 \\
\hline THF & 0.43 & $\begin{array}{c}444 \\
(22510)\end{array}$ & $\begin{array}{c}486 \\
(20400)^{[c]}\end{array}$ & 2110 & $\begin{array}{c}524 \\
(19070)\end{array}$ & 3440 \\
\hline $\mathrm{CH}_{2} \mathrm{Cl}_{2}$ & 0.40 & $\begin{array}{c}445 \\
(22470)\end{array}$ & $\begin{array}{c}484 \\
(20450)\end{array}$ & 2020 & $\begin{array}{c}525 \\
(19100)\end{array}$ & 3370 \\
\hline Acetone & 0.16 & $\begin{array}{c}443 \\
(22570)\end{array}$ & $\begin{array}{c}478 \\
(20510)\end{array}$ & 2060 & $\begin{array}{c}521 \\
(19160)\end{array}$ & 3410 \\
\hline DMF & 0.42 & $\begin{array}{c}446 \\
(22410)\end{array}$ & $\begin{array}{c}493 \\
(20010)^{[\mathrm{c}]}\end{array}$ & 2400 & $\begin{array}{c}527 \\
(18940)\end{array}$ & 3470 \\
\hline DMSO & 0.08 & $\begin{array}{c}450 \\
(22250)\end{array}$ & $\begin{array}{c}505 \\
(19690)^{[\mathrm{cc}]}\end{array}$ & 2560 & $\begin{array}{c}531 \\
(18780)\end{array}$ & 3470 \\
\hline
\end{tabular}

[a] FL maxima around 450-500 $\mathrm{nm}$ attributed to the FL from the V-shaped form. [b] FL maxima around $525 \mathrm{~nm}$ assigned to the FL from the planar structure. [c] FL maxima of the shoulder peaks were estimated using Eq. 8 .

Table S4.4. Optical properties of Wing1-H measured in different solvents

\begin{tabular}{|c|c|c|c|c|}
\hline & $\Phi_{\mathrm{FL}}$ & $\begin{array}{c}\lambda_{\mathrm{abs}} / \mathrm{nm} \\
\left(\tilde{v}_{\mathrm{abs}} / \mathrm{cm}^{-1}\right)\end{array}$ & $\begin{array}{c}\lambda_{\mathrm{FL}} / \mathrm{nm} \\
\left(\tilde{v}_{\mathrm{FL}} / \mathrm{cm}^{-1}\right)\end{array}$ & $\begin{array}{l}\text { Stokes shift } \\
\Delta \tilde{\nu} / \mathrm{cm}^{-1}\end{array}$ \\
\hline Cyclohexane & 0.18 & $\begin{array}{c}428 \\
(23390)\end{array}$ & $\begin{array}{c}456 \\
(21930)\end{array}$ & 1460 \\
\hline Toluene & 0.36 & $\begin{array}{c}431 \\
(23230)\end{array}$ & $\begin{array}{c}468 \\
(21120)\end{array}$ & 2110 \\
\hline $\mathrm{Bu}_{2} \mathrm{O}$ & 0.23 & $\begin{array}{c}428 \\
(23390)\end{array}$ & $\begin{array}{c}458 \\
(21810)\end{array}$ & 1580 \\
\hline CPME & 0.27 & $\begin{array}{c}428 \\
(23360)\end{array}$ & $\begin{array}{c}460 \\
(21650)\end{array}$ & 1710 \\
\hline $\mathrm{CHCl}_{3}$ & 0.37 & $\begin{array}{c}430 \\
(23260)\end{array}$ & $\begin{array}{c}492 \\
(19980)\end{array}$ & 3280 \\
\hline THF & 0.30 & $\begin{array}{c}428 \\
(23360)\end{array}$ & $\begin{array}{c}473 \\
(20920)\end{array}$ & 2440 \\
\hline $\mathrm{CH}_{2} \mathrm{Cl}_{2}$ & 0.37 & $\begin{array}{c}429 \\
(23310)\end{array}$ & $\begin{array}{c}493 \\
(19980)\end{array}$ & 3330 \\
\hline Acetone & 0.31 & $\begin{array}{c}427 \\
(23450)\end{array}$ & $\begin{array}{c}481 \\
(20530)\end{array}$ & 2920 \\
\hline DMF & 0.41 & $\begin{array}{c}429 \\
(23310)\end{array}$ & $\begin{array}{c}492 \\
(19940)\end{array}$ & 3370 \\
\hline DMSO & 0.03 & $\begin{array}{c}430 \\
(23230)\end{array}$ & $\begin{array}{c}506 \\
(19570)\end{array}$ & 3660 \\
\hline
\end{tabular}




\section{Details of the Lippert-Mataga plot}

The solvent polarity effect on the absorption/FL spectra of FLAP1-H and Wing1-H was quantitatively estimated by Lippert-Mataga plots (Figure S4.13), in which Stokes shifts $\Delta \tilde{v}$ were plotted against the solvent polarity parameter $\Delta f$ defined as follows:

$$
\Delta f=\frac{\epsilon_{r}-1}{2 \epsilon_{r}+1}-\frac{n^{2}-1}{2 n^{2}+1}
$$

where $\epsilon_{r}$ is relative permittivity, and $n$ is refractive index of the solvents. From the well-known LippertMataga equation (Eq. 10), ${ }^{[\mathrm{S} 10]}$ the difference in dipole moments between the ground state $\left(\mu_{g}\right)$ and the excited state $\left(\mu_{e}\right)$ was calculated for Wing1-H and the V-shaped form of FLAP1-H.

$$
\Delta \tilde{v}=\frac{1}{h c} \cdot \frac{2\left(\mu_{e}-\mu_{g}\right)^{2}}{4 \pi \epsilon_{0} a^{3}} \cdot \Delta f+\text { const. }
$$

The parameter $a$ is the Onsager's cavity radius, which was estimated to be $5.55 \AA$ for Wing1-H and $7.02 \AA$ for FLAP1-H by DFT calculations $\left(\mathrm{S}_{0}, \mathrm{PBE} 0 / 6-31+\mathrm{G}(\mathrm{d}) / \mathrm{PCM}\right.$ (toluene)). Since the coefficient of $\Delta f$ in Eq. 10 corresponds to the slope $b$ in Figure S4.13, the difference in dipole moments $\left(\mu_{e}-\mu_{g}\right)$ was calculated to be 10 Debye for Wing1-H and 12 Debye for the V-shaped form of FLAP1-H, suggesting the similar excited-state electronic character bearing a large excited-state dipole moment.

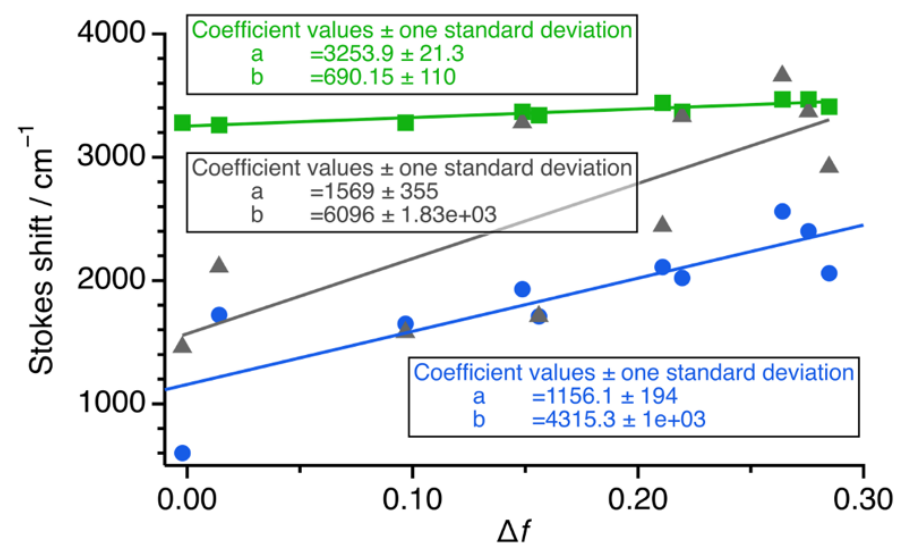

Figure S4.13. Lippert-Mataga plots of Wing1-H (gray triangles) and FLAP1-H (blue circles for the V-shaped form, and green squares for the planar form) fitted with a linear function $y=a+b x$. 


\section{Density functional theory (DFT) calculations}

DFT calculations of the isolated molecules were performed using the Gaussian 16 program, ${ }^{[\mathrm{S} 11]}$ and Kohn-Sham orbitals are displayed by the Avogadro program. ${ }^{\left[{ }^{[S 12]}\right.}$ Model structures FLAP1' and Wing1' were calculated, which have hydrogen atoms in place of the 2,6-diisopropylphenyl groups of the corresponding molecules (Figure S5.1). The COT bending angle was defined as the dihedral angle between the $\mathrm{C} 1-\mathrm{C} 2-\mathrm{C} 3$ and $\mathrm{C} 2-\mathrm{C} 3-\mathrm{C} 4$ planes in Figure S5.2. Constrained geometry optimization was performed with the fixed COT bending angles using the ModRedundant keyword.

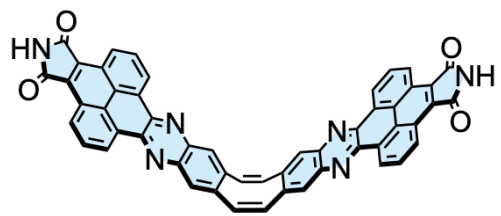

FLAP1'

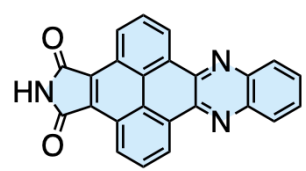

Wing1'

Figure S5.1. Structures of FLAP1' and Wing1'.

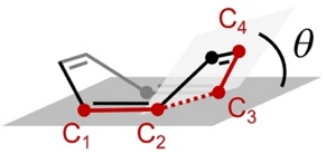

Figure S5.2. Definition of the COT bending angle $\theta$ used in the constrained geometry optimization.

\subsection{Assignment of the absorption spectra in toluene}

In Section 4.4, we confirmed the solvent dependence of the Stokes shifts of FLAP1-H and Wing1-H, and we will subsequently discuss the reasons for this dependence by DFT calculations. The calculation conditions were selected based on the experimental absorption spectra and excited-state behaviors (See details in Section 5.5 of SI). For Wing1-H, the transition energies and oscillator strengths calculated by TD-DFT calculations well reproduced the absorption spectrum (Figure S5.3a). In particular, the absorption maximum with the longest wavelength can be well described by the HOMO-LUMO transition from HOMO mainly distributed on the pyrene moiety (PYR) to LUMO localized on the five-membered imide ring (IMD). The transitions with higher energies involve the HOMO-1 and LUMO+1 localized on the phenazine moiety (PZH) (Figure S5.3c, left side). Furthermore, although the agreement of transition energies and oscillator strengths is not as perfect as Wing1-H, the longest wavelength absorption of FLAP1-H is similarly described by the transition from the pyrene-distributed orbital to the imide-localized orbital. 

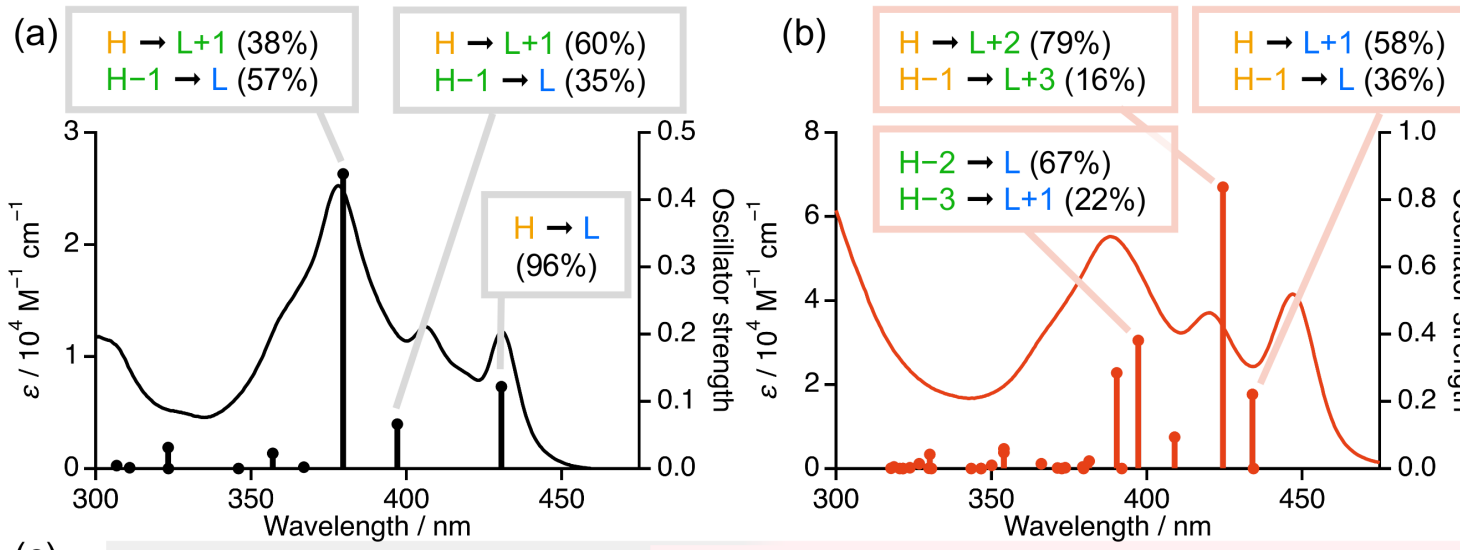

(c)

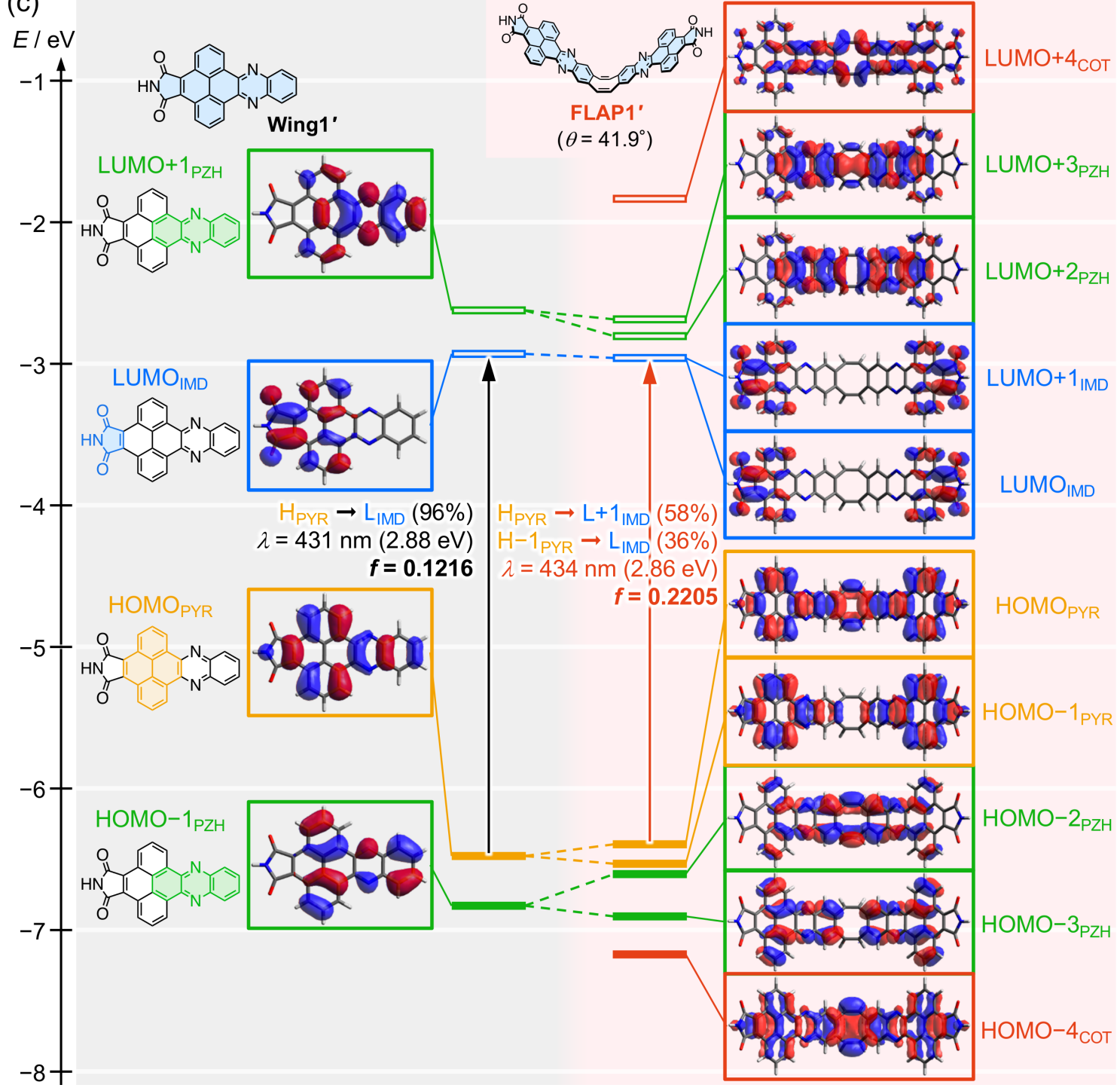

Figure S5.3. Calculated oscillator strength (bars) and observed UV-visible absorption spectra (line) of (a) Wing1' and (b) FLAP1' in toluene. (c) Kohn-Sham molecular orbitals of Wing1' and FLAP1' in the $\mathrm{S}_{0}$ optimized geometries and selected transition characters with non-zero oscillator strengths, calculated at the (TD-)PBE0/6-31+G(d)/PCM(toluene) level. H = HOMO, L = LUMO. 
Table S5.1. Excitation energies and oscillator strengths of the $S_{0} \rightarrow S_{n}(n \leq 5)$ transitions for the $S_{0}$ optimized Wing1' calculated at the TD-PBE0/6-31+G(d)/PCM(toluene) level

\begin{tabular}{cccc}
\hline Transition & Excitation energy & Configurations & $f$ \\
\hline $\mathrm{S}_{0} \rightarrow \mathrm{S}_{1}\left(B_{2}\right)$ & $2.88 \mathrm{eV}(431 \mathrm{~nm})$ & HOMO $\rightarrow$ LUMO $(96 \%)$ & 0.1216 \\
& & HOMO $\rightarrow$ LUMO+1 (60\%) & 0.0661 \\
$\mathrm{~S}_{0} \rightarrow \mathrm{S}_{2}\left(A_{1}\right)$ & $3.12 \mathrm{eV}(397 \mathrm{~nm})$ & HOMO-1 $\rightarrow$ LUMO (35\%) & \\
& & HOMO-1 $\rightarrow$ LUMO (57\%) & 0.4382 \\
$\mathrm{~S}_{0} \rightarrow \mathrm{S}_{3}\left(A_{1}\right)$ & $3.27 \mathrm{eV}(380 \mathrm{~nm})$ & HOMO $\rightarrow$ LUMO+1 (38\%) & \\
& & HOMO-3 $\rightarrow$ LUMO+2 (98\%) & 0.0018 \\
$\mathrm{~S}_{0} \rightarrow \mathrm{S}_{4}\left(B_{1}\right)$ & $3.38 \mathrm{eV}(367 \mathrm{~nm})$ & HOMO-1 $\rightarrow$ LUMO+1 (96\%) & 0.0226 \\
$\mathrm{~S}_{0} \rightarrow \mathrm{S}_{5}\left(B_{2}\right)$ & $3.47 \mathrm{eV}(357 \mathrm{~nm})$ &
\end{tabular}

Table S5.2. Excitation energies and oscillator strengths of the $S_{0} \rightarrow S_{n}(n \leq 5)$ transitions for the $S_{0}$ optimized FLAP1' calculated at the TD-PBE0/6-31+G(d)/PCM(toluene) level

\begin{tabular}{|c|c|c|c|}
\hline Transition & Excitation energy & Configurations & $f$ \\
\hline $\mathrm{S}_{0} \rightarrow \mathrm{S}_{1}\left(A_{2}\right)$ & $2.85 \mathrm{eV}(434 \mathrm{~nm})$ & $\begin{array}{c}\text { HOMO } \rightarrow \text { LUMO (58\%) } \\
\text { HOMO-1 } \rightarrow \text { LUMO+1 (37\%) }\end{array}$ & 0 \\
\hline $\mathrm{S}_{0} \rightarrow \mathrm{S}_{2}\left(B_{1}\right)$ & $2.86 \mathrm{eV}(434 \mathrm{~nm})$ & $\begin{array}{l}\mathrm{HOMO} \rightarrow \text { LUMO+1 }(58 \%) \\
\mathrm{HOMO}^{-1} \rightarrow \text { LUMO }(36 \%)\end{array}$ & 0.2205 \\
\hline $\mathrm{S}_{0} \rightarrow \mathrm{S}_{3}\left(B_{2}\right)$ & $2.92 \mathrm{eV}(425 \mathrm{~nm})$ & $\begin{array}{c}\mathrm{HOMO} \rightarrow \mathrm{LUMO}+2(79 \%) \\
\mathrm{HOMO}-1 \rightarrow \mathrm{LUMO}+3(16 \%)\end{array}$ & 0.8369 \\
\hline $\mathrm{S}_{0} \rightarrow \mathrm{S}_{4}\left(A_{1}\right)$ & $3.03 \mathrm{eV}(409 \mathrm{~nm})$ & $\begin{array}{c}\mathrm{HOMO} \rightarrow \text { LUMO+3 (38\%) } \\
\mathrm{HOMO}-1 \rightarrow \text { LUMO+2 (29\%) } \\
\mathrm{HOMO}-2 \rightarrow \text { LUMO+1 (19\%) }\end{array}$ & 0.0930 \\
\hline $\mathrm{S}_{0} \rightarrow \mathrm{S}_{5}\left(B_{2}\right)$ & $3.12 \mathrm{eV}(397 \mathrm{~nm})$ & $\begin{array}{c}\text { HOMO-2 } \rightarrow \text { LUMO (67\%) } \\
\text { HOMO-3 } \rightarrow \text { LUMO+1 (22\%) }\end{array}$ & 0.3814 \\
\hline
\end{tabular}


(a)
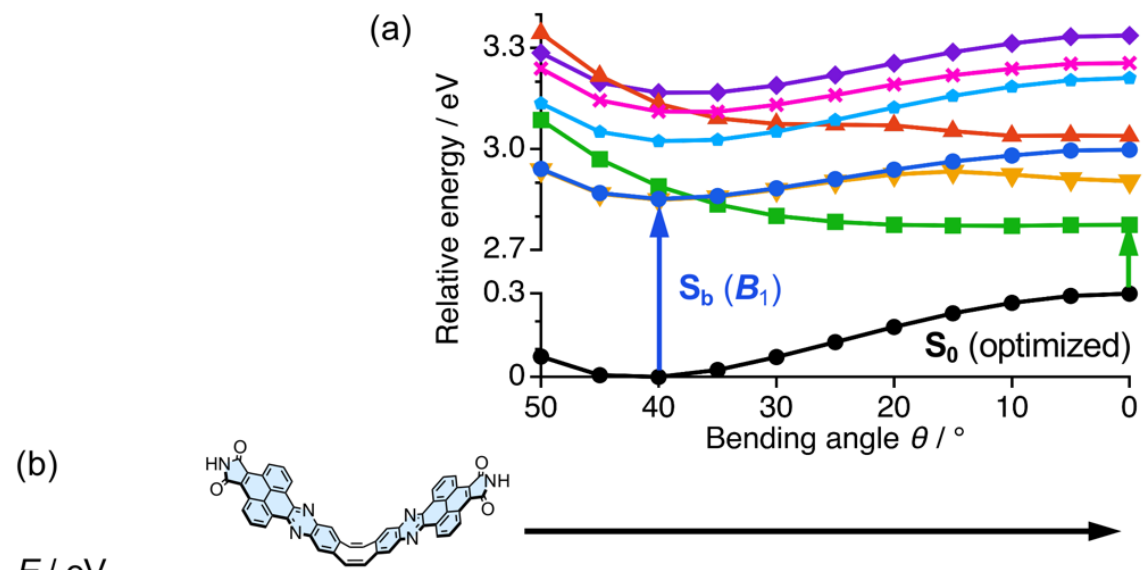

$E / \mathrm{eV}$

-1 f $L+4_{\mathrm{COT}}$
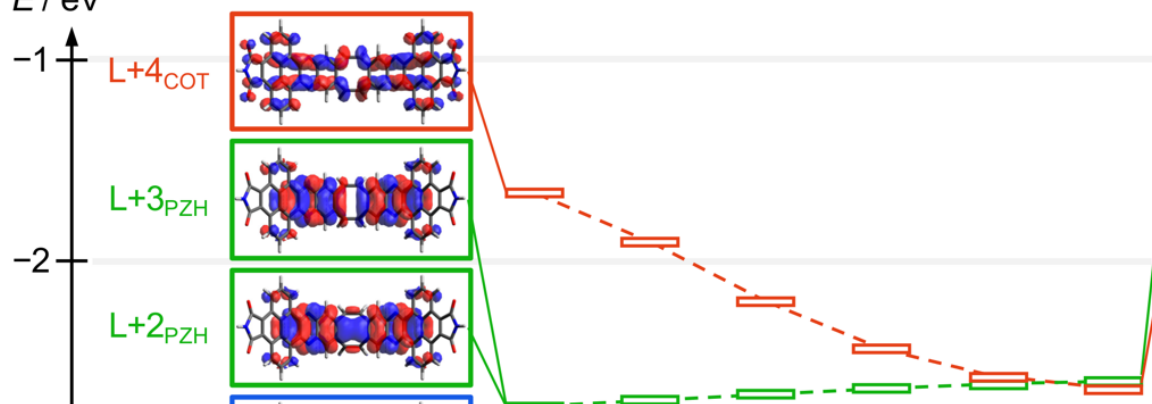

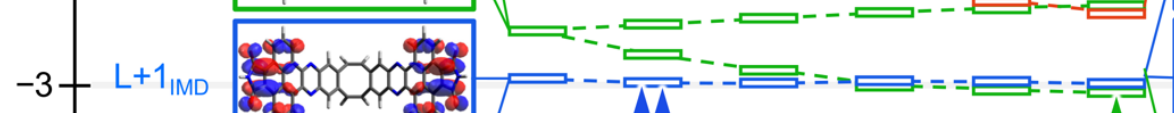

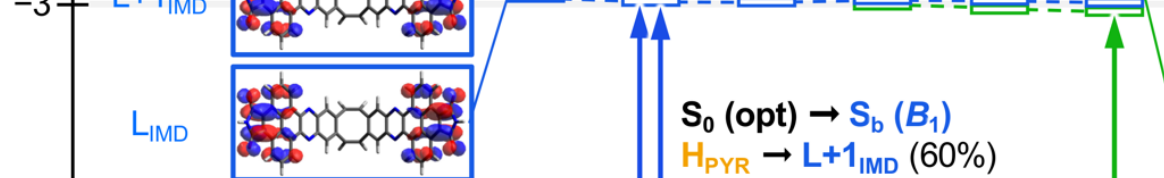

$-4-\longrightarrow \quad \begin{aligned} & H-1_{\text {PYR }} \rightarrow L_{\text {IMD }}(34 \%) \\ & \lambda-435\end{aligned}$

$\lambda=435 \mathrm{~nm}(2.85 \mathrm{eV})$
$f=0.2174$

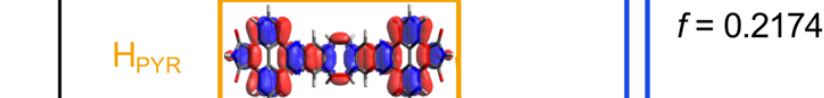

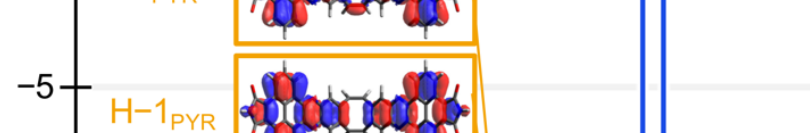

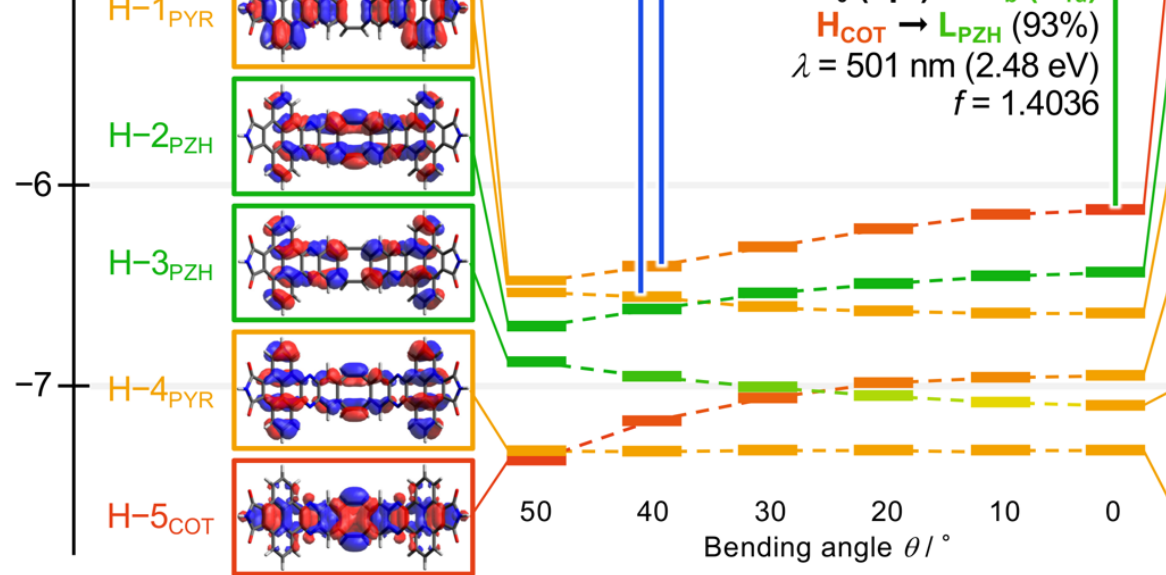

$S_{g}\left(A_{1}\right)$

$S_{f}\left(B_{2}\right)$

$\mathrm{S}_{\mathrm{e}}\left(A_{1}\right)$

$\mathrm{S}_{\mathrm{d}}\left(A_{2}\right)$

$\mathrm{S}_{\mathrm{c}}\left(A_{2}\right)$

$\mathrm{S}_{\mathrm{a}}\left(B_{2}\right)$

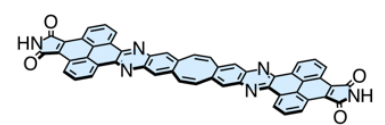

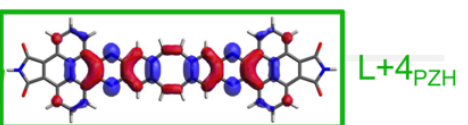

सें

:20

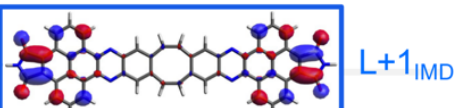

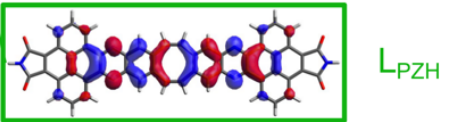

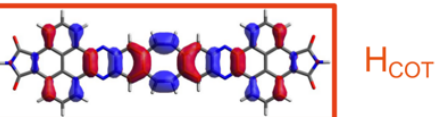

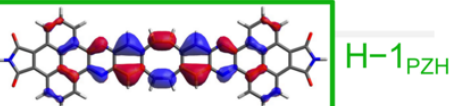

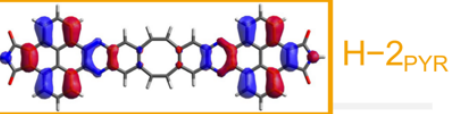

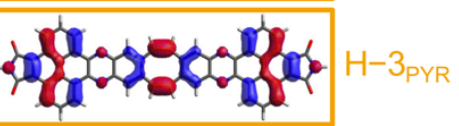

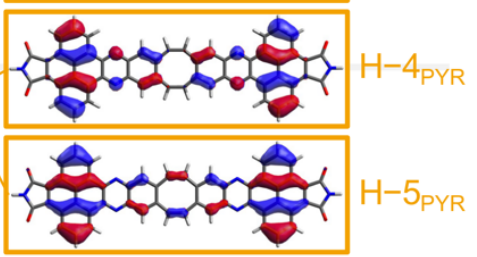

Figure S5.4. (a) Energy profiles of $\mathrm{S}_{0}$ and vertically excited states $\left(\mathrm{S}_{\mathrm{a}}-\mathrm{S}_{\mathrm{f}}\right)$ of FLAP1' calculated at the (TD)PBE0/6-31+G(d)/PCM(toluene) level. Geometries are optimized in $\mathrm{S}_{0}$ with the fixed COT bending angle. (b) Change in transition characters during the ground-state planarization. $\mathrm{H}=\mathrm{HOMO}, \mathrm{L}=\mathrm{LUMO}$. 


\subsection{Calculated geometries and structural parameters in $S_{0}$ and $S_{1}$}

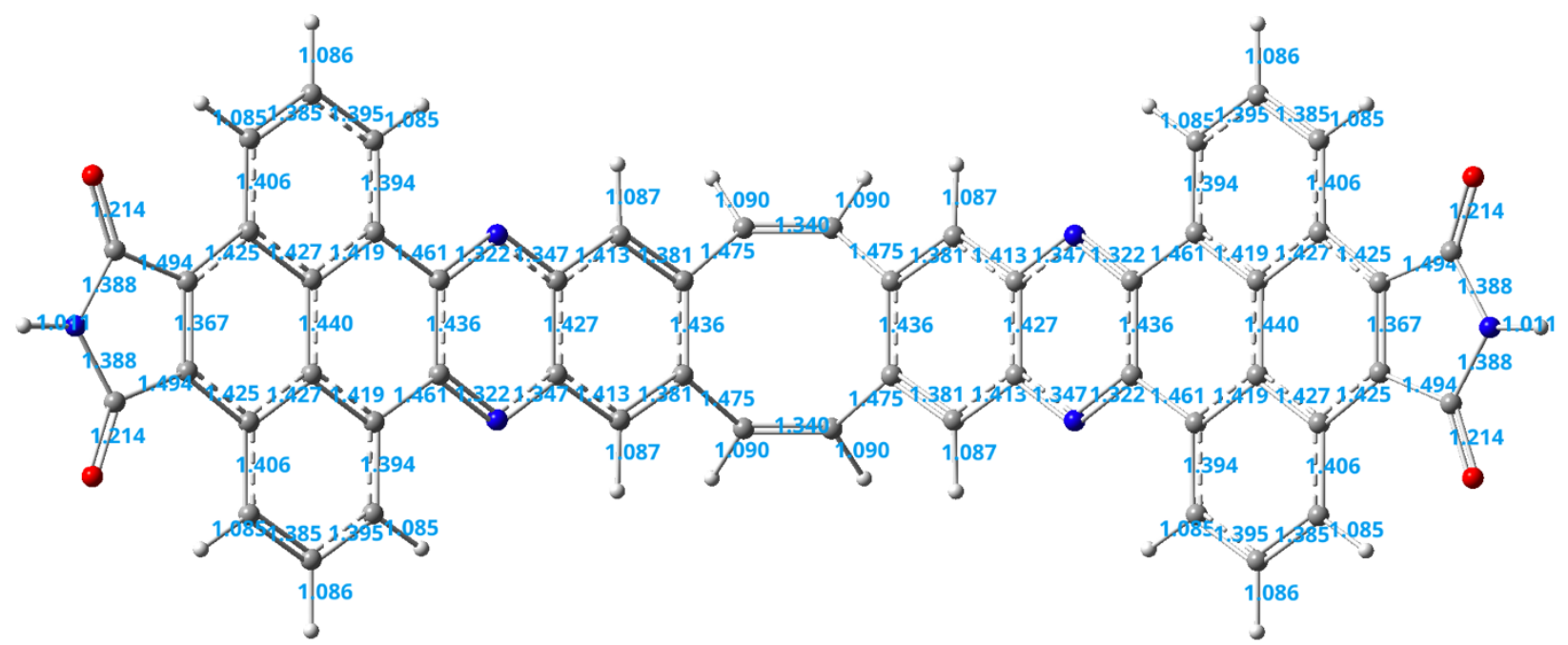

Figure S5.5. Bond lengths $(\AA)$ of FLAP1' based on the $\mathrm{S}_{0}$ optimized geometry $\left(\theta=41.9^{\circ}\right)$ calculated at the (TD-)PBE0/6-31+G(d)/PCM(toluene) level.

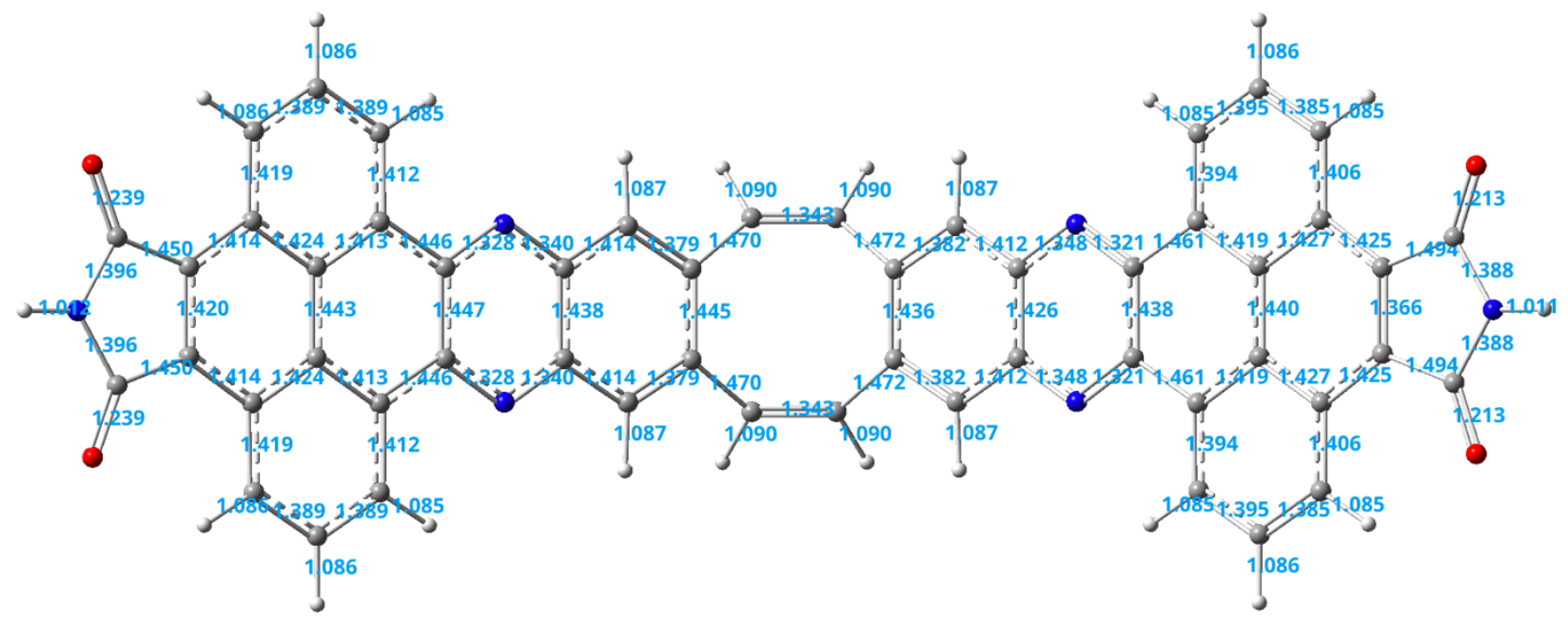

Figure S5.6. Bond lengths $(\AA)$ of FLAP1' based on the $\mathrm{S}_{1}$ optimized geometry $\left(A^{\prime \prime}\right.$ state, $\theta=39.5^{\circ}$ and $\left.39.3^{\circ}\right)$ calculated at the (TD-)PBE0/6-31+G(d)/PCM(toluene) level. 


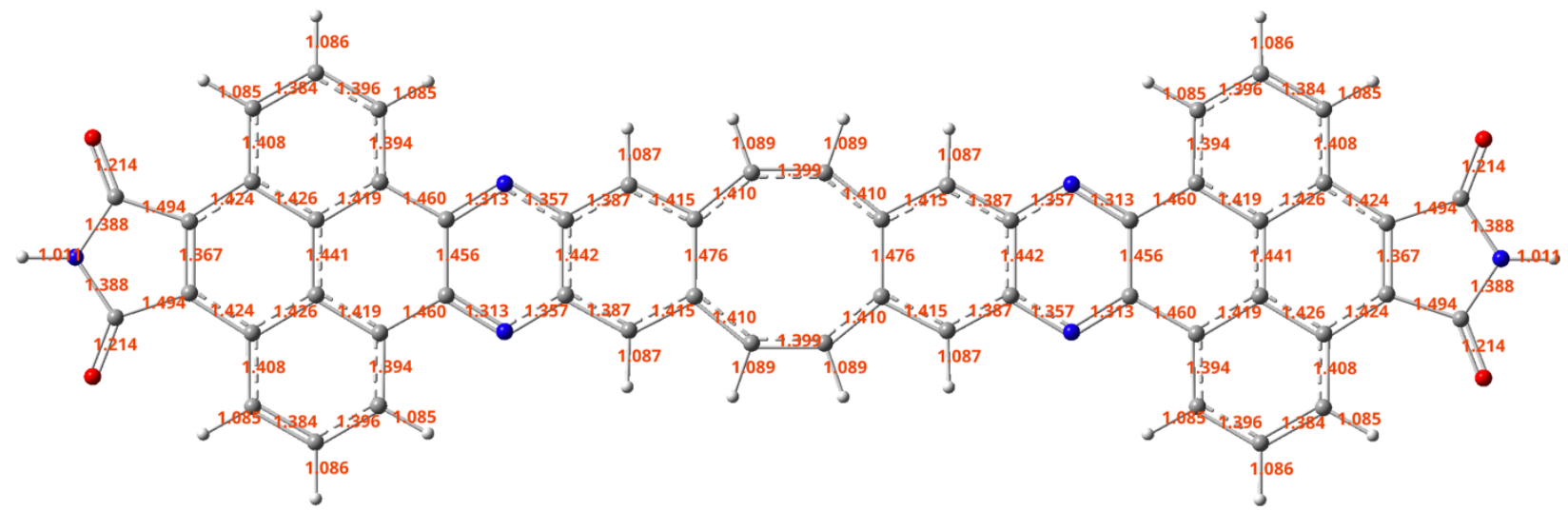

Figure S5.7. Bond lengths $(\AA)$ of FLAP1' based on the $\mathrm{S}_{1}$ optimized geometry $\left(A_{2}\right.$ state, $\left.\theta=0^{\circ}\right)$ calculated at the (TD-)PBE0/6-31+G(d)/PCM(toluene) level.

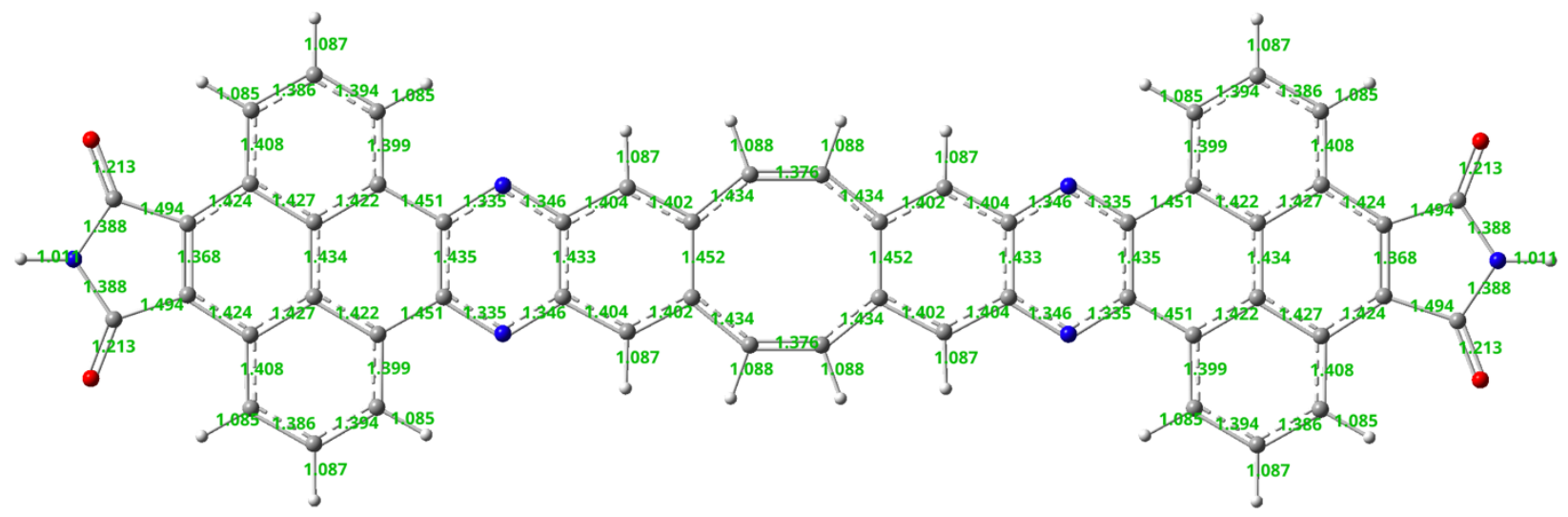

Figure S5.8. Bond lengths $(\AA)$ of FLAP1' based on the $\mathrm{S}_{1}$ optimized geometry $\left(B_{2}\right.$ state, $\left.\theta=0^{\circ}\right)$ calculated at the (TD-)PBE0/6-31+G(d)/PCM(toluene) level. 


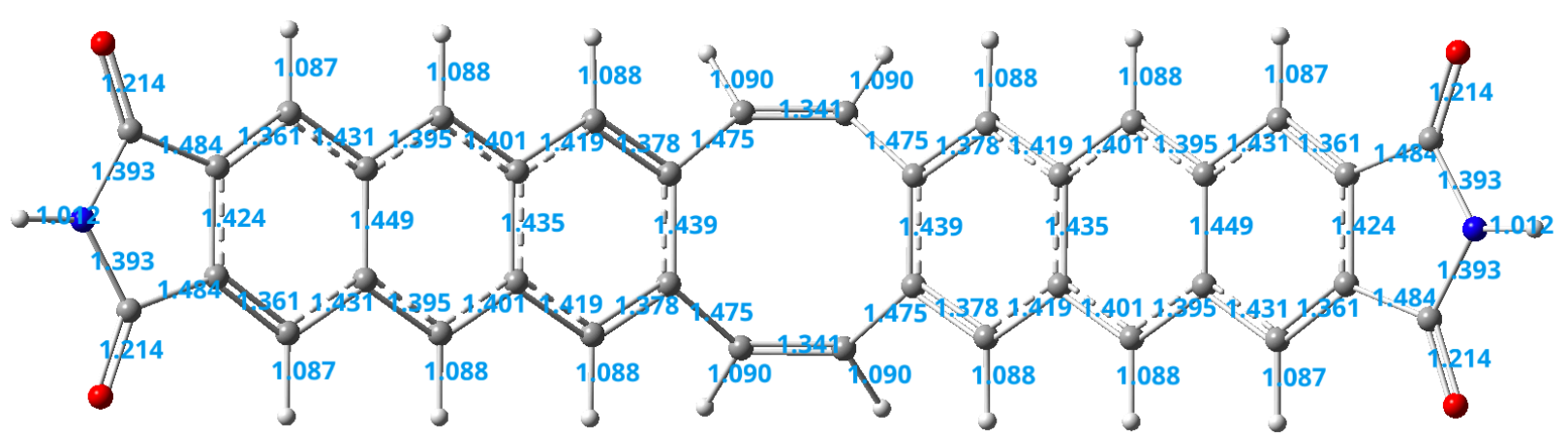

Figure S5.9. Bond lengths $(\AA)$ of FLAP0' based on the $\mathrm{S}_{0}$ optimized geometry $\left(\theta=41.0^{\circ}\right)$ calculated at the (TD-)PBE0/6-31+G(d)/PCM(toluene) level.

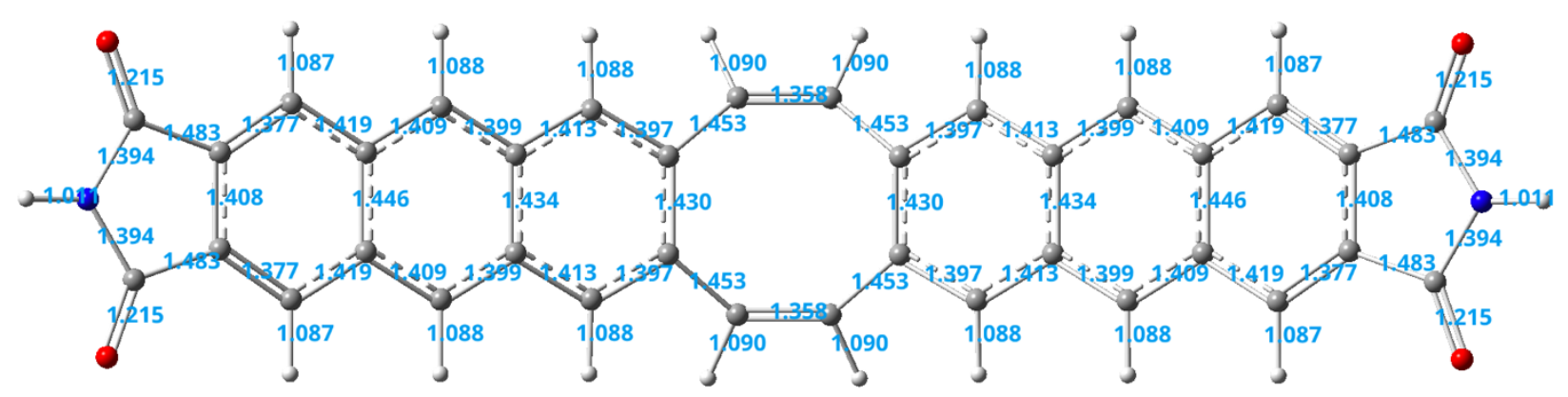

Figure S5.10. Bond lengths $(\AA)$ of FLAP0' based on the $\mathrm{S}_{1}$ optimized geometry $\left(\theta=29.5^{\circ}\right)$ calculated at the (TD-)PBE0/6-31+G(d)/PCM(toluene) level.

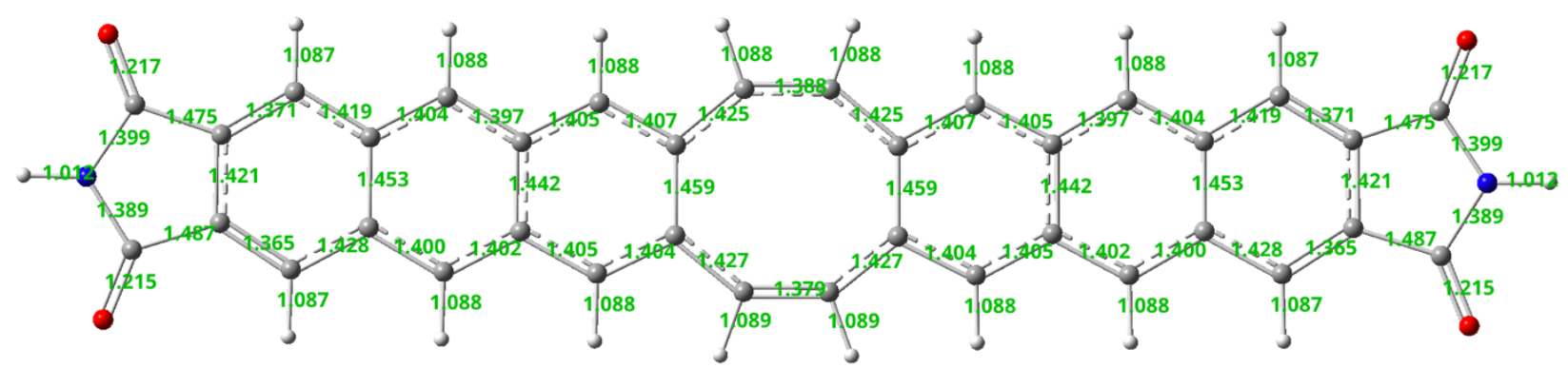

Figure S5.11. Bond lengths $(\AA)$ of FLAP0' based on the $S_{1}$ optimized geometry $\left(\theta=0^{\circ}\right)$ calculated at the (TD-)PBE0/6-31+G(d)/PCM(toluene) level. 


\subsection{Selection of a calculation level for the interpretation of the observed FL spectra}

To explain the dual FL behavior of FLAP1-H from a theoretical point of view, we considered the proper conditions for DFT calculations. First, we compared the $\mathrm{S}_{1}$ energy profiles of the model compound FLAP1' under several calculation conditions (Figure S5.12 and S5.14). First, the TD-PBE0/6-31+G(d) level employed in previous calculations of anthracene-based $\mathrm{FLAP}^{[\mathrm{S8]}}$ resulted in a double-well potential energy curve (Figure S5.12). However, under these conditions, the global energy minimum becomes a nonluminescent $A_{2}$ state $(f=0)$, and the oscillator strength does not agree with the experimental results. On the other hand, the bright $B_{2}$ state $(f \sim 0.8)$, which reasonably explains the dual FL in the solution, was found at a higher energy level than that of the $A_{2}$ state. Therefore, we focused on the energy difference between the $B_{2}$ and $A_{2}$ states and the transition energy of the $B_{2}$ state to further examine the calculation conditions (Table S5.3).

Figure S5.13 summarizes the correlation between the calculation results and the fraction of HartreeFock (HF) exchange in the functional. As for the FL wavelengths, PBE0 was in the best agreement with the experimental results ( $\lambda_{\mathrm{FL}}=523 \mathrm{~nm}$ in toluene), while CAM-B3LYP underestimated the FL wavelength and the other functionals overestimated them (Figure S5.13a). Although the energy of the $B_{2}$ state approaches that of the $A_{2}$ state as the fraction of HF exchange decreases, no conditions were found under which the bright $B_{2}$ state is the most stable in the planar form. In the case of TPSSh, which reproduces the experimental results of the reported phenazine-based FLAP, the $B_{2}$ and $A_{2}$ states have almost the same energy. However, the energy barrier between the V-shaped and planar structures disappears, which is qualitatively incompatible with the experimental results (Figure S5.14c).

Since TD-DFT calculations sometimes give incorrect state orderings in $\pi \pi^{*}$ states even for the simple heteroaromatic systems, higher levels of theory such as double hybrid functionals, CC2, or ADC(2) are preferred. ${ }^{[\mathrm{S} 13]}$ In the case of FLAP1', we tried to use the B2PLYP functional by the ORCA program, ${ }^{[\mathrm{S} 14]}$ but the $S_{1}$ calculations were difficult due to the computational cost. Therefore, we determined the calculation conditions by giving more importance to the agreement with the absorption spectra and the shape of the potential energy curves, regardless of the oscillator strength of the planar form. Finally, the TD-PBE0/6$31+\mathrm{G}(\mathrm{d})$ level, together with the polarizable continuum model (PCM) for considering the solvent effect, reproduced the absorption spectrum of Wing1-H (Figure S5.3a) and the double-well S potential of FLAP1-H (Figure S5.14d).
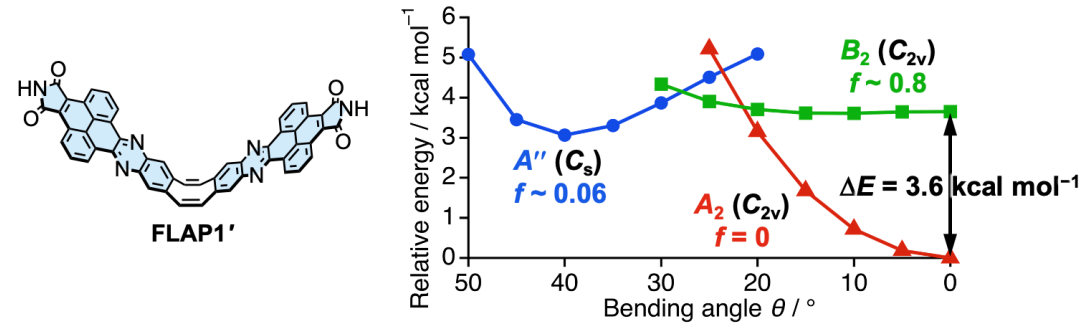

Figure S5.12. $S_{1}$ energy profiles of FLAP1' calculated at the TD-PBE0/6-31+G(d) level. See Figure S5.14e for details of the electronic configuration of each excited state. 
Table S5.3. Attempted DFT calculations of FLAP1' for selecting optimal calculation conditions

\begin{tabular}{|c|c|c|c|c|c|}
\hline Functional & $\begin{array}{c}\mathrm{HF} \\
\text { exchange }\end{array}$ & Basis set & $\begin{array}{l}\text { Additional } \\
\text { conditions }\end{array}$ & $\Delta E=E\left(B_{2}\right)-E\left(A_{2}\right)$ & $\lambda_{\mathrm{FL}}\left(\mathrm{S}_{0} \rightarrow \mathrm{S}_{1}\left(B_{2}\right)\right)$ \\
\hline \multirow[t]{6}{*}{ PBE0 } & $25 \%$ & $6-31+G(d)$ & - & $3.6 \mathrm{kcal} / \mathrm{mol}$ & $534 \mathrm{~nm}$ \\
\hline & & $6-31+G(d)$ & D3BJ & $3.6 \mathrm{kcal} / \mathrm{mol}$ & $535 \mathrm{~nm}$ \\
\hline & & $6-31+G(d)$ & PCM(toluene) & $2.5 \mathrm{kcal} / \mathrm{mol}$ & $547 \mathrm{~nm}$ \\
\hline & & def2-SVP & - & $4.1 \mathrm{kcal} / \mathrm{mol}$ & $528 \mathrm{~nm}$ \\
\hline & & D95+(d) & - & $3.6 \mathrm{kcal} / \mathrm{mol}$ & $536 \mathrm{~nm}$ \\
\hline & & Others $^{[\mathrm{a}]}$ & - & \multicolumn{2}{|c|}{ SCF convergence failure } \\
\hline M06 & $27 \%$ & $6-31+G(d)$ & - & $4.2 \mathrm{kcal} / \mathrm{mol}$ & $539 \mathrm{~nm}$ \\
\hline HSE06 & $25 \%$ & $6-31+G(d)$ & - & $2.4 \mathrm{kcal} / \mathrm{mol}$ & $560 \mathrm{~nm}$ \\
\hline X3LYP & $21 \%$ & $6-31+G(d)$ & - & $3.1 \mathrm{kcal} / \mathrm{mol}$ & $555 \mathrm{~nm}$ \\
\hline \multirow[t]{2}{*}{ B3LYP } & $20 \%$ & $6-31+G(d)$ & - & $2.8 \mathrm{kcal} / \mathrm{mol}$ & $565 \mathrm{~nm}$ \\
\hline & & $6-31+G(d)$ & PCM(toluene) & $1.7 \mathrm{kcal} / \mathrm{mol}$ & $579 \mathrm{~nm}$ \\
\hline tHCTHhyb & $15 \%$ & $6-31+G(d)$ & - & $1.8 \mathrm{kcal} / \mathrm{mol}$ & $595 \mathrm{~nm}$ \\
\hline O3LYP & $11.61 \%$ & $6-31+G(d)$ & - & $1.2 \mathrm{kcal} / \mathrm{mol}$ & $610 \mathrm{~nm}$ \\
\hline TPSSh & $10 \%$ & $6-31+G(d)$ & - & $0.7 \mathrm{kcal} / \mathrm{mol}$ & $610 \mathrm{~nm}$ \\
\hline CAM-B3LYP & $19-65 \%$ & $6-31+G(d)$ & - & $9.0 \mathrm{kcal} / \mathrm{mol}$ & $434 \mathrm{~nm}$ \\
\hline Others $^{[\mathrm{b}]}$ & & $6-31+G(d)$ & - & \multicolumn{2}{|c|}{$B_{2}$ state was not found. } \\
\hline
\end{tabular}

[a] def2-SVPD, aug-cc-pVDZ, jul-cc-pVDZ, jun-cc-pVDZ. [b] TPSS, M06-L, M06-2X, BMK, BHandHLYP, $\omega B 97 X-D$, LC- $\omega$ HPBE

(a)

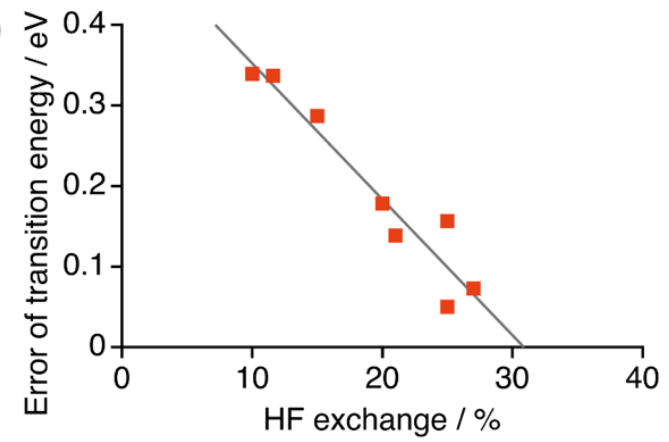

(b)

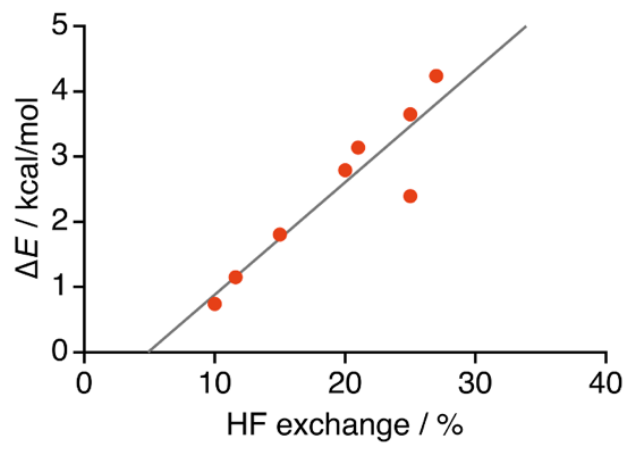

Figure S5.13. Calculation results of FLAP1' in the planar form $\left(\theta=0^{\circ}\right)$ in relation to the fraction of HF exchange in the functionals: (a) the error of the estimated transition energy of the bright $B_{2}$ state from the observed fluorescence (523 nm) of FLAP1-H in the planar form in toluene, (b) the energy difference between the $A_{2}$ and $B_{2}$ states $\Delta E=E\left(B_{2}\right)-E\left(A_{2}\right)$. 
(a) TD-B3LYP/6-31+G(d)/PCM(toluene)

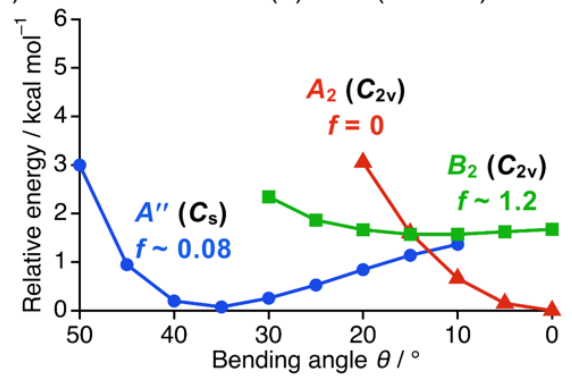

(c) TD-TPSSh/6-31+G(d)

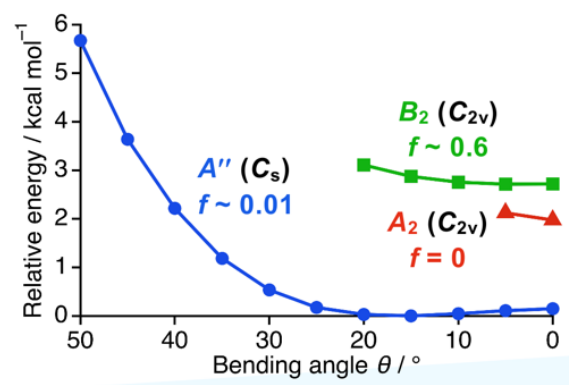

(e)

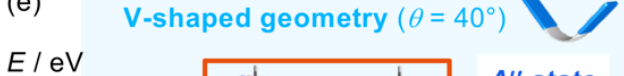

(b) TD-CAM-B3LYP/6-31+G(d)

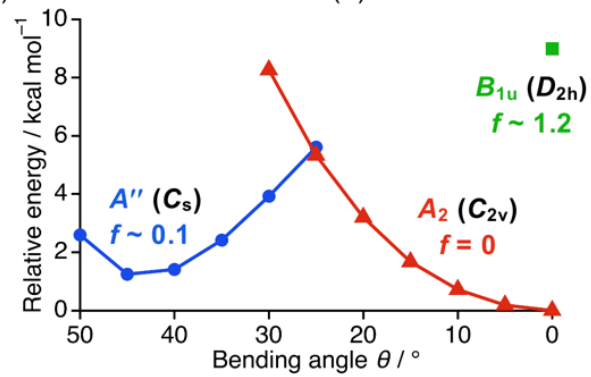

(d) TD-PBE0/6-31+G(d)/PCM(toluene)

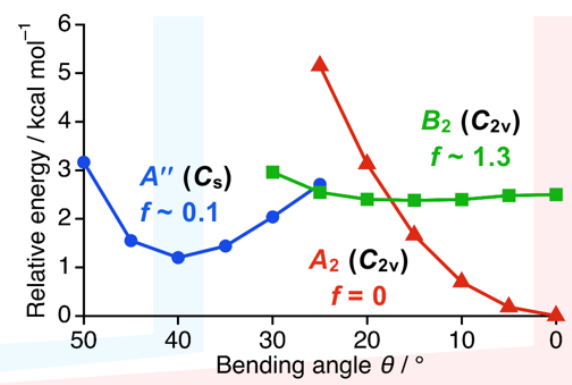

Planar geometry $\left(\theta=0^{\circ}, D_{2 h}\right)$

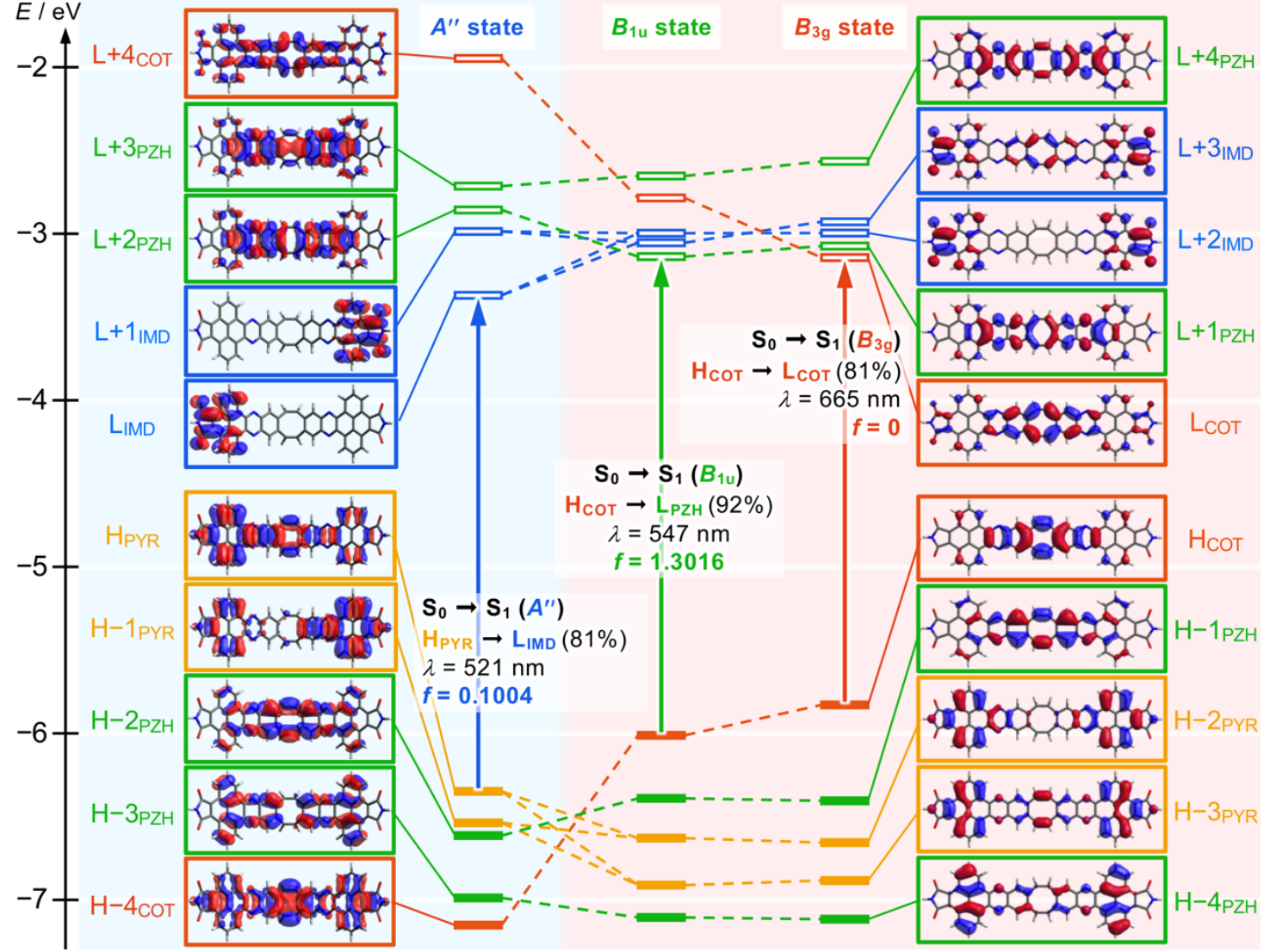

Figure S5.14. (a-d) $S_{1}$ energy profiles of FLAP1' using different functionals. (e) Kohn-Sham orbitals and their energy levels of the V-shaped and planar form of FLAP1' (TD-PBE0/6-31+G(d)/PCM(toluene)). The $B_{1 \mathrm{u}}$ and $B_{3 \mathrm{~g}}$ states in $D_{2 \mathrm{~h}}$ symmetry correspond to the $B_{2}$ and $A_{2}$ states in $C_{2 \mathrm{v}}$ symmetry, and the orbital shapes of the $B_{1 \mathrm{u}}$ state are almost the same as that of the $B_{3 \mathrm{~g}}$ state. 


\section{Synthesis and properties of the segmented polyurethanes (SPUs)}

\subsection{Synthesis and preparation of the SPU films}

(a)
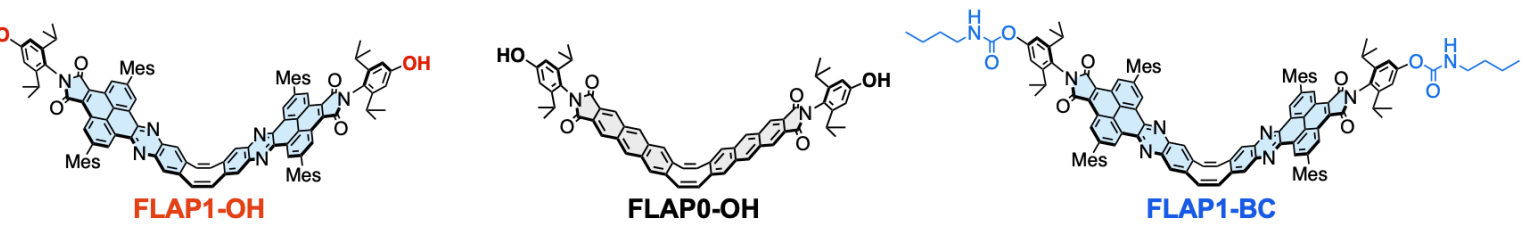

(b)

Hot of $_{\mathrm{n}}$

PTHF (1.0 eq.)

$\left(M_{\mathrm{n}} \approx 1000\right)$

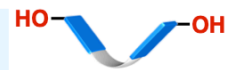

FLAP1-BC
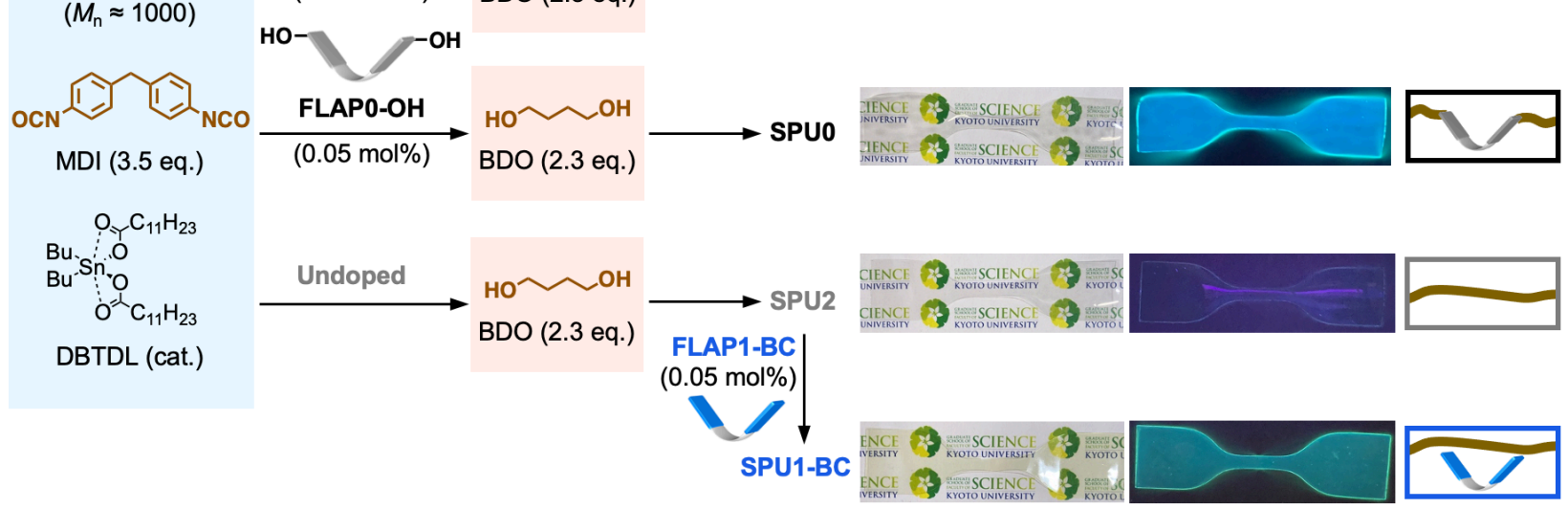

(c)

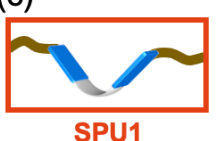

$\equiv$
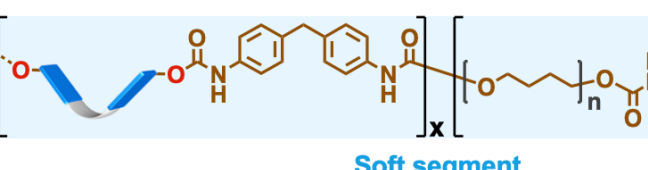

Soft segment
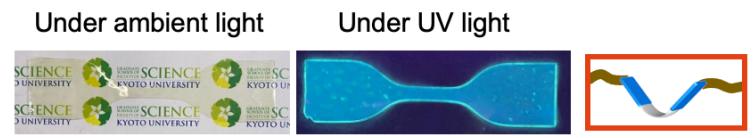

Figure S6.1. (a) Chemical structures of the FLAP dopants. (b) Synthesis of SPUs and photographs of the SPU films for stretching. (c) Chemical structure of the representative SPU (SPU1).

Synthesis of the segmented polyurethanes (SPUs) was performed according to the reported procedure. ${ }^{[\mathrm{S} 15]}$ Poly(tetrahydrofuran) (PTHF, $M_{\mathrm{n}} \approx 1000,3.00 \mathrm{~g}, 3.00 \mathrm{mmol}$ ) was placed in a two-neck flask, which was dried under vacuum at $100{ }^{\circ} \mathrm{C}$ for $2 \mathrm{~h}$. After cooling to room temperature, anhydrous THF $(60 \mathrm{~mL})$, the FLAP dopants (FLAP0-OH or FLAP1-OH, $1.5 \mu \mathrm{mol}$ ), methylenediphenyl 4,4'-diisocyanate (MDI, 10.5 mmol, $2.63 \mathrm{~g}$ ), and dibutyltin dilaurate (DBTDL, 6 drops) were added. The reaction mixture was stirred at room temperature for $3 \mathrm{~h}$, and then a solution of 1,4-butanediol (BDO, $7.0 \mathrm{mmol}, 0.63 \mathrm{~mL}$ ) in anhydrous THF $(20 \mathrm{~mL})$ was added. After stirring $48 \mathrm{~h}$ at room temperature, the reaction was quenched by adding methanol (4 $\mathrm{mL})$, and the mixture was further stirred for $30 \mathrm{~min}$. The mixture was poured into ethanol $(500 \mathrm{~mL})$ to precipitate the polymer, which was collected by filtration. The obtained precipitates were dissolved into THF $(300 \mathrm{~mL})$ and filtrated. The filtrate was concentrated by evaporating half of the solvent and poured into hexane $(400 \mathrm{~mL})$ to reprecipitate the polymer. The precipitates were dried under vacuum to afford SPUs (SPU0 or SPU1) as a very pale yellow solid. SPU2 was synthesized without adding FLAP dopants. 


\section{Preparation of the films}

The synthesized SPUs $(5.0 \mathrm{~g})$ was dissolved into anhydrous THF $(50 \mathrm{~mL})$ and casted into a stainless steel tray. SPU1-BC was prepared by adding FLAP1-BC (0.05 mol\%) to the solution of SPU2 before casting. After evaporation of THF under ambient conditions, the film was further dried under vacuum. Transparent specimens for the tensile tests were made by punching the SPU sheets with a dumbbell-shaped die cutter.

\section{Average distance between the FLAP molecules in SPUs}

The concentration of FLAP in SPUs calculated from the feed ratio is $0.24 \mu \mathrm{mol} / \mathrm{g}$, which is equal to $0.22 \mu \mathrm{mol} / \mathrm{cm}^{3}$ (density of SPUs: $1.1 \mathrm{~g} / \mathrm{cm}^{3}$ ). By converting this molar concentration to number density and then taking the reciprocal, the average volume occupied by a single FLAP molecule was calculated to be $7.5 \times$

$10^{-24} \mathrm{~m}^{3}$. Therefore, by taking the cube root, the average distance between the FLAP molecules was determined to be $20 \mathrm{~nm}$. 

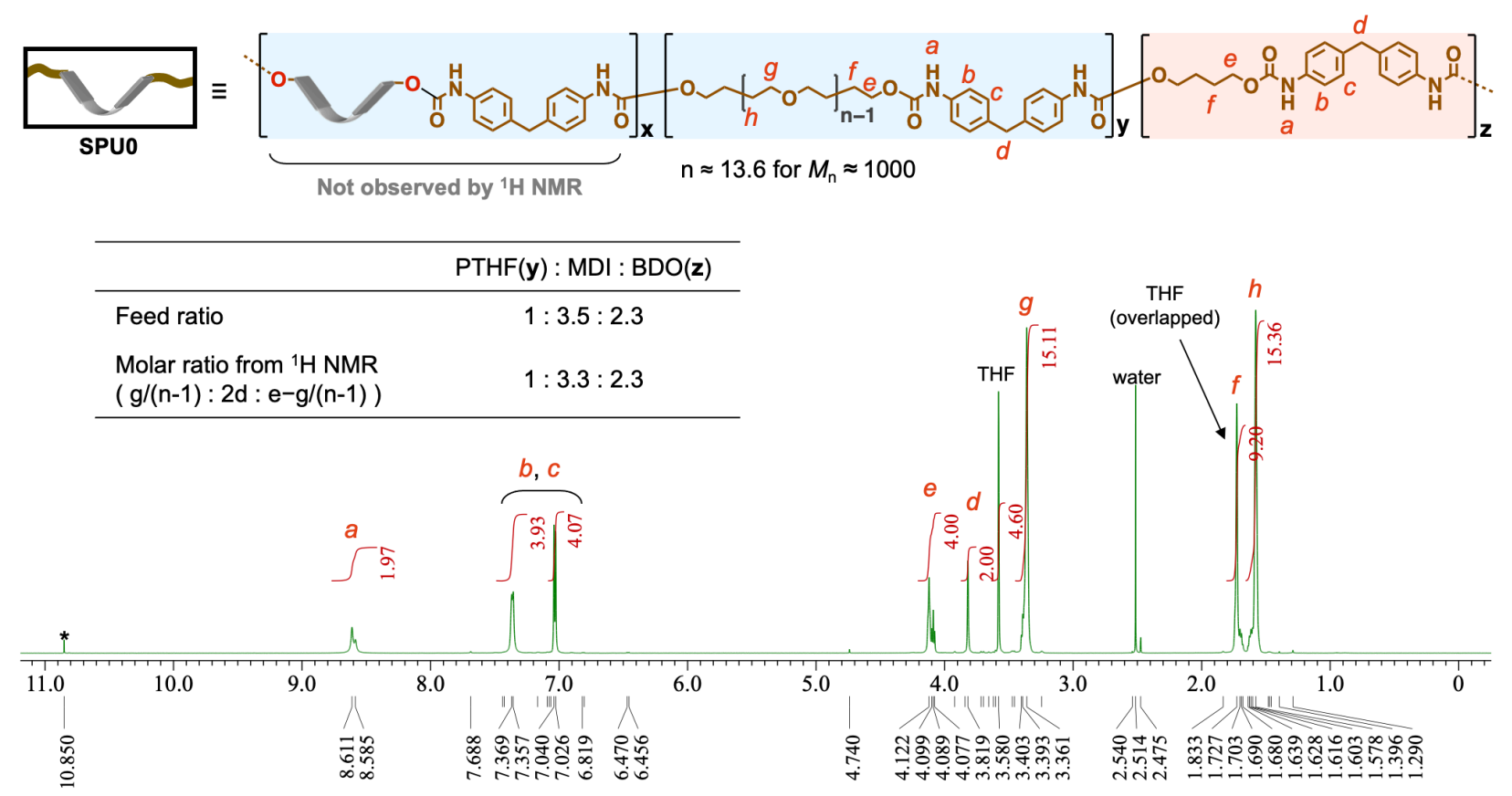

Figure S6.2. ${ }^{1} \mathrm{H}$ NMR spectrum of SPU0 in THF- $d_{8}$ at room temperature. Peaks marked with asterisks indicate impurities.

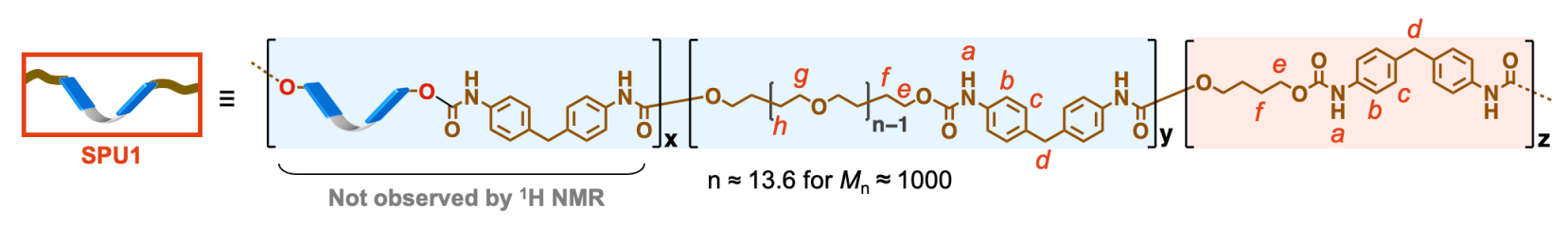

\begin{tabular}{lc}
\hline & $\operatorname{PTHF}(\mathbf{y}):$ MDI : BDO(z) \\
\hline Feed ratio & $1: 3.5: 2.3$ \\
Molar ratio from ${ }^{1} \mathrm{H}$ NMR & $1: 3.3: 2.3$ \\
$\left(\mathrm{~g} /(\mathrm{n}-1): 2 \mathrm{~d}: \mathrm{e}^{-\mathrm{g} /(\mathrm{n}-1))}\right.$ & \\
\hline
\end{tabular}

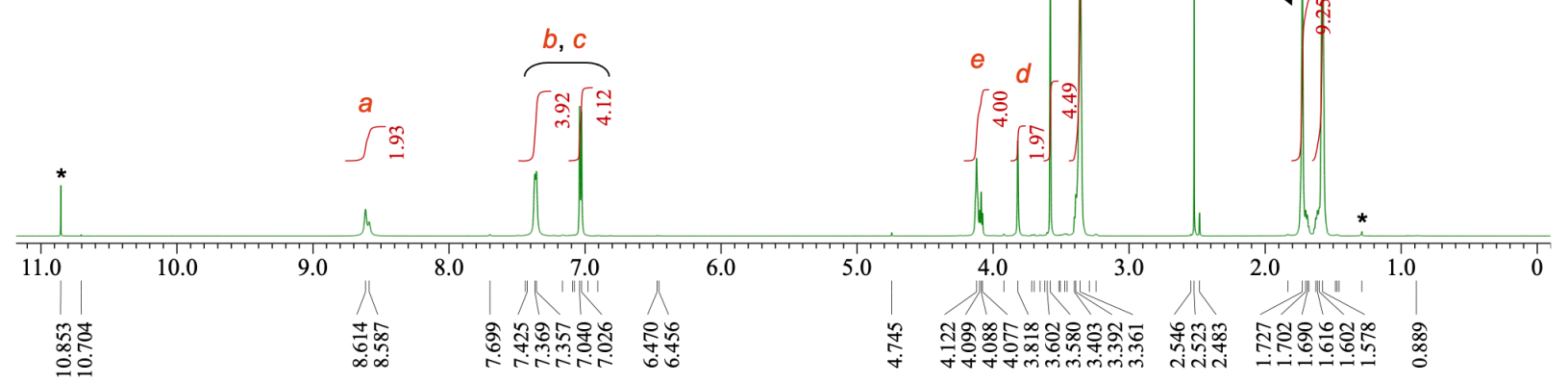

Figure S6.3. ${ }^{1} \mathrm{H}$ NMR spectrum of SPU1 in THF- $d_{8}$ at room temperature. Peaks marked with asterisks indicate impurities. 


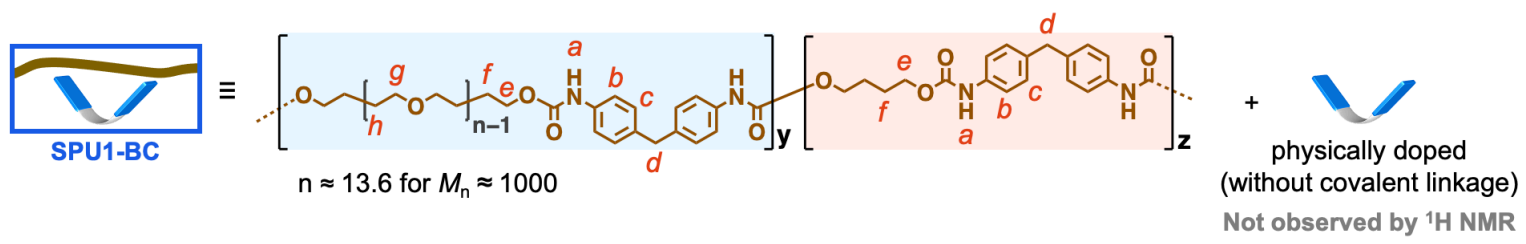

\begin{tabular}{lc}
\hline & $\operatorname{PTHF}(\mathbf{y}):$ MDI $:$ BDO $(\mathbf{z})$ \\
\hline Feed ratio & $1: 3.5: 2.3$ \\
$\begin{array}{l}\text { Molar ratio from }{ }^{1} H \text { NMR } \\
(g /(n-1): 2 d: e-g /(n-1))\end{array}$ & $1: 3.3: 2.3$ \\
\hline
\end{tabular}

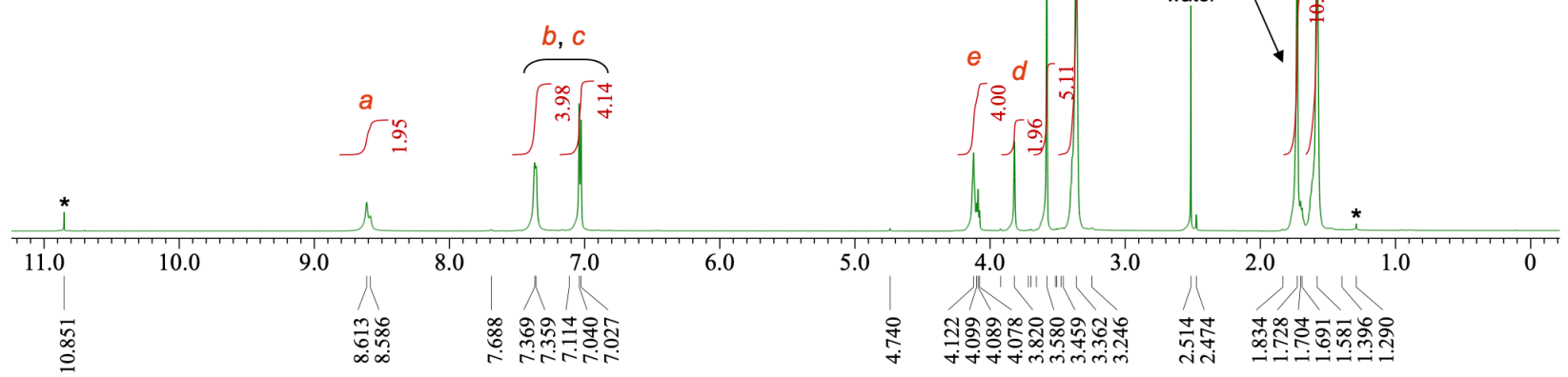

Figure S6.4. ${ }^{1} \mathrm{H}$ NMR spectrum of SPU1-BC in THF- $d_{8}$ at room temperature. Peaks marked with asterisks indicate impurities.
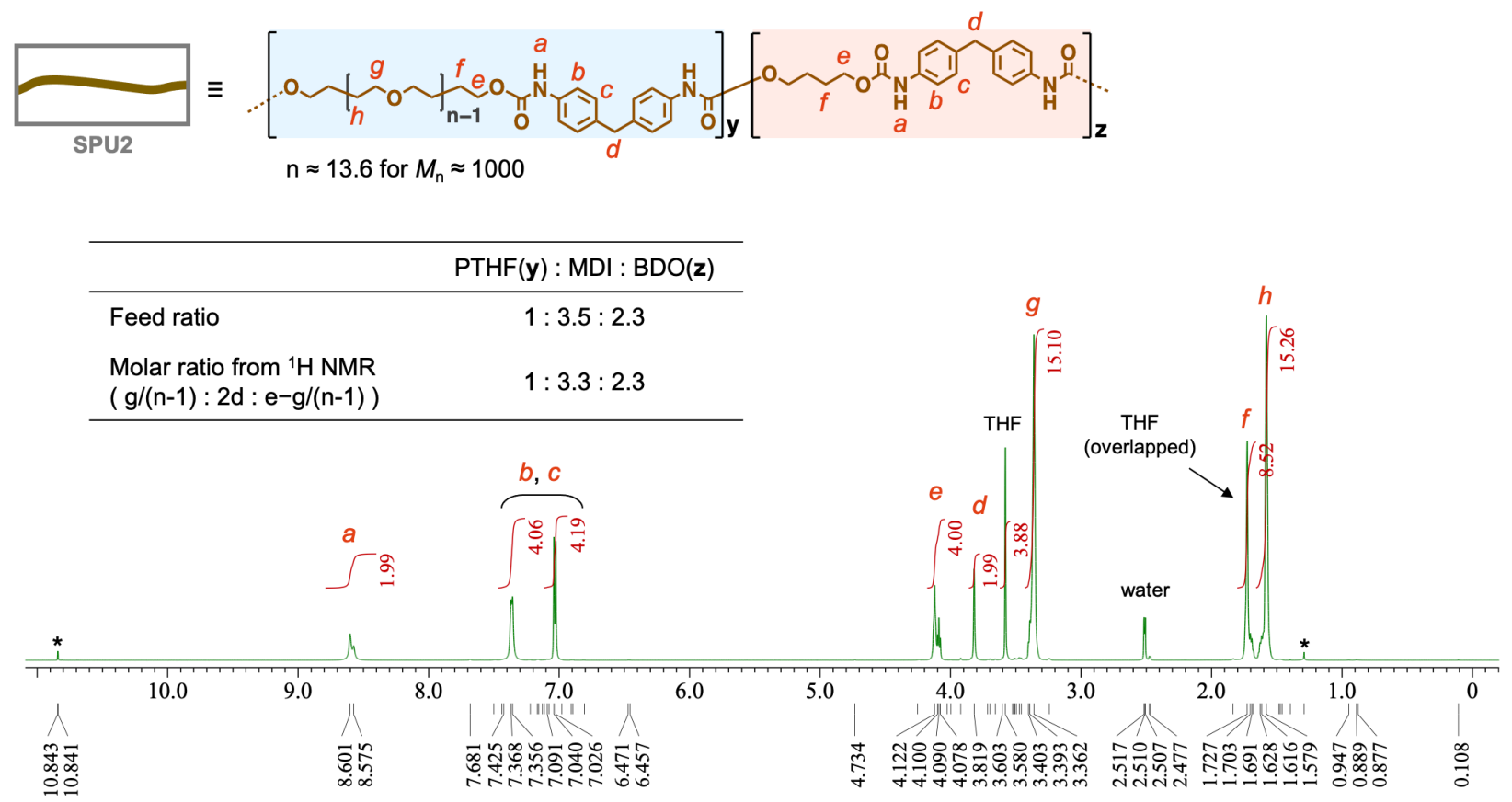

Figure S6.5. ${ }^{1} \mathrm{H}$ NMR spectrum of SPU2 in THF- $d_{8}$ at room temperature. Peaks marked with asterisks indicate impurities. 


\subsection{Differential scanning calorimetry (DSC) analysis of the SPUs}

DSC measurements of the SPU specimens were performed under $\mathrm{N}_{2}$ atmosphere at a flow rate of $30 \mathrm{~mL}$ $\mathrm{mm}^{-1}$. Programmed heating and cooling cycles are shown in Figure S6.6. DSC profiles are displayed in Figure S6.7 for the 2nd cooling $(\mathbf{E} \rightarrow \mathbf{F})$ and heating $(\mathbf{G} \rightarrow \mathbf{H})$ cycles. Each SPU sample was placed into an aluminum pan, covered with an aluminum cover, and then pressed with a designated tool. As a reference sample, a vacant pan was also pressed with the cover.

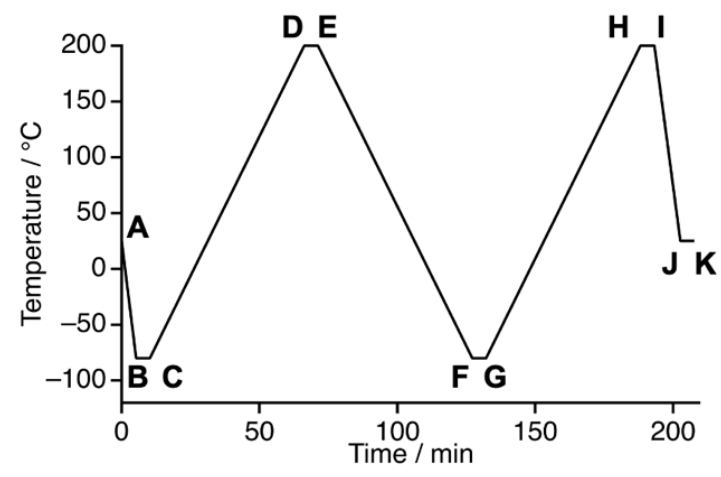

$$
\begin{aligned}
& \text { A } \rightarrow \text { B: } 25^{\circ} \mathrm{C} \text { to }-80^{\circ} \mathrm{C}\left(20^{\circ} \mathrm{C} \mathrm{min}-1\right) \\
& B \rightarrow C \text { : }-80^{\circ} \mathrm{C} \text { (Hold for } 5 \mathrm{~min} \text { ) } \\
& \text { C } \rightarrow \text { D: }-80^{\circ} \mathrm{C} \text { to } 200^{\circ} \mathrm{C}\left(5^{\circ} \mathrm{C} \mathrm{min}^{-1}\right) \\
& D \rightarrow E: 200^{\circ} \mathrm{C} \text { (Hold for } 5 \mathrm{~min} \text { ) } \\
& \mathrm{E} \rightarrow \mathrm{F}: 200^{\circ} \mathrm{C} \text { to }-80^{\circ} \mathrm{C}\left(5^{\circ} \mathrm{C} \mathrm{min}-1\right) \\
& \text { F } \rightarrow \mathbf{G} \text { : }-80^{\circ} \mathrm{C} \text { (Hold for } 5 \mathrm{~min} \text { ) } \\
& \mathbf{G} \rightarrow \mathbf{H}:-80^{\circ} \mathrm{C} \text { to } 200^{\circ} \mathrm{C}\left(5^{\circ} \mathrm{C} \mathrm{min}-1\right) \\
& \mathrm{H} \rightarrow \text { I: } 200^{\circ} \mathrm{C} \text { (Hold for } 5 \mathrm{~min} \text { ) } \\
& \text { I } \rightarrow \text { J: } 200^{\circ} \mathrm{C} \text { to } 25^{\circ} \mathrm{C}\left(20^{\circ} \mathrm{C} \mathrm{min}^{-1}\right) \\
& \mathrm{J} \rightarrow \mathrm{K}: 25^{\circ} \mathrm{C} \text { (Hold for } 5 \mathrm{~min} \text { ) }
\end{aligned}
$$

Figure S6.6. Programmed heating and cooling cycles in the DSC measurements of the SPUs.
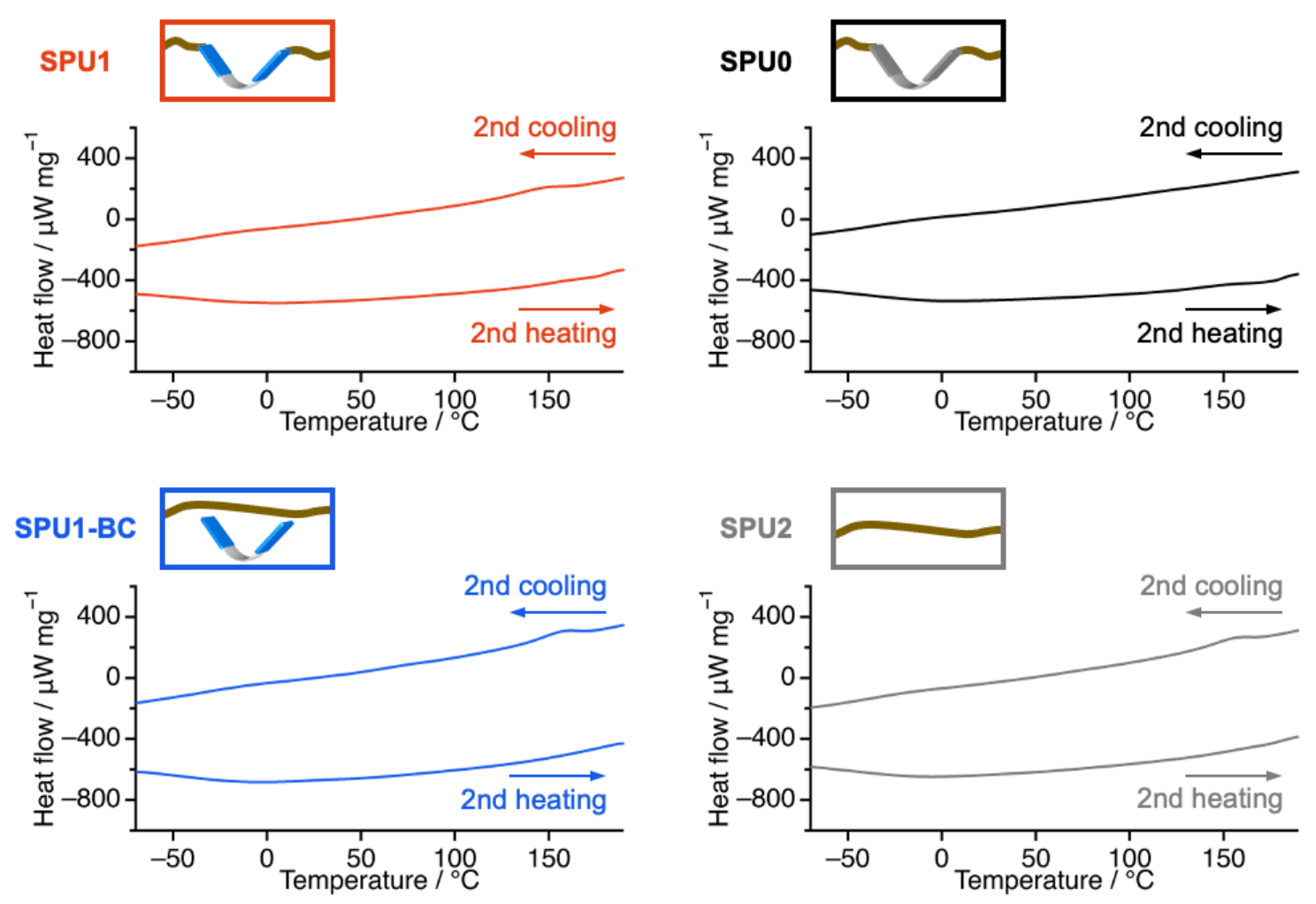

Figure S6.7. DSC profiles of the segmented polyurethanes (SPUs). 


\subsection{Mechanical and optical properties of the SPUs during stretching}
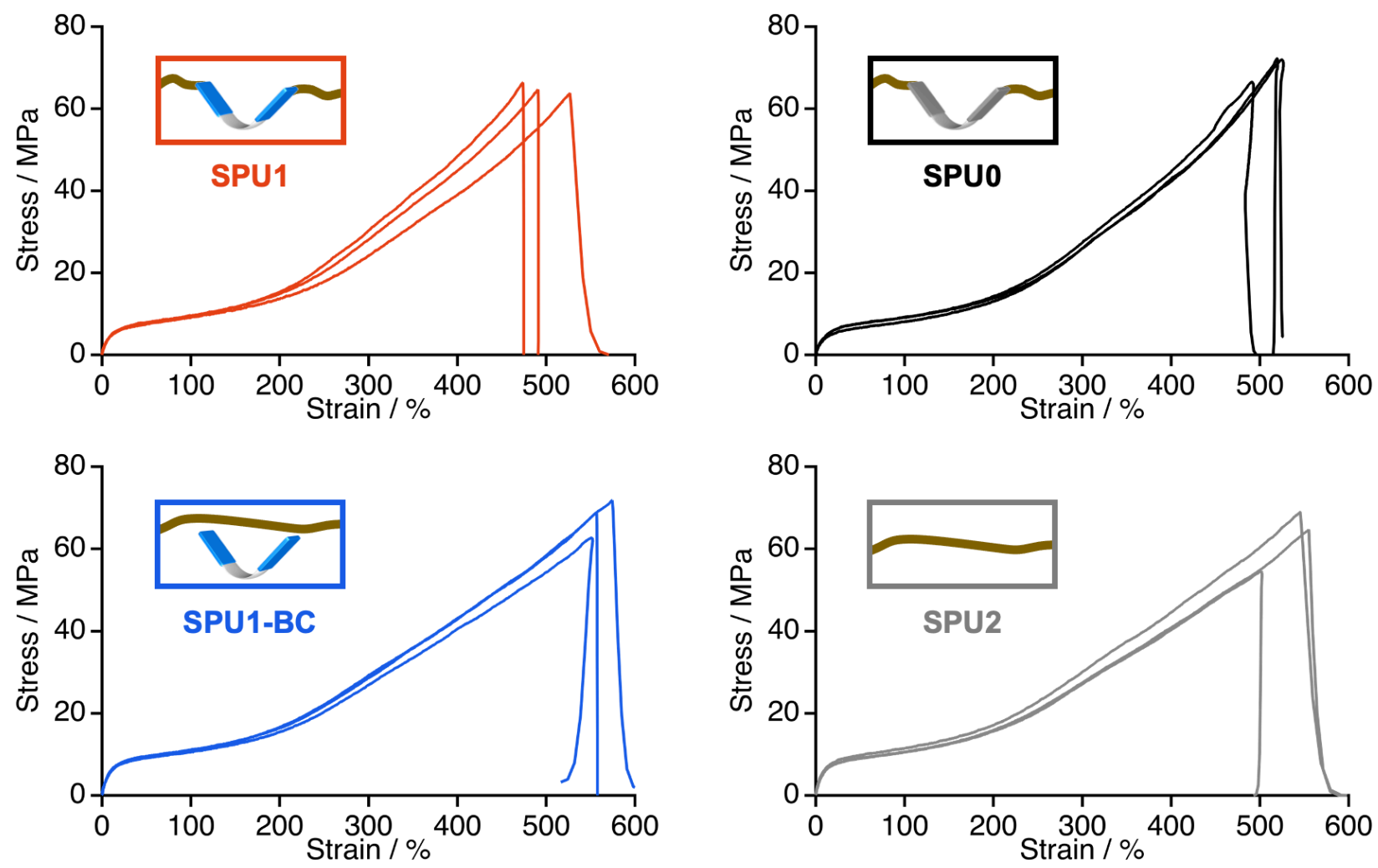

Figure S6.8. Stress-strain curves of the SPUs.

Table S6.1. Mechanical properties of the SPUs in the uniaxial tensile testing ${ }^{[a]}$

\begin{tabular}{ccccc}
\hline & Rupture strain $/ \%$ & Rupture stress / MPa & Toughness / $\mathrm{MJ} \mathrm{m}^{-3}$ & Young's modulus / MPa \\
\hline SPU1 & $512 \pm 18$ & $69 \pm 3$ & $134 \pm 8$ & $47 \pm 6$ \\
SPU1 & $497 \pm 27$ & $65 \pm 1$ & $126 \pm 5$ & $59 \pm 2$ \\
SPU1-BC & $561 \pm 12$ & $68 \pm 5$ & $166 \pm 13$ & $71 \pm 10$ \\
SPU2 & $534 \pm 28$ & $62 \pm 8$ & $149 \pm 22$ & $78 \pm 3$ \\
\hline
\end{tabular}

[a] Values of average \pm standard deviation of three specimens were shown. 

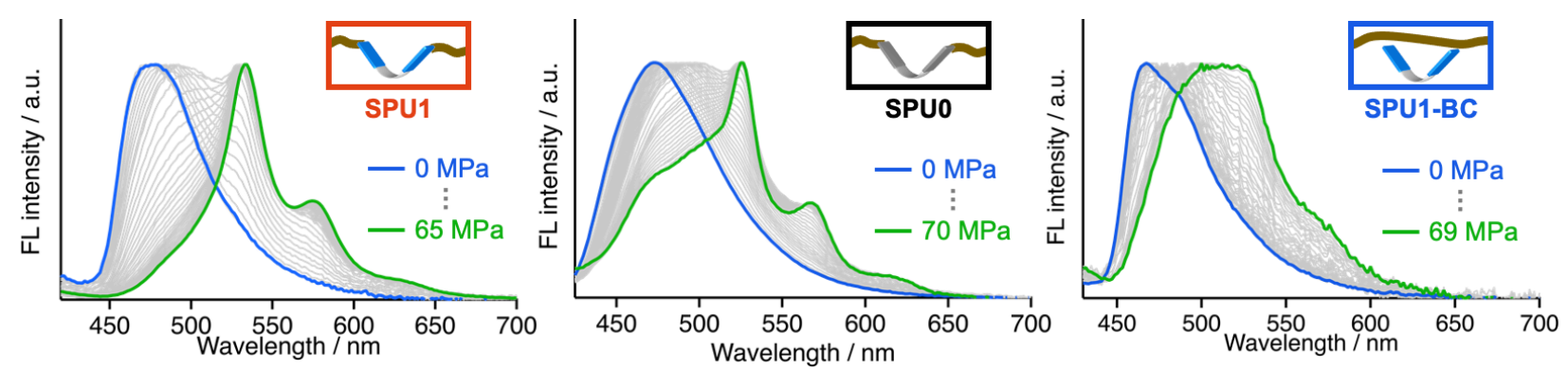

Figure S6.9. FL spectral change during the tensile tests of the SPUs. FL spectra are normalized at each maximum.

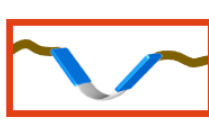

SPU1
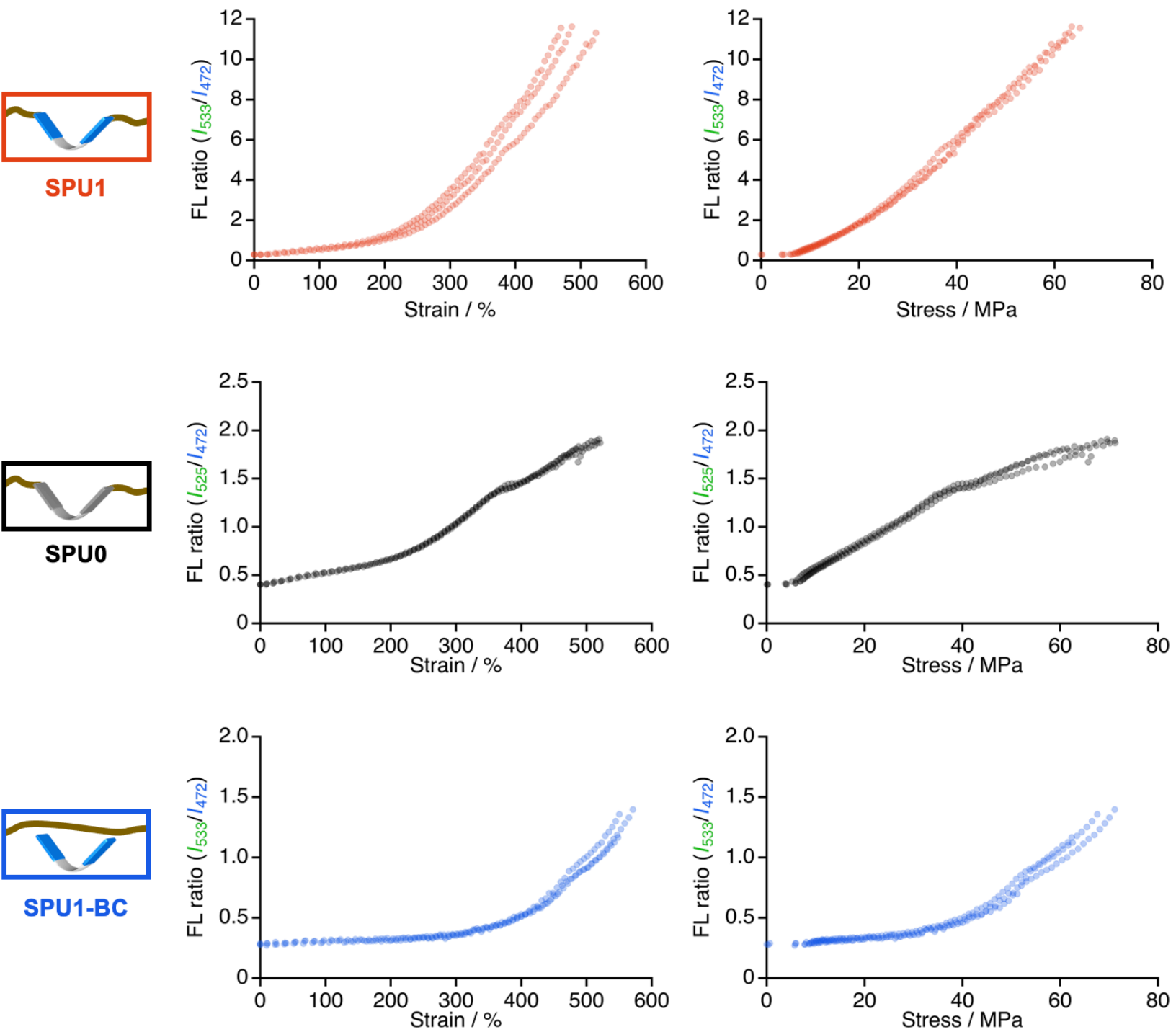

Figure S6.10. FL ratiometric analysis of the SPUs plotted against strain and stress in the tensile tests. The results of the three measurements are superimposed. 


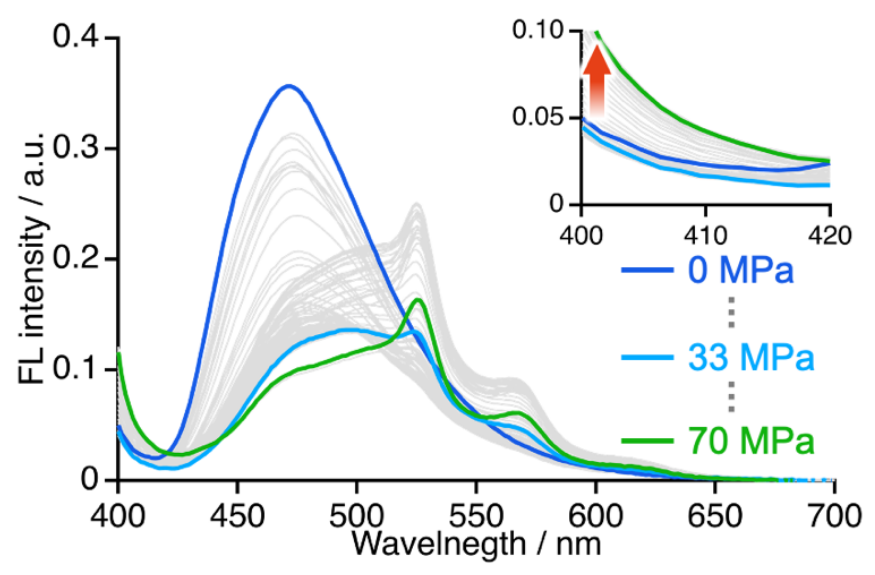

Figure S6.11. FL spectral change during the tensile tests of SPU0 before normalization. The red arrow indicates the increase of the scattered excitation light intensity during stretching.

(a)

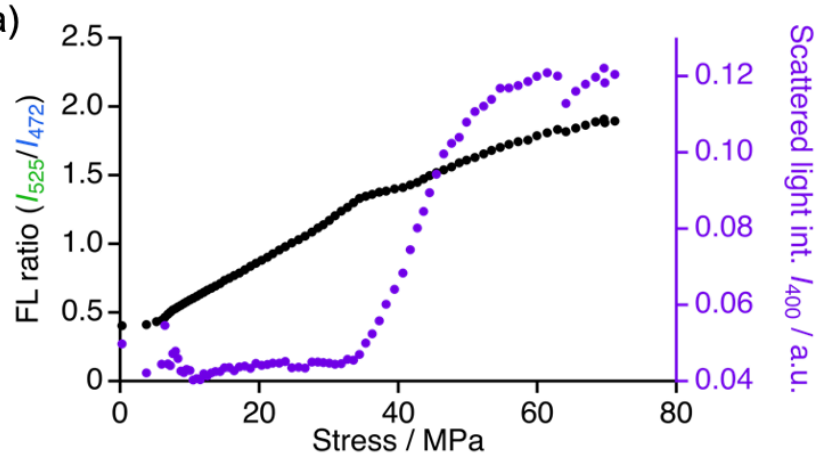

(b)

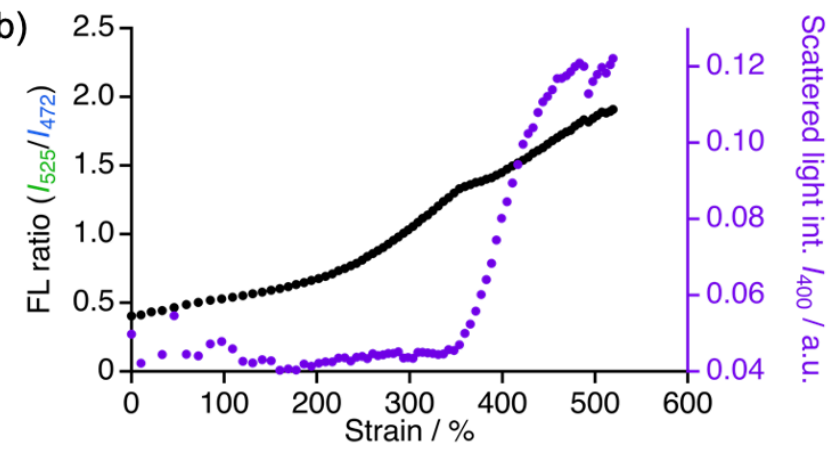

(c)

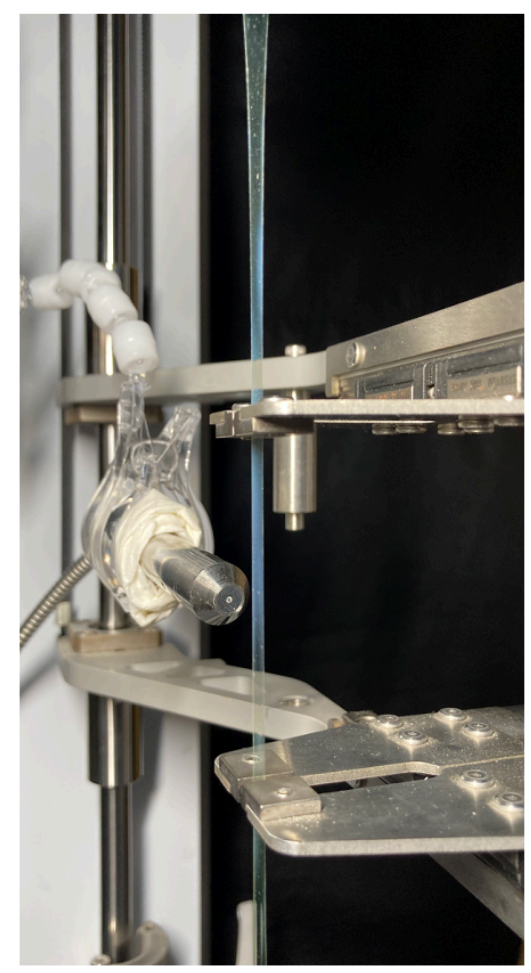

Figure S6.12. Scattered excitation light intensity plotted against (a) stress and (b) strain. (c) A photograph of SPUO with cloudy white center at 500\% strain under an ambient light. 


\section{Synthesis and properties of the crosslinked polyurethanes (PUs) before swelling}

\subsection{Synthesis and preparation of the crosslinked PU films}

(a)

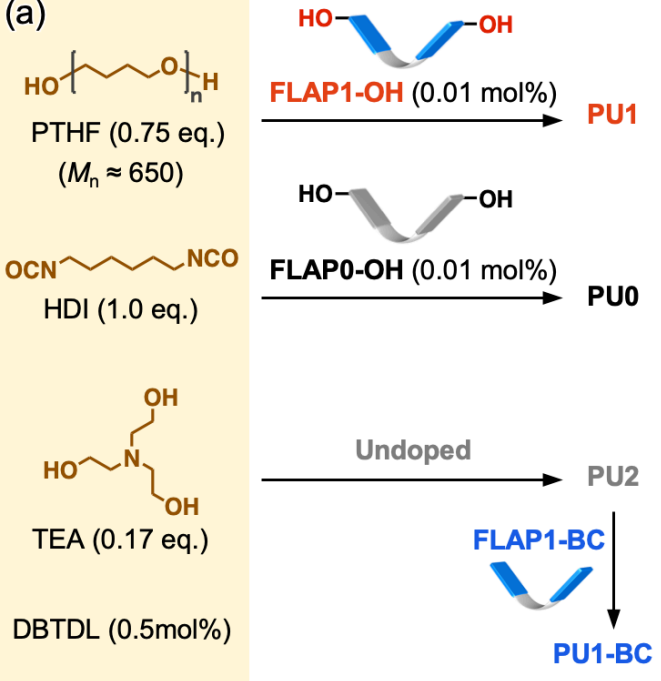

(b)
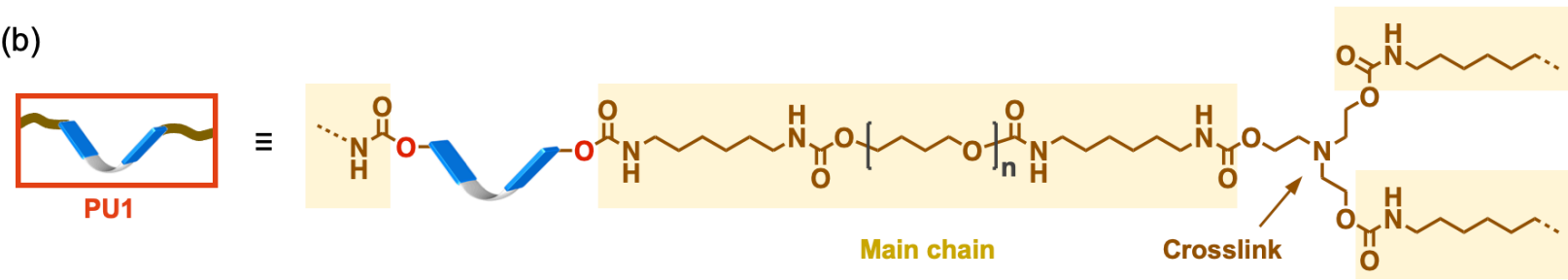

Figure S7.1. (a) Synthesis of PUs and photographs of the PU films for stretching. (b) Chemical structure of the representative PU (PU1).

Synthesis of the crosslinked polyurethanes (PUs) was performed according to the previous report. ${ }^{[\mathrm{S} 3]}$ Poly(tetrahydrofuran) (PTHF, $M_{\mathrm{n}} \approx 650,5.95 \mathrm{~g}, 9.15 \mathrm{mmol}$ ) was placed in a two-neck flask, which was dried under vacuum at $100{ }^{\circ} \mathrm{C}$ for $2 \mathrm{~h}$. After cooling to room temperature, anhydrous DMF (16 mL), the FLAP dopants (FLAP0-OH or FLAP1-OH, $1.5 \mu \mathrm{mol}$ ), hexamethylene diisocyanate (HDI, $1.96 \mathrm{~mL}, 12.2 \mathrm{mmol}$ ), and triethanolamine (TEA, $0.27 \mathrm{~mL}, 2.0 \mathrm{mmol}$ ) were added. The mixture was stirred at $27{ }^{\circ} \mathrm{C}$ for $10 \mathrm{~min}$, and then a $0.2 \mathrm{M}$ solution of dibutyltin dilaurate in anhydrous THF $(0.35 \mathrm{~mL}, 0.07 \mathrm{mmol})$ was added. After stirring at $27{ }^{\circ} \mathrm{C}$ for $2 \mathrm{~min}$, the reaction mixture was poured into a custom-made mold of poly(tetrafluoroethylene) (PTFE) and polymerized under $\mathrm{N}_{2}$ atmosphere at room temperature for $48 \mathrm{~h}$. Next, the PU specimens were soaked in acetone for 4 hours and then in fresh acetone for 12 hours to remove DMF. The acetone-containing specimens were dried under vacuum for $8 \mathrm{~h}$ at $50^{\circ} \mathrm{C}$ to obtain transparent PU specimens (PU0 and PU1). PU2 was synthesized without adding FLAP dopants. 


\section{Average distance between the FLAP molecules in PUO and PU1}

The concentration of FLAP in PUs calculated from the feed ratio is $0.15 \mu \mathrm{mol} / \mathrm{g}$, which is equal to 0.15 $\mu \mathrm{mol} / \mathrm{cm}^{3}$ (density of PUs: $1.0 \mathrm{~g} / \mathrm{cm}^{3}$ ). By converting this molar concentration to number density and taking the reciprocal, the average volume occupied by a single FLAP molecule was calculated to be $1.1 \times 10^{-23} \mathrm{~m}^{3}$. Thus, by taking the cube root, the average distance between the FLAP molecules was determined to be $23 \mathrm{~nm}$.

\section{Preparation of PU1-BC}

PU1-BC was prepared by soaking the swollen specimens into a solution of FLAP1-BC in acetone after removing DMF. Namely, FLAP1-BC $(2.9 \mathrm{mg}, 1.3 \mu \mathrm{mol})$ was dissolved into acetone $(50 \mathrm{~mL})$, and then acetone-swollen PU2 specimens (6 pieces, $V_{\text {total }} \sim 17 \mathrm{~cm}^{3}$ ) were soaked into the solution. After $48 \mathrm{~h}$, the surface of specimens was washed with acetone and dried under vacuum for $8 \mathrm{~h}$ at $50^{\circ} \mathrm{C}$ to obtain PU1-BC samples. The concentration of PU1-BC was estimated as follows: assuming that FLAP1-BC is dispersed throughout the system, the concentration in the swollen specimen is $1.9 \times 10^{-5} \mathrm{M}$. Because the swelling ratio of PU in acetone is 3.7 (see Section 8 in SI), the concentration of FLAP1-BC in the dry specimen is estimated to be $7 \times 10^{-5} \mathrm{M}$. Since the concentration of FLAP in PU0 and PU1 is $1.5 \times 10^{-4} \mathrm{M}$ (see above), the concentration of FLAP is slightly lower in PU1-BC, but it does not affect the discussion of the FL measurements.

\section{Preparation of PUs with a fluorescent internal standard (rhodamine)}

Rhodamine 640 perchlorate was employed as a fluorescent internal standard. Rhodamine 640 perchlorate $(0.74 \mathrm{mg}, 1.3 \mu \mathrm{mol})$ was dissolved into acetone $(250 \mathrm{~mL})$, then acetone-swollen PU specimens (PU0, PU1, and PU2) were soaked into the solution. After $48 \mathrm{~h}$, the specimens were dried under vacuum for 8 $\mathrm{h}$ at $50^{\circ} \mathrm{C}$ to obtain rhodamine-doped PU specimens (PU0-Rho, PU1-Rho, and PU2-Rho). The concentration of rhodamine was similarly estimated to be $5 \times 10^{-6} \mathrm{M}$, which is lower than that of the FLAP dopants.

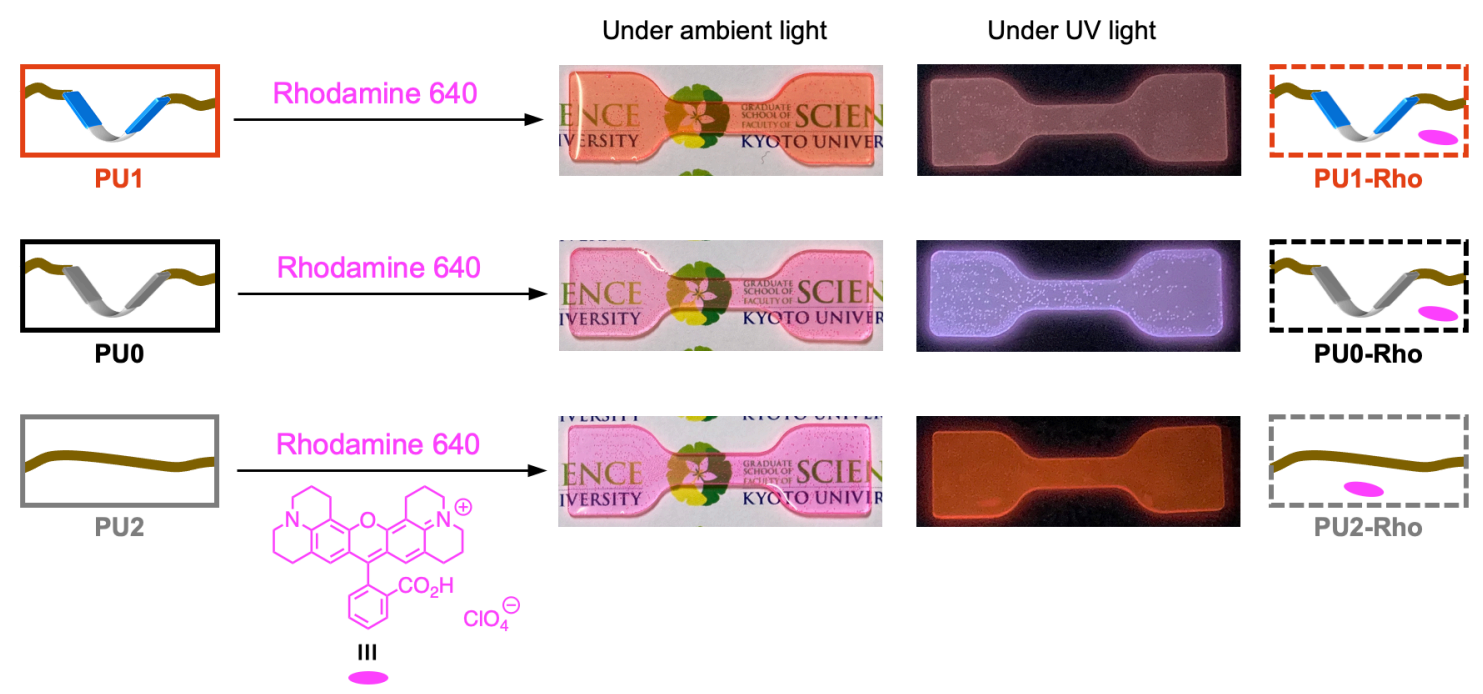

Figure S7.2. Preparation of PUs with the fluorescent internal standard. 


\subsection{Differential scanning calorimetry (DSC) analysis of the crosslinked PUs}

DSC measurements of the PU specimens were performed under $\mathrm{N}_{2}$ atmosphere at a flow rate of $30 \mathrm{~mL}$ $\mathrm{mm}^{-1}$. Programmed heating and cooling cycles are shown in Figure S7.3. DSC profiles are displayed in Figure S7.4 for the 2nd cooling $(\mathbf{E} \rightarrow \mathbf{F})$ and heating $(\mathbf{G} \rightarrow \mathbf{H})$ cycles. Each PU sample was placed into an aluminum pan, covered with an aluminum cover, and then pressed with a designated tool. As a reference sample, a vacant pan was also pressed with the cover.

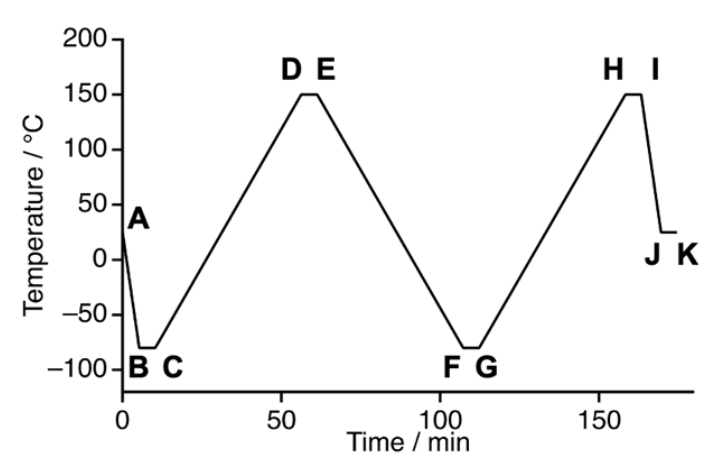

$$
\begin{aligned}
& \text { A } \rightarrow B: 25^{\circ} \mathrm{C} \text { to }-80^{\circ} \mathrm{C}\left(20^{\circ} \mathrm{C} \mathrm{min}-1\right) \\
& B \rightarrow C \text { : }-80^{\circ} \mathrm{C} \text { (Hold for } 5 \mathrm{~min} \text { ) } \\
& \text { C } \rightarrow \text { D: }-80^{\circ} \mathrm{C} \text { to } 150^{\circ} \mathrm{C}\left(5^{\circ} \mathrm{C} \mathrm{min}^{-1}\right) \\
& D \rightarrow E: 150{ }^{\circ} \mathrm{C} \text { (Hold for } 5 \mathrm{~min} \text { ) } \\
& \mathrm{E} \rightarrow \mathrm{F}: 150^{\circ} \mathrm{C} \text { to }-80^{\circ} \mathrm{C}\left(5^{\circ} \mathrm{C} \mathrm{min}^{-1}\right) \\
& \text { F } \rightarrow \mathbf{G}:-80^{\circ} \mathrm{C} \text { (Hold for } 5 \mathrm{~min} \text { ) } \\
& \mathbf{G} \rightarrow \mathbf{H}:-80^{\circ} \mathrm{C} \text { to } 150^{\circ} \mathrm{C}\left(5^{\circ} \mathrm{C} \mathrm{min}-1\right) \\
& \mathrm{H} \rightarrow \mathrm{I}: 150^{\circ} \mathrm{C} \text { (Hold for } 5 \mathrm{~min} \text { ) } \\
& \text { I } \rightarrow \text { J: } 150^{\circ} \mathrm{C} \text { to } 25^{\circ} \mathrm{C}\left(20^{\circ} \mathrm{C} \mathrm{min}-1\right) \\
& \mathrm{J} \rightarrow \mathrm{K}: 25^{\circ} \mathrm{C} \text { (Hold for } 5 \mathrm{~min} \text { ) }
\end{aligned}
$$

Figure S7.3. Programmed heating and cooling cycles in the DSC measurements of the PUs.

Table S7.1. DSC parameters of the PU films.

\begin{tabular}{cccccc}
\hline & $T_{\mathrm{g}}{ }^{[\mathrm{a}]} /{ }^{\circ} \mathrm{C}$ & $T_{\mathrm{r} \rightarrow \mathrm{c}}{ }^{[\mathrm{b}]} /{ }^{\circ} \mathrm{C}$ & $\Delta H_{\mathrm{r} \rightarrow \mathrm{c}}[\mathrm{c}] / \mathrm{J} \mathrm{g}^{-1}$ & $T_{\mathrm{c} \rightarrow \mathrm{r}}[\mathrm{d}] /{ }^{\circ} \mathrm{C}$ & $\Delta H_{\mathrm{c} \rightarrow \mathrm{r}}[\mathrm{e}] / \mathrm{J} \mathrm{g}^{-1}$ \\
\hline PU0 & -58 & -10 & -21 & 31 & 22 \\
PU1 & -57 & 1 & -22 & 33 & 21 \\
PU1-BC & -58 & -3 & -23 & 34 & 20 \\
PU2 & -58 & -8 & -23 & 31 & 20 \\
PU0-Rho & -57 & -8 & -25 & 34 & 24 \\
PU1-Rho & -57 & -7 & -20 & 32 & 22 \\
PU2-Rho & -57 & -4 & -26 & 34 & 23 \\
\hline
\end{tabular}

[a] Glass transition temperature determined by the 2nd heating profile.

[b] Rubbery-to-semicrystalline transition temperature determined by the 2 nd cooling profile.

[c] Enthalpy change in the rubbery-to-semicrystalline transition determined by the DSC signal area.

[d] Semicrystalline-to-rubbery transition temperature determined by the 2 nd heating profile.

[e] Enthalpy change in the semicrystalline-to-rubbery transition determined by the DSC signal area. 

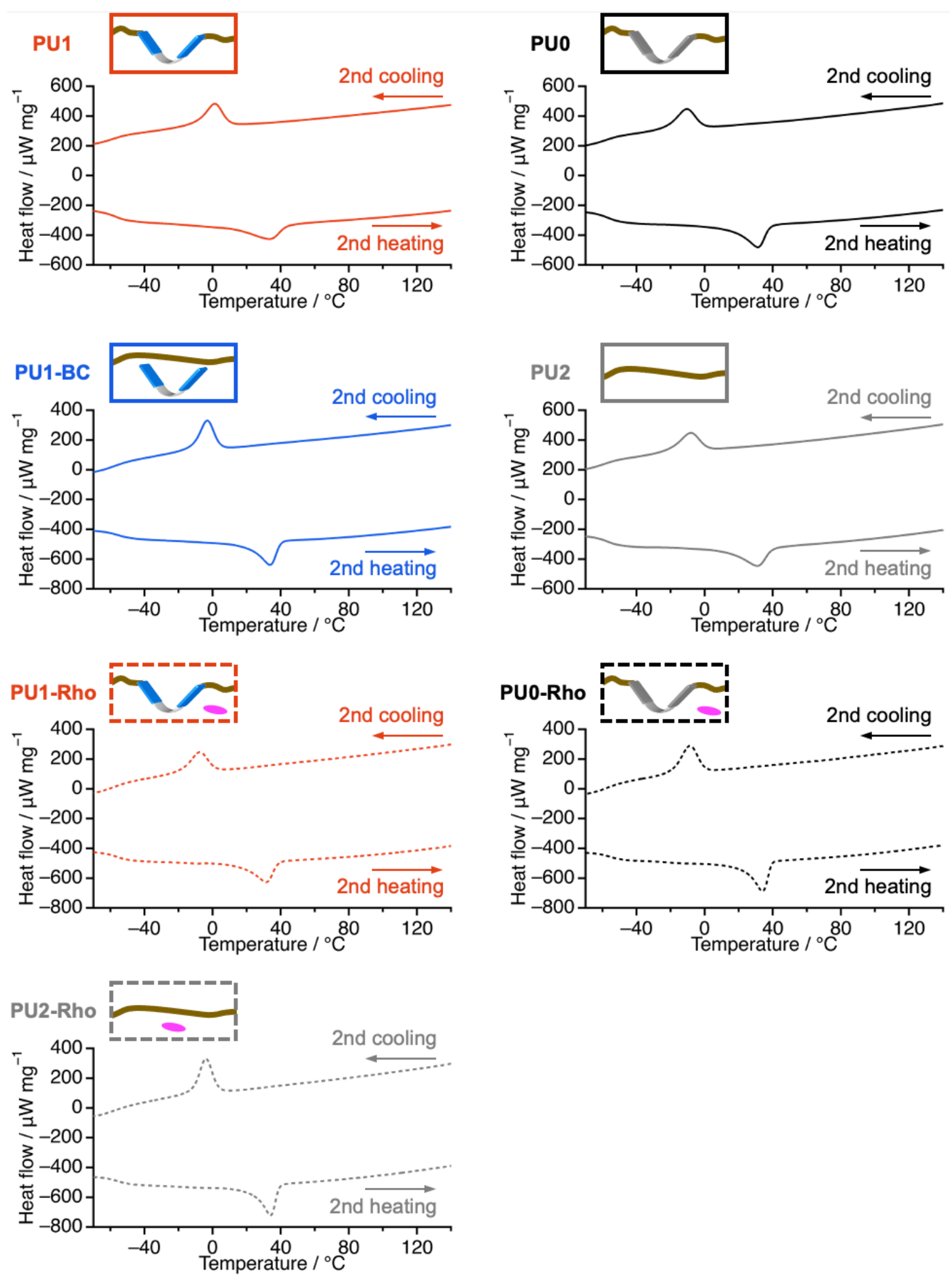

Figure S7.4. DSC profiles of the crosslinked polyurethanes (PUs). 
7.3. Mechanical and optical properties of the PUs during stretching before swelling
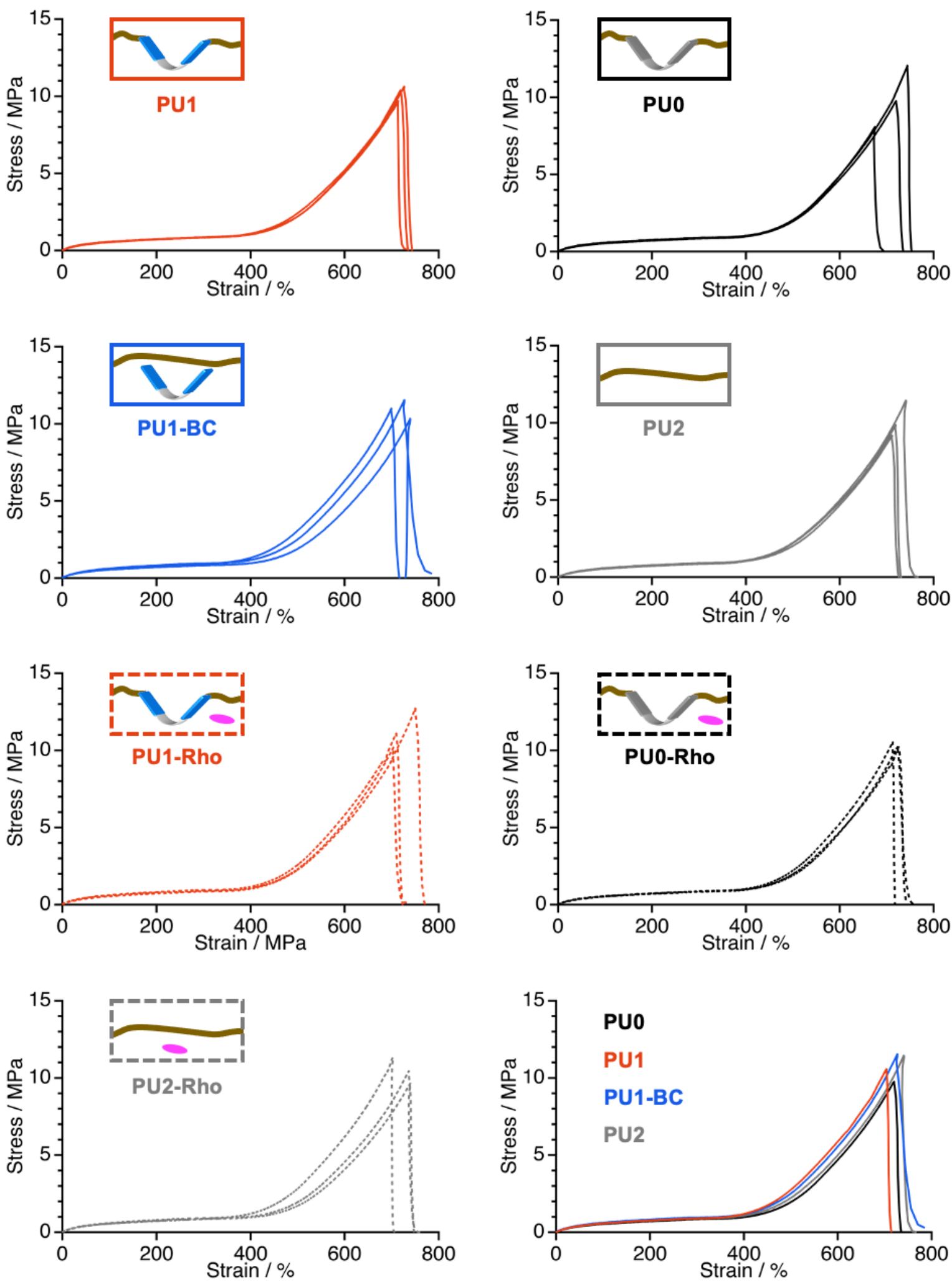

Figure S7.5. Stress-strain curves of the crosslinked polyurethanes (PUs). 
Table S7.2. Mechanical properties of the crosslinked PUs in the uniaxial tensile testing ${ }^{[a]}$

\begin{tabular}{ccccc}
\hline & Rupture strain / \% & Rupture stress / MPa & Toughness / $\mathrm{MJ} \mathrm{m}^{-3}$ & Young's modulus / MPa \\
\hline PU0 & $713 \pm 35$ & $9.9 \pm 2.1$ & $15.7 \pm 3.5$ & $1.4 \pm 0.1$ \\
PU1 & $713 \pm 8$ & $10.2 \pm 0.5$ & $16.8 \pm 0.7$ & $1.5 \pm 0.1$ \\
PU1-BC & $722 \pm 20$ & $10.8 \pm 0.7$ & $18.0 \pm 1.2$ & $1.6 \pm 0.1$ \\
PU2 & $724 \pm 15$ & $10.1 \pm 1.1$ & $16.7 \pm 2.0$ & $1.5 \pm 0.1$ \\
PU0-Rho & $721 \pm 7$ & $10.3 \pm 0.2$ & $16.3 \pm 0.1$ & $1.4 \pm 0.1$ \\
PU1-Rho & $721 \pm 25$ & $11.3 \pm 1.3$ & $18.1 \pm 2.2$ & $1.6 \pm 0.3$ \\
PU2-Rho & $726 \pm 20$ & $10.4 \pm 0.9$ & $16.9 \pm 1.0$ & $1.5 \pm 0.1$ \\
\hline
\end{tabular}

[a] Values of average \pm standard deviation of three specimens were shown. 

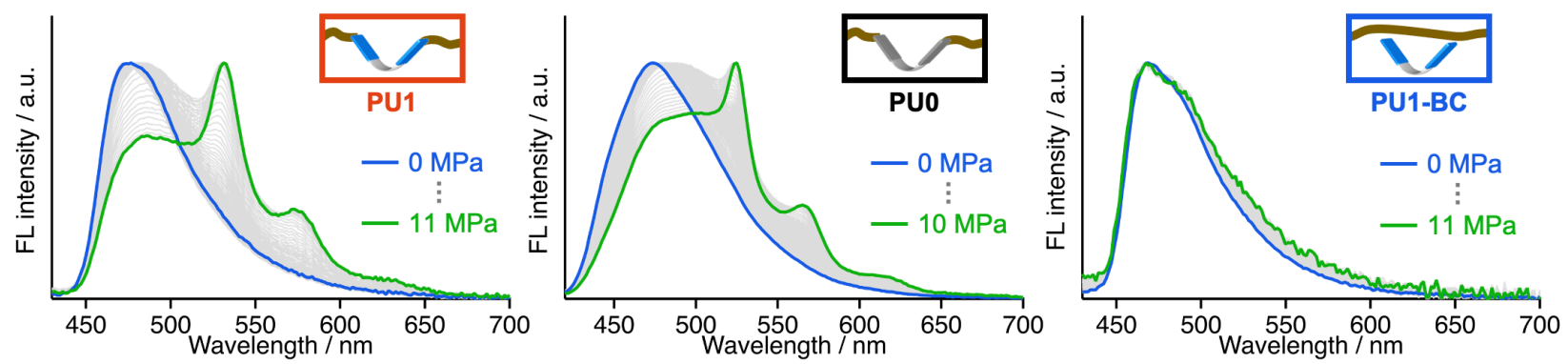

Figure S7.6. FL spectral change during the tensile tests of the crosslinked PUs before swelling. FL spectra are normalized at each maximum.

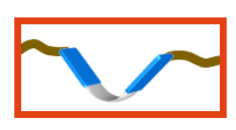

PU1
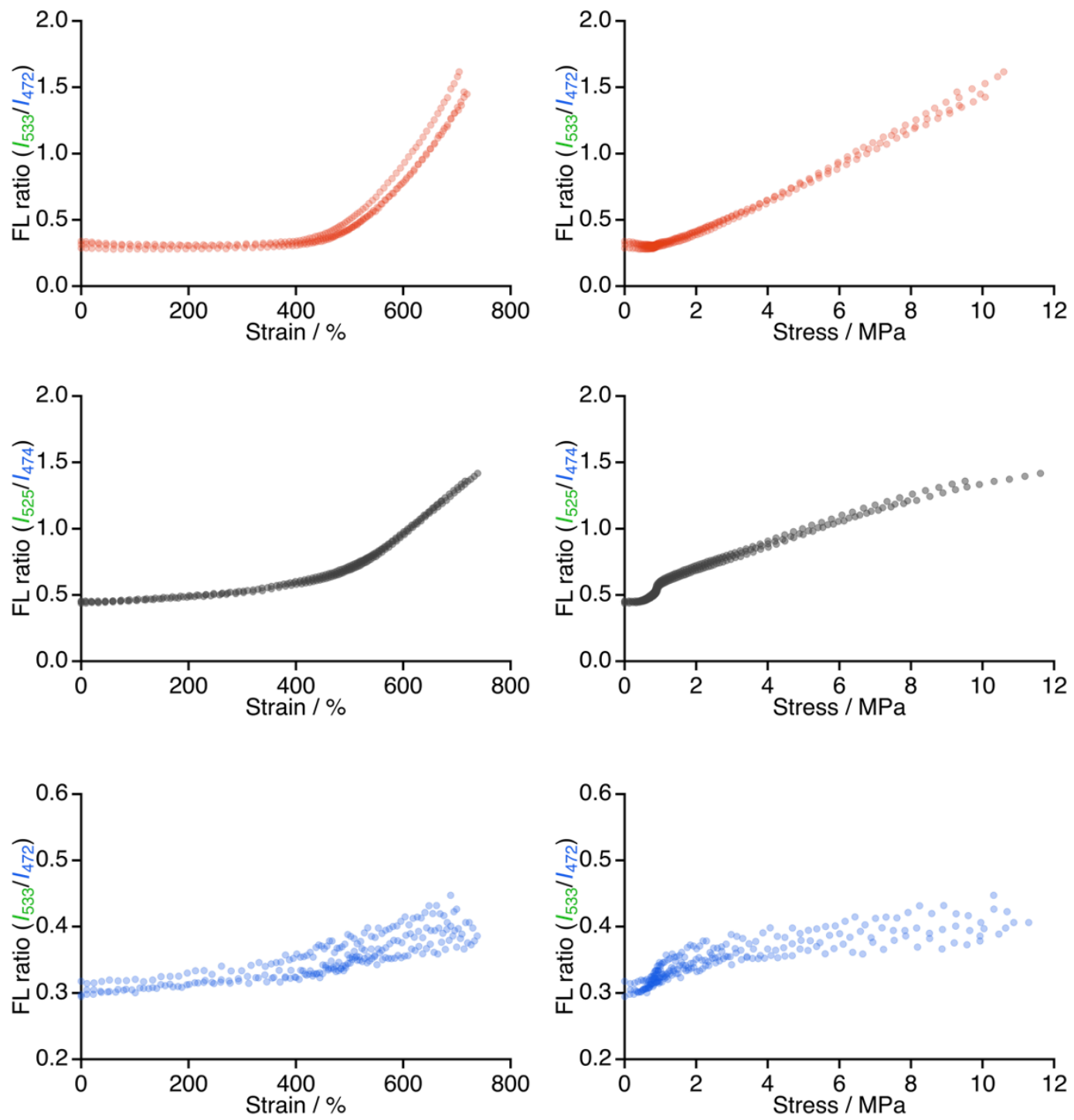

Figure S7.7. FL ratiometric analysis of the crosslinked PUs before swelling plotted against strain and stress in the tensile tests. The results of the three measurements are superimposed. 


\subsection{Measurements of the absorption spectrum of PU1}

The absorption spectra $A(\lambda, \Delta x)$ were obtained from the following equation: $A(\lambda, \Delta x)=-$ $\log \left[I(\lambda, \Delta x) / I_{0}(\lambda)\right]$, where $I_{0}(\lambda)$ is the spectrum of the incident tungsten light, and $I(\lambda, \Delta x)$ is a spectrum of the tungsten light transmitted through a specimen with the distance between grips is $\Delta x$ in the tensile test. Here, nominal strain $\left(\varepsilon_{N}\right)$ was not measured to avoid light reflection by the strain gauge. When we measured the absorption spectrum of PU1 based on this method, the contribution of light scattering by the sample was observed on the long-wavelength side (Figure S7.8a). Therefore, the absorption spectrum of PU2 without FLAP was measured as a baseline in the same way (Figure S7.8b). Since the difference in the degree of scattering due to individual specimens was unavoidable, the baseline was employed after normalization so that the value at $600 \mathrm{~nm}$ is the same as that of the uncorrected absorption spectrum of PU1. Namely, the corrected absorption spectrum of PU1 $A_{\mathrm{PU} 1}(\lambda, \Delta x)$ was obtained by the following equation:

$$
A_{\mathrm{PU} 1}(\lambda, \Delta x)=A_{\mathrm{PU} 1}^{\text {uncorrected }}(\lambda, \Delta x)-A_{\mathrm{PU} 2}(\lambda, \Delta x) \cdot \frac{A_{\mathrm{PU} 1}^{\text {uncorrected }}(600 \mathrm{~nm}, \Delta x)}{A_{\mathrm{PU} 2}(600 \mathrm{~nm}, \Delta x)} .
$$
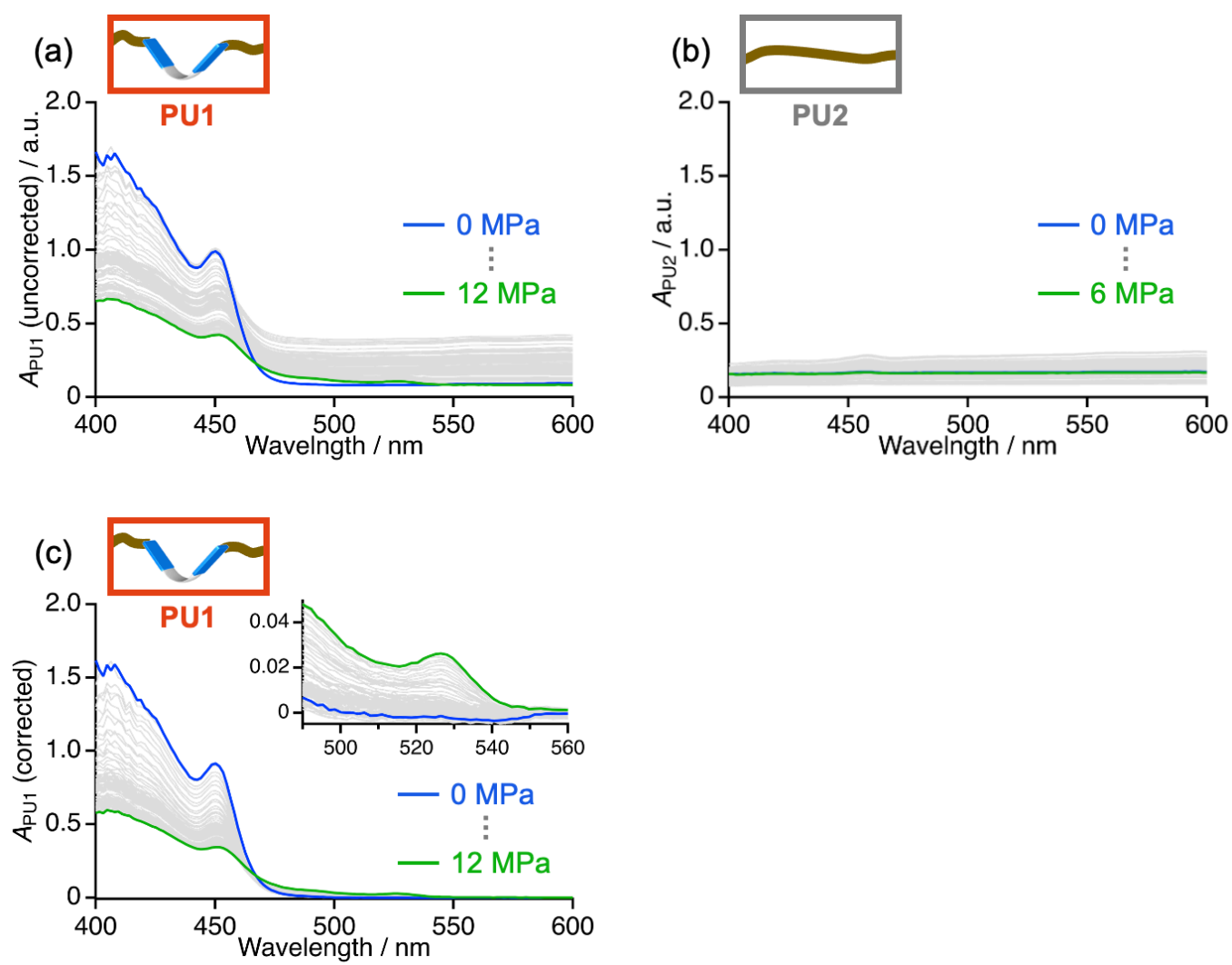

Figure S7.8. (a) Absorption spectrum of PU1 before baseline correction. (b) Absorption spectrum of PU0 employed as baseline. (c) Absorption spectrum of PU1 after baseline correction. 


\subsection{Discussion on the FL response of FLAP-doped PU before swelling}

Since the concentration of the force probes is minimal, the occurrence of FRET can be ignored, and the stress-strain curves (Figure S7.9a) and DSC profiles (Figure S7.4) of the dry elastomers are almost identical regardless of the presence of the probes. The FL spectral changes during tensile testing of the dry elastomer PU1 are qualitatively similar to the behavior of SPUs in that PU1 showed a more pronounced response than PU0 (Figures S7.9b and S7.9c), but the threshold for the FL response ( 1 MPa) was lower than SPUs (Figure S7.9c). Since no FL response was observed in the stretched PU1-BC specimen, the FL response of PU1 is indeed due to the force transmitted through the covalent bond (Figure S7.9c). In addition, measurement of absorption spectra of PU1 by a modified experimental setup (Figure S1.3) showed that the threshold for the FL response is smaller than that of the absorption response (around 3-6 MPa) (Figures S7.9e). This result supports the hypothesis in previous studies that the flapping force probe spontaneously planarizes in $\mathrm{S}_{1}$ to emit FL prior to the complete planarization in $\mathrm{S}_{0}{ }^{[\mathrm{S} 3]}$

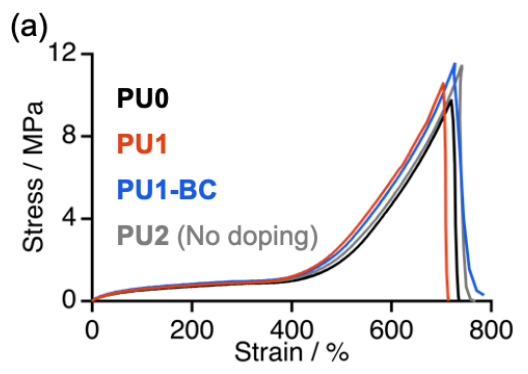

(b) PU1
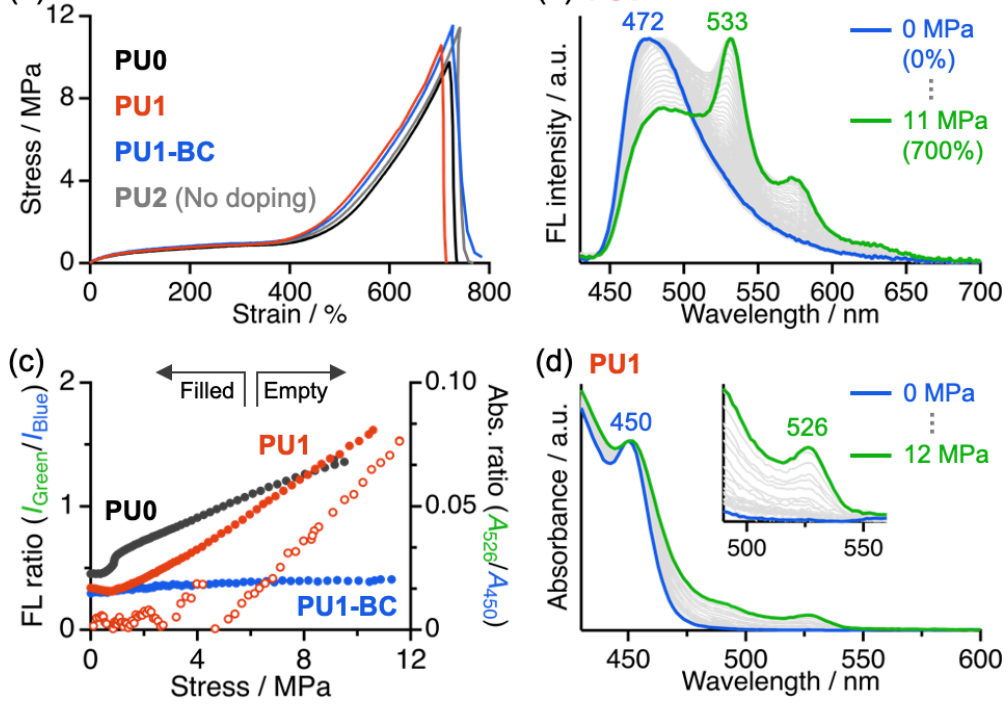

Figure S7.9. (a) Stress-strain curves of the PUs. (b) FL spectral change of PU1 during the tensile test. (c) FL intensity ratio (filled) and absorbance ratio (empty) plotted against stress in the tensile test. (d) Absorption spectra of PU1 recorded in the tensile test. 


\subsection{Estimation of the activation ratio of the flapping force probes in PUs before swelling}

The activation ratio of the force probes while stretching the PU specimens was calculated from the degree of decrease in FL intensity derived from the V-shaped form $\left(\lambda_{\mathrm{FL}}=475 \mathrm{~nm}\right)$. The change in the amount of the force probes in the region of detection due to the deformation of the specimen was taken into account by adding Rhodamine 640 perchlorate as a fluorescent internal standard, as shown in Figure S7.2. It should be noted that the FL spectral shape of Rhodamine 640 does not change during the tensile test, which was confirmed by stretching PU2-Rho (Figure S7.10). In addition, since the concentration of FLAP and Rhodamine 640 is very low, the possibility of FRET (Förster resonant energy transfer) between fluorophores can be ignored. Indeed, the intermolecular distance of fluorophores in PU1-Rho is estimated to be $22 \mathrm{~nm}$ based on the discussion on page S69, much farther than the typical distance allowed for FRET $(<10 \mathrm{~nm})$. Furthermore, as shown in Figure S7.11, Rhodamine 640 does not have significant absorption at around $475 \mathrm{~nm}$, and thus the effect of fluorescence reabsorption in the specimen is also negligible.

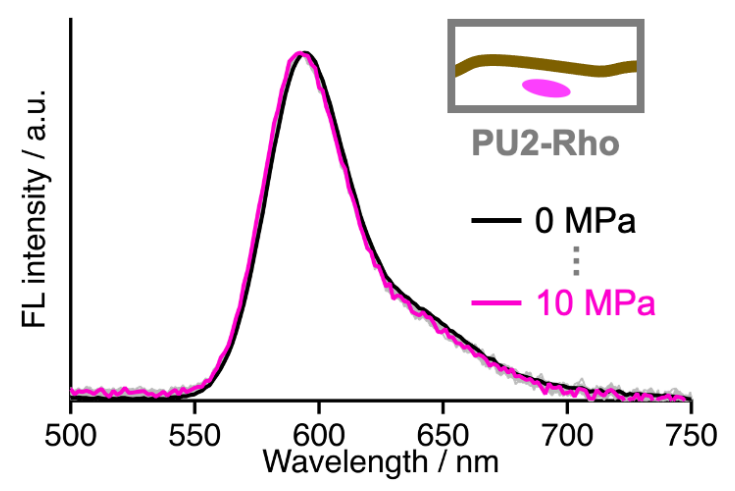

Figure S7.10 FL spectra recorded during the tensile test of PU2-Rho. FL spectra are normalized at each maximum.

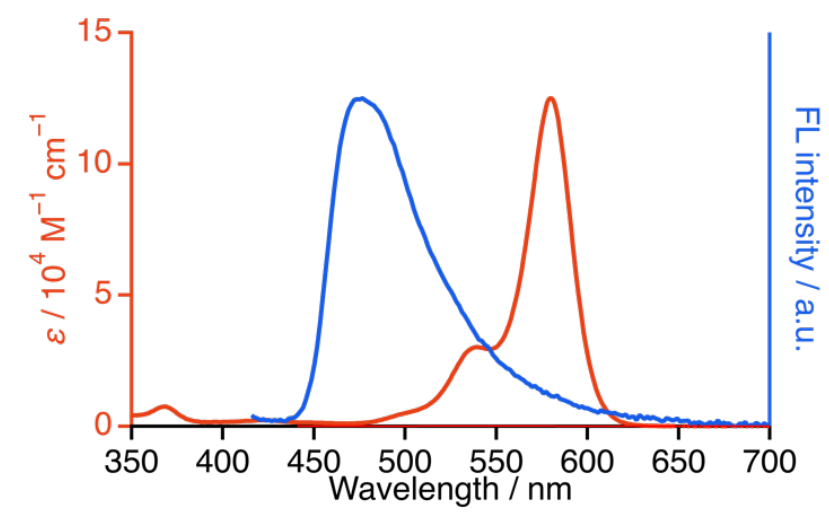

Figure S7.11 Absorption spectrum of Rhodamine 640 perchlorate in $\mathrm{CH}_{2} \mathrm{Cl}_{2}$ and fluorescence spectrum of PU1 before stretching. 
(a)
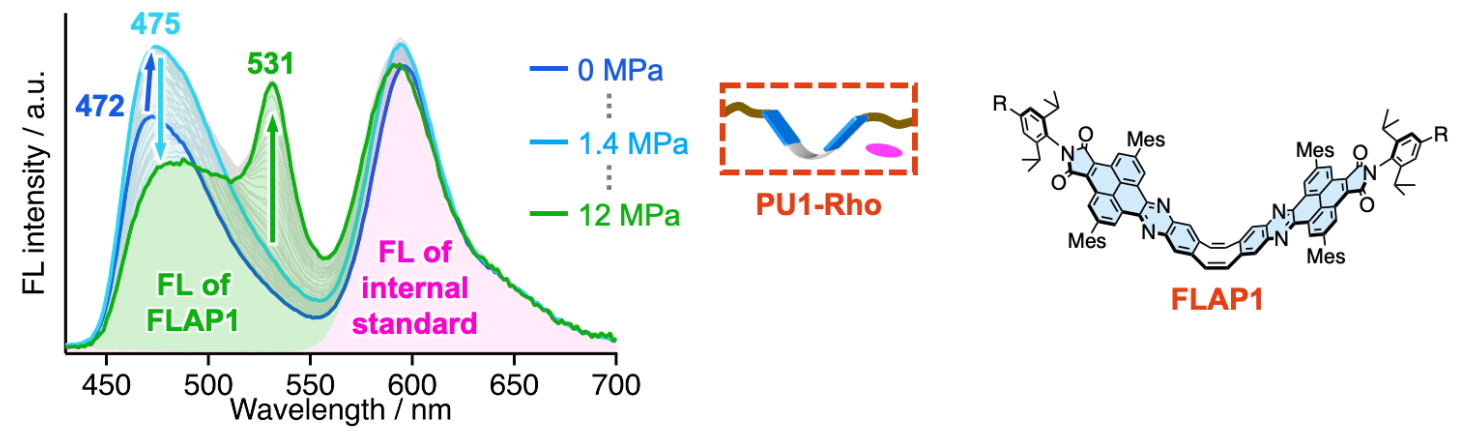

(b)

(c)
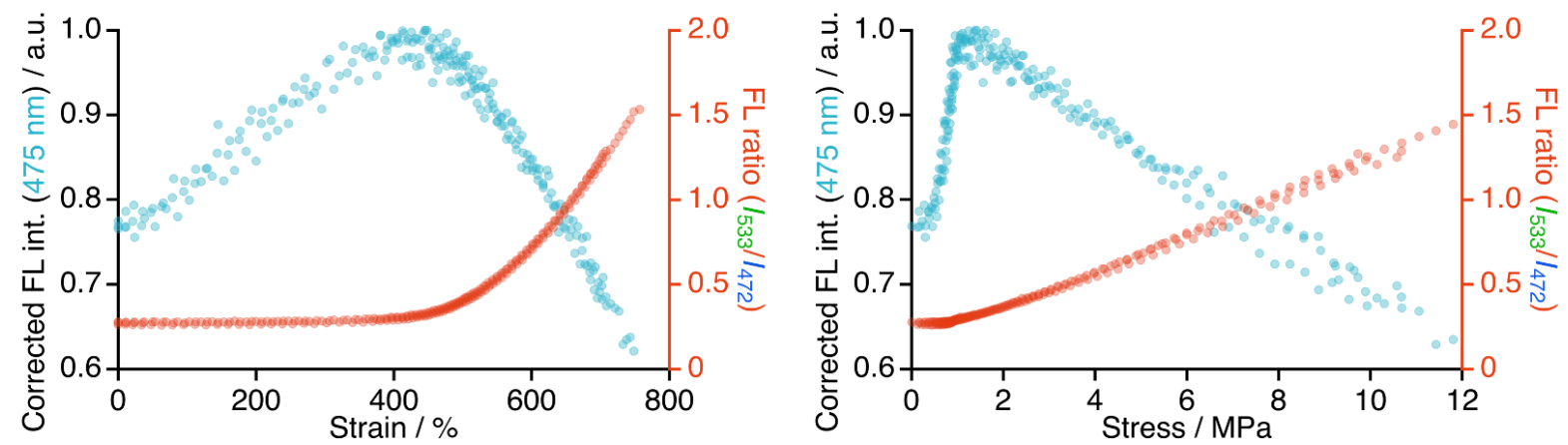

Figure S7.12 (a) FL spectral change during the tensile tests of PU1-Rho. FL intensity are corrected by normalization at $650 \mathrm{~nm}$, where only the internal standard shows FL. (b,c) FL intensity of the V-shaped form and FL intensity ratio plotted against (b) strain and (c) stress in the three tensile tests.

(a)
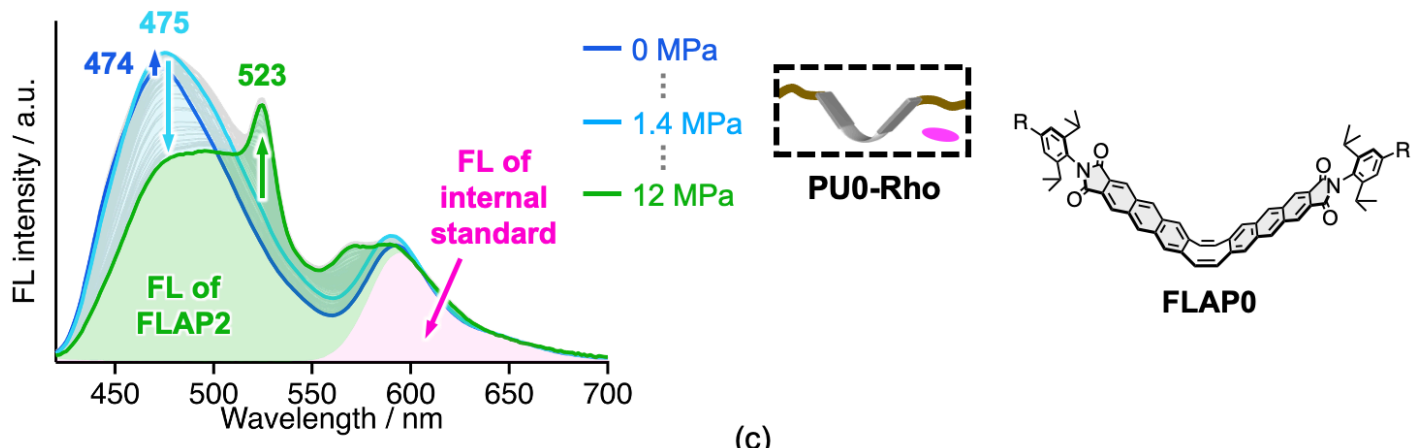

(b)

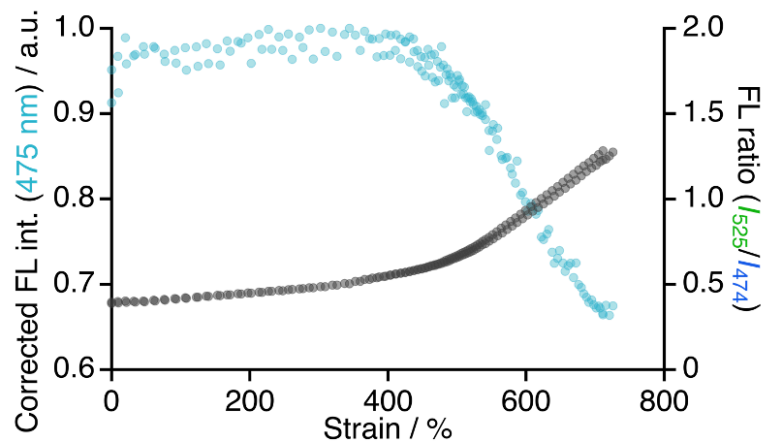

(c)

Figure S7.13 (a) FL spectral change during the tensile tests of PU0-Rho. FL intensity are corrected by normalization at $650 \mathrm{~nm}$, where only the internal standard shows FL. (b,c) FL intensity of the V-shaped form and FL intensity ratio plotted against (b) strain and (c) stress in the two tensile tests. 
The percentage of the stressed force probe in stretched polyurethanes was evaluated to gain insight into the intrinsic properties of FLAP0 and FLAP1 as force probes. Since the flapping force probes are dualfluorescent, the ratio of the stressed force probes can be experimentally estimated by the decrease in the FL intensity of the V-shaped form. The change in FL intensity due to deformation of the specimen was corrected by doping rhodamine 640 perchlorate as a fluorescent internal standard. It should be noted that the properties of the cross-linked polyurethanes were not affected by the addition of rhodamine (Figures S7.4 and S7.5), and the FL spectral shape of the rhodamine was not affected by stretching (Figure S7.10). Figure S7.12a displays the FL spectrum of PU1-Rho, which was prepared by doping PU1 with the rhodamine.

Interestingly, the FL intensity of the V-shaped form of FLAP1 first increased with a slight peak shift $(475 \mathrm{~nm})$ and then decreased with a critical stress of 1-2 MPa (Figure S7.12c). Since this threshold is comparable to that of the fluorescence intensity ratio $\left(I_{533} / I_{472}\right)$, the FL intensity of the V-shaped form initially increased with keeping the spectral shape, and then the $\mathrm{V}$-shaped form was stretched into the planar form. Although we cannot identify the reason for the increase in FL intensity at this stage, it is meaningful to relate it to the reported rigidochromic molecules in that the non-radiative decay of the V-shaped form might be suppressed. ${ }^{\left[{ }^{16]}\right.}$ Assuming that there is no change in the FL quantum yield in the decreasing region of the FL intensity at $475 \mathrm{~nm}$, the ratio of the stressed FLAP can be calculated by the percentage decrease in the FL intensity from the maximum value. The results show that the ratio of stressed probes at $10 \mathrm{MPa}$ is $37 \pm 4 \%$ for FLAP0 and $31 \pm 3 \%$ for FLAP1, which are comparable (Figures S7.14). From Figure S7.9c, the FL intensity ratio $\left(I_{525} / I_{474}\right)$ in PUO at $10 \mathrm{MPa}$ is estimated to be about 1.4. On the other hand, the percentage of the stressed probe reported based on the theoretically estimated molar absorption coefficients is around $17 \%$ at the same $I_{525} / I_{474}$ value ${ }^{[S 3]}$ which is slightly different but of the same order as the experimental results.

(a) PU0-Rho

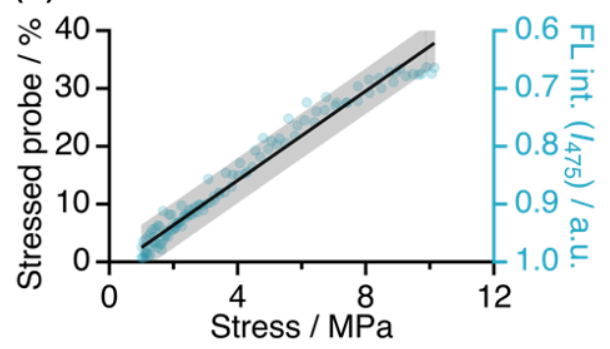

(b) PU1-Rho

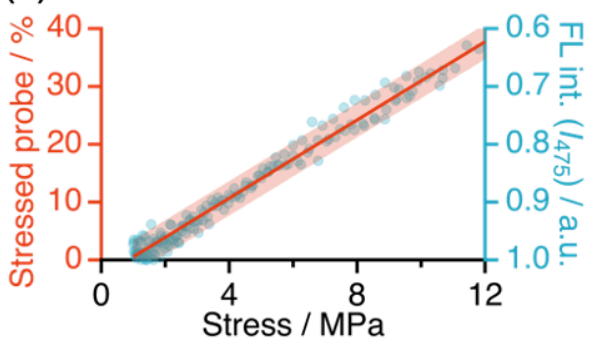

Figure S7.14. Ratio of the stressed FLAP calculated from the decrease in FL intensity of the V-shaped probe. The solid line represents the mean of the linear fit to the results of 2-3 experiments, and the shade represents the $95 \%$ prediction interval of the fitting. 


\section{Swelling behavior of the crosslinked polyurethanes (PUs)}

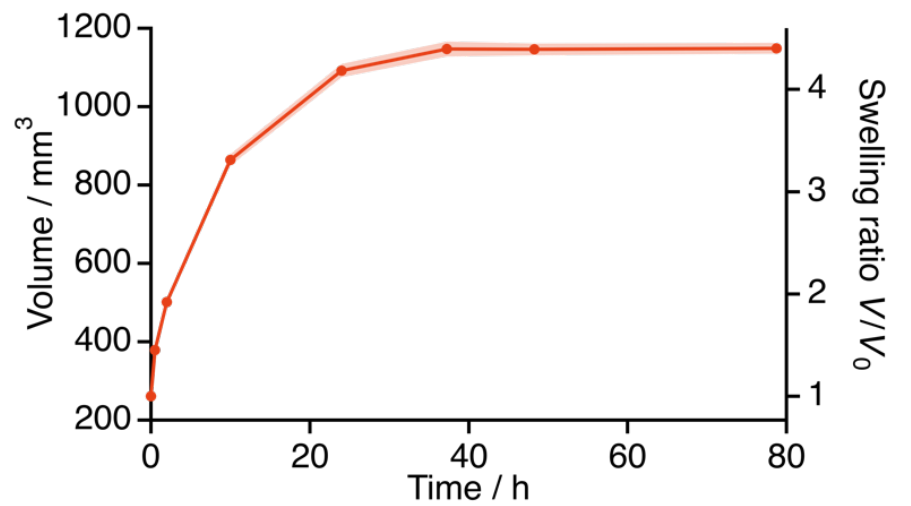

Figure S8.1 Volume change of cylindrical PU1 specimens when swollen with CPME, showing the mean (red line) and standard deviation (shading) measured for three specimens. The cylindrical specimens that reached the equilibrium swelling state after 48 hours were used as Gel1 for the compression tests. 


\section{Mechanical and photophysical properties of the polyurethanes gels}
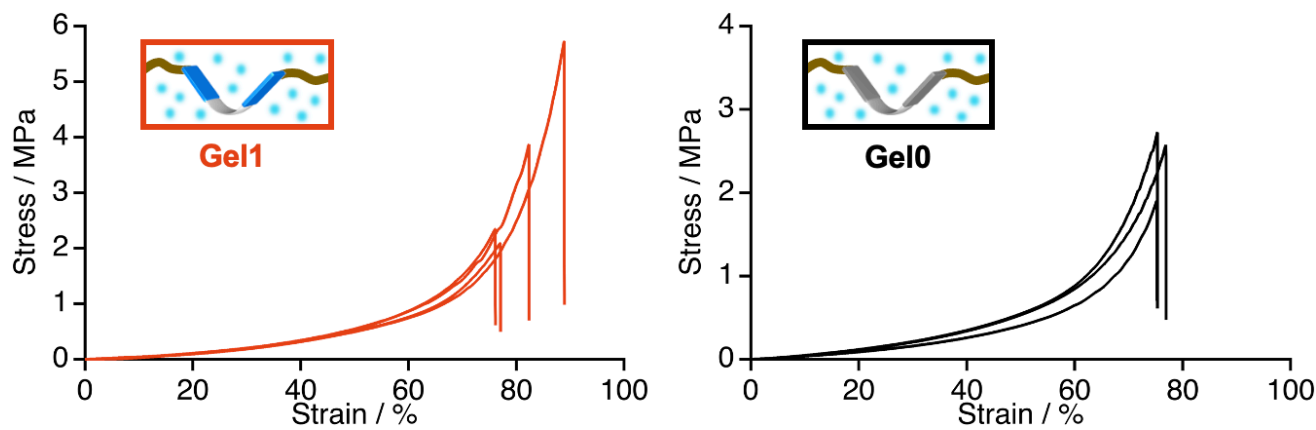

Figure S9.1. Stress-strain curves of the polyurethane gels swollen with CPME.

Table S9.1. Mechanical properties of the polyurethane gels swollen with CPME in the compression test ${ }^{[a]}$ Rupture strain / \% Rupture stress / $\mathrm{MPa} \quad$ Toughness / $\mathrm{MJ} \mathrm{m}^{-3} \quad$ Young's modulus / $\mathrm{MPa}$

\begin{tabular}{ccccc}
\hline Gel0 & $76 \pm 1$ & $2.6 \pm 0.1$ & $0.410 \pm 0.02$ & $0.12 \pm 0.05$ \\
Gel1 & $81 \pm 6$ & $3.5 \pm 1.7$ & $0.52 \pm 0.18$ & $0.13 \pm 0.07$ \\
\hline
\end{tabular}

[a] Values of average \pm standard deviation of 3-4 specimens were shown.

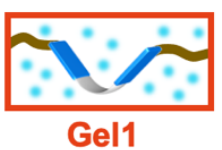

Gel1

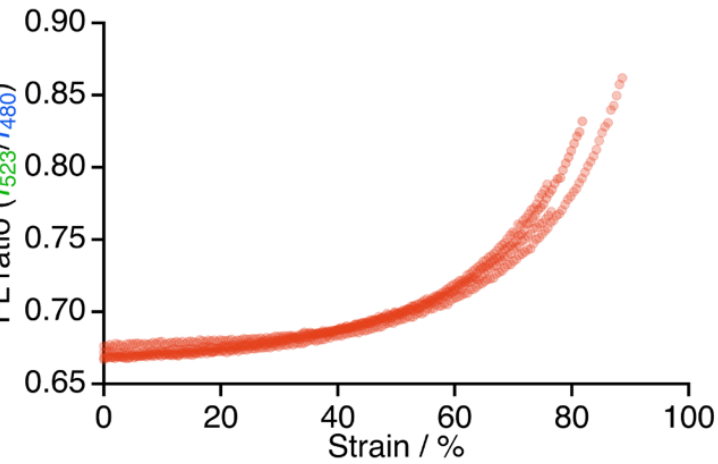

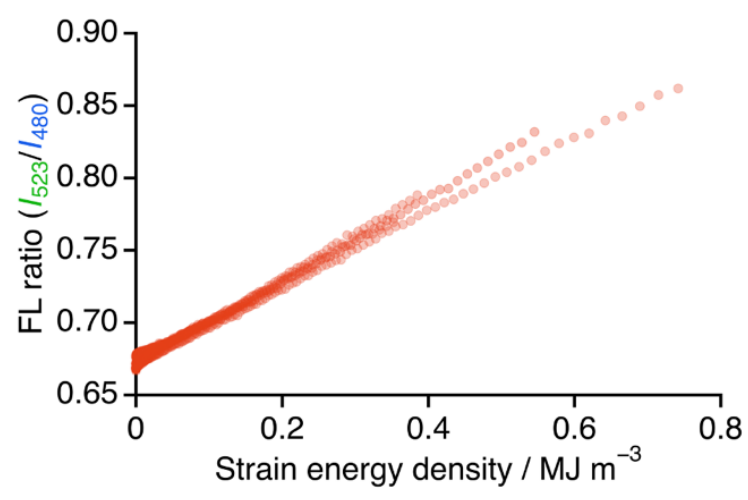

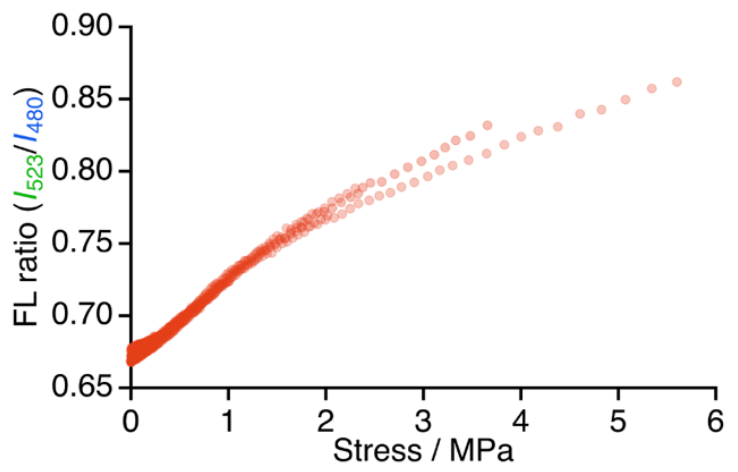

Figure S9.2. FL ratiometric analysis of the polyurethane gels swollen with CPME (Gel1) plotted against strain, stress, and strain energy density in the compression. The results of the four measurements are superimposed. 

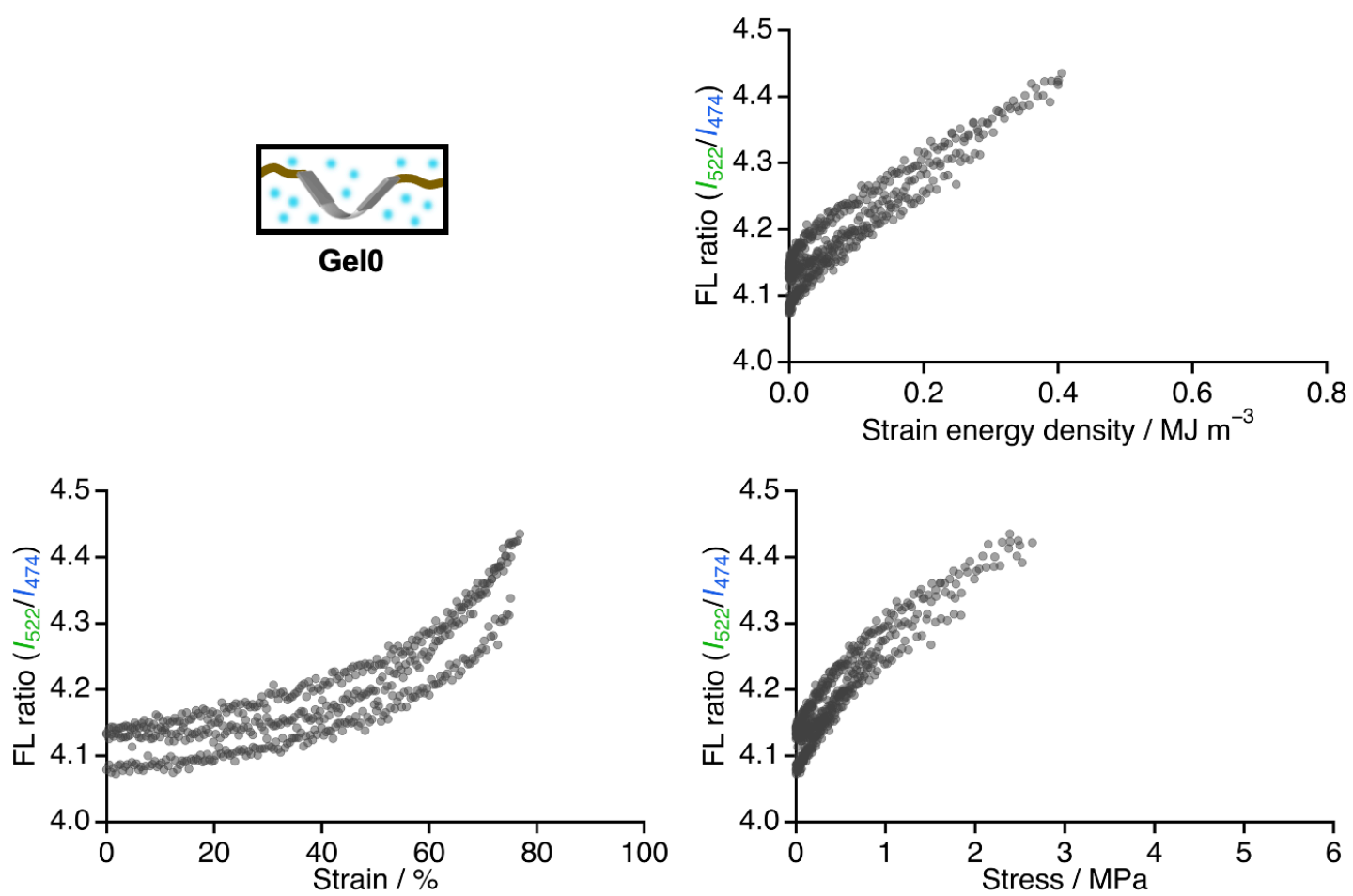

Figure S9.3. FL ratiometric analysis of the polyurethane gels swollen with CPME (Gel0) plotted against strain, stress, and strain energy density in the compression. The results of the three measurements are superimposed.
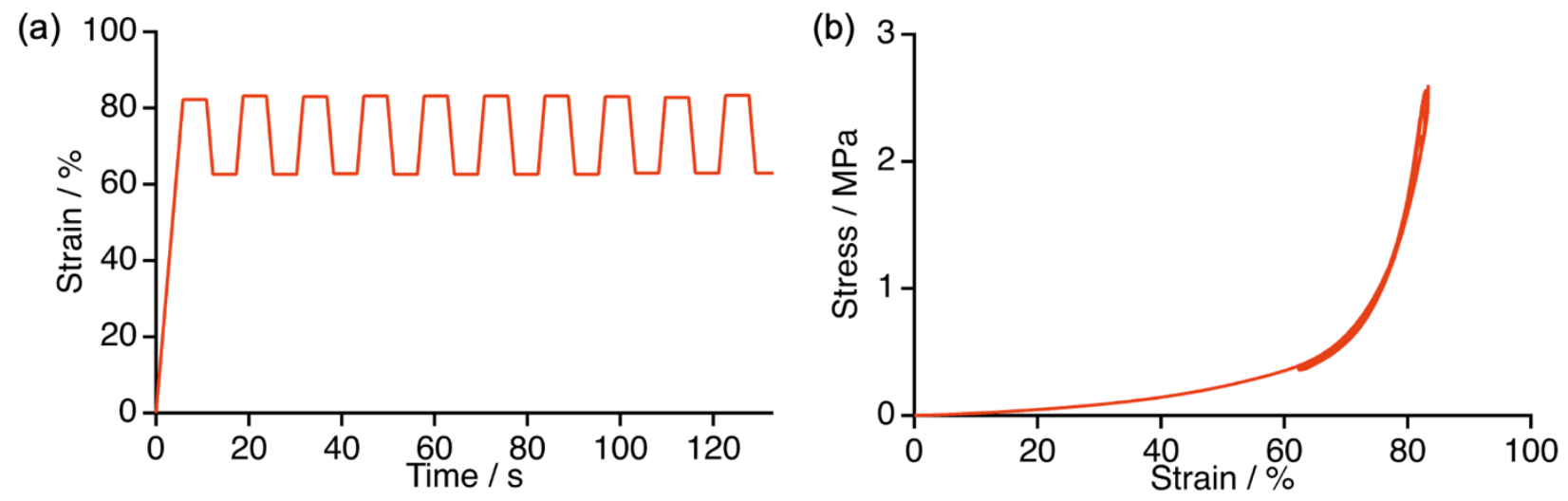

Figure S9.4. (a) Strain-time profile and (b) stress-strain curve for the repeated compression test of Gel1 (See Figure $10 \mathrm{~h}$ in the main text). 
(a) $0 \mathrm{~s}$
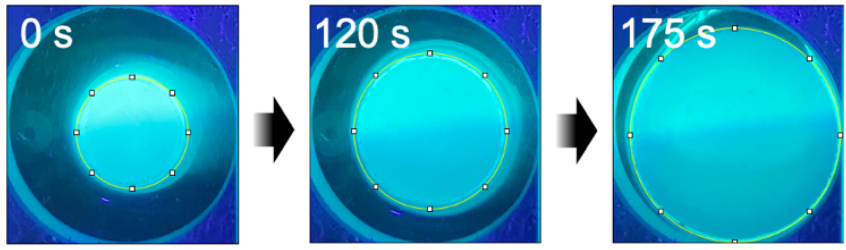

(b)

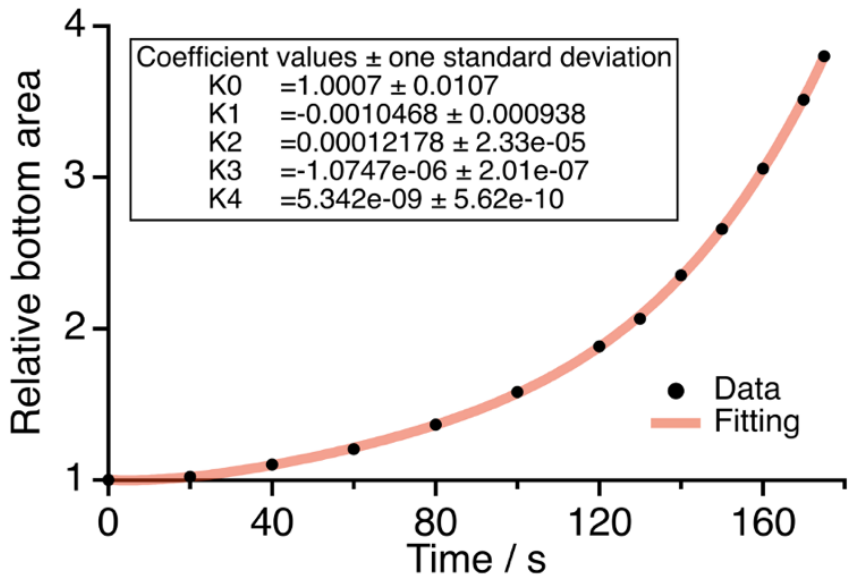

Figure S9.5. Calculation of the change in the bottom area of the cylindrical specimen during compression to estimate true stress applied to Gel1. (a) Evaluation of the relative bottom area of a cylindrical specimen using the ImageJ software. (b) Calibration curve (red) for calculating true stress from nominal stress. The calibration curve was obtained by fitting the discrete data from ImageJ (black dots) with the quartic function $y=K_{0}+$ $K_{1} x+K_{2} x^{2}+K_{3} x^{3}+K_{4} x^{4}$. 


\section{Supporting references}

[S1] Wu, Z.-H.; Sun, W.-J.; Tian, H.-H.; Yu. Z.-F.; Guo, R.-X.; Shao, X.; Zhang, H.-L. Adv. Electron. Mater. 2019, 5, 1800598.

[S2] Suga, K.; Yamakado, T.; Saito, S. Bull. Chem. Soc. Jpn. 2021, 94, 1999-2002.

[S3] Kotani, R.; Yokoyama, S.; Nobusue, S.; Yamaguchi, S.; Osuka, A.; Yabu, H.; Saito, S. arXiv:2011.00202v2.

[S4] Sheldrick, G. M. Acta Crystallogr. 2015, A71, 3-8.

[S5] Sheldrick, G. M. Acta Crystallogr. 2015, C71, 3-8.

[S6] Spek, A. L. Acta Crystallogr. 2015, C71, 9-18.

[S7] (a) Stevens, B.; Ban, M. I. Trans. Faraday Soc. 1964, 60, 1515-1523.

(b) Grabowski, Z. R.; Rotkiewicz, K.; Rettig, W. Chem. Rev. 2003, 103, 3899-4031.

[S8] Yamakado, T.; Takahashi, S.; Watanabe, K.; Matsumoto, Y.; Osuka, A.; Saito, S. Angew. Chem. Int. Ed. 2018, 57, 5438-5443.

[S9] (a) Burstein, E. A.; Emelyanenko, V. I. Photochem. Photobiol. 1996, 64, 316-320.

(b) Maroncelli, M.; Fleming, G. R. J. Chem. Phys. 1987, 86, 6221-6239.

[S10] (a) Lippert, E. V.; Z. Elektrochem. 1957, 61, 962-975.

(b) Mataga, N.; Kaifu, Y.; Koizumi, M. Bull. Chem. Soc. Jpn. 1956, 29, 465-470.

[S11] Frisch, M. J.; Trucks, G. W.; Schlegel, H. B.; Scuseria, G. E.; Robb, M. A.; Cheeseman, J. R.; Scalmani, G.; Barone, V.; Petersson, G. A.; Nakatsuji, H.; Li, X.; Caricato, M.; Marenich, A. V.; Bloino, J.; Janesko, B. G.; Gomperts, R.; Mennucci, B.; Hratchian, H. P.; Ortiz, J. V.; Izmaylov, A. F.; Sonnenberg, J. L.; Williams-Young, D.; Ding, F.; Lipparini, F.; Egidi, F.; Goings, J.; Peng, B.; Petrone, A.; Henderson, T.; Ranasinghe, D.; Zakrzewski, V. G.; Gao, J.; Rega, N.; Zheng, G.; Liang, W.; Hada, M.; Ehara, M.; Toyota, K.; Fukuda, R.; Hasegawa, J.; Ishida, M.; Nakajima, T.; Honda, Y.; Kitao, O.; Nakai, H.; Vreven, T.; Throssell, K.; Montgomery, J. A., Jr.; Peralta, J. E.; Ogliaro, F.; Bearpark, M. J.; Heyd, J. J.; Brothers, E. N.; Kudin, K. N.; Staroverov, V. N.; Keith, T. A.; Kobayashi, R.; Normand, J.; Raghavachari, K.; Rendell, A. P.; Burant, J. C.; Iyengar, S. S.; Tomasi, J.; Cossi, M.; Millam, J. M.; Klene, M.; Adamo, C.; Cammi, R.; Ochterski, J. W.; Martin, R. L.; Morokuma, K.; Farkas, O.; Foresman, J. B.; Fox, D. J. Gaussian 16, Revision B.01, Gaussian, Inc., Wallingford, CT, 2016.

[S12] Hanwell, M. D.; Curtis, D. E.; Lonie, D. C.; Vandermeersch, T.; Zurek, E.; Hutchison, G. R. J. Cheminfomatics 2012, 4, 17.

[S13] (a) Prlj, A.; Curchod, B. F. E.; Fabrizio, A.; Floryan, L.; Corminboeuf, C. J. Phys. Chem. Lett. 2015, 6, 13-21.

(b) Prlj, A.; Sandoval-Salinas, M. E.; Casanova, D.; Jacquemin, D.; Corminboeuf, C. J. Chem. Thoery Comput. 2016, 12, 2652-2660.

[S14] Neese, F. WIREs Comput. Mol. Sci. 2012, 2, 73-78. 
[S15] Sagara, Y.; Karman, M.; Verde-Sesto, E.; Matsuo, K.; Kim, Y.; Tamaoki, N.; Weder, C. J. Am. Chem. Soc. 2018, 140, 1584-1857.

[S16] Weber, B.; Suhina, T.; Junge, T.; Pastewka, L.; Brouwer, A. M.; Bonn, D. Molecular probes reveal deviations from Amontons' law in multi-asperity frictional contacts. Nature Commun. 2018, 9, 888. 